Nevada

Environmental

Restoration

Project

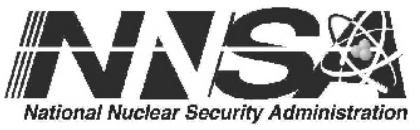

Closure Report for

Corrective Action Unit 121:

Storage Tanks and Miscellaneous

Sites, Nevada Test Site, Nevada

Controlled Copy No.:

Revision: 0

September 2008

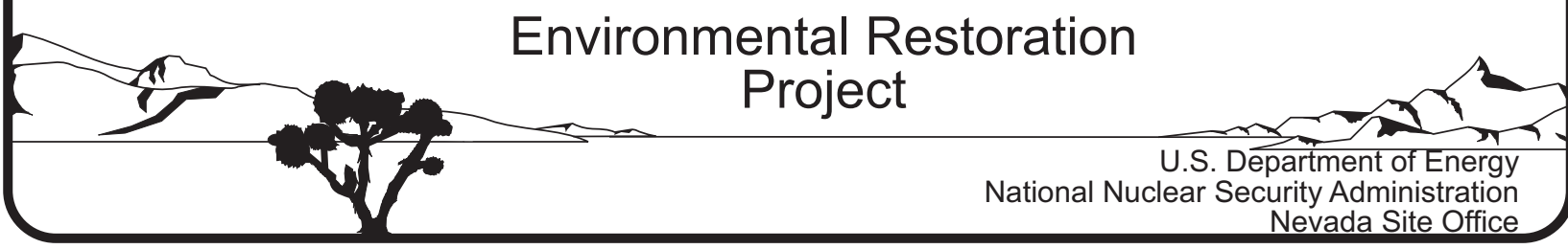




\section{DISCLAIMER}

Reference herein to any specific commercial product, process, or service by trade name, trademark, manufacturer, or otherwise, does not necessarily constitute or imply its endorsement, recommendation, or favoring by the United States Government or any agency thereof.

This report has been reproduced directly from the best available copy.

Available for sale to the public from:

U.S. Department of Commerce

National Technical Information Service

5285 Port Royal Road

Springfield, VA 22161-0002

Telephone: (800) 553-6847

Fax: (703) 605-6900

E-mail: orders@ntis.gov

Online ordering: http://www.ntis.gov/ordering.htm

Available electronically at http://www.osti.gov/bridge.

Available for a processing fee to the U.S. Department of Energy and its contractors, in paper, from:

U.S. Department of Energy

Office of Scientific and Technical Information

P.O. Box 62

Oak Ridge, TN 37831-0062

Telephone: (865) 576-8401

Fax: (865) 576-5728

E-mail: reports@adonis.osti.gov 


\title{
CLOSURE REPORT FOR CORRECTIVE ACTION UNIT 121: STORAGE TANKS AND MISCELLANEOUS SITES, NEVADA TEST SITE, NEVADA
}

\author{
U.S. Department of Energy \\ National Nuclear Security Administration \\ Nevada Site Office \\ Las Vegas, Nevada
}

Controlled Copy No.

Revision: 0

September 2008 
THIS PAGE INTENTIONALLY LEFT BLANK 


\section{CLOSURE REPORT FOR CORRECTIVE ACTION UNIT 121: STORAGE TANKS AND MISCELLANEOUS SITES, NEVADA TEST SITE, NEVADA}

/s/ Kevin Cabble

Approved By:

Kevin J. Cabble

Federal Sub-Project Director

Industrial Sites Sub-Project

Approved By: , /s/ W. R. Wilborn

for Robert F. Boehlecke

Federal Project Director

Environmental Restoration Project
Date: $2 / 10 / 08$

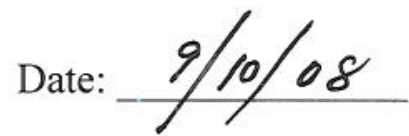


THIS PAGE INTENTIONALLY LEFT BLANK 


\section{TABLE OF CONTENTS}

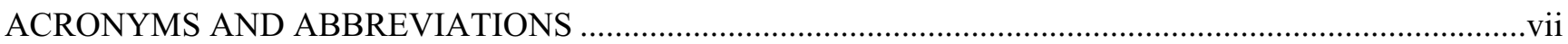

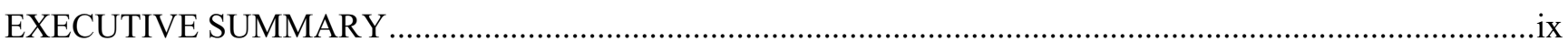

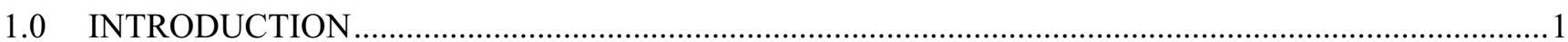

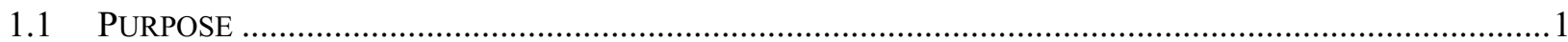

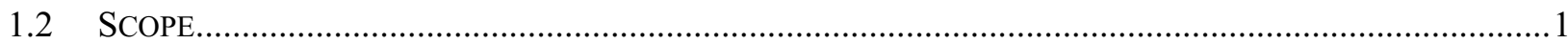

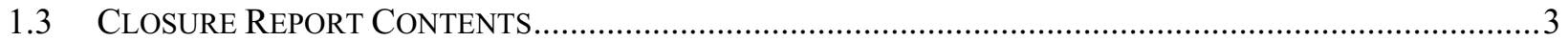

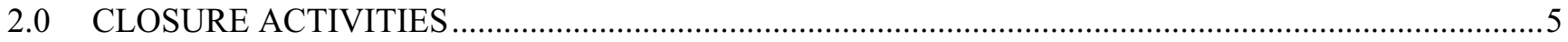

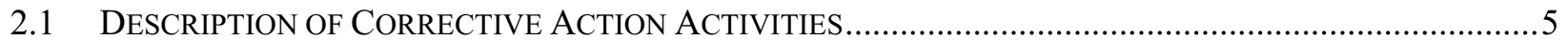

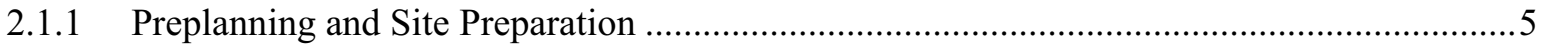

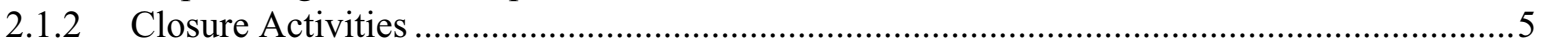

2.1.2.1 Corrective Action Site 12-01-01, Aboveground Storage Tank ..............................5

2.1.2.2 Corrective Action Site 12-01-02, Aboveground Storage Tank ............................. 8

2.1.2.3 Corrective Action Site 12-22-26, Drums; 2 AST's s................................................ 17

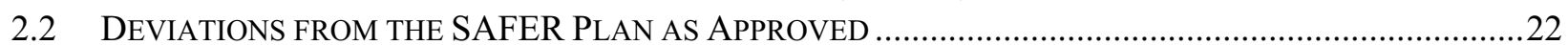

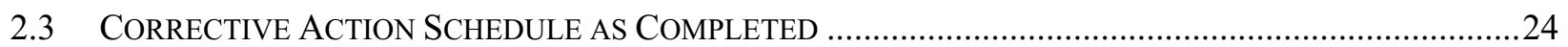

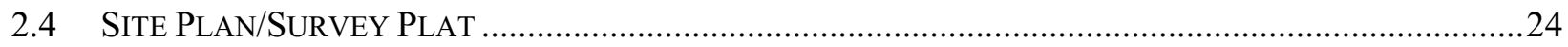

3.0 WASTE DISPOSITION

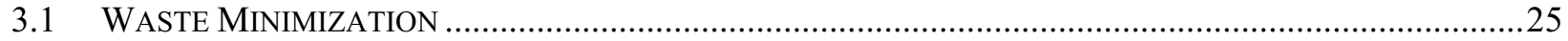

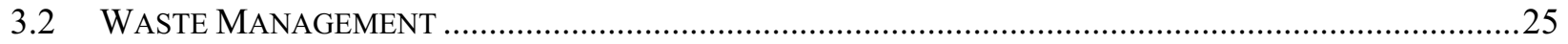

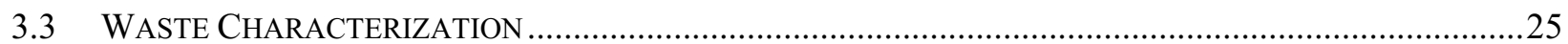

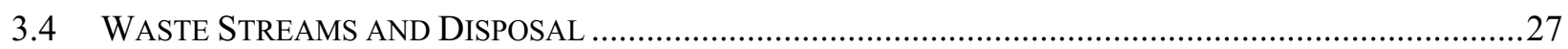

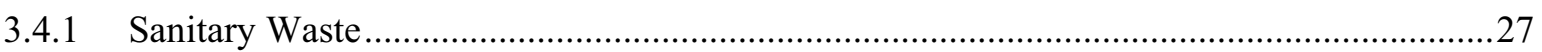

3.4.2 Petroleum Hydrocarbon PCB Remediation Waste ......................................................27

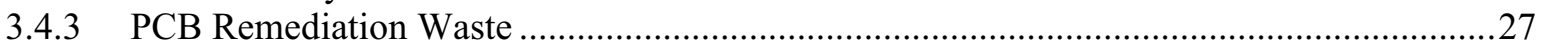

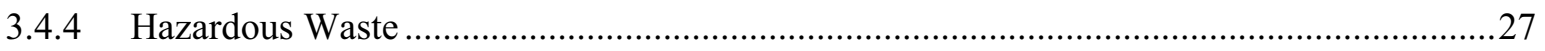

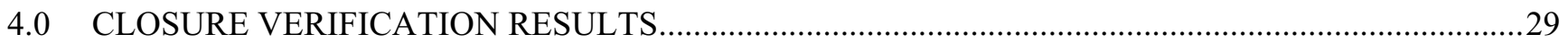

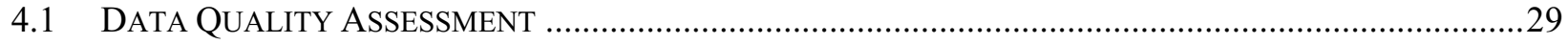

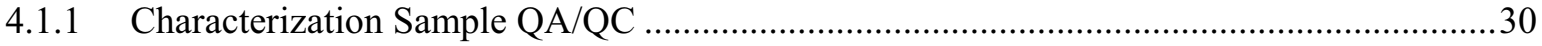

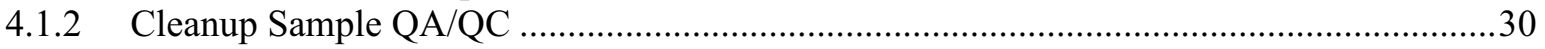

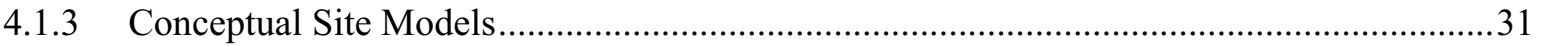

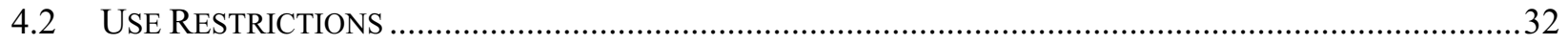

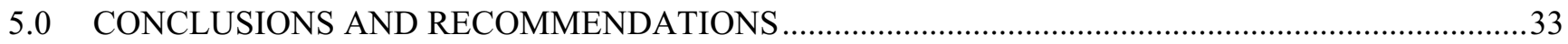

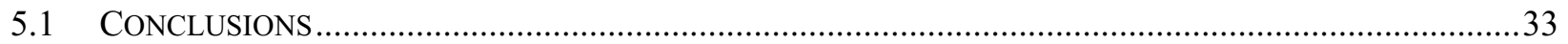

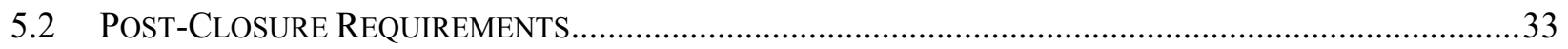

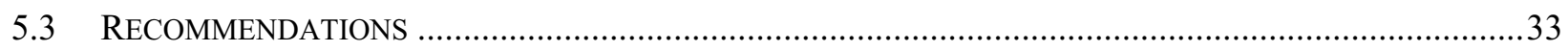

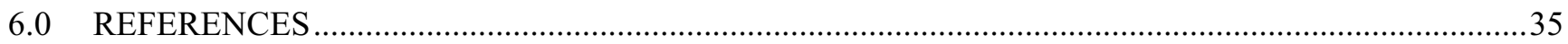

LIBRARY DISTRIBUTION LIST 


\section{LIST OF FIGURES}

Figure 1. Corrective Action Unit 121 Site Location Map ......................................................2

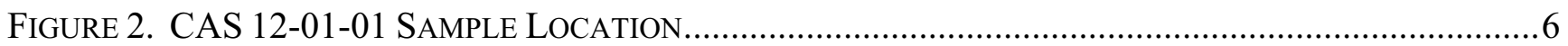

Figure 3. CAS 12-01-02 CHARACTERIZATION SAMPLE LOCATION ....................................................9

Figure 4. CAS 12-01-02 EXCAVATION AND SAMPLE LOCATIONS .................................................... 12

Figure 5. TAR Sealant-Like Material Near Area 12 CAMP Water TANKS, 07/07/2008.............. 16

Figure 6. ASPHalt-Like Material NeAR Area 12 CAMP Water TANKS, 07/07/2008 ....................16

Figure 7. CAS 12-22-26 InVESTIGATION AREAS AND SAMPlE LOCATIONS ....................................... 18

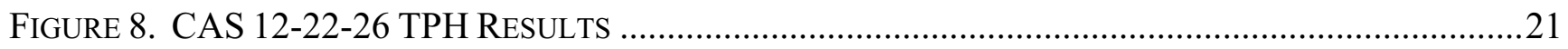

\section{LIST OF TABLES}

Table 1. Summary of Corrective Action Unit 121 Closure Activities .................................. X

TABle 2. CAS 12-01-01 CharaCterization SAMPLE AnAlytiCAl RESUltS ....................................

TABle 3. CAS 12-01-02 Characterization SAMPLE AnAlytiCAl RESUlts .................................. 10

Table 4. CAS 12-01-02 Phase 1 Cleanup Sample Analytical Results ....................................... 13

Table 5. CAS 12-01-02 Phase 2 Cleanup Sample Analytical Results .................................... 15

Table 6. CAS 12-01-02 Phase 3 Cleanup Sample Analytical Results ..................................... 15

Table 7. CAS 12-22-26 Drum Area Characterization SAMPle Analytical Results ................ 19

Table 8. CAS 12-22-26 TAnK Area Characterization Sample Analytical Results .................20

TABle 9. Chemical Components of Diesel And Associated FALs ..........................................23

Table 10. Corrective Action Unit 121 Closure Activities Schedule .....................................24

TABle 11. Corrective Action Unit 121 Waste Disposition Summary .......................................26

\section{APPENDICES}

APPENDIX A. DATA QUALITY OBJECTIVES

APPENDiX B. SAMPLE ANALYTICAL RESUlts

APPENDIX C. WASTE DisPOSITION DOCUMENTATION

APPENDiX D. Site ClOSURE PHOTOGRAPHS

APPENDIX E. NEVADA DIVISION OF ENVIRONMENTAL PROTECTION COMMENT RESPONSE FORM 


\section{ACRONYMS AND ABBREVIATIONS}

AST aboveground storage tank

B detected in trip blank

BMP best management practice

CAS Corrective Action Site

CAU Corrective Action Unit

COC contaminant of concern

CR Closure Report

CSM conceptual site model

D diluted

EPA U.S. Environmental Protection Agency

FAL final action level

FFACO Federal Facility Agreement and Consent Order

gal gallon(s)

HW hazardous waste

J estimated

LT less than requested detection limit but greater than method detection limit

$\mathrm{mg} / \mathrm{kg} \quad$ milligram(s) per kilogram

MS/MSD matrix spike/matrix spike duplicate

NBMG Nevada Bureau of Mines and Geology

ND not detected

NDEP Nevada Division of Environmental Protection

NE none established

NNSA/NSO U.S. Department of Energy, National Nuclear Security Administration Nevada Site Office

NNSA/NV U.S. Department of Energy, National Nuclear Security Administration Nevada Operations Office

NTS Nevada Test Site

PAL preliminary action level

PCBs polychlorinated biphenyls

$\mathrm{pCi} / \mathrm{g} \quad$ picocuries(s) per gram

PRG preliminary remediation goal 


\section{ACRONYMS AND ABBREVIATIONS (continued)}

QA quality assurance

QAPP Quality Assurance Project Plan

QC quality control

RCRA Resource Conservation and Recovery Act

RPD relative percent difference

SAFER Streamlined Approach for Environmental Restoration

SDG sample delivery group

SVOC semi-volatile organic compound

TI tentatively identified

TPH total petroleum hydrocarbons

VOC volatile organic compound

WMA waste management area

$\mathrm{yd}^{3} \quad$ cubic yard(s) 


\section{EXECUTIVE SUMMARY}

Corrective Action Unit (CAU) 121 is identified in the Federal Facility Agreement and Consent Order (FFACO) (1996, as amended February 2008) as Storage Tanks and Miscellaneous Sites. CAU 121 consists of the following three Corrective Action Sites (CASs) located in Area 12 of the Nevada Test Site, which is approximately 65 miles northwest of Las Vegas, Nevada.

- CAS 12-01-01, Aboveground Storage Tank

- CAS 12-01-02, Aboveground Storage Tank

- CAS 12-22-26, Drums; 2 AST's

CAU 121 closure activities were conducted according to the FFACO and the Streamlined Approach for Environmental Restoration Plan for CAU 121 (U.S. Department of Energy, National Nuclear Security Administration Nevada Site Office, 2007). Field work took place from February through September 2008. Samples were collected to determine the path forward to close each site. Closure activities were completed as defined in the plan based on sample analytical results and site conditions.

No contaminants of concern (COCs) were present at CAS 12-01-01; therefore, no further action was chosen as the corrective action alternative. As a best management practice (BMP), the empty aboveground storage tank (AST) was removed and disposed as sanitary waste.

At CAS 12-01-02, polychlorinated biphenyls (PCBs) were present above the preliminary action level (PAL) in the soil beneath the AST that could possibly have originated from the AST contents. Therefore, PCBs were considered COCs, and the site was clean closed by excavating and disposing of soil containing PCBs. Approximately 5 cubic yards $\left(\mathrm{yd}^{3}\right)$ of soil were excavated and disposed as petroleum hydrocarbon PCB remediation waste, and approximately $13 \mathrm{yd}^{3}$ of soil were excavated and disposed as PCB remediation waste. Cleanup samples were collected to confirm that the remaining soil did not contain PCBs above the PAL. Other compounds detected in the soil above PALs (i.e., total petroleum hydrocarbons [TPH] and semi-volatile organic compounds [SVOCs]) were determined to not likely have originated from the tank. Additional sample results showed that the compounds were likely present as a result of degraded asphalt around the adjacent, active water tank and not from the abandoned AST; therefore, they were not considered COCs. As a BMP, the empty AST was removed and disposed as sanitary waste.

No COCs were present at CAS 12-22-26; therefore, no further action was chosen as the corrective action alternative. Although TPH was present at concentrations that exceeded the PAL, the volatile organic compound and SVOC hazardous constituents of TPH did not exceed the final action levels (FALs); therefore, TPH was not considered a COC. As a BMP, the empty AST was removed and disposed as sanitary waste.

Closure activities generated sanitary waste, petroleum hydrocarbon PCB remediation waste, PCB remediation waste, and hazardous waste. Waste was appropriately managed and disposed. Waste that is currently staged on site is being appropriately managed and will be disposed under approved waste profiles in permitted landfills. Waste minimization activities included waste characterization sampling and segregation of waste streams. 


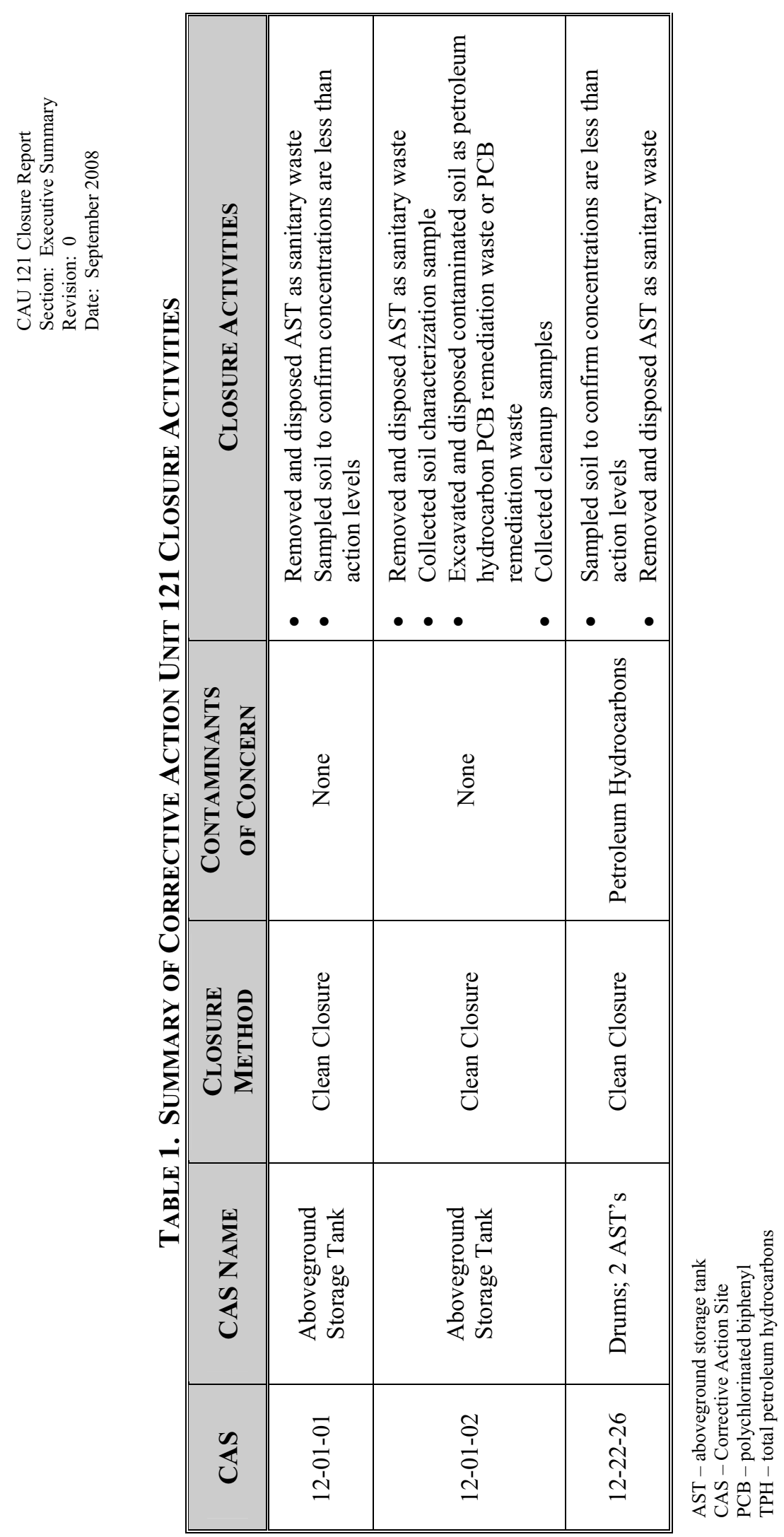




\subsection{INTRODUCTION}

This Closure Report (CR) documents closure activities for Corrective Action Unit (CAU) 121, Storage Tanks and Miscellaneous Sites, according to the Federal Facility Agreement and Consent Order (FFACO) (1996, as amended February 2008) and the Streamlined Approach for Environmental Restoration (SAFER) Plan (U.S. Department of Energy, National Nuclear Security Administration Nevada Site Office [NNSA/NSO], 2007). CAU 121 consists of the following three Corrective Action Sites (CASs) located in Area 12 of the Nevada Test Site (NTS) (Figure 1):

- CAS 12-01-01, Aboveground Storage Tank

- CAS 12-01-02, Aboveground Storage Tank

- CAS 12-22-26, Drums; 2 AST's

\subsection{Purpose}

CAU 121, Storage Tanks and Miscellaneous Sites, consists of three CASs located in Area 12 of the NTS. No further action with implementation of best management practices (BMPs) was the corrective action alternative chosen for CASs 12-01-01 and 12-22-26, and clean closure was the corrective action alternative chosen for CAS 12-01-02. The purpose of this CR is to provide a summary of the completed closure activities, documentation of waste disposal, and analytical data to confirm that the remediation goals were met.

\subsection{SCOPE}

The closure strategy for CAU 121 was as follows:

- CAS 12-01-01, Aboveground Storage Tank, consisted of one empty aboveground storage tank (AST) and associated impacted soil, if any. No contaminants of concern (COCs) were present; therefore, no further action was chosen as the corrective action alternative. As a best management practice (BMP), the empty AST was removed and disposed as sanitary waste.

- CAS 12-01-02, Aboveground Storage Tank, consisted of one empty AST and associated impacted soil, if any. Sample results showed that polychlorinated biphenyls (PCBs) exceeded the preliminary action level (PAL) in the soil beneath the AST. PCBs could possibly have originated from the AST contents; therefore, PCBs were considered COCs, and clean closure was chosen as the corrective action alternative. Approximately 5 cubic yards $\left(\mathrm{yd}^{3}\right)$ of soil were excavated and disposed as petroleum hydrocarbon PCB remediation waste, and approximately $13 \mathrm{yd}^{3}$ of soil were disposed as PCB remediation waste. Cleanup samples were collected to confirm that the remaining soil did not contain PCBs above the PAL. Benzo(a)pyrene, dibenz(a,h)anthracene, and total petroleum hydrocarbons (TPH) were also present above the PALs. Sample results indicated that the degraded asphalt adjacent to the site and surrounding the Area 12 Camp water tank was the likely source of these compounds; therefore, they were not considered COCs. As a BMP, the empty AST was removed and disposed as sanitary waste. 


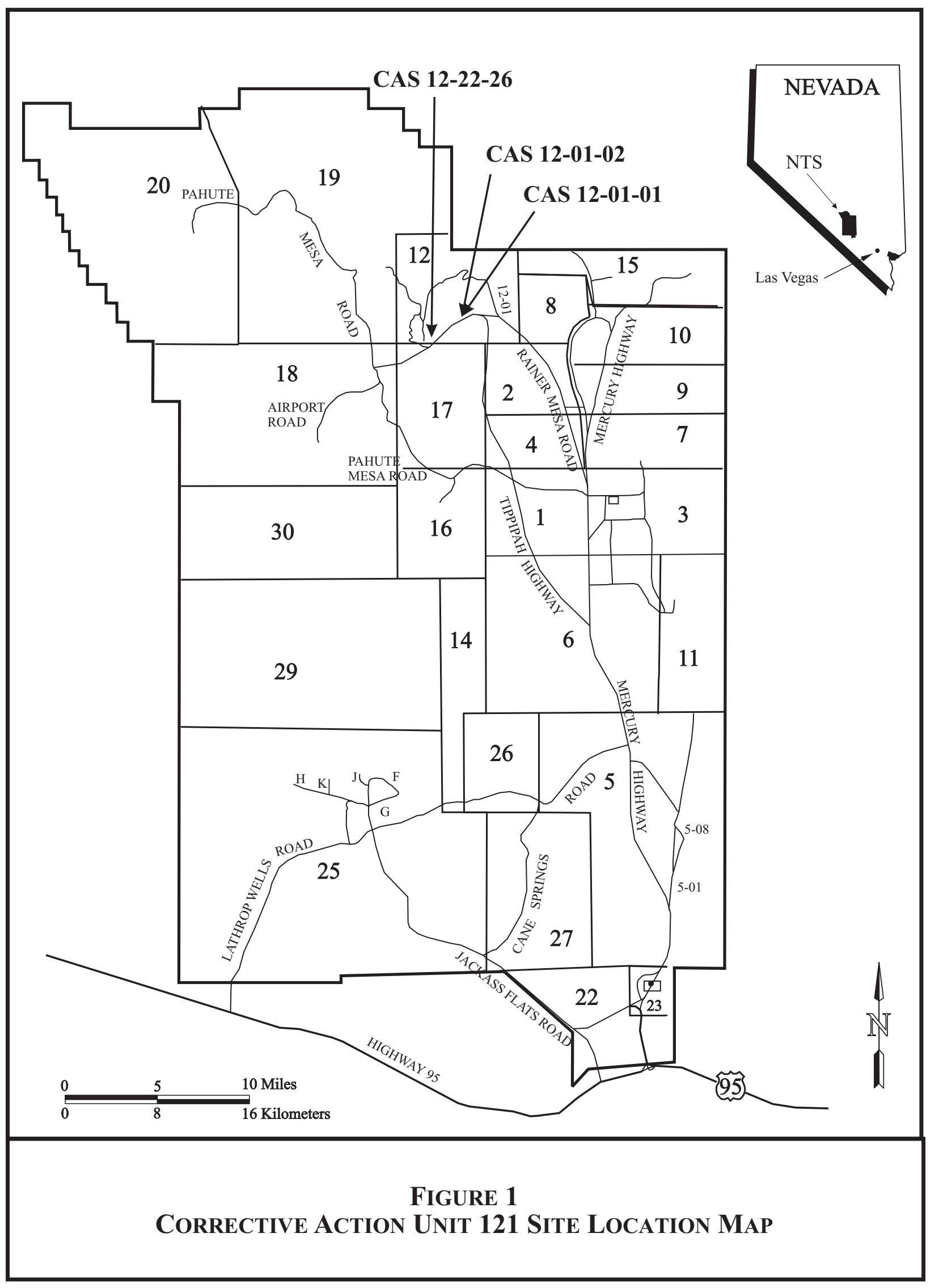


- CAS 12-22-26, Drums; 2 AST's, consists of two areas. The first area, the drum area, consisted of soil in an area where drums of unknown contents or condition had previously been stored. The second area, the tank area, consisted of an AST and associated impacted soil, if any. Sample results showed that TPH exceeded the PAL in both the drum area and the tank area; however, the volatile organic compound (VOC) and semi-volatile organic compound (SVOC) hazardous constituents of TPH did not exceed the final action levels (FALs). Therefore, TPH was not considered a COC, and no further action was chosen as the corrective action alternative. As a BMP, the empty AST was removed and disposed as sanitary waste.

\subsection{Closure Report Contents}

This CR includes the following sections:

- Section 1.0 - Introduction

- Section 2.0 - Closure Activities

- Section 3.0 - Waste Disposition

- Section 4.0 - Closure Verification Results

- Section 5.0 - Conclusions and Recommendations

- Section 6.0 - References

- Appendix A - Data Quality Objectives

- Appendix B - Sample Analytical Results

- Appendix C - Waste Disposition Documentation

- Appendix D - Site Closure Photographs

- Appendix E - Nevada Division of Environmental Protection Comment Response Form

- Library Distribution List

This report was developed using information and guidance from the following documents:

- SAFER Plan for CAU 121 (NNSA/NSO, 2007)

- Industrial Sites Quality Assurance Project Plan (QAPP) (U.S. Department of Energy, National Nuclear Security Administration Nevada Operations Office [NNSA/NV], 2002)

Data quality objectives developed for site characterization of CAU 121 are presented in the CAU 121 SAFER Plan (NNSA/NSO, 2007). Conceptual site models (CSMs) were developed for CAU 121 based on process knowledge, historical information, and personnel interviews. No variations to the CSM were identified. The following CSMs were confirmed through inspections, sample collection and analysis, and excavation activities:

- At CAS 12-01-01, the primary CSM of no release greater than action levels was confirmed.

- At CAS 12-01-02, the alternate CSM of a possible release from the tank was confirmed. 
CAU 121 Closure Report

Section: Introduction

Revision: 0

Date: September 2008

- At CAS 12-22-26, the primary CSM of no release greater than FALs was confirmed for the drum area, and the alternate CSM of no release greater than the FALs was confirmed for the tank area. 


\subsection{CLOSURE ACTIVITIES}

This section details the specific activities completed during the closure of CAU 121, deviations from the SAFER Plan, the schedule of completed activities, and the final site plan. Photographs in Appendix D document the conditions of the sites before corrective actions were implemented, while field work was in progress, and after completion of work.

\subsection{Description OF CORRECTIVE ACTION ACTIVITIES}

Closure activities for CAU 121 were completed according to the SAFER Plan (NNSA/NSO, 2007). The following sections detail the closure activities as completed.

\subsubsection{Preplanning and Site Preparation}

Prior to closure activities, the following documents were prepared:

- National Environmental Policy Act Checklist

- Site-Specific Health and Safety Plans

- Field Management Plan

- NNSA/NSO Real Estate/Operations Permits

- Work control packages

\subsubsection{Closure Activities}

The following sections detail the closure activities completed at each CAS.

\subsubsection{Corrective Action Site 12-01-01, Aboveground Storage Tank}

This site, located in Area 12 near the Area 12 Camp, consisted of one 650-gallon (gal) AST and soil below the AST that may have been impacted by the AST contents. Staining was not observed, and the tank was not rusted through. One soil sample and a field duplicate were collected from below the open tank port, which was considered to be the most likely location for contamination of the soil (Figure 2). The samples were analyzed for VOCs, SVOCs, Resource Conservation and Recovery Act (RCRA) metals, PCBs, TPH, gross alpha and beta, and gamma emitters.

Sample analytical results showed all concentrations to be less than the PALs with the exception of arsenic (Table 2). Arsenic was detected in the sample and the field duplicate at concentrations of 2.6 and 3.0 milligrams per kilogram $(\mathrm{mg} / \mathrm{kg})$, respectively, which exceeds the U.S.

Environmental Protection Agency (EPA) Region IX preliminary remediation goal (PRG) (EPA, 2004 ) of $1.65 \mathrm{mg} / \mathrm{kg}$. However, the natural background concentration of arsenic in soil at the NTS exceeds the PRG. The FAL for arsenic is therefore established as the natural background concentration, $23 \mathrm{mg} / \mathrm{kg}$, which is calculated as the mean plus two times the standard deviation of the mean for sediment samples collected by the Nevada Bureau of Mines and Geology (NBMG) throughout the Nevada Test and Training Range (formerly the Nellis Air Force Range) 


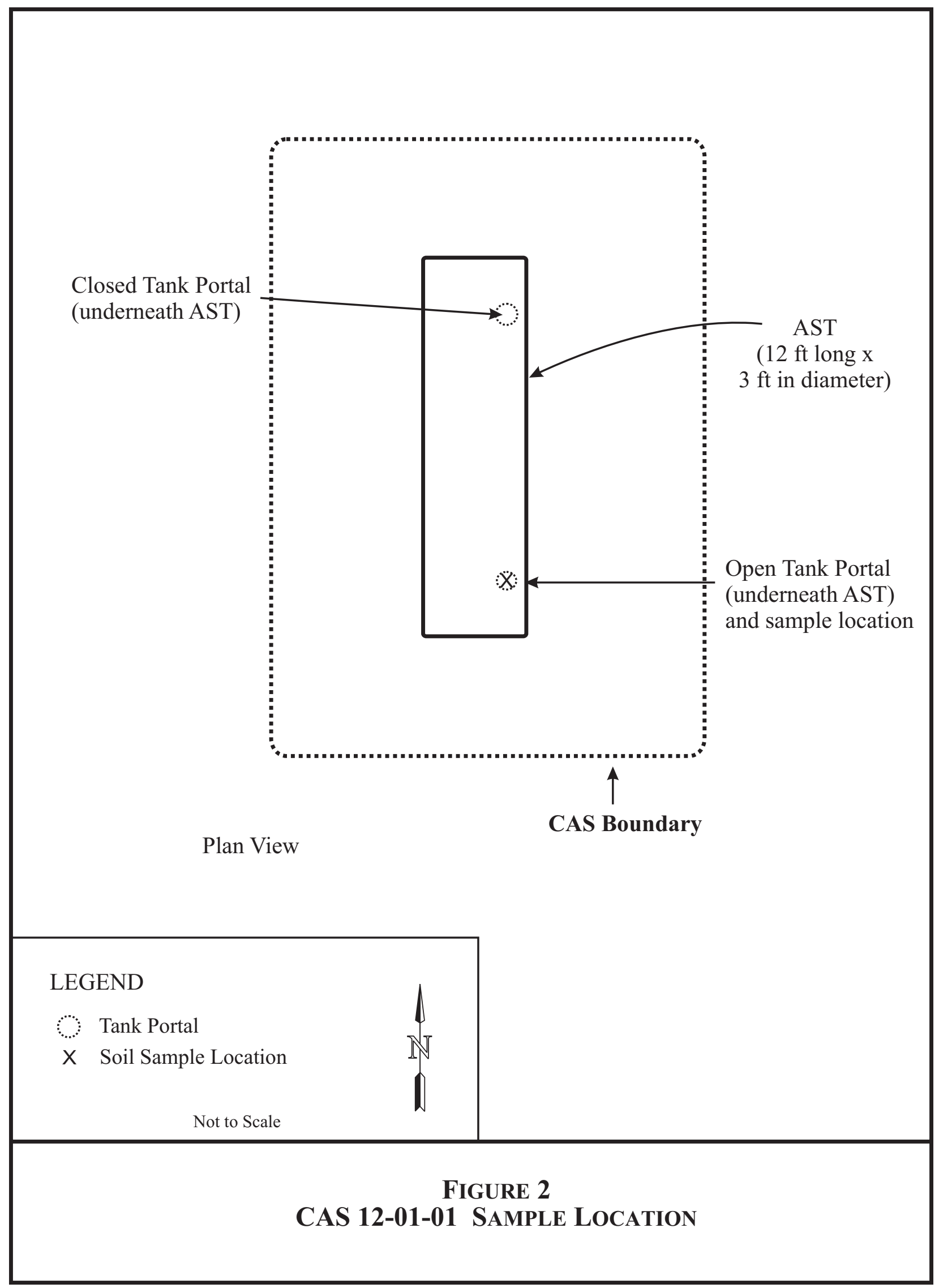


TABLe 2. CAS 12-01-01 Characterization SAMPLe ANAlytical Results

\begin{tabular}{|c|c|c|c|}
\hline \multirow{2}{*}{ CONTAMINANTS OF POTENTIAL CONCERN } & \multicolumn{3}{|c|}{ CONCENTRATION } \\
\hline & PAL & $\begin{array}{c}\text { SAMPLE \# } \\
\text { 120101-1 }\end{array}$ & $\begin{array}{c}\text { SAMPLE \# } \\
120101-2 \\
\end{array}$ \\
\hline \multicolumn{4}{|c|}{ VOCs (mg/kg) } \\
\hline Methylene Chloride & 21 & $0.024(\mathrm{~B})$ & $0.015(\mathrm{~B})$ \\
\hline \multicolumn{4}{|c|}{ SVOCs (mg/kg) } \\
\hline Bis(2-Ethylhexyl)phthalate & 120 & $0.035(\mathrm{~J})$ & $0.032(\mathrm{~J})$ \\
\hline \multicolumn{4}{|c|}{ RCRA Metals (mg/kg) } \\
\hline Arsenic & 1.65 & 2.6 & 3 \\
\hline Barium & 67,000 & 123 & 128 \\
\hline Cadmium & 450 & $0.37(\mathrm{LT})$ & $0.38(\mathrm{LT})$ \\
\hline Chromium & 450 & 3.9 & 4.4 \\
\hline Lead & 800 & 9.4 & 14.2 \\
\hline \multicolumn{4}{|c|}{ TPH (mg/kg) } \\
\hline Diesel-Range Organics & $\mathrm{NE}$ & 21 & $3.1(\mathrm{~J})$ \\
\hline Oil-Range Organics & $\mathrm{NE}$ & 54 & 15 \\
\hline $\mathrm{TPH}$ & 100 & 75 & 18 \\
\hline \multicolumn{4}{|c|}{ Radiological (pCi/g) } \\
\hline Gross alpha & $\mathrm{NE}$ & 6.46 & 4.76 \\
\hline Gross beta & $\mathrm{NE}$ & 10.5 & 10.8 \\
\hline Cesium-137 & 12.2 & 1.27 & $0.951(\mathrm{LT})$ \\
\hline Thorium-234 & 143 & $3.07(\mathrm{TI})$ & 3.36 \\
\hline
\end{tabular}

B - detected in trip blank at 4 micrograms per liter

$\mathrm{J}$ - estimated

LT - less than requested detection limit but greater than method detection limit. The laboratory report for RCRA metals (in Appendix B) uses a "B" for this flag.

$\mathrm{mg} / \mathrm{kg}$ - milligram(s) per kilogram

$\mathrm{ND}$ - not detected above detection limit

$\mathrm{NE}$ - none established

PAL - preliminary action level

$\mathrm{pCi} / \mathrm{g}$ - picocuries(s) per gram

RCRA - Resource Conservation and Recovery Act

SVOCs - semi-volatile organic compounds

$\mathrm{TI}$ - tentatively identified

TPH - total petroleum hydrocarbons

VOCs - volatile organic compounds 
(NBMG, 1998; Moore, 1999). The concentration of arsenic is below the FAL; therefore, arsenic is not a COC for this site. An evaluation of the data quality is provided in Section 4.0, and laboratory data summary reports are included in Appendix B.

No further action was chosen as the corrective action alternative. As a BMP, the tank was removed and disposed as sanitary waste at the Area 9 U10c Industrial Landfill. Waste disposition documentation is provided in Appendix C.

\subsubsection{Corrective Action Site 12-01-02, Aboveground Storage Tank}

This site, located near the water supply tanks for the Area 12 Camp, consisted of one 140-gal AST and soil below the AST that may have been impacted by the AST contents. Radiological field screening showed no indication of elevated radioactivity. Staining was not observed, and the tank was not rusted through; however, there were numerous tank openings from which AST contents could have been released to the soil (Figure 3). One sample was collected from below the open tank portal that was the lowest tank opening and the most likely location for a release from the AST. The sample was analyzed for VOCs, SVOCs, PCBs, RCRA metals, TPH, gross alpha and beta, and gamma emitters. The tank was removed and disposed as sanitary waste at the Area 9 U10c Industrial Landfill.

Characterization analytical results greater than the detection limits are presented in Table 3. VOCs and radiological compounds were less than the PALs. RCRA metals were less than the PALs with the exception of arsenic, which was at concentrations consistent with local native soil conditions (see Section 2.1.2.1). The PALs were exceeded for oil-range petroleum hydrocarbons and SVOCs (i.e., benzo(a)pyrene and dibenz(a,h)anthracene). PCBs, at $0.96 \mathrm{mg} / \mathrm{kg}$, were less than the PAL of $1 \mathrm{mg} / \mathrm{kg}$; however, the actual PCB concentration could be greater than the PAL because of low recovery in the spiked sample. Oil-range petroleum hydrocarbons, benzo(a)pyrene, dibenz(a,h)anthracene, and PCBs were therefore the target compounds for additional investigation and/or cleanup.

Phase 1 cleanup activities took place in June 2008. Approximately $5 \mathrm{yd}^{3}$ of soil were excavated down to a hard layer of volcanic tuff that was encountered from 6 inches to several feet below the ground surface. Based on characterization results, the excavated soil met the criteria for disposal at the Area 9 U10c Industrial Landfill and was disposed as petroleum hydrocarbon PCB remediation waste. Six cleanup samples were collected from the base and sides of the excavation (Figure 4) and analyzed for SVOCs, TPH, and PCBs (Table 4). TPH and dibenz(a,h)anthracene were less than the PALs. PCBs (1.1 mg/kg Aroclor 1254) and benzo(a)pyrene $(0.23 \mathrm{mg} / \mathrm{kg})$ were still present at concentrations greater than the PALs $(1.0$ and $0.21 \mathrm{mg} / \mathrm{kg}$, respectively) at sample location 120102-V4, on the east side of the excavation.

$\operatorname{Dibenz}(\mathrm{a}, \mathrm{h})$ anthracene and benzo(a)pyrene were less than the detection limit in several samples; however, the detection limit $(0.350 \mathrm{mg} / \mathrm{kg})$ was greater than the PAL for these compounds. The analytical laboratory was contacted to review the data and determine whether these compounds were present at concentrations greater than the $0.210 \mathrm{mg} / \mathrm{kg}$ PAL. The laboratory responded that if either of these two compounds was present at concentrations at or above $0.210 \mathrm{mg} / \mathrm{kg}$, they would have been detected and flagged as an estimated value ("J"). The absence of this flag indicates that they were not present above the PAL. Updated reports could not be provided because the sample hold times had been exceeded when this was found. 


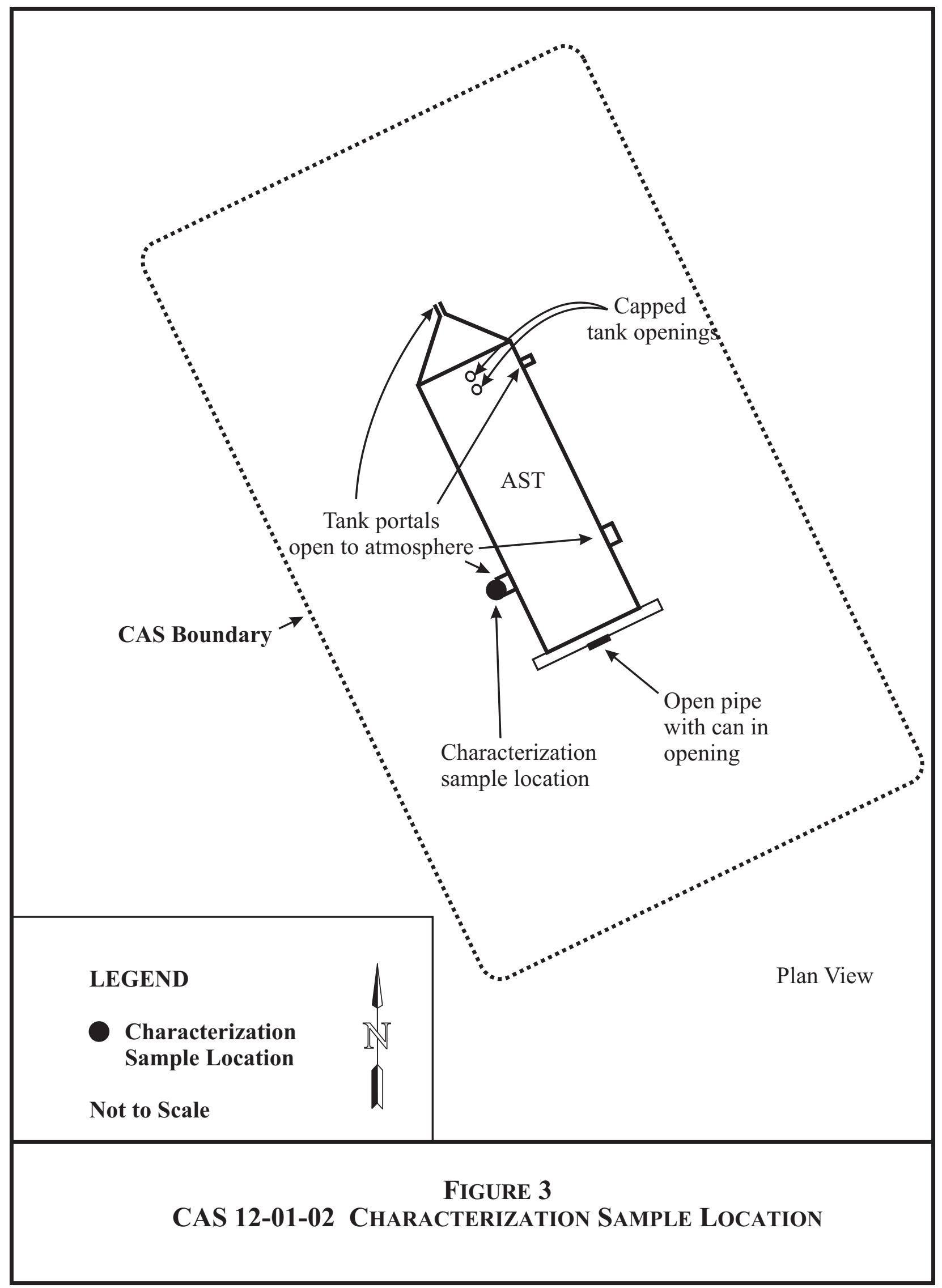


TABle 3. CAS 12-01-02 CharaCterization SAMPle ANALYTICAL Results

\begin{tabular}{|c|c|c|}
\hline \multirow[b]{2}{*}{$\begin{array}{l}\text { CONTAMINANTS OF POTENTIAL } \\
\text { CONCERN } \\
\end{array}$} & \multicolumn{2}{|c|}{ CONCENTRATION } \\
\hline & PAL & $\begin{array}{c}\text { SAMPLE } \\
120102-1\end{array}$ \\
\hline \multicolumn{3}{|c|}{$\operatorname{VOCs}(\mathrm{mg} / \mathrm{kg})$} \\
\hline Methylene Chloride & 21 & $0.014(\mathrm{~B})$ \\
\hline \multicolumn{3}{|c|}{ SVOCs (mg/kg) } \\
\hline Acenaphthene & 29,000 & $0.12(\mathrm{~J})$ \\
\hline Anthracene & 100,000 & $0.17(\mathrm{~J})$ \\
\hline Benzo(a)antrhacene & 21 & 1.6 \\
\hline Benzo(b)fluoranthene & 2.1 & 1.1 \\
\hline Benzo(k)fluoranthene & 21 & 1.4 \\
\hline Benzo(g,h,i)perylene & $\mathrm{NE}$ & 0.88 \\
\hline Benzo(a)pyrene & 0.21 & 1.5 \\
\hline bis(2-Ethylhexyl)phthalate & 120 & $0.066(J)$ \\
\hline Butylbenzylphthalate & 100,000 & 0.97 \\
\hline Carbazole & 86 & $0.15(\mathrm{~J})$ \\
\hline Chrysene & 0.21 & 2.0 \\
\hline Dibenz(a,h)anthracene & 0.21 & 0.39 \\
\hline Di-n-butylphthalate & 62,000 & $0.044(\mathrm{~J})$ \\
\hline Fluoranthene & 22,000 & $3.8(\mathrm{D})$ \\
\hline Fluorene & 26,000 & $0.046(\mathrm{~J})$ \\
\hline Indeno(1,2,3-cd)pyrene & 2.1 & 0.87 \\
\hline Phenanthrene & $\mathrm{NE}$ & 1.3 \\
\hline Pyrene & 29,000 & $4.4(\mathrm{D})$ \\
\hline \multicolumn{3}{|c|}{ RCRA Metals (mg/kg) } \\
\hline Arsenic & 1.65 & $1.9(\mathrm{LT})$ \\
\hline Barium & 67,000 & 124 \\
\hline Cadmium & 450 & $0.2(\mathrm{LT})$ \\
\hline Chromium & 450 & 2.4 \\
\hline Lead & 800 & 24.1 \\
\hline
\end{tabular}


TABle 3. CAS 12-01-02 Characterization SAMPle ANAlytical Results (CONTINUED)

\begin{tabular}{|c|c|c|}
\hline \multirow[b]{2}{*}{$\begin{array}{c}\text { CONTAMINANTS OF POTENTIAL } \\
\text { CONCERN }\end{array}$} & \multicolumn{2}{|c|}{ CONCENTRATION } \\
\hline & PAL & $\begin{array}{l}\text { SAMPLE \# } \\
\text { 120102-1 }\end{array}$ \\
\hline \multicolumn{3}{|c|}{ TPH (mg/kg) } \\
\hline Diesel-range organics & $\mathrm{NE}$ & 60 \\
\hline Oil-range organics & $\mathrm{NE}$ & 110 \\
\hline ТРН & 100 & 170 \\
\hline \multicolumn{3}{|c|}{ PCBs (mg/kg) } \\
\hline Aroclor 1254 & $\mathrm{NE}$ & 0.67 \\
\hline Aroclor 1260 & $\mathrm{NE}$ & 0.29 \\
\hline PCBs & 1 & 0.96 \\
\hline \multicolumn{3}{|c|}{ Radiological (pCi/g) } \\
\hline Gross alpha & $\mathrm{NE}$ & 6.42 \\
\hline Gross beta & $\mathrm{NE}$ & 7.7 \\
\hline Cs-137 & 12.2 & $0.196(\mathrm{LT})$ \\
\hline Th-234 & 143 & 2.27 \\
\hline
\end{tabular}

$\mathrm{B}$ - detected in trip blank at 4 micrograms per liter

$\mathrm{D}$ - diluted

J-estimated

LT - less than requested detection limit but greater than method detection limit. The laboratory report for RCRA metals (in Appendix B) uses a "B" for this flag.

$\mathrm{mg} / \mathrm{kg}$ - milligram(s) per kilogram

$\mathrm{NE}$ - none established

PCBs - polychlorinated biphenyls

$\mathrm{pCi} / \mathrm{g}$ - picocuries(s) per gram

RCRA - Resource Conservation and Recovery Act

SVOCs - semi-volatile organic compounds

TI - tentatively identified

$\mathrm{TPH}$ - total petroleum hydrocarbons

VOCs - volatile organic compounds 


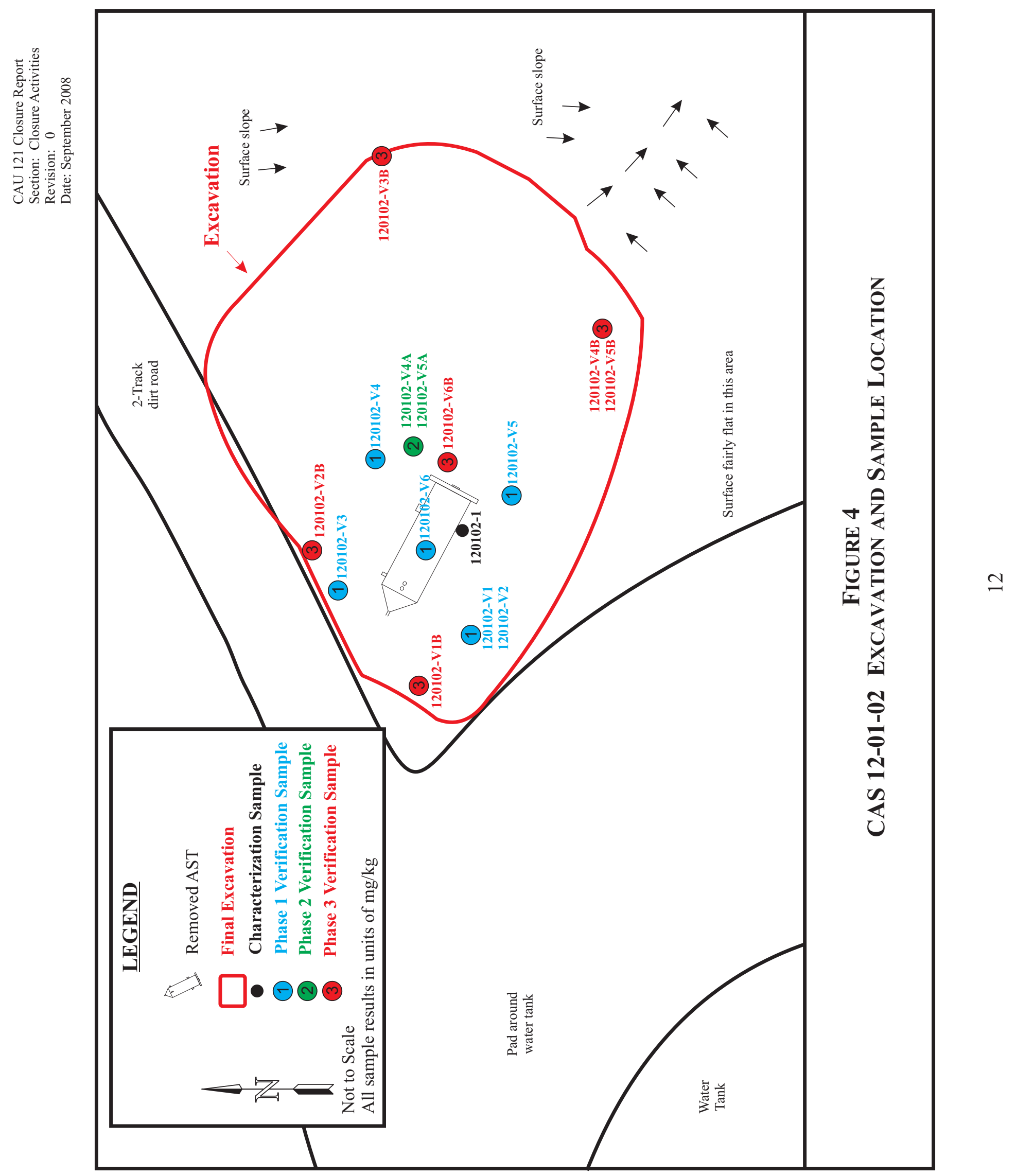



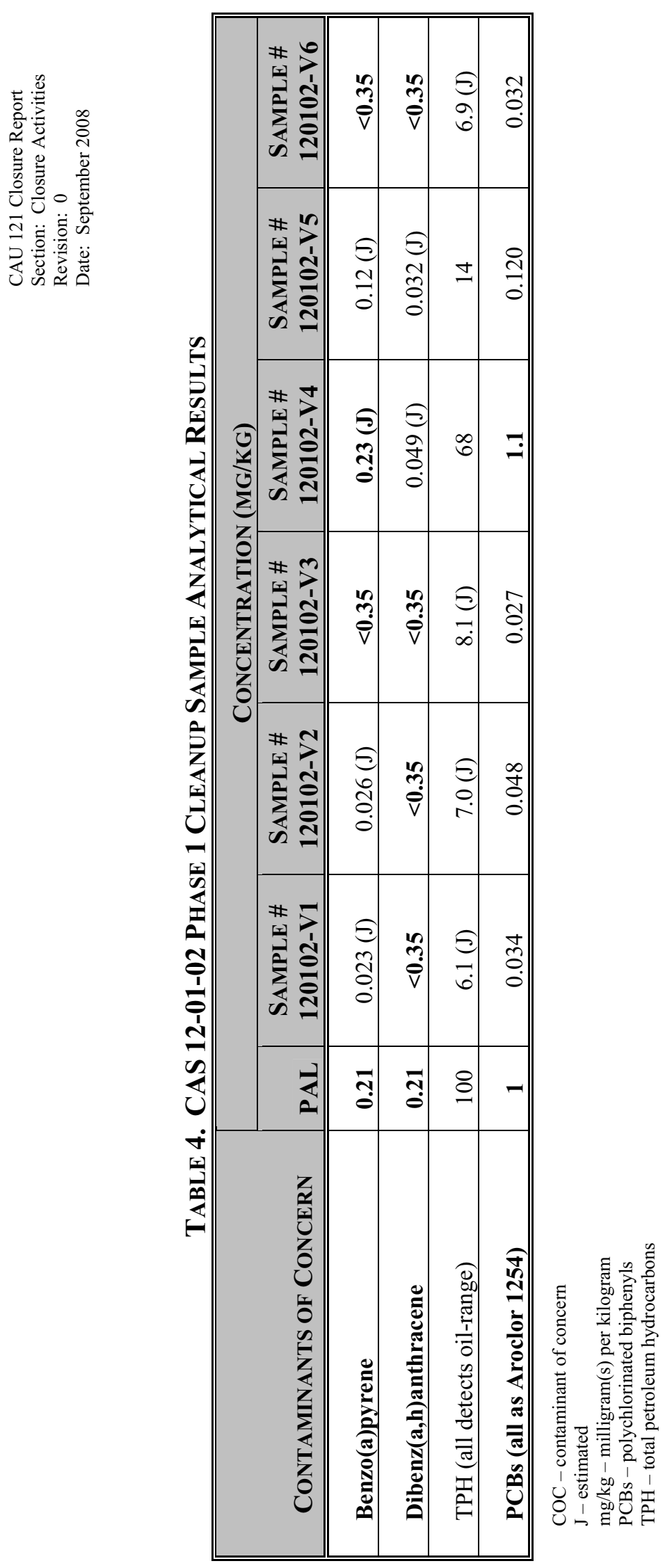
On June 19, 2008, phase 2 cleanup activities were conducted. Approximately $8 \mathrm{yd}^{3}$ of soil were excavated from the eastern corner of the existing excavation (in the vicinity of the 120102-V4 sample). Excavated soil met the criteria for disposal at the Area 9 U10c Industrial Landfill and was disposed as PCB remediation waste. One cleanup sample and a field duplicate were collected from the base of the excavation (Figure 4) and analyzed for dibenz(a,h)anthracene, benzo(a)pyrene, and PCBs (Table 5). PCBs and dibenz(a,h)anthracene were less than the PALs. However, benzo(a)pyrene $(0.260 \mathrm{mg} / \mathrm{kg})$ remained at concentrations greater than the PAL.

On July 10, 2008, phase 3 cleanup activities were conducted. Approximately $5 \mathrm{yd}^{3}$ of soil were excavated to the east of the original excavation and down to the volcanic tuff layer. Excavated soil met the criteria for disposal at the Area 9 U10c Industrial Landfill and was disposed as PCB remediation waste. The excavation was approximately 20 feet across from east to west and 18 feet across from north to south. Six cleanup samples were collected from the base and sides of the excavation (Figure 4) and analyzed for dibenz(a,h)anthracene, benzo(a)pyrene, and TPH (Table 6). TPH was below the PAL. Dibenz(a,h)anthracene and benzo(a)pyrene remained at concentrations greater than the PALs on the east and south sides of the excavation.

The slope of the volcanic tuff was planar and to the south, as illustrated in Photograph 8 in Appendix D. The samples collected on the eastern edge of the excavation were at approximately the same elevation as the characterization sample collected from below the AST (120102-V6), indicating that the contamination did not likely originate from the tank. Additionally, the concentrations of SVOCs on the eastern edge of the excavation are as high as or higher than their concentrations in the characterization sample collected from below the AST. A more critical evaluation of the analytical results and other potential sources in the area was performed.

The excavation was adjacent to the Area 12 Camp water tanks. Closer investigation of the area revealed the presence of a black material that appeared to be a tar sealant (Figure 5) and a black granular material that may have been degraded paving material (Figure 6) consistent with asphalt-type material ubiquitous around the NTS. Dibenz(a,h)anthracene and benzo(a)pyrene are known components of asphalt (Irwin, 1997; U.S. Department of Health and Human Services, 2005; EPA, 2008). In addition, background samples of asphalt material collected during CAU 219 corrective action investigation activities contained dibenz(a,h)anthracene and benzo(a)pyrene (NNSA/NSO, 2006a). Based on CAU 219 sample results and the pervasive nature of this material in the vicinity of CAS 12-01-02, the determination was made that the source of the compounds is likely asphalt-type material. Asphalt does not require corrective action, and TPH and SVOCs that were associated with the asphalt are not considered COCs for this site.

Although the source of the PCBs is unknown, they may have originated from the AST and have been considered COCs for this site. The excavation activities have been successful in removing PCBs that exceed the PAL; therefore, the site has been clean closed. The excavation was backfilled with clean soil. The backfilled area is shown in Photograph 9 in Appendix D. Waste disposition documentation for the tank and excavated soil is provided in Appendix C. An evaluation of the data quality is provided in Section 4.0, and laboratory data summary reports are included in Appendix B. 

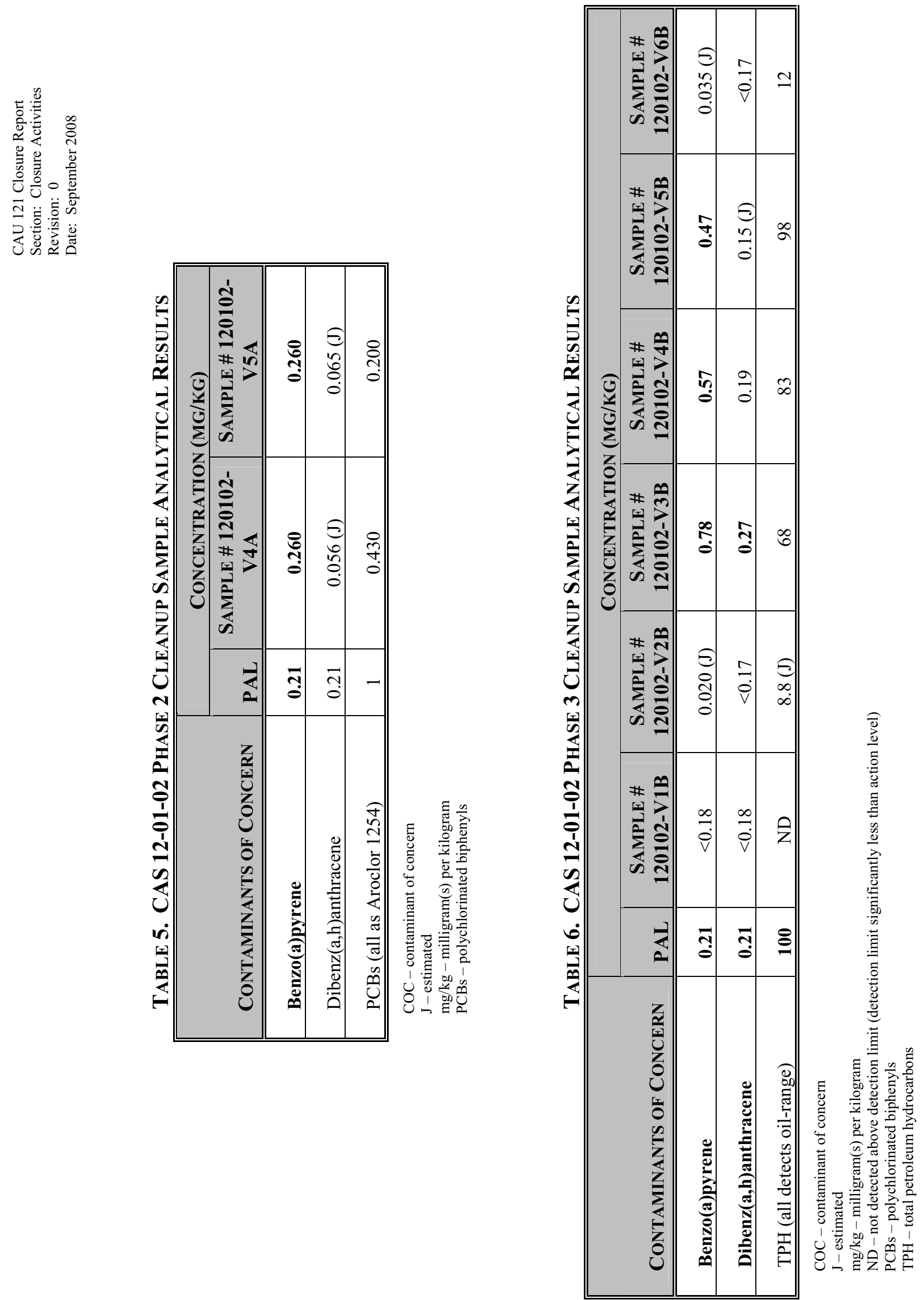


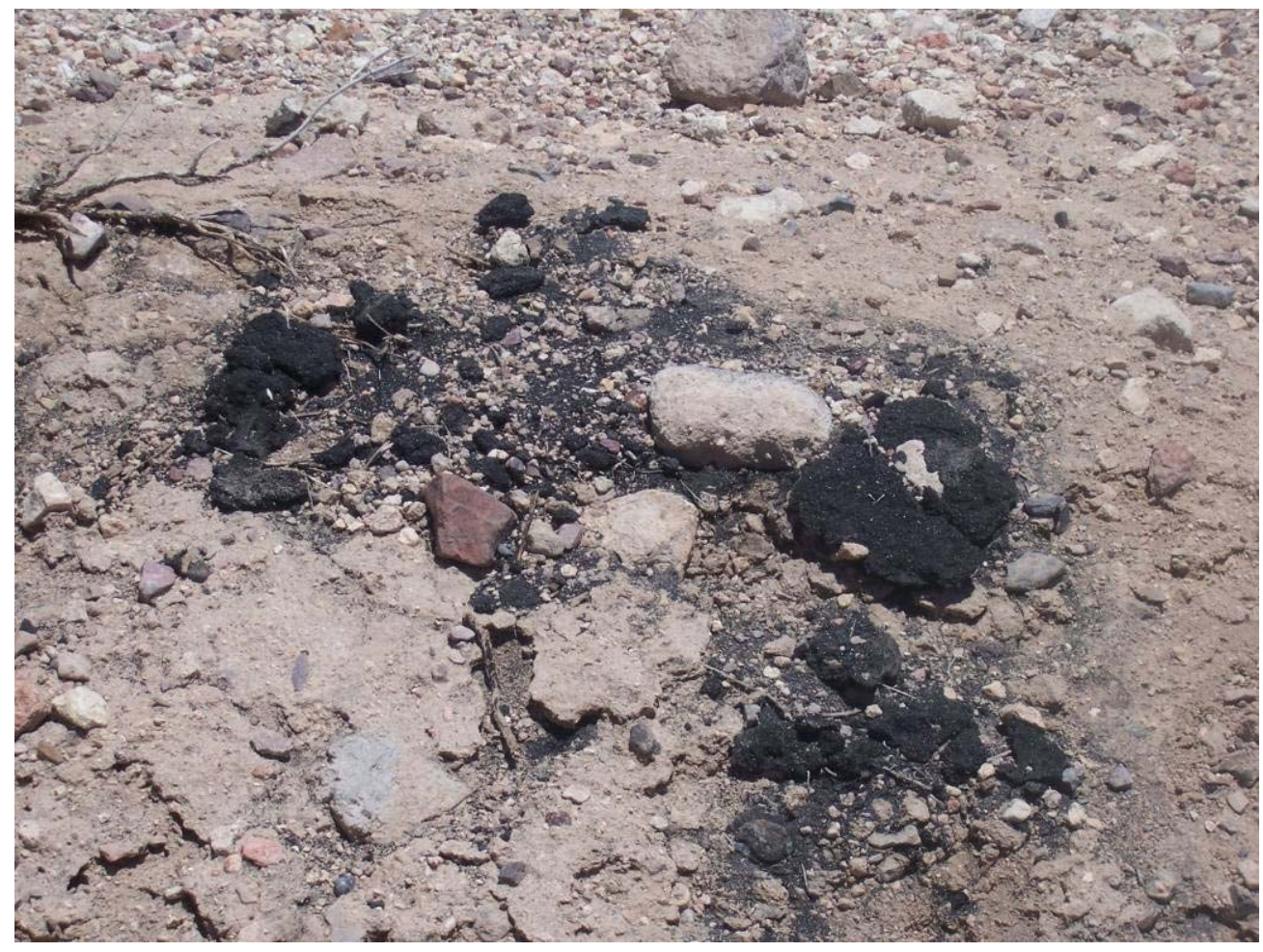

Figure 5. Tar Sealant-Like Material Near Area 12 Camp Water Tanks, 07/07/2008

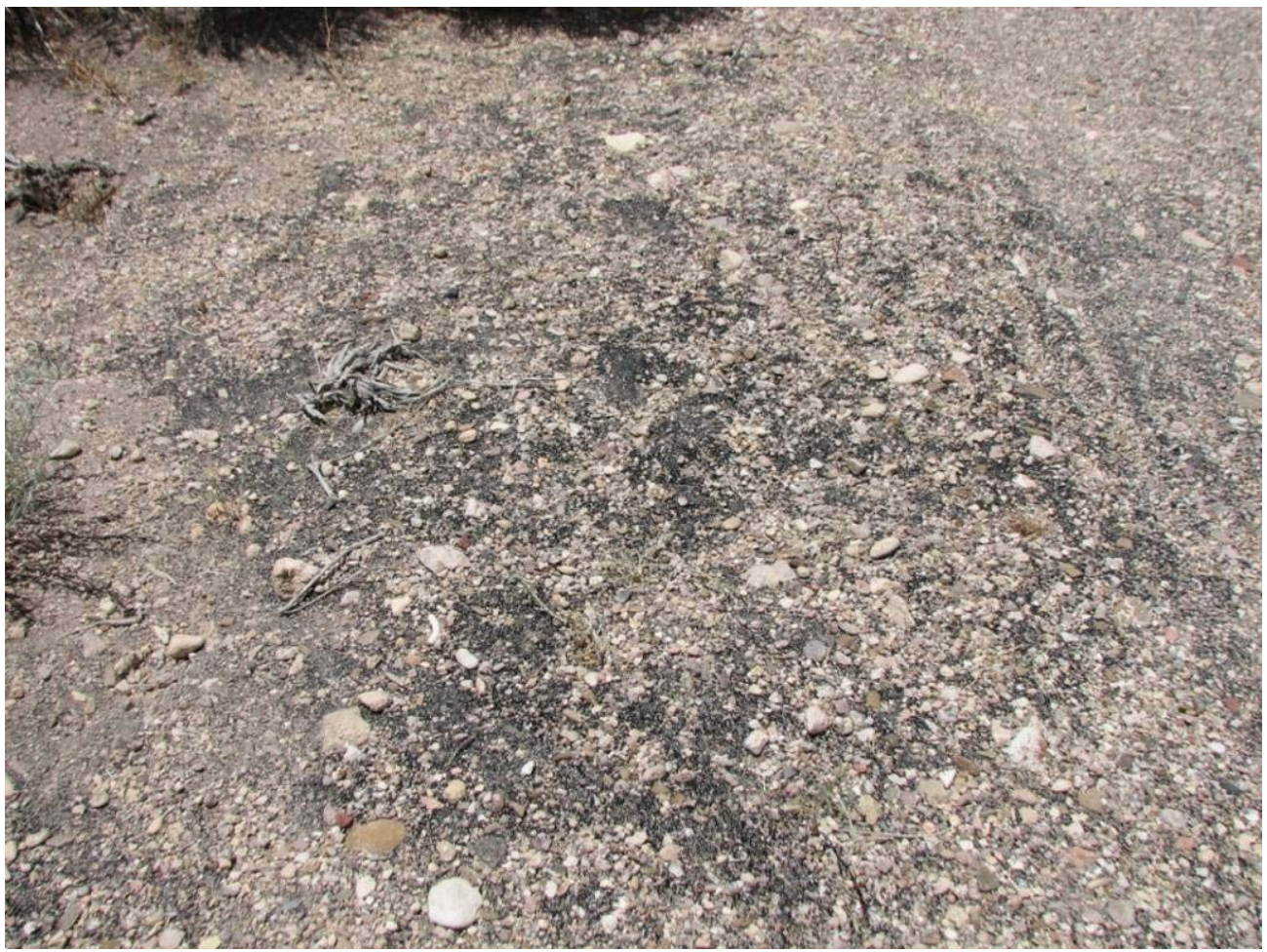

Figure 6. Asphalt-Like Material Near Area 12 Camp Water Tanks, 07/07/2008 


\subsubsection{Corrective Action Site 12-22-26, Drums; 2 AST's}

This site, located on the muckpile at the entrance to G-Tunnel in Area 12, consisted of one 1,800-gal AST, soil below the AST at two operational locations, and soil where drums were previously located near the AST.

Field screening and visual observations showed no indication of contamination. The most likely cause for AST-related releases would have been spills during filling of and dispensing from the tank. These operations would have taken place near the ends of the tank.

\subsection{Drum Area}

In the drum area, there were no biasing factors to indicate the presence of contamination, and drums were no longer present. Soil samples were collected from the grid locations identified by the Visual Sampling Program modeling software (Pacific Northwest National Laboratory, 2005) and as described in the SAFER Plan (NNSA/NSO, 2007) (Figure 7). Samples were analyzed for VOCs, SVOCs, RCRA metals, PCBs, TPH, gross alpha and beta, and gamma emitters.

Soil sample analytical results show VOCs, SVOCs, PCBs, and radiological compounds to be less than the PALs (Table 7). The only RCRA metal that exceeded the PAL was arsenic, and arsenic concentrations were consistent with local native soil concentrations (see Section 2.1.2.1). The only other contaminant exceeding PALs in the drum area was TPH, predominantly in the oil range.

\subsection{Tank Area}

In the tank area, soil samples were collected from locations most likely to have been impacted by releases from the tank. Soil samples were collected from where the ends of the tank would have been when the tank was located on both the north and the south sides of the train tracks (Figure 7). One additional soil sample was collected from where the tank had been temporarily stored when no longer in use, to the north of the tank area. Samples were analyzed for TPH.

TPH exceeded the PAL in three samples at the former operational area to the south of the train tracks and at the temporary tank storage location (Table 8, Figure 8). TPH concentrations at the former operational area to the north of the train tracks were less than the PAL. Petroleum hydrocarbons were in the oil range and similar to the drum area. 


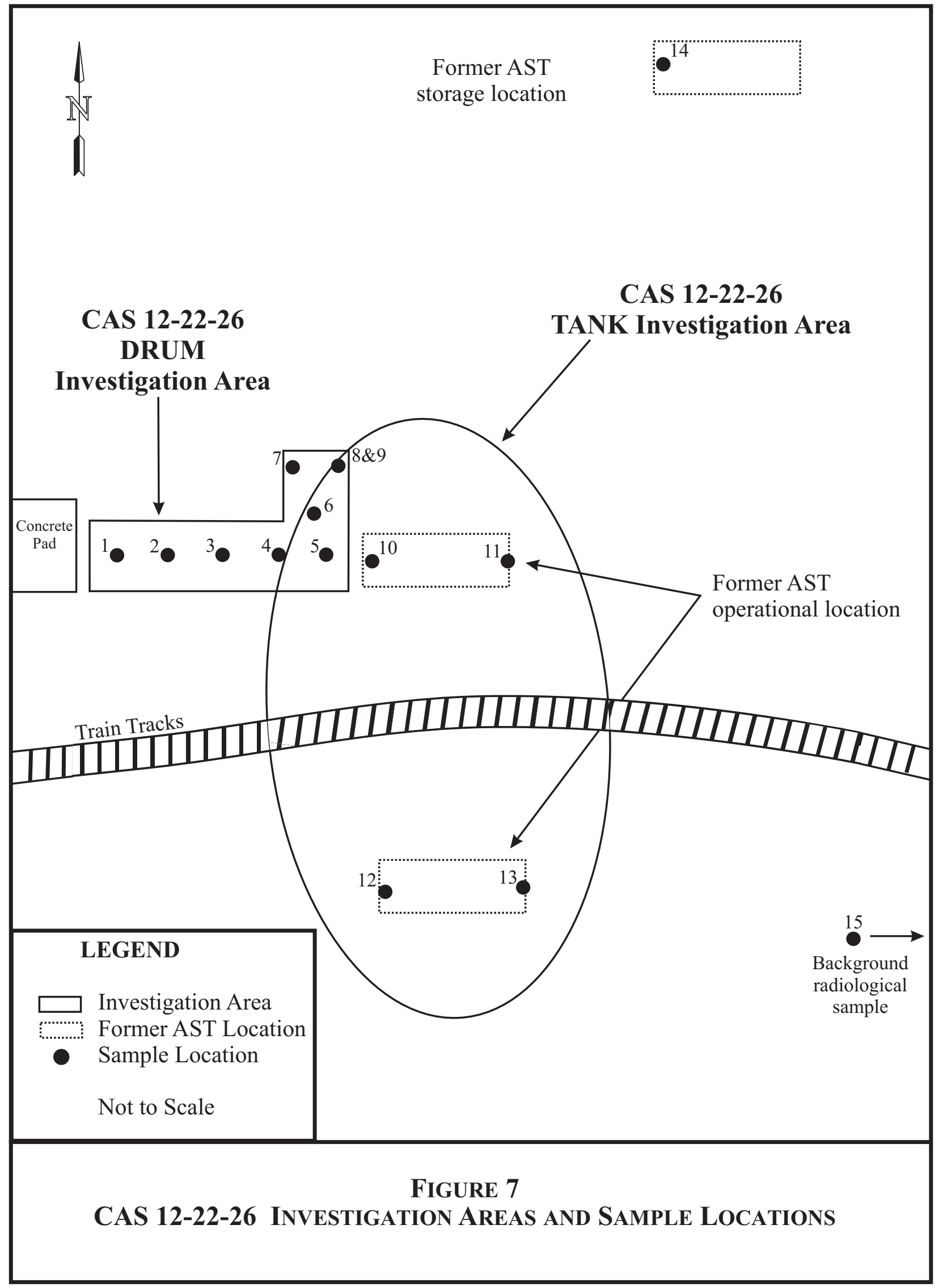




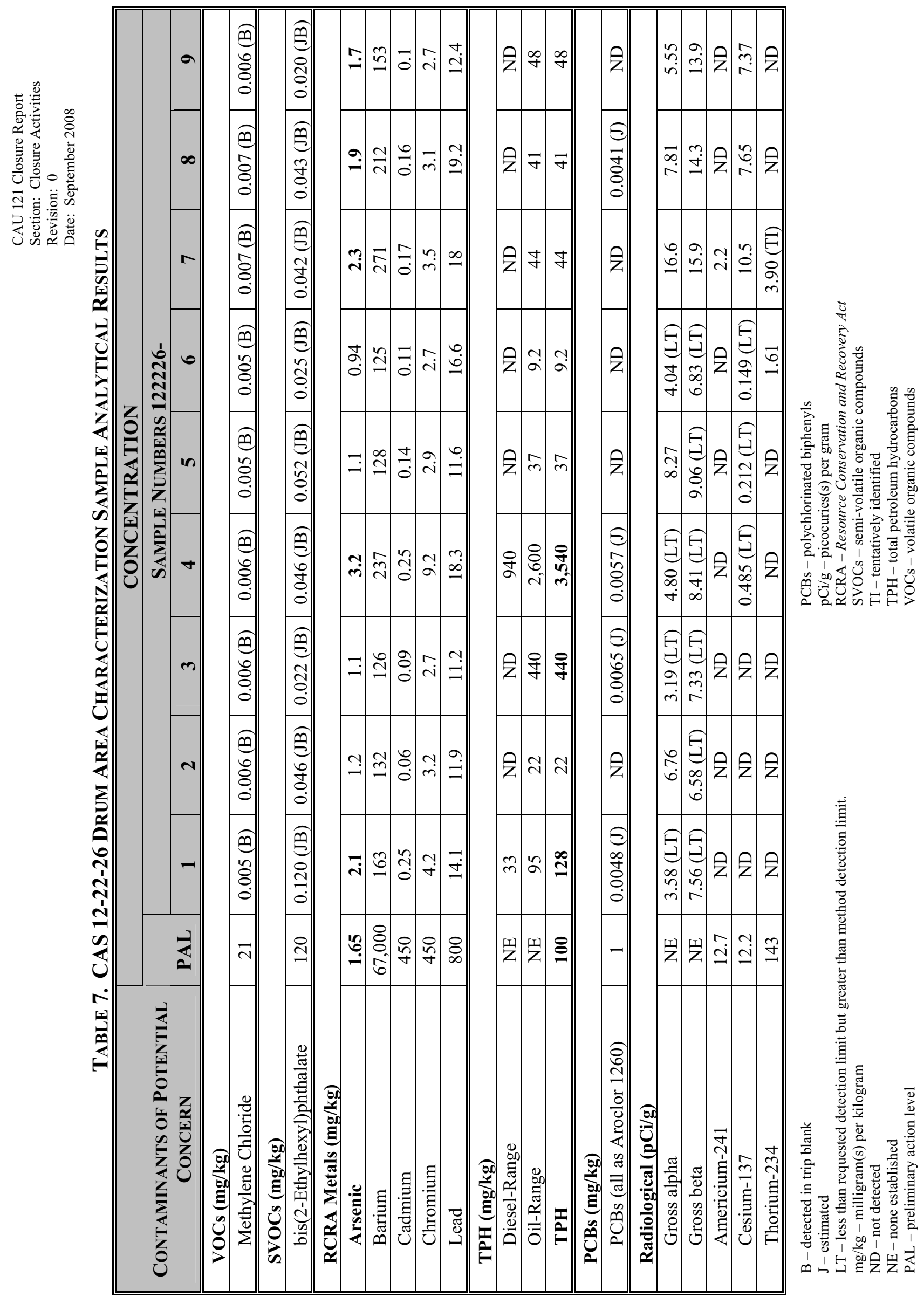


TAble 8. CAS 12-22-26 TANK Area Characterization SAMPle Analytical Results

\begin{tabular}{|c|c|c|c|c|c|c|}
\hline \multirow{3}{*}{$\begin{array}{l}\text { CONTAMINANTS OF } \\
\text { POTENTIAL CONCERN }\end{array}$} & \multicolumn{6}{|c|}{ CONCENTRATION (MG/KG) } \\
\hline & \multirow[b]{2}{*}{ PAL } & \multicolumn{5}{|c|}{ SAMPLE NUMBERS 122226- } \\
\hline & & 10 & 11 & 12 & 13 & 14 \\
\hline TPH (oil-range) & 100 & 31 & 13 & 210 & 210 & 250 \\
\hline
\end{tabular}

$\mathrm{mg} / \mathrm{kg}$ - milligram(s) per kilogram

$\mathrm{PAL}$ - preliminary action level

$\mathrm{TPH}$ - total petroleum hydrocarbons 


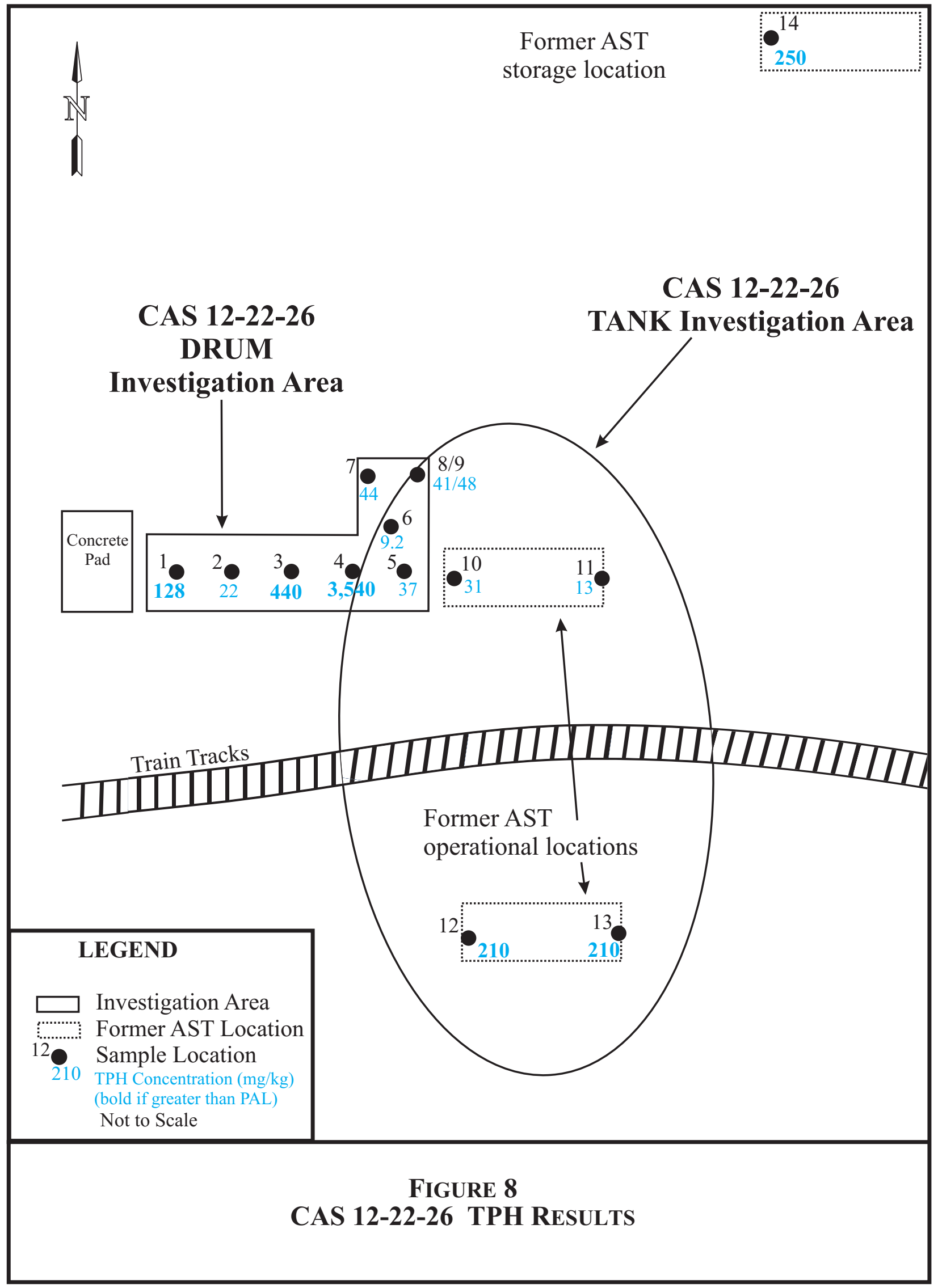




\subsection{Evaluation of CAS 12-22-26 Results}

TPH results are presented in Figure 8. Analytical results indicated that TPH, predominantely in the oil range, was present in both areas. In accordance with the Industrial Sites Project Establishment of Final Action Levels document (NNSA/NSO, 2006b), where TPH results exceed the $100 \mathrm{mg} / \mathrm{kg}$ PAL, a risk-based evaluation was conducted by individually evaluating the risk posed by the specific hazardous constituents of TPH. The hazardous constituents in motor oil are similar to diesel, although of lesser concentrations. The industrial PRGs for the hazardous constituents of diesel were therefore used as the site-specific FALs for this site.

Table 9 presents the VOC and SVOC hazardous constituents of diesel, the associated industrial PRGs for those constituents (i.e., the EPA Region IX PRGs), and the analytical results for soil sample 122226-4. The concentrations of VOCs and SVOCs in sample 122226-4 were compared with the PRGs to evaluate whether concentrations at the site exceed FALs. This sample was used because it had the highest TPH concentration of all the samples at this CAS. As indicated in Table 9, FALs were not exceeded for any of the hazardous constituents.

No further action was chosen as the corrective action alternative. As a BMP, the tank was removed and disposed as sanitary waste at the Area 9 U10c Industrial Landfill. Waste disposition documentation is provided in Appendix C. An evaluation of the sample data is included in Section 4.0, and laboratory data summary reports are included in Appendix B.

\subsection{DEVIATIONS FROM THE SAFER Plan AS APPROVED}

The SAFER Plan (NNSA/NSO, 2007) calls for a use restriction to be implemented if concentrations in the soil exceeding the PAL are not removed. TPH exceeded the PAL at CAS 12-22-26; however, the hazardous constituents of diesel did not exceed the PRGs, which were established as the FALs for this CAS. Therefore, TPH was not considered a COC, and a use restriction was not implemented.

At CAS 12-01-02, SVOCs (i.e., dibenz(a,h)anthracene and benzo(a)pyrene) remained at concentrations above the PALs. Because the contamination was deduced to likely be associated with asphalt-type material that is ubiquitous around the NTS, the SVOCs were not considered COCs, and a use restriction was not implemented. 
Table 9. Chemical Components of Diesel And Associated FALs

\begin{tabular}{|c|c|c|}
\hline CHEMICAL COMPOUND & $\begin{array}{c}\text { FAL } \\
\text { (MG/KG) }\end{array}$ & $\begin{array}{c}\text { SAMPLE } \\
\text { NUMBER } \\
122226-4 \\
\text { (MG/KG) }\end{array}$ \\
\hline 1,3,5-Trimethylbenzene & 70 & $<0.005$ \\
\hline 2-Methylnaphthalene ${ }^{1}$ & 190 & $<0.350$ \\
\hline Anthracene & 100,000 & $<0.350$ \\
\hline Benzo(a)anthracene & 2.1 & $<0.350$ \\
\hline Benzene & 1.4 & $<0.005$ \\
\hline Benzo(a)pyrene & 0.2 & $<0.350$ \\
\hline Benzo(b)fluoranthene & 21 & $<0.350$ \\
\hline Benzo(g,h,i)perylene & 29,000 & $<0.350$ \\
\hline Benzo(k)fluoranthene & 21 & $<0.350$ \\
\hline Chrysene & 210 & $<0.350$ \\
\hline Ethylbenzene & 400 & $<0.005$ \\
\hline Fluoranthene & 22,000 & $<0.350$ \\
\hline Fluorene & 26,000 & $<0.350$ \\
\hline Naphthalene & 190 & $<0.350$ \\
\hline n-Butylbenzene & 240 & $<0.005$ \\
\hline n-Propylbenzene & 240 & $<0.005$ \\
\hline Phenanthrene & 100,000 & $<0.350$ \\
\hline Pyrene & 29,000 & $<0.350$ \\
\hline Toluene & 520 & $<0.005$ \\
\hline Xylenes $^{2}$ & 420 & $<0.005$ \\
\hline
\end{tabular}

${ }^{1}$ Uses PRG for napthalene

${ }^{2}$ Total of $\mathrm{m}$-, $\mathrm{o}-$, and $\mathrm{p}$-xylenes

FAL - final action level

$\mathrm{mg} / \mathrm{kg}$ - milligram(s) per kilogram 


\subsection{Corrective ACtion SCHEdule as COMPleted}

Closure activities began in February 2008 and were completed in September 2008. Details of the schedule are provided in Table 10.

Table 10. Corrective ACtion Unit 121 Closure ACtivities Schedule

\begin{tabular}{|l|l|l||}
\hline \multicolumn{1}{|c|}{ CORRECTIVE ACTION SITE OR ACTIVITY } & \multicolumn{1}{c|}{ START DATE } & \multicolumn{1}{c|}{ END DATE } \\
\hline \hline Waste Characterization Sampling & February 13, 2008 & April 23, 2008 \\
\hline 12-01-01, Aboveground Storage Tank & February 13, 2008 & February 13, 2008 \\
\hline 12-01-02, Aboveground Storage Tank & February 13, 2008 & September 15, 2008 \\
\hline 12-22-26, Drums; 2 AST's & April 17, 2008 & April 23, 2008 \\
\hline
\end{tabular}

\subsection{Site Plan/Survey Plat}

As-built drawings were not required for CAU 121 closure activities. 


\subsection{WASTE DISPOSITION}

This section describes the waste streams generated during closure activities and their final disposition. Waste streams included sanitary waste, petroleum hydrocarbon PCB remediation waste, PCB remediation waste, and hazardous waste (HW). Waste disposition is summarized in Table 11 and discussed in detail in the following sections. Waste disposition documentation is included in Appendix C.

\subsection{Waste Minimization}

Industry standard waste minimization practices were applied throughout the course of closure activities. These practices included laboratory analysis of characterization samples to correctly characterize and segregate waste streams and to determine whether waste generation was needed. Empty tanks were crushed before being placed in the landfill units to minimize the volume occupied within the landfill.

\subsection{Waste MANAGEMENT}

All waste was managed according to applicable federal and state regulations, U.S. Department of Energy orders, and company procedures. Waste management areas (WMAs) were established throughout the project, as needed. All WMAs were identified with appropriate signs and boundaries to restrict unauthorized access. The WMAs were inspected on a weekly or monthly basis, as required, to ensure that all containers were intact, not leaking, and not exceeding storage duration times.

Waste containers were purchased either new or reconditioned. Prior to use, all containers were inspected to verify that they were in good condition (e.g., no leaks, rust, or dents), lined or made of material that would not react with the waste, and in compliance with U.S. Department of Transportation requirements. The containers remained closed while stored unless waste was being added. Containers were also handled in such a manner that the integrity of the container was not compromised. Appropriate labels were affixed, and relevant information was marked on the containers with an indelible marker. All information was legible and clearly visible.

\subsection{Waste Characterization}

Accurate and defensible analytical data were collected to correctly characterize waste. All tanks were empty and did not require sampling for waste determination. Process knowledge and field screening was adequate for determination of this waste stream. Samples collected to characterize the sites were adequate to determine waste disposition requirements for excavated soil. The laboratory data reports for waste characterization samples are included in Appendix B. All waste was screened to verify that radiological contamination was less than the free-release limit established in the NV/YMP Radiological Control Manual (NNSA/NSO, 2004). 

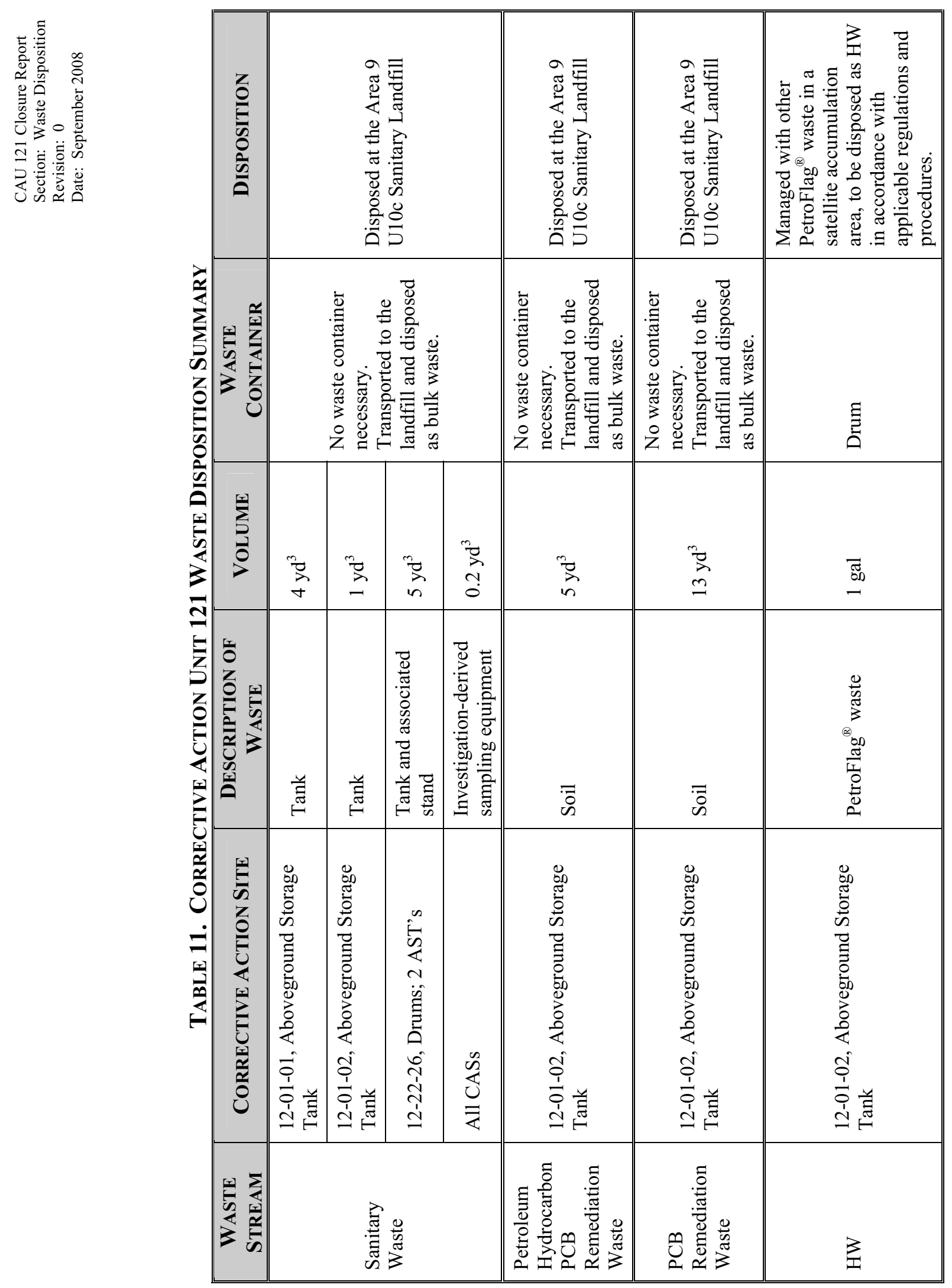
Samples were collected with disposable sampling equipment, placed in appropriately labeled sample containers, and secured with custody seals. All samples were labeled with a unique sample number, placed on ice, and transported under a chain of custody to the analytical laboratory. Standard quality assurance (QA)/quality control (QC) samples were collected. One blind duplicate was collected for each day's sampling event. A trip blank accompanied the samples whenever samples were collected for volatile organic analyses. Samples were analyzed by certified offsite contract laboratories. Analytical results were validated at the laboratory using stringent QA/QC procedures, including matrix spike/matrix spike duplicates (MS/MSDs), spiked surrogate recovery analysis, verification of analytical results, and data quality indicator requirements. Detailed information regarding the QA/QC program requirements can be found in the Industrial Sites QAPP (NNSA/NV, 2002).

\subsection{WASTE STREAMS ANd Disposal}

Waste streams generated during closure activities at CAU 121 included sanitary waste, petroleum hydrocarbon PCB remediation waste, PCB remediation waste, and HW. Waste disposition documentation is included in Appendix C.

\subsubsection{Sanitary Waste}

Sanitary waste included tanks, sampling equipment, and other investigation-derived waste. Approximately $10 \mathrm{yd}^{3}$ of sanitary waste were transported in end-dump trucks to the Area $9 \mathrm{U10c}$ Industrial Landfill for disposal.

\subsubsection{Petroleum Hydrocarbon PCB Remediation Waste}

Petroleum hydrocarbon PCB remediation waste consisted of soil that was excavated at CAS 12-01-02. Approximately $5 \mathrm{yd}^{3}$ of soil were transported via end-dump truck to the Area 9 U10c Industrial Landfill. The Area 9 U10c Sanitary Landfill accepts a limited amount of hydrocarbon-impacted waste and PCB remediation waste at concentrations less than $50 \mathrm{mg} / \mathrm{kg}$ PCB.

\subsubsection{PCB Remediation Waste}

PCB remediation waste consisted of soil that was excavated at CAS 12-01-02. Approximately $13 \mathrm{yd}^{3}$ of soil were transported via end-dump truck to the Area 9 U10c Industrial Landfill. The Area 9 U10c Sanitary Landfill accepts a limited amount of PCB remediation waste at concentrations less than $50 \mathrm{mg} / \mathrm{kg}$ PCB.

\subsubsection{Hazardous Waste}

A total of approximately 1 gal of HW was generated during closure activities. This waste consisted solely of PetroFlag ${ }^{\circledR}$ waste from field-screening soil for petroleum hydrocarbon concentrations at CAS 12-01-02. PetroFlag ${ }^{\circledR}$ waste is an ongoing investigation and remediation waste stream that is managed in a satellite accumulation area. This waste stream is managed and disposed in accordance with applicable regulations. 
CAU 121 Closure Report

Section: Waste Disposition

Revision: 0

Date: September 2008

THIS PAGE INTENTIONALLY LEFT BLANK 


\subsection{CLOSURE VERIFICATION RESULTS}

Site closure was accomplished by collecting and analyzing characterization samples, by excavating soil with concentrations greater than the PALs, by collecting and analyzing soil samples to determine whether remaining concentrations are less than FALs or to determine site conditions, and by visual observations and site closure photographs. Characterization samples were collected at all of the CASs. Cleanup samples were collected in three phases at CAS 12-01-02. Final cleanup sample results showed that dibenz(a,h)anthracene and benzo(a)pyrene were still present at concentrations greater than the PALs at this CAS; however, the source is neither from the CAS nor something requiring corrective action.

Details on closure activities and analytical results are presented in Section 2.0. Laboratory summary sheets with analytical results are provided in Appendix B. Photographs showing the stages of the closure activities and documenting removal of ASTs are provided in Appendix D.

\subsection{Data Quality Assessment}

Accurate and defensible analytical data were collected to verify that the CAU 121 closure objectives were met. Samples were collected with disposable sampling equipment and placed in appropriately labeled sample containers secured with custody seals. All samples were labeled with a unique sample number, placed on ice, and transported under a chain of custody. Standard QA/QC samples that were collected consisted of (1) a minimum of 1 blind duplicate per 20 samples and/or sample batch, (2) a trip blank that accompanied each batch of samples requiring VOC analysis, and (3) MS/MSD samples.

Samples were analyzed by certified offsite contract laboratories using methods identified in the CAU 121 SAFER Plan. Samples were analyzed for chemical compounds in accordance with the Test Methods for Evaluating Solid Waste Physical/Chemical Methods (EPA, 1996):

- VOCs - Method 8260B

- $\quad$ SVOCs - Method 8270C

- $\quad$ RCRA Metals - Method 6010B

- $\quad \mathrm{TPH}-$ Method 8015B

- $\quad$ PCBs - Method 8082

Analytical results were validated at the laboratory using stringent QA/QC procedures that included MS/MSD sample analysis, spiked surrogate recovery analysis, verification of analytical results, and evaluation of data quality indicator requirements. More detailed information regarding the $\mathrm{QA} / \mathrm{QC}$ program requirements and procedures can be found in the Industrial Sites QAPP (NNSA/NV, 2002) and the CAU 121 SAFER Plan (NNSA/NSO, 2007).

Data validation was performed according to the Industrial Sites QAPP (NNSA/NV, 2002), which is based on the EPA functional guidelines for data quality (EPA, 1994; 1999). Data were reviewed to ensure that samples were appropriately processed and analyzed and that the results are valid. All sample data were verified and validated at the Tier I, II, and III levels. The excavation at CAS 12-01-02 was resampled because of anomalies in the phase 1 analytical 
results. The following sections provide details on the results of specific data quality indicators and specifics regarding other anomalies identified during the data review.

\subsubsection{Characterization Sample QA/QC}

Characterization samples were collected to verify the CSM for each site and to confirm the appropriate path forward for closure. Results for CASs 12-01-01 and 12-01-02 are in sample delivery groups (SDGs) V3056 (chemical) and V3057 (radiological). Results for CAS 12-22-26 are in SDGs V3097 (chemical) and V3098 (radiological).

Data met the required data quality indicators (i.e., precision, accuracy, sensitivity, completeness, comparability, and representativeness) with the following exceptions:

- Methylene chloride was detected at low concentrations in the method blanks, the samples, and the trip blanks. Methylene chloride in these results is considered a laboratory contaminant and is not considered to be present in the samples. All of the sample results for methylene chloride are orders of magnitude less than the action level; therefore, the data are usable for making a decision.

- Field duplicates exceed the 20-percent relative percent difference (RPD) for oil-range petroleum hydrocarbons (113 percent) in CAS 12-01-01 samples. The large discrepancy in hydrocarbon analytical field duplicates could indicate the presence of petroleum hydrocarbons at concentrations that approach the PAL; however, the hazardous VOC and SVOC constituents present in petroleum hydrocarbons are not present in these samples. Therefore, the decision that concentrations to do not exceed the PALs is valid.

- Field duplicates exceed the 20-percent RPD for several metals; however, all concentrations are orders of magnitude less than the action level; therefore, the data are viable for making a decision.

- Gross alpha recovery exceeded the laboratory's upper control limit for CASs 12-01-01 and 12-01-02; therefore, gross alpha results may be biased high. This does not affect the ability to use the results for a decision.

- All sample times were not included on the SDG V3057 chain of custody form. The analytical laboratory noted the missing times, which were identified on the sample jars.

While only summary laboratory QC data for closure samples are included in Appendix B, the complete data sets, including validation reports for waste characterization and cleanup samples, are maintained in the Management and Operations Contractor project files.

\subsubsection{Cleanup Sample QA/QC}

Cleanup samples were collected after each phase of excavation at CAS 12-01-02 to determine whether cleanup activities were successful in reducing compounds to concentrations less than the PALs. Cleanup sample analytical results are located in SDGs V3106, V3112, and V3130. Data met the required data quality indicators (i.e., precision, accuracy, sensitivity, completeness, comparability, and representativeness) with the following exceptions:

- All phase 1 analytical results are valid and meet acceptance criteria with the exception of benzo(a)pyrene and dibenz(a,h)anthracene results. Laboratory analytical results for several 
samples show that concentrations in several samples are less than the detection limit; however, the detection limit provided $(0.350 \mathrm{mg} / \mathrm{kg})$ is greater than the PAL for these compounds. The phase 1 analytical results for these compounds were therefore not used to determine that concentrations were less than the action level where this occurred. Additional samples were collected after phase 3 excavation to confirm the concentrations of these compounds after the final excavation.

- Only two samples were collected upon conclusion of the phase 2 excavation activities. These were both collected from the same location (i.e., one sample plus one duplicate sample). At 73 percent, the 20-percent RPD requirement was exceeded for Aroclor 1254. Both samples required a 10-fold instrument dilution due to high concentrations of non-target and target analytes. The combination of matrix heterogeneity and sample dilution contributed to the differences. Both concentrations are still significantly less than the action level and can be used to make a decision.

\subsubsection{Conceptual Site Models}

CSMs were developed and presented in the approved SAFER Plan for CAU 121 (NNSA/NSO, 2007). The following identifies how the CSM was confirmed at each site, and which CSM was found to be applicable at each site.

- CAS 12-01-01, Aboveground Storage Tank: The primary CSM for this site consisted of a tank with no release of its contents (i.e., deposited at the site empty). Analytical results showed that the concentrations of all analytes were less than the PALs, thereby confirming the primary CSM.

- CAS 12-01-02, Aboveground Storage Tank: The primary CSM for this site consisted of a tank with no release of its contents (i.e., deposited at the site empty). The alternate CSM consisted of a tank with a release of its contents. The alternate CSM was found to be more applicable due to the presence of PCBs exceeding the PAL that may possibly have originated from the tank contents. TPH and SVOCs present at the site were likely associated with asphalt and are not considered COCs for this site.

- CAS 12-22-26, Drums; 2 AST's: Two CSMs were presented for this CAS, one for the drum area and one for the tank area.

- For the drum area, the primary CSM assumed no release from the drums, and the alternate CSM assumed minimal releases of limited quantities. Analytical results showed that only TPH exceeded the PAL, and that the hazardous constituents did not exceed the FALs. The primary CSM of no release greater than FALs was confirmed for the drum area.

- For the tank area, the primary CSM assumed a significant release from the AST in its operational location, and the alternate CSM assumed no release from the AST. The alternate CSM is consistent with the findings because the tank only contained diesel, and no diesel-range hydrocarbons were found in the tank area. 
CAU 121 Closure Report

Section: Closure Verification

Revision: 0

Date: September 2008

\subsection{USE RESTRICTIONS}

Use restrictions were not implemented for any CASs in CAU 121. 


\subsection{CONCLUSIONS AND RECOMMENDATIONS}

\subsection{CONCLUSIONS}

The following site closure activities were performed at CAU 121 and are documented in this CR:

- CAS 12-01-01, Aboveground Storage Tank, consisted of one empty AST and associated impacted soil, if any. No COCs were present; therefore, no further action was chosen as the corrective action alternative. As a BMP, the empty AST was removed and disposed as sanitary waste.

- CAS 12-01-02, Aboveground Storage Tank, consisted of one empty AST and associated impacted soil, if any. Sample results showed that PCBs exceeded the PAL in the soil beneath the AST. PCBs could possibly have originated from the AST contents; therefore, PCBs were considered COCs, and clean closure was chosen as the corrective action alternative. Approximately $5 \mathrm{yd}^{3}$ of soil were excavated and disposed as petroleum hydrocarbon PCB remediation waste, and approximately $13 \mathrm{yd}^{3}$ of soil were disposed as PCB remediation waste. Cleanup samples were collected to confirm that the remaining soil did not contain PCBs above the PAL. Benzo(a)pyrene, dibenz(a,h)anthracene, and TPH were also present above the PALs. Sample results indicated that the degraded asphalt adjacent to the site and surrounding the Area 12 Camp water tank was the likely source of these compounds; therefore, they were not considered COCs. As a BMP, the empty AST was removed and disposed as sanitary waste.

- CAS 12-22-26, Drums; 2 AST's, consists of two areas. The first area, the drum area, consisted of soil in an area where drums of unknown contents or condition had previously been stored. The second area, the tank area, consisted of an AST and associated impacted soil, if any. Sample results showed that TPH exceeded the PAL in both the drum area and the tank area; however, the VOC and SVOC hazardous constituents of TPH did not exceed the FALs. Therefore, TPH was not considered a COC, and no further action was chosen as the corrective action alternative. As a BMP, the empty AST was removed and disposed as sanitary waste.

\subsection{Post-Closure ReQuirements}

No use restrictions were implemented, and there are no post-closure requirements.

\subsection{RECOMMENDATIONS}

Since closure activities for CAU 121 have been completed following the Nevada Division of Environmental Protection (NDEP) approved SAFER Plan (NNSA/NSO, 2007), as documented in this report, NNSA/NSO requests the following:

- A Notice of Completion provided by the NDEP to NNSA/NSO for the closure of CAU 121

- The transfer of CAU 121 from Appendix III to Appendix IV, Closed Corrective Action Units, of the FFACO (FFACO, 1996; as amended February 2008) 
CAU 121 Closure Report

Section: Conclusions \& Recom.

Revision: 0

Date: September 2008

THIS PAGE INTENTIONALLY LEFT BLANK 


\subsection{REFERENCES}

EPA, see U.S. Environmental Protection Agency.

Federal Facility Agreement and Consent Order, 1996 (as amended February 2008). Agreed to by the State of Nevada; U.S. Department of Energy, Environmental Management; U.S. Department of Defense; and U.S. Department of Energy, Legacy Management.

FFACO, see Federal Facility Agreement and Consent Order.

Irwin, R. J., M. VanMouwerik, L. Stevens, M.D., Seese, and W. Basham, 1997. Environmental Contaminants Encyclopedia. National Park Service, Water Resources Division. Fort Collins, CO.

Distributed within the Federal Government as an

Electronic Document (Projected public availability

on the internet or NTIS: 1998).

Moore, J., 1999. Science Applications International Corporation. Memorandum to M. Todd (SAIC) entitled, "Background Concentrations for NTS and TTR Soil Samples, February 3, 1999. Las Vegas, NV.

NBMG, see Nevada Bureau of Mines and Geology.

Nevada Bureau of Mines and Geology, 1998. Mineral and Energy Resource Assessment of the Nellis Air Force Range, Open-File Report 98-1. Reno, NV.

NNSA/NSO, see U.S. Department of Energy, National Nuclear Security Administration Nevada Site Office.

NNSA/NV, see U.S. Department of Energy, National Nuclear Security Administration Nevada Operations Office.

Pacific Northwest National Laboratory, 2005. Visual Sample Plan Software, Version 4.6. Prepared for the U.S. Department of Energy under Contract DE-AC05-76RL01830.

U.S. Department of Energy, National Nuclear Security Administration Nevada Operations Office, 2002. Nevada Environmental Restoration Project Industrial Sites Quality Assurance Project Plan, Nevada Test Site, Nevada. DOE/NV--372-REV.3. Las Vegas, NV.

U.S. Department of Energy, National Nuclear Security Administration, Nevada Site Office, 2004. NV/YMP Radiological Control Manual. DOE/NV/11718--079 Rev. 5. Las Vegas, NV. 
U.S. Department of Energy, National Nuclear Security Administration Nevada Site Office, 2006a. Corrective Action Decision Document/Closure Report for Corrective Action Unit 219: Septic Systems and Injection Wells Nevada Test Site, Nevada. DOE/NV--1125. Las Vegas, NV.

U.S. Department of Energy, National Nuclear Security Administration Nevada Site Office, 2006b. Industrial Sites Project Establishment of Final Action Levels. DOE/NV--1107. Las Vegas, NV.

U.S. Department of Energy, National Nuclear Security Administration Nevada Site Office, 2007. Streamlined Approach for Environmental Restoration Plan for Corrective Action Unit 121: Storage Tanks and Miscellaneous Sites, Nevada Test Site, Nevada. DOE/NV--1208. Las Vegas, NV.

U.S. Department of Health and Human Services, 2005. "Polycyclic Aromatic Hydrocarbons, 15 Listings," Report on Carcinogens, Eleventh Edition. Public Health Service, National Toxicology Program. Washington, D.C.

U.S. Environmental Protection Agency, 1994. Guidance for the Data Quality Objectives Process. EPA QA/G-4. Washington D.C.

U.S. Environmental Protection Agency, 1996. Test Methods for Evaluating Solid Waste Physical/Chemical Methods, SW-846, 3rd Edition. Washington, D.C.

U.S. Environmental Protection Agency, 1999. Contract Laboratory Program National Functional Guidelines for Organic Data Review. EPA540/R-99/008. Washington D.C.

U.S. Environmental Protection Agency, 2004. Region IX Preliminary Remediation Goals. Available at: http://www.epa.gov/region09/waste/sfund/prg/files/04prgtable.pdf. [August 7, 2008].

U.S. Environmental Protection Agency, 2008. Consumer Factsheet on: BENZO(A)PYRENE. Available at: http://www.epa.gov/ogwdw000/contaminants/dw_contamfs/benzopyr.html. [September 18, 2008]. 


\section{APPENDIX A*}

\section{DATA QUALITY OBJECTIVES}

* As presented and published in Section 3.0 of the approved Streamlined Approach for Environmental Restoration Plan for Corrective Action Unit 121: Storage Tanks and Miscellaneous Sites, Nevada Test Site, Nevada. 2007. DOE/NV--1208. Las Vegas, NV. 
CAU 121 Closure Report

Section: Appendix A

Revision: 0

Date: September 2008

\section{THIS PAGE INTENTIONALLY LEFT BLANK}




\subsection{DATA QUALITY OBJECTIVES}

The DQO process is a seven-step systematic planning method based on the scientific method that was used to plan data collection and field investigation activities for CAU 121, Storage Tanks and Miscellaneous Sites. The seven steps of the DQO process presented in this report were developed according to the U.S. Environmental Protection Agency (EPA) Guidance on Systematic Planning Using the DQO Process (EPA, 2006). DQOs are designed to ensure that the data collected will provide sufficient and reliable information to support the potential closure alternatives for CAU 121. Although sufficient information is available about the nature and extent of contamination at CAU 121 to suggest a closure activity, additional data are needed to verify the existing information, confirm the existence of contamination and/or waste, and affirm the closure decision.

During DQO discussions for CAU 121, data needed to resolve problem statements and decision statements were identified. Criteria for data collection and analysis were defined and agreed upon, and the appropriate quality assurance (QA) / quality control (QC) required for particular data collection activities were assigned. The analytical methods and reporting limits prescribed through the DQO process and the data quality indicators (DQIs) for laboratory analysis, such as precision and accuracy requirements, are provided in more detail in Section 7.0 of this SAFER plan.

\subsection{SumMaRY OF DQO ANALYSIS}

\subsubsection{State The Problem (Step 1)}

Step 1 of the DQO process describes the problem to be studied and develops a conceptual site model (CSM) to gain a sufficient understanding of the problem.

The problem statement for CAU 121 is: "Additional information is required to verify existing information, identify the appropriate disposal pathway(s) for waste, confirm the absence or presence of COCs, and affirm the closure decision." A COC is defined as any contaminant in the soil that is present at concentrations exceeding its PAL. If a COC is present, then the appropriate FAL will be determined above which a closure action is required.

\subsubsection{1 $\underline{\text { CSM }}$}

The CSM is used to organize and communicate information about site characteristics. It reflects the best interpretation of available information at any point in time. The CSM is based on historical documentation, personnel interviews, site process knowledge, site walk-downs, photographs, engineering drawings, field screening, and analytical results. The CSM describes the most probable scenario for current conditions at the site and defines the assumptions that are the basis for identifying an appropriate sampling strategy and data collection methods.

The CSM for CAU 121 consists of localized, limited contamination sources (i.e., ASTs or drums) that have released none, all, or a portion of their contents to the surrounding soil. The CSM for each of the CASs is as follows.

CAS 12-01-01, Aboveground Storage Tank, consists of one 650-gal AST and soil below the AST that may have been impacted by the AST contents. The tank is expected to have been left at the 
CAS location after it had been emptied; therefore, the primary CSM is that there is nothing inside the AST or in the soil below the AST. The alternate CSM assumes that the contents of the AST (some or all) were released to the soil after it had been brought to the site.

CAS 12-01-02, Aboveground Storage Tank, consists of one 140-gal AST and soil below the AST that may have been impacted by the AST contents. The tank is expected to have been left at the CAS location after it had been emptied; therefore, the primary CSM is that there is nothing inside the AST or in the soil below the AST. The alternate CSM assumes that the contents of the AST (some or all) were released to the soil after it had been brought to the site. The primary and alternate CSMs for CASs 12-01-01 and 12-01-02 are presented in Figure 2.

CAS 12-22-26, Drums; 2 AST's, consists of one remaining 1,800-gal diesel AST and soil below the original and former locations of the AST, soil at the location of a former $\mathrm{MgCl}$ AST, and soil where drums were previously located near the diesel AST (at its former location). Based on process knowledge, the diesel AST was used to store fuel for locomotives. Historical aerial photos also indicate that the AST has been located at corresponding locations on the north and south sides of the train tracks. There is no evidence that the AST is currently leaking; however, spillage and overfilling was historically common nationwide around fuel tanks and dispensing operations.

Based on process knowledge, the $\mathrm{MgCl} \mathrm{AST}$ was used to store chilled water for grouting operations and, later, to store $\mathrm{MgCl} . \mathrm{MgCl}$ is not considered an environmental concern; hence, the soil below this former AST is not an area of concern.

This CAS also includes soil that may have been impacted by releases from drums that were previously stored to the west of the diesel AST when it was located on the north side of the train tracks. This location was identified from photographs in the Nevada Test Site Inventory of Inactive and Abandoned Facilities and Waste Sites report (REECo, 1991). Because the drums are limited in size, any release of regulated waste is expected to be limited to shallow soil in the drum area. There is no evidence that the drums released any of their contents.

Based on the information presented above, the primary CSM for CAS 12-22-26 assumes that there has been a release of diesel to the soil below and around the remaining AST (original location), its former location, and possibly the soil between both locations; and that there has been no release from drums to soil. The CSM for the drum area is depicted in Figure 2. The alternate CSM for the drum area of CAS 12-22-26 is similar to the CSM for CASs 12-01-01 and 12-01-02, with the only difference being the source as a drum rather than an AST. The CSM for the AST area is depicted in Figure 3. The alternate CSM for the AST area assumes that there has been no release from the diesel AST to the soil.

Waste that is expected to be generated from CAU 121 includes ASTs and soil that has become impacted by releases from the ASTs and drums. The area around G-tunnel and the Area 12 Camp are active areas. CAU 121 only includes the ASTs and soil impacted by releases from the ASTs and said drums. If additional CSM elements that are outside the scope of the CSM are 


\section{Primary Conceptual Site Model}

(No release from AST or drum)

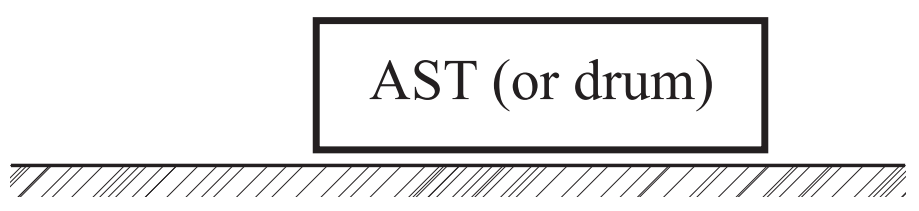

Profile Views

\section{Alternate Conceptual Site Model}

(Release from AST or drum)

AST (or drum)

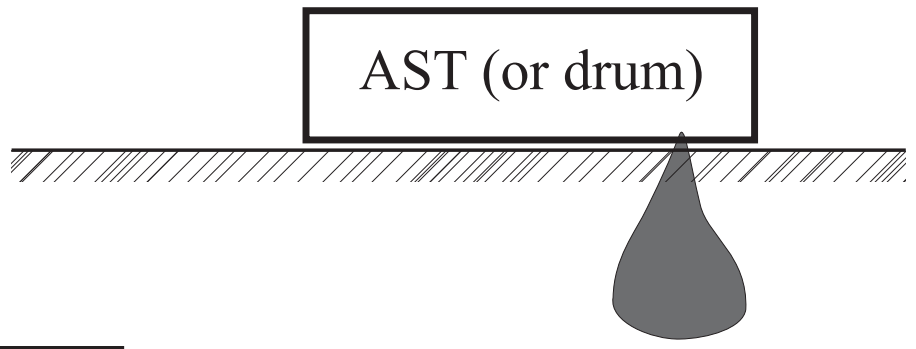

LEGEND

TITIT, Ground surface

Contaminated soil

Not to Scale

\section{FIGURE 2}

CSM FOR CASS 12-01-01, 12-01-02, AND 12-22-26 DRUM AREA 
Profile View

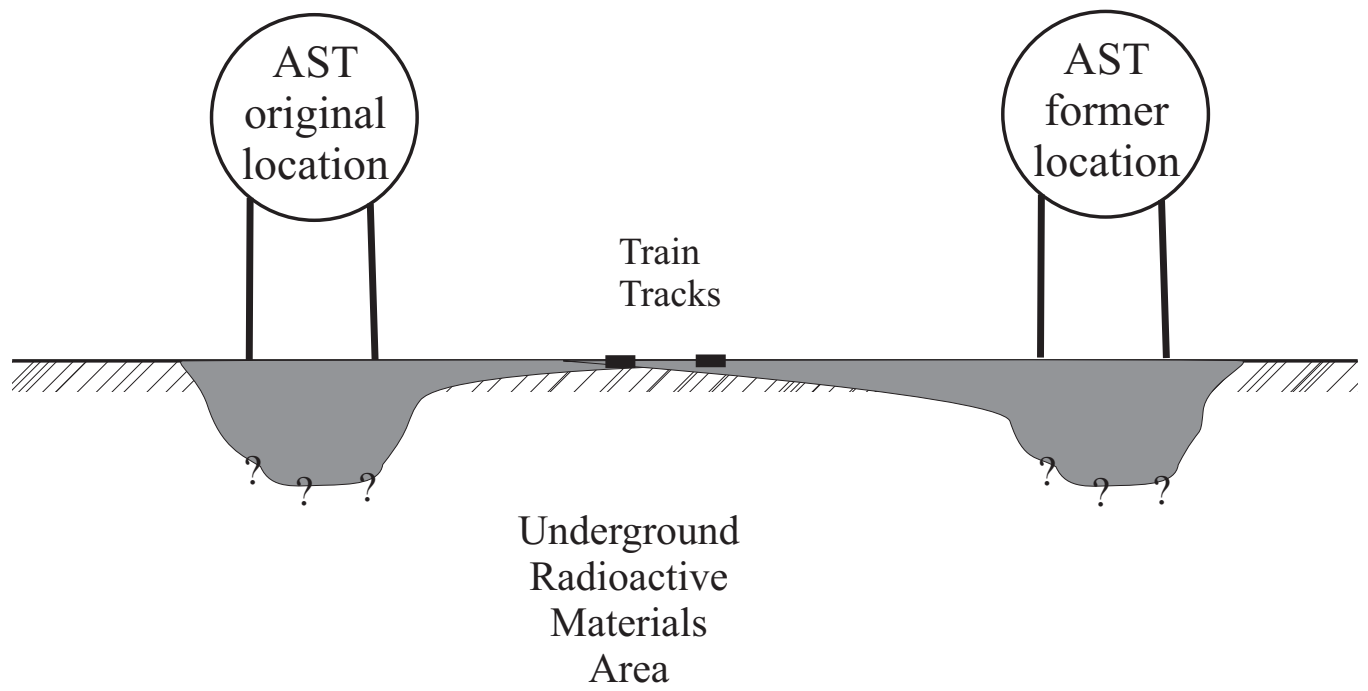

LEGEND

TIIIITTll Ground Surface

TPH-Contaminated Soil

- Train Tracks

Not to Scale

FIGURE 3

CSM FOR CAS 12-22-26 AST Area 
identified during remediation, the situation will be reviewed and a recommendation will be made as to how to proceed. In such cases, the NDEP will be notified and given the opportunity to comment on, or concur with, the recommendation.

\subsubsection{IDENTIFY THE GOAL OF THE STUdy (STEP 2)}

Step 2 of the DQO process identifies the questions the study will attempt to resolve and what actions may result. The goal of the study is to answer the following questions satisfactorily. The questions are arranged in the order that they will be addressed.

1. Do the existing ASTs contain regulated waste or are the containers themselves a regulated waste? The result will be an identification of the disposal pathway for the ASTs and their contents.

2. Is the soil impacted with contamination that exceeds action levels? The result will be excavation of impacted soil (CASs 12-01-01 and 12-01-02) or evaluation of site-specific hazards to determine whether excavation of impacted soil is justifiable (CAS 12-22-26).

3. Does the risk to personnel and the environment justify the removal (excavation) of impacted soil (CAS 12-22-26 only)? The result will be to either excavate impacted soil or close the site using other methods (e.g., URs).

4. Has excavation of soil reduced the contamination levels to acceptable concentrations? The result will be to verify that resulting concentrations are at acceptable levels or, if not, to continue excavating until that result has been reached.

\subsubsection{IDENTIFY INFORMATION INPUTS (STEP 3)}

Step 3 of the DQO process identifies the information available, the information needed, the sources of information, and sampling and analysis methods that can meet the data requirements. Table 1 presents information available, information needed, and proposed methods to obtain the information that is needed to meet the closure goal.

\subsubsection{Information Needs}

In order to confirm the CSM and determine the nature and extent of contamination, data must be collected and analyzed using the following criteria:

- Data will be collected from locations most likely to be contaminated (judgmental, or biased, sampling approach) at CASs 12-01-01, 12-01-02, and 12-22-26 AST area.

- Samples will be collected from statistically determined locations in the CAS 12-22-26 drum area.

- The analytical suite selected will be adequate to detect contaminants present in the samples. 

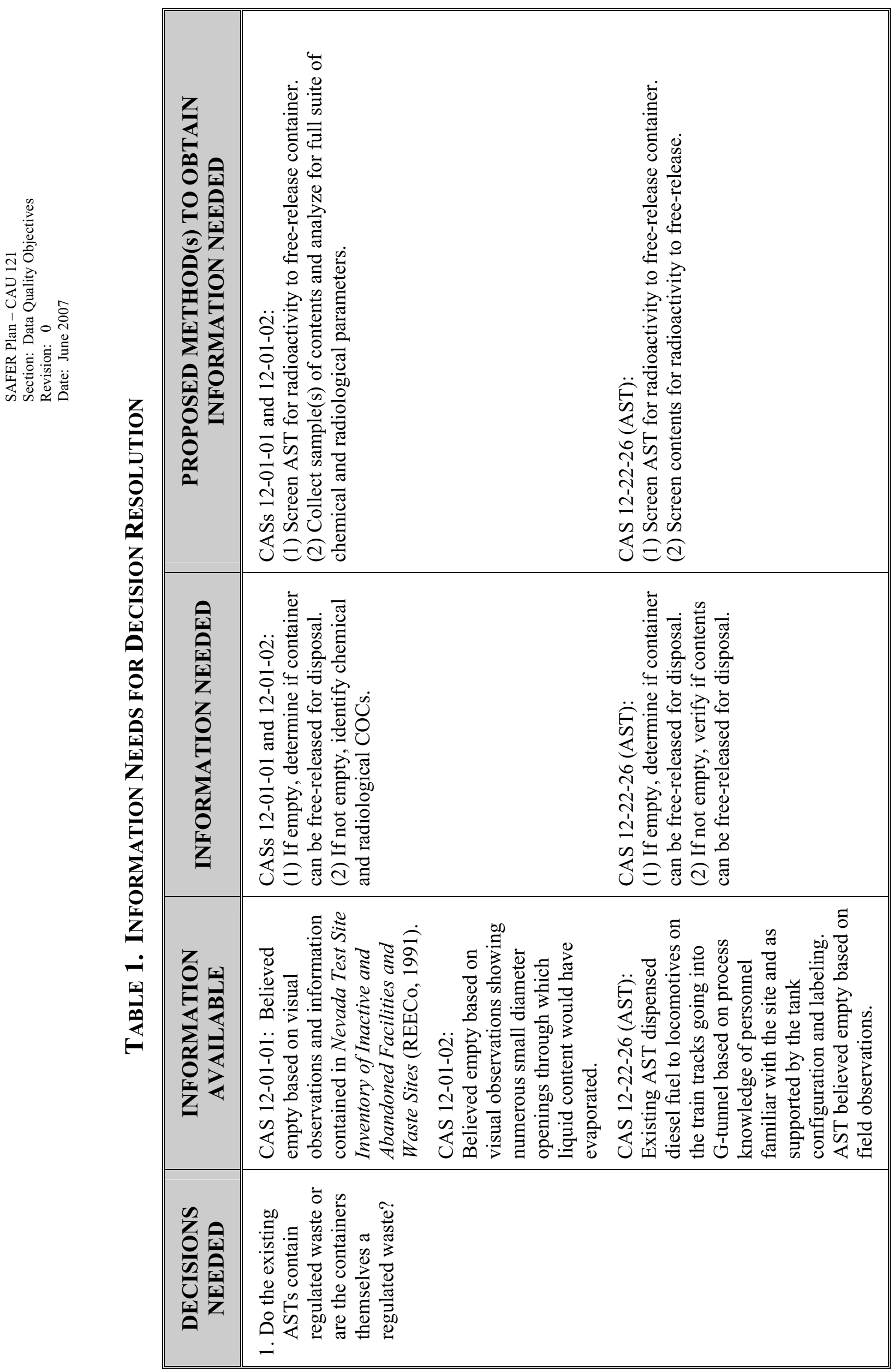


\begin{tabular}{|c|c|c|c|c|c|}
\hline \multirow[t]{4}{*}{ 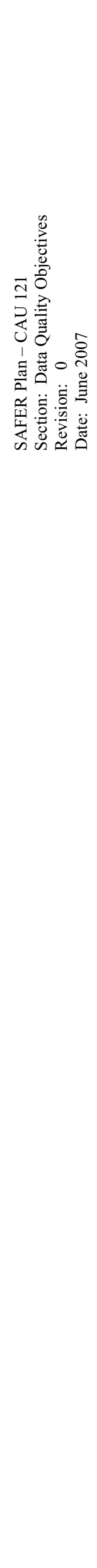 } & \multirow{4}{*}{ 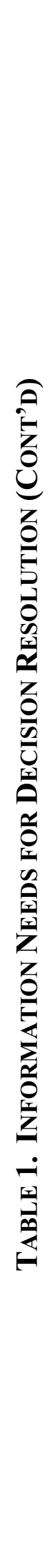 } & 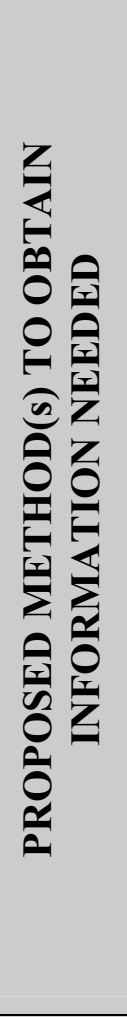 & 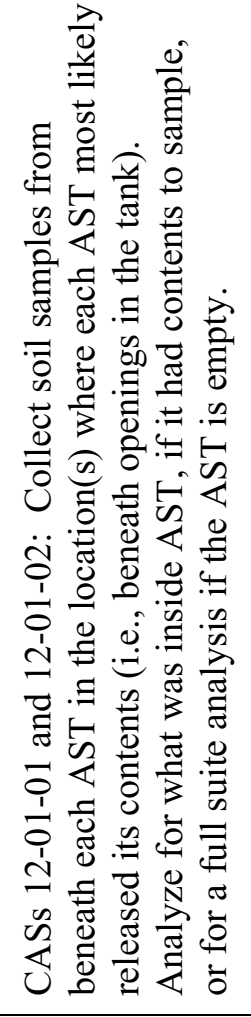 & 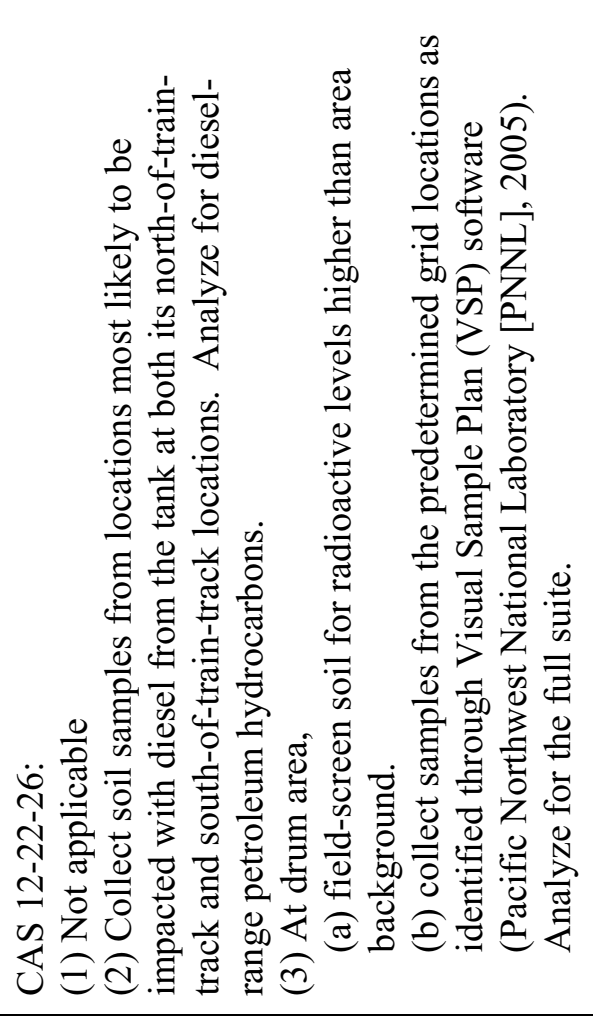 & 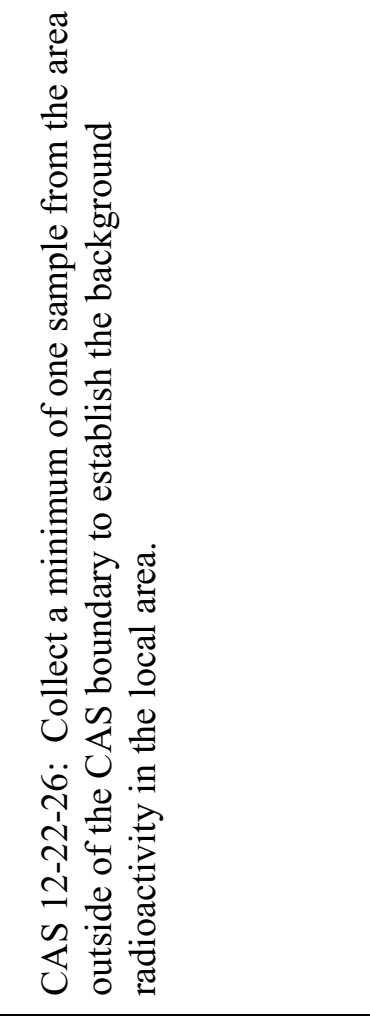 \\
\hline & & 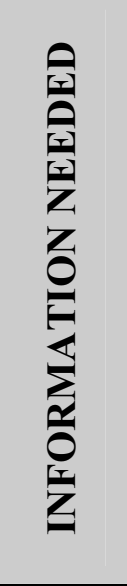 & 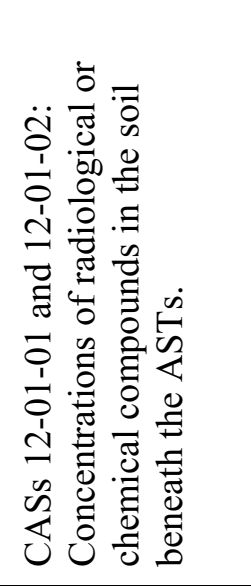 & 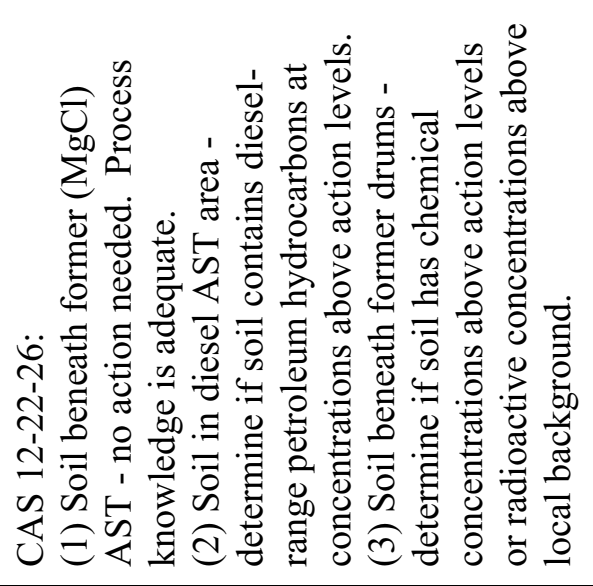 & 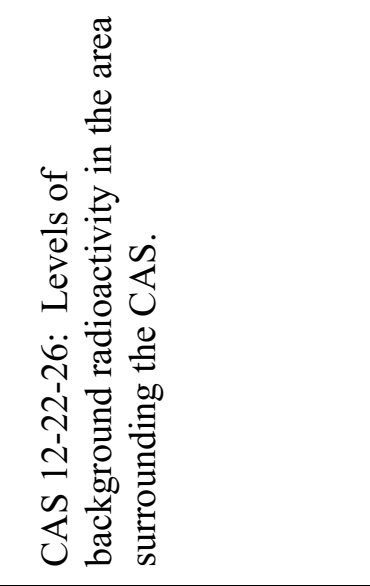 \\
\hline & & 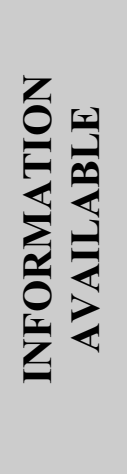 & 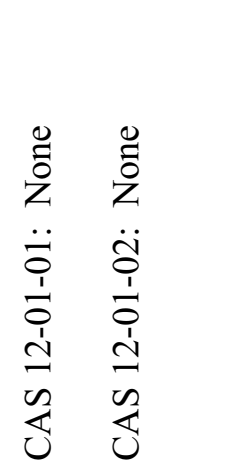 & 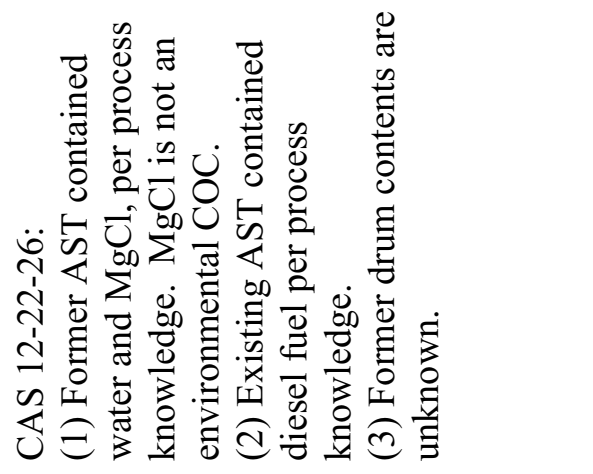 & 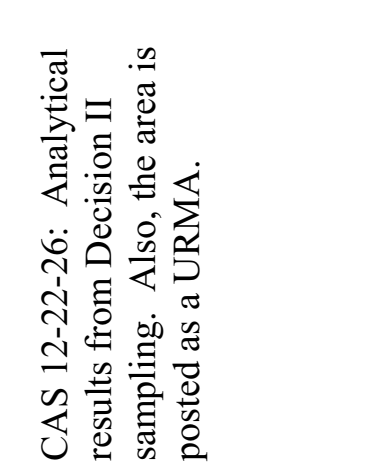 \\
\hline & & 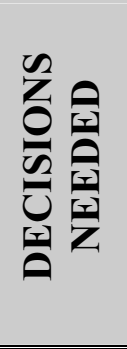 & 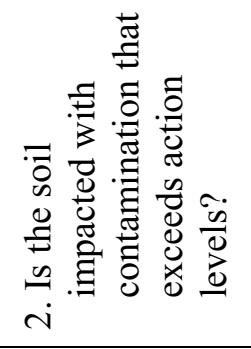 & & 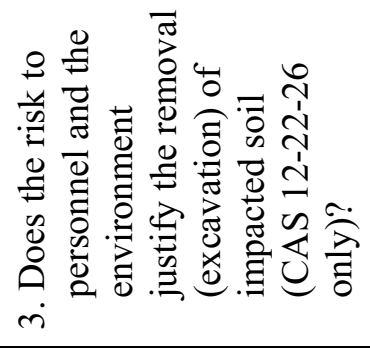 \\
\hline
\end{tabular}




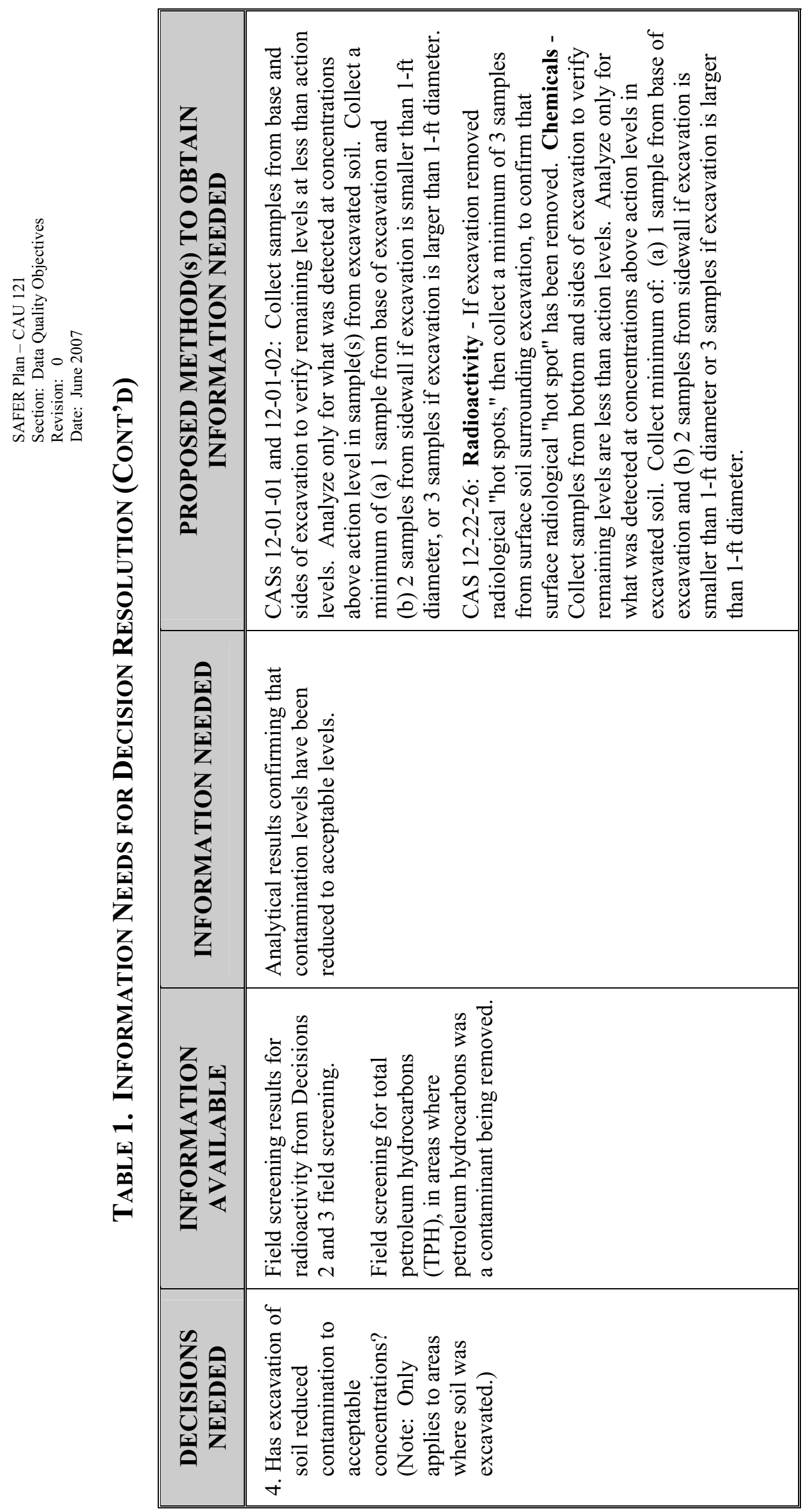




\subsubsection{2 $\quad$ Sources of Information}

Information needed to satisfy the decisions will be generated by visually confirming the absence (or presence) of waste within containers, collecting samples of AST contents (if any), conducting radiological surveys, and collecting soil samples.

\section{Qualitative Data}

Qualitative data identify or describe the characteristics or components of the site. The QA/QC requirements are the least rigorous on data collection methods and measurement systems for qualitative data. The intended use of the data is for information purposes, to refine conceptual models, and to guide investigations rather than resolve primary decisions. This measurement of quality is typically assigned to historical information and data where QA/QC may be highly variable or not known. Professional judgment is often used to generate qualitative data.

Visual observations will be made to identify the presence of biasing factors such as stained soil and to confirm the presence or absence of waste within the ASTs.

\section{Semi-quantitative Data}

Semi-quantitative data indirectly measure the quantity or amount of a characteristic or component. Inferences are drawn about the quantity or amount of a characteristic or component because a correlation has been shown to exist between the indirect measurement and the results from a quantitative measurement. The QA/QC requirements on semi-quantitative collection and measurement systems are high but may not be as rigorous as for quantitative data. Semiquantitative data contribute to decision making but are not used alone to resolve primary decisions. Field-screening data are generally considered semi-quantitative. The data are often used to guide investigations toward quantitative data collection.

Field screening activities will be conducted for alpha and beta/gamma radiation to identify any areas where samples should be collected due to elevated radioactivity that might indicate a release from either ASTs or drums and subsequent soil contamination. A handheld radiological survey instrument will be used to identify any areas with radioactivity that is elevated above the surrounding area. In areas where TPH concentrations are greater than action levels, TPH field screening will also be used to get an indication of where the concentrations are less than action levels. These field screening techniques will provide semi-quantitative data that can be used to guide sampling (e.g., obtain locations for biased sample collection) and waste management activities.

\section{Quantitative Data}

Quantitative data measure the quantity or amount of a characteristic or component. These data require the highest level of QA/QC in collection and measurement systems because the intended use of the data is to resolve primary decisions and/or to verify that closure standards have been met. Laboratory analytical data are generally considered quantitative.

A judgmental (biased) sampling approach will be used to collect samples beneath the ASTs at CASs 12-01-01 and 12-01-02, and at the CAS 12-22-26 diesel AST area. Biasing factors consist of stained soil, elevated radioactivity (as identified through radiological onsite screening), and soil located below AST openings. The locations with potential for contamination are summarized in Table 1. Biasing factors (i.e., either stained soil or AST openings) are present at 
all AST sample locations. Samples collected from CASs 12-01-01 and 12-01-02 will be analyzed for the full suite parameters unless the tanks contain adequate volume for sampling, in which case soil samples (from below the AST) will only be analyzed for those constituents greater than action levels within the AST.

Historical aerial photos indicate that the existing AST at CAS 12-22-26 was previously located at corresponding locations on both the north and south sides of the train tracks. Samples will be collected from both locations to identify whether there may have been a release from this AST at either location. At least one sample will be collected from under each half of the tank at each of these locations, where there is staining or other biasing factors (e.g., tank openings) are present. Samples collected from this area will only be analyzed for diesel-range petroleum hydrocarbons. The tank is currently in a G-tunnel storage area and not at either of the locations where it was previously used; therefore, as a best management practice (BMP), at least one sample will be collected from a biased location beneath the tank's current location and analyzed for diesel-range petroleum hydrocarbons to confirm that there has been no release at its current location.

For the drum area of CAS 12-22-26, a photograph from the Nevada Test Site Inventory of Inactive and Abandoned Facilities and Waste Sites report (REECo, 1991), from which this site was originally listed in the FFACO, shows the drums to be off the west end of the diesel AST when it was located to the north of the train tracks. Recent site visits indicate that visible biasing factors are not present. In the absence of radiological biasing factors, all samples will be collected from a statistically-determined sampling grid determined using VSP software (PNNL, 2005) for identification of "hot spots" within the drum areas. The statistical grid has been determined to identify "hot spots" to a 95 percent confidence level. These samples will be submitted for a full suite analysis.

Samples will be collected from locations likely to be contaminated using appropriate sampling methods. Samples will be submitted to analytical laboratories meeting the quality criteria stipulated in the Industrial Sites QAPP (NNSA/NV, 2002). Validated data from analytical laboratories will be used to support DQO decisions. Sample collection and handling activities will follow standard procedures.

Because CAS 12-22-26 is near the Area 12 G-tunnel, above a URMA, and in an area of potentially elevated background radioactivity due to releases from the G-tunnel, one sample will also be collected from an area at least $25 \mathrm{ft}$ outside of the CAS boundary to establish local radioactivity baseline levels.

\subsubsection{DEFINE THE Boundaries OF THE STUdy (STEP 4)}

Step 4 of the DQO process defines the target population of interest, specifies the spatial boundaries and time constraints of that population pertinent for decision making, and determines practical constraints on data collection.

\subsubsection{Population of Interest}

The population of interest to resolve the decisions includes the ASTs themselves, materials contained within them, and soil containing contaminants above the action levels below the ASTs and the former drums. 


\subsubsection{Spatial Boundaries}

CAS boundaries and proposed sample locations (in absence of biasing factors such as staining or elevated radiological screening results) are described below. The spatial boundaries include the following:

- CAS 12-01-01 includes the AST, its contents, and soil impacted by the AST contents. The CAS boundaries are considered to be the AST perimeter plus $5 \mathrm{ft}$ (Figure 4).

- CAS 12-01-02 includes the AST, its contents, and soil impacted by the AST contents. The CAS boundaries are considered to be the AST perimeter plus $5 \mathrm{ft}$ (Figure 5).

- CAS 12-22-26 consists of two overlapping study areas. The AST area contains the diesel AST, its contents, and soil impacted by the AST contents (original and former locations). The CAS boundary for the AST area is limited to that area encompassed by both tank locations (when it was in use adjacent to the train tracks), the area between the tanks, plus an area $20 \mathrm{ft}$ laterally. The drums were arranged in an "L"-shaped pattern off the west end of the diesel AST when it was located to the north of the train tracks. The area measures approximately $20 \mathrm{ft}$ long by $7 \mathrm{ft}$ wide, with one section $14 \mathrm{ft}$ wide. Figure 6 depicts the CAS boundaries for these two areas.

\subsubsection{Time Constraints}

The study data should be collected considering the length of time that will be required to complete the closure process and the Closure Report (CR), as allowed for by the SAFER process under the FFACO agreement (FFACO, 1996). Data will be collected at times that meet the security and safety constraints of the NTS and at times when weather conditions allow adequate site access and safe working conditions. Time constraints that may affect the schedule of this project include the following:

- Approval of SAFER Plan and DQOs

- Activities in the vicinity of G-tunnel that restrict access to CAS 12-22-26

- Activities in the vicinity of the Area 12 Camp that restrict access to CASs 12-01-01 and 12-01-02

Closure activities are currently scheduled to begin in fiscal year (FY) 2008.

\subsubsection{Practical Constraints}

Other constraints that may affect the ability to collect data include the following:

- Equipment access and availability at NTS

- Adverse weather conditions (e.g., snow and ice in the winter months)

- Acceptance of waste disposal pathways

- Other unsafe working conditions 


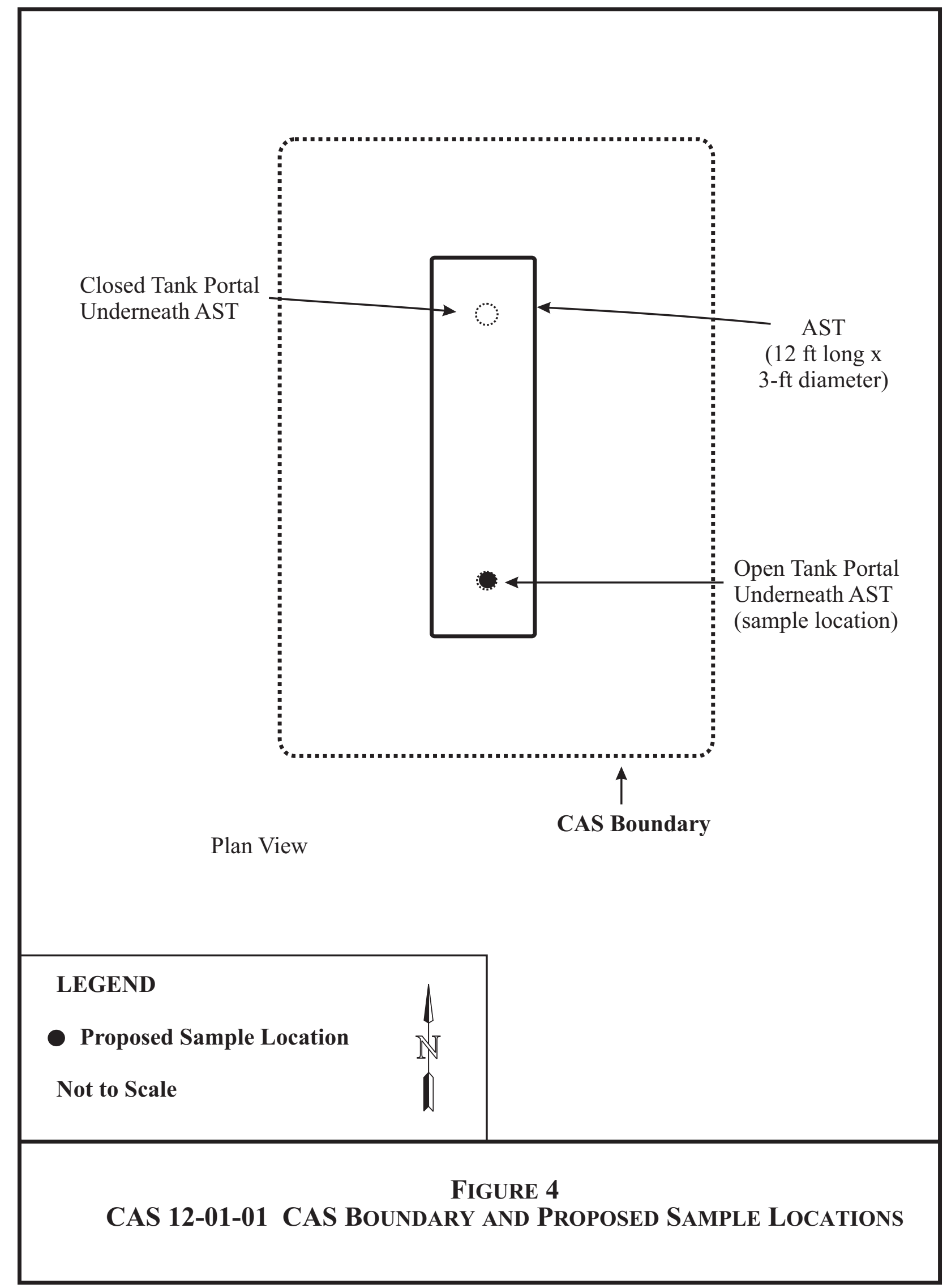




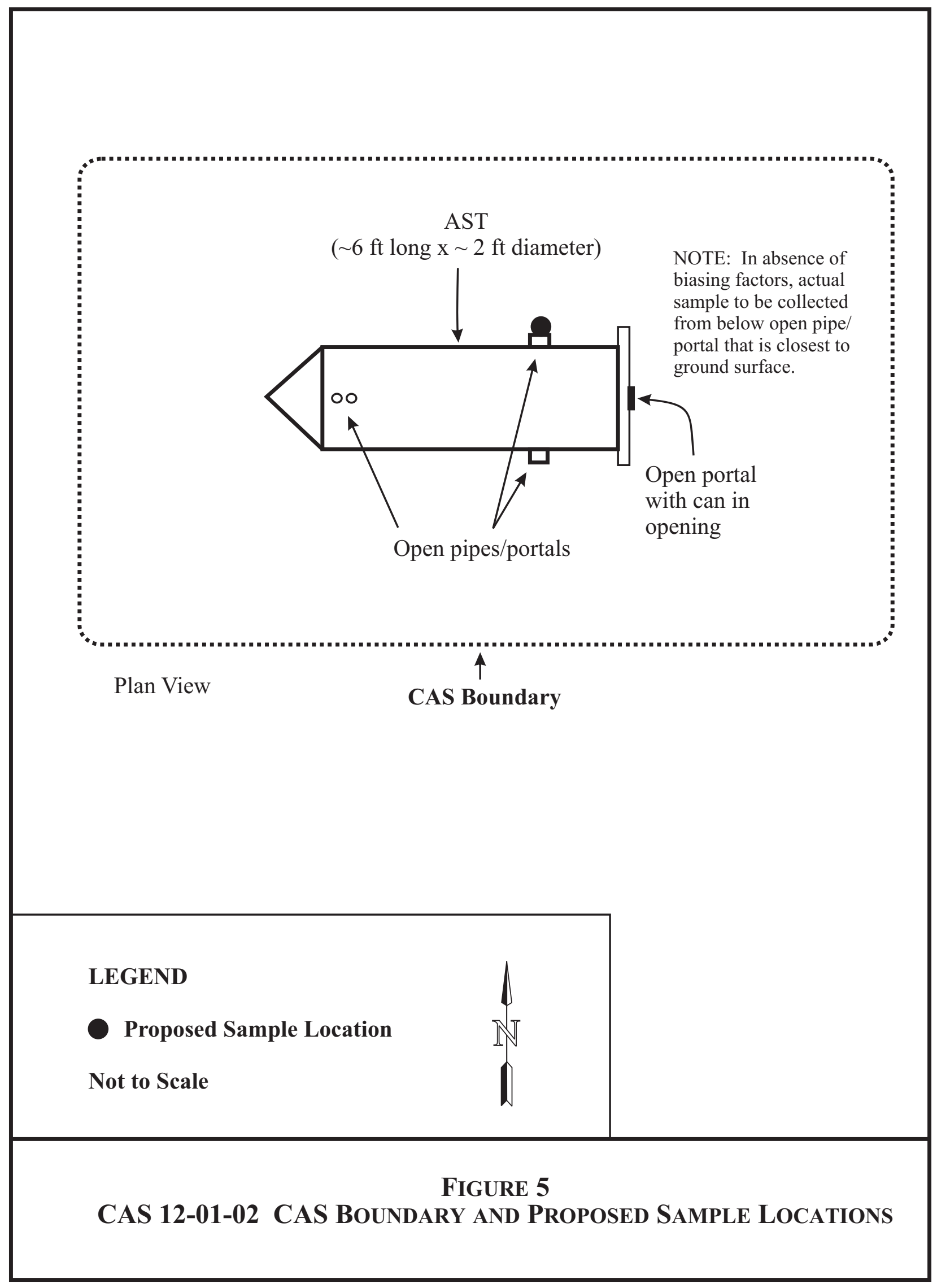




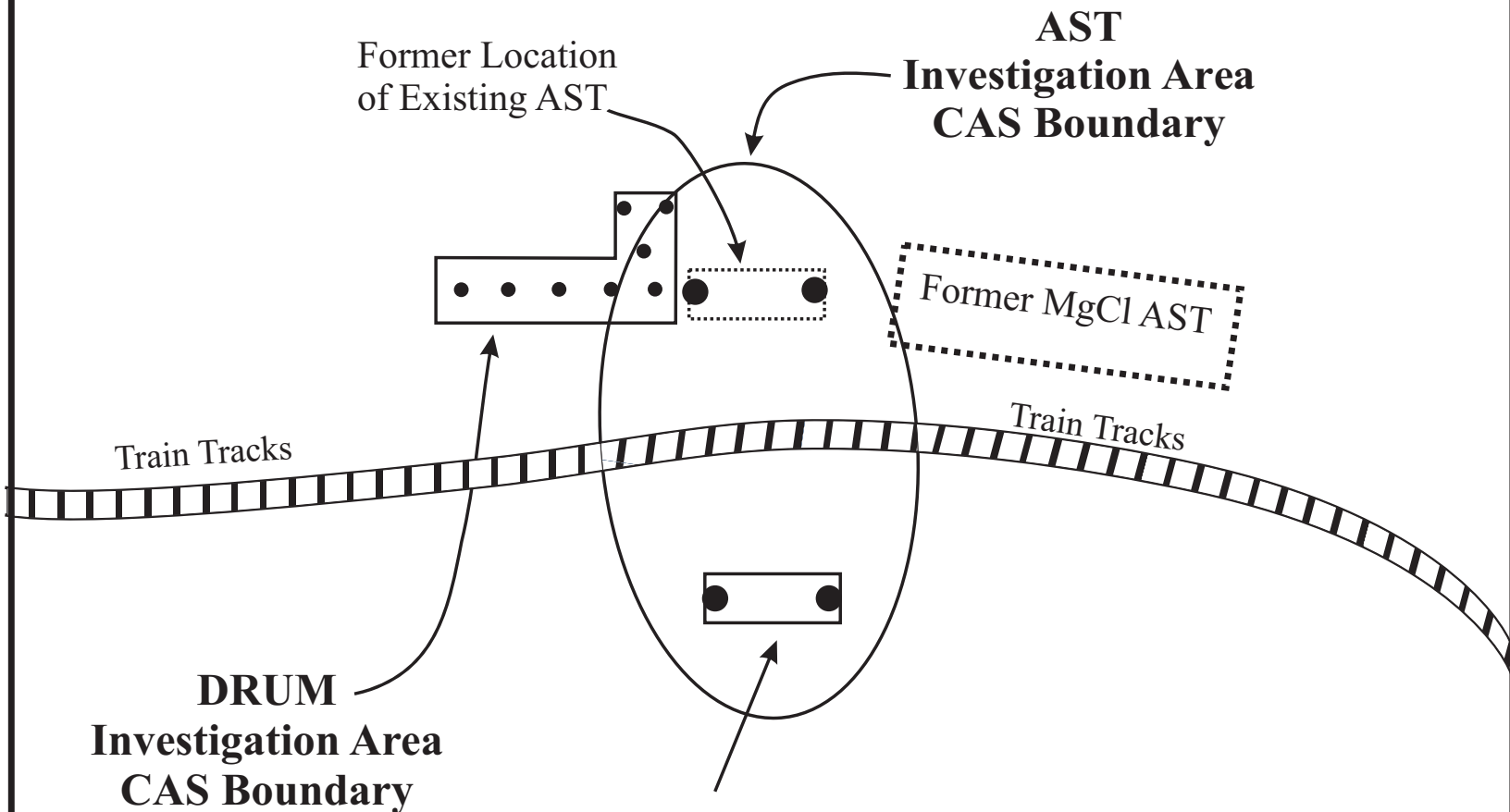

Original Location

of Existing AST

\section{LEGEND}

Existing AST

Former AST Location

- Proposed Sample Locations

Not to Scale

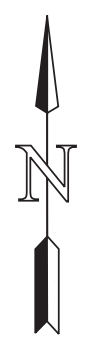

Plan View

FIGURE 6

CAS 12-22-26 CAS Boundaries AND Proposed SAMPle LoCATIONS 


\subsubsection{Develop the Analytic Approach (Step 5)}

Step 5 of the DQO process develops a decision rule statement ("If..., then...") that defines the conditions under which possible alternative actions will be chosen. In this step, the statistical parameters that characterize the population of interest are specified, the action levels are specified, and the measurement and analysis limits capable of detecting action levels are confirmed.

\subsubsection{Population Parameters}

Each sample result within the population of interest defined in Step 4 will be compared to the action levels to determine the appropriate resolution to the decisions.

\subsubsection{Decision Rules}

The decision rules for Decision I and Decision II are as follows.

\section{Decision I}

- If an AST contains no regulated waste and itself is not a regulated waste, then the AST (and contents, if any) will be disposed of at a sanitary landfill.

- If an AST contains a regulated waste or if the container itself is a regulated waste, then the AST and/or its contents will be disposed of at an appropriate facility.

\section{Decision II}

- If radiological and chemical concentrations in the soil are less than the PALs, then no further action is required. Closure is complete.

- CASs 12-01-01 and 12-01-02: If radiological and/or chemical concentrations are greater than PALs, then the appropriate FALs will be determined above which a closure action is required. If concentrations in the soil exceed the FALs, then impacted soil will be excavated and disposed of at the appropriate facility. Proceed to Decision IV.

- CAS 12-22-26: If radiological and/or chemical concentrations in the soil are greater than PALs at CAS 12-22-26, then proceed to Decision III.

\section{Decision III (CAS 12-22-26 only)}

- Radioactivity: If surface radioactivity levels are greater than in the surrounding area, then impacted soil will be excavated to a depth of $1 \mathrm{ft}$ bgs and backfilled with clean fill. Because this is a URMA, subsurface radioactivity is expected to be elevated and may, indeed, increase with depth. The purpose of this effort is not to remediate the URMA or the entire area (if the local area background is elevated) but, rather, to reduce worker exposure to surface spills. This will be done by removing the surface contamination and then replacing the excavated soil with clean fill. Additional precautions are not considered necessary because intrusion into the subsurface is already restricted through the URMA and associated protocol. 
- Chemicals: The "Industrial Sites Project Establishment of Final Action Levels" (NNSA/NSO, 2006) will be used to identify the FAL for any chemical with a concentration that exceeds the PAL. The following inputs and expected outcomes are anticipated:

- Diesel-range petroleum hydrocarbons: If diesel-range petroleum hydrocarbons is the only COC, then a UR will be implemented. There may be no excavation because the area is a URMA that could have mixed fission products of unknown concentrations. Excavation of soil containing diesel-range petroleum hydrocarbons could pose significantly greater risk to human health from the buried radioactivity than would the diesel-range petroleum hydrocarbons in the surface soil. If diesel-range petroleum hydrocarbon concentrations at the surface are also a health hazard, then a layer of clean fill can be placed over the area or the use-restricted area can be fenced to keep workers from tracking surface contamination out of the area.

- Chemicals (volatile organic compounds [VOCs], semi-volatile organic compounds [SVOCs], Metals, and PCBs): If chemical concentrations exceed the FALs, then soil will be excavated until chemical concentrations are less than the FALs or can be appropriately controlled with a UR (e.g., PCBs greater than 1 ppm but less than $50 \mathrm{ppm}$ ). Based on existing knowledge of the site history, there is currently no reason to believe that releases from drums would have impacted such volumes of soil that would require extensive excavation. However, if radioactivity becomes elevated such that the risk to human health is significant from radioactivity, then NNSA/NSO will contact the NDEP and propose alternative closure options, such as closure in place with URs.

\section{Decision IV}

- CASs 12-01-01 and 12-01-02: If verification sample results show that radiological and chemical concentrations are less than the FALs, then the excavation(s) will be backfilled with clean fill and closure is complete. A minimum of one sample will be collected from the base of the excavation. A minimum of two samples will be collected from sidewalls of excavations $1 \mathrm{ft}$ or less in diameter, and a minimum of three samples will be collected from the sidewalls of excavations larger than $1 \mathrm{ft}$ in diameter to confirm that closure is complete. Samples will only be analyzed for those contaminants that exceeded the action level and triggered the requirement to excavate soil.

- CAS 12-22-26: If verification sample results show that (1) surface radioactivity is at or less than area background concentrations, and (2) chemical concentrations (other than TPH) are less than FALs, then the excavation(s) will be backfilled with clean fill. Radioactivity - If excavation removed soil with elevated radiation levels, then a minimum of three samples will be collected from surface soil adjacent to the excavation to confirm that surface soil with elevated radiation levels has been removed. Chemicals and Metals - If excavation removed other chemicals and/or metals, then samples will be collected from the bottom and sides of the excavation to verify that remaining levels are less than action levels. A minimum of one sample will be collected from the base of the excavation. A minimum of two samples will be collected from sidewalls of excavations $1 \mathrm{ft}$ or less in diameter and a minimum of three samples will be collected from the sidewalls of excavations larger than $1 \mathrm{ft}$ in diameter to confirm that closure is complete. Samples will only be analyzed for those contaminants that exceeded the action level and triggered the requirement to excavate soil. 
- If URs will be implemented, the use-restricted area will be fenced and/or posted, as appropriate, and signs will be erected.

\subsubsection{Action Levels}

The following PALs have been established for CAU 121:

- PCBs: The PCB action level will be $1 \mathrm{ppm}$ for unrestricted access/use, as is established in 40 CFR Part 761.61 for PCB remediation waste (CFR, 2006).

- TPH: The TPH PAL will be 100 milligrams per kilogram $(\mathrm{mg} / \mathrm{kg})$, as is established in the Nevada Administrative Code (NAC), Section 445A.2272, "Contamination of soil: Establishment of action levels" (NAC, 2006).

- Chemicals: Action levels for other chemical contaminants are defined as the EPA Region 9 risk-based preliminary remediation goals for chemical constituents in industrial soils (EPA, 2004).

- Radiological: The action levels for radiological contaminants are based on the National Council on Radiation Protection (NCRP) Report No. 129 recommended screening limits for construction, commercial, and industrial land-use scenarios (NCRP, 1999) scaled to 25 millirem per year (mrem/yr) dose constraint (Murphy, 2004) and the generic guidelines for residual concentration of radionuclides in U.S. Department of Energy (DOE) Order 5400.5 (DOE, 1993). The radiological action level for solid media will be defined as the unrestricted-release criteria defined in the NV/YMP Radiological Control (RadCon) Manual (NNSA/NSO, 2004). Remaining radiological contamination, per Decision II of the decision rules, will be posted per the NV/YMP RadCon Manual (NNSA/NSO, 2004). Because of expected elevated background levels in the vicinity of G-tunnel, the action levels for radiological contaminants at CAS 12-22-26 will be the greater of either the levels described above or the local area background levels (as determined through a sample collected from the local area but outside of the CAS boundary).

\subsubsection{Measurement and Analysis Sensitivity}

The measurement and analysis methods listed in the Industrial Sites QAPP (NNSA/NV, 2002) are capable of measuring analyte concentrations at or below the corresponding action levels for each constituent.

\subsubsection{SPecify Performance OR ACCEPTANCE CRITERIA (STEP 6)}

Step 6 of the DQO process specifies performance criteria for the decision rules. Setting tolerable limits on decision errors requires the planning team to weigh the relative effects of threats to human health and the environment, expenditure of resources, and the consequences of an incorrect decision. This section provides an assessment of the possible outcomes of DQO decisions and the impact of those outcomes if the decisions are in error.

CAU 121 will be sampled using both statistical and judgmental sampling approaches. Statistical sampling will only be performed in the drum area of CAS 12-22-26 because of the lack of biasing factors. The number and location of samples to be collected from this area will be determined based on statistical modeling that will identify a localized "hot spot" to a 95 percent confidence level. After analytical results have been evaluated, the actual data will be 
reevaluated to verify that the 95 percent confidence level has been attained. Standard measurement errors will also be reduced using the same methods as in the judgmental sampling approach.

EPA's DQO guidelines state that if a judgmental sampling approach is used, quantitative statements about data quality will be limited to measurement error (EPA, 2006). Measurement error is influenced by imperfections in the measurement and analysis system. Random and systematic measurement errors are introduced in the measurement process during physical sample collection, sample handling, sample preparation, sample analysis, and data reduction. If measurement errors are not controlled, they may lead to errors in making the DQO decisions.

In general, confidence in DQO decisions based on judgmental sampling results will be established qualitatively by:

- Developing CSMs,

- Testing the validity of the CSMs based on investigation results

- Evaluating the quality of the data based on DQI parameters

\subsubsection{Decision Errors}

There are two baseline conditions (i.e., null hypotheses) and associated alternative conditions for CAU 121 depending on their location and source of potential contamination. The decision errors for each of these conditions will be reviewed separately for each of the baseline conditions.

\subsection{CASs 12-01-01, 12-01-02, and 12-22-26 Drum Area}

The baseline condition at these locations is that soil below the ASTs in CASs 12-01-01 and 12-01-02 and in the drum area of CAS 12-22-26 has not been impacted at concentrations above action levels by releases from these containers. The alternative condition is that the soil has been impacted at concentrations above action levels by releases from these containers.

\section{False Rejection (False Positive)}

This error would mean deciding that the baseline condition is false when, in fact, it is true. This error means deciding that the soil below the ASTs in CASs 12-01-01 and 12-01-02 and the drum area of CAS 12-22-26 is contaminated when it is not. The consequence of this decision is increased cost both for the closure effort and post-closure requirements (at CAS 12-22-26) that should not be needed. False positive errors are typically attributed to laboratory and/or sampling errors that could cause cross contamination. To control against cross contamination, disposable sampling equipment will be predominantly used and/or decontamination of sampling equipment will be conducted according to established and approved procedures, and only clean sample containers will be used.

At CAS 12-22-26, a false positive error could also involve excavation of soil, which would increase the potential for exposure to radioactivity in the URMA. Additional precautions that will be taken to protect workers for any excavations at CAS 12-22-26 include:

- Completing any excavation work at CAS 12-22-26 under a Radiological Work Permit (RWP), based on the area being posted as a URMA. The RWP will identify at what 
radioactivity levels the risk becomes elevated and poses significant risk to workers involved in the excavation and sample collection activities.

- Performing regular radiological surveys of the excavation, the area around the excavation, and the workers.

- Stopping work immediately if radiological screening indicates that radioactivity has increased to unacceptable levels without additional precautions. Before proceeding with excavation, site conditions and waste concentrations will be reevaluated to determine if the conditions warrant the additional precautions that will be needed to continue with excavation activities.

\section{False Acceptance (False Negative)}

This error would mean deciding that the baseline condition is true when, in fact, it is false. This error means deciding that the soil below the ASTs in CASs 12-01-01 and 12-01-02 and the drum area of CAS 12-22-26 is not contaminated when, in fact, it is contaminated above action levels. The potential consequence is an increased risk to human health and the environment. This error will be controlled by meeting these criteria:

- Having a high degree of confidence that the selected sample locations will identify contamination, if present. To satisfy this criterion, samples will be collected in areas most likely to be contaminated. For the ASTs, the most likely locations will be below openings in the tanks, whether intended openings (e.g., open ports and pipes) or unintended openings (e.g., corroded holes in tank). Additional biasing factors, such as stained soil or elevated radioactivity identified through field screening, will be used to identify those areas where contamination is likely. If no biasing factors are found at the CAS 12-22-26 drum area, all samples will be collected from the grid locations identified by the VSP statistical software (PNNL, 2005) intended to identify any "hot spots" in these areas with a 95 percent confidence level.

- Analyzing samples for a full suite of parameters where historical background or analytical results are not available to identify what may be present.

- Analyzing cleanup verification samples for all compounds greater than FALs in the soil being removed.

- Having a high degree of confidence that the analyses conducted will be sufficient to detect any contamination present in the samples. To satisfy this criterion, the DQIs of sensitivity will be assessed for all analytical results to ensure that all sample analyses had detection limits that were less than or equal to the corresponding action level.

- Having a high degree of confidence that the data set is of sufficient quality. To satisfy this criterion, the data will be assessed against the DQIs of precision, accuracy, comparability, and completeness, and the appropriate QC samples will be collected as defined in the Industrial Sites QAPP (NNSA/NV, 2002).

\subsection{CAS 12-22-26 AST Area}

The baseline condition at this location is that soil below the tank at its location to the north and south sides of the train tracks has been impacted with diesel at concentrations above the action level. The alternative condition is that the soil has not been impacted at these concentrations. 


\section{False Rejection (False Positive)}

This error would mean deciding that the baseline condition is false when, in fact, it is true. For the AST area of CAS 12-22-26, the error means deciding that the soil has not been impacted by diesel when it does have concentrations greater than $100 \mathrm{mg} / \mathrm{kg}$. The error would mean that the area would not be use-restricted and could increase risk to human health from surface exposure to diesel. However, since the area is already a URMA, the expected overall impact to workers would be minimal because of the precautions and worker protections that are already in place for excavating in this area. Regardless, this error will be controlled by meeting these criteria:

- Field-screening samples for TPH to identify those areas where elevated levels of diesel are expected to be found.

- Having a high degree of confidence that the selected sample locations will identify contamination, if present. To satisfy this criterion, samples will be collected in areas most likely to be contaminated. Samples will be collected from any stained soil where the AST has been located. If no staining is present, then samples will be collected from below fill ports or other locations where a release is likely to have occurred.

- Having a high degree of confidence that the analyses conducted will be sufficient to detect any contamination present in the samples. To satisfy this criterion, the DQIs of sensitivity will be assessed for all analytical results to ensure that all sample analyses had detection limits that were less than or equal to the corresponding action level.

- Having a high degree of confidence that the data set is of sufficient quality. To satisfy this criterion, the data will be assessed against the DQIs of precision, accuracy, comparability, and completeness, and the appropriate QC samples will be collected as defined in the Industrial Sites QAPP (NNSA/NV, 2002).

\section{False Acceptance (False Negative)}

This error would mean deciding that the baseline condition is true when, in fact, it is false. For the AST area of CAS 12-22-26, the error means deciding that the soil has been impacted by diesel when it does not have concentrations greater than $100 \mathrm{mg} / \mathrm{kg}$. The consequence of this error is increased cost both for UR implementation and post-closure monitoring, if deemed necessary. False negative errors are typically attributed to laboratory and/or sampling errors that could cause cross contamination. To control against cross contamination, disposable sampling equipment will be predominantly used and/or decontamination of sampling equipment will be conducted according to established and approved procedures, and only clean sample containers will be used.

\subsubsection{Develop the Plan for Obtaining Data (SteP 7)}

Step 7 of the DQO process provides the general approach for obtaining the information necessary to resolve the decisions. Table 1 summarizes the locations where samples will be collected. Table 2 summarizes the analyses to be performed.

A judgmental sampling scheme will be implemented to select sample locations and evaluate analytical results for CASs 12-01-01, 12-01-02, and the 12-22-26 AST area. EPA's DQO guidelines state that a judgmental sampling approach can be used when there is sufficient information on the contamination sources and history to develop a valid CSM and to select 


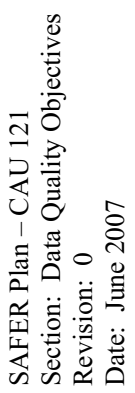

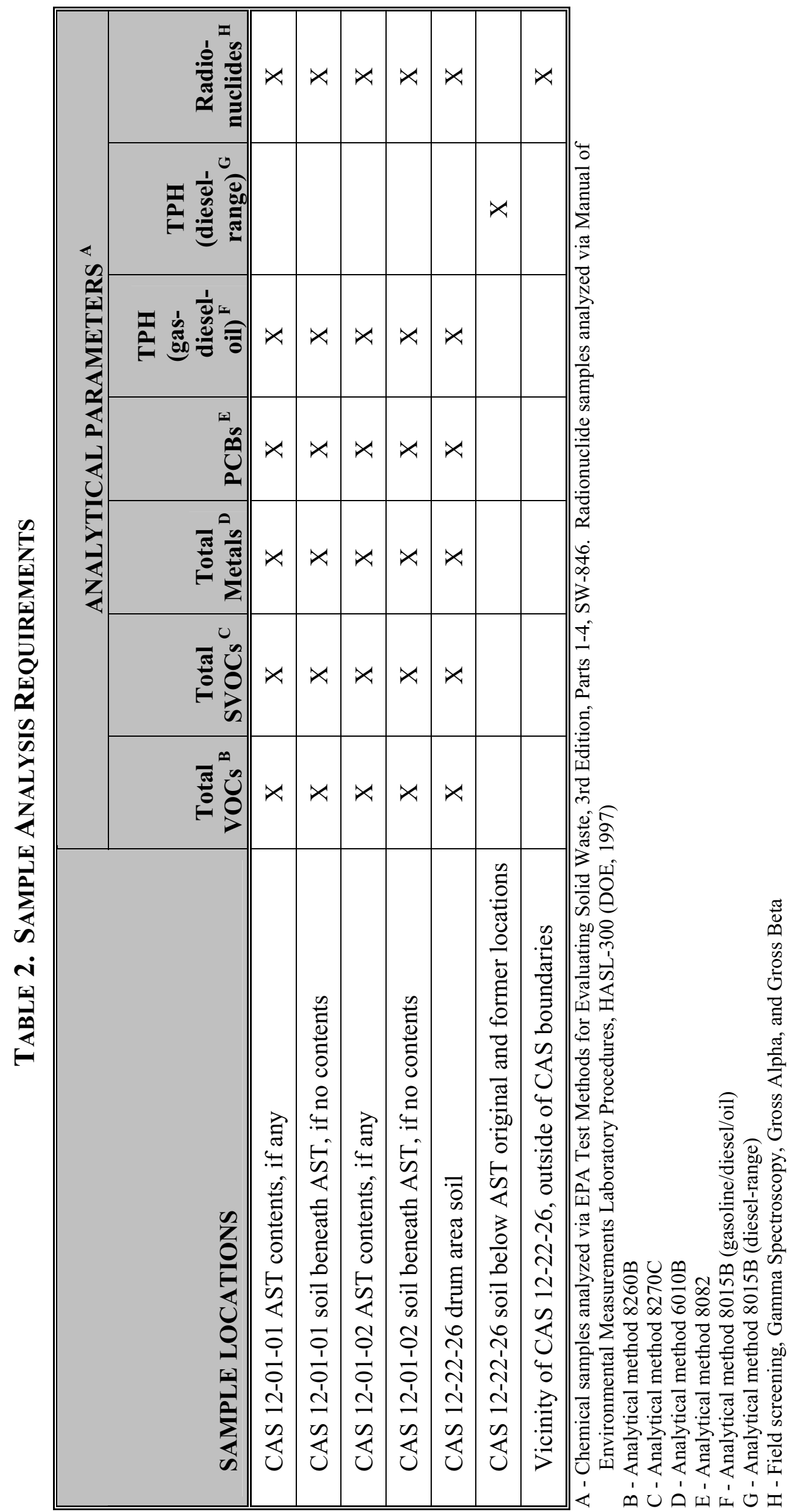


specific sampling locations (EPA, 2006). This design is used to confirm the existence of contamination at specific locations and to provide information about specific areas of the site. Sample locations for judgmental sampling will be determined based on process knowledge and previously acquired data.

For CASs 12-01-01 and 12-01-02, if the AST is not empty, then samples will be collected from the contents of the tank and analyzed for full-suite of parameters. Soil samples will be collected from below each AST, in a location most likely to be impacted by a release from the tank. If the tank is empty, then the soil sample will be analyzed for the full suite (as indicated in Table 2). If the tank is not empty, then the soil sample will only be analyzed for any constituents within the tank whose concentrations exceed the PALs. If sampling indicates that the soil below the AST is impacted at chemical or radiological levels greater than the PALs, then FALs will be determined for that site. If concentrations present at the site are less than the FALs, then the site will be closed with no further action taken. If concentrations exceed the FALs, then the area will be excavated to remove soil containing concentrations greater than the FALs. If needed prior to excavation, additional samples may be collected using the Geoprobe ${ }^{\circledR}$ to identify the depth of contamination, after which the impacted soil will be excavated and cleanup verification samples will be collected. Figure 7 provides a flowchart of the closure decision pathways for CASs 12-01-01 and 12-01-02.

For the CAS 12-22-26 diesel AST area, soil samples will be collected and analyzed for dieselrange petroleum hydrocarbons to identify whether soil in this area has been impacted by releases from the tank system. If diesel concentrations are less than the $100 \mathrm{mg} / \mathrm{kg} \mathrm{PAL}$, then no further action is needed and this portion of the site will be clean closed. If results show that diesel concentrations exceed the FAL, then additional soil samples will be collected and field-screened for TPH to identify the lateral extent of TPH that exceeds the FAL. When field screening results indicate that the boundaries of the area exceeding the FAL have been identified, then a minimum of three samples will be collected and submitted for laboratory analysis to confirm that the area containing diesel in excess of the FAL has been bounded. A UR will be implemented for this area.

A combination of statistical and judgmental sampling will be implemented to select sample locations at the CAS 12-22-26 drum area and to evaluate whether results confirm that an adequate number of samples has been collected. A minimum of eight samples will be collected from random locations within the drum storage area. If biasing factors are identified, additional biased samples will be collected from these locations. After results have been received, they will be reviewed to verify that they have achieved the 95 percent confidence level. If results indicate that additional samples are necessary to adequately characterize the areas of interest, then additional samples will be collected for the parameters of interest. Soil samples will be collected from the CAS 12-22-26 drum area and analyzed for the full suite of parameters.

A flowchart of the closure decision pathway for CAS 12-22-26 is presented in Figure 8. Because of the URMA beneath this site, attempts will be made to keep excavation of this area to a minimum. 


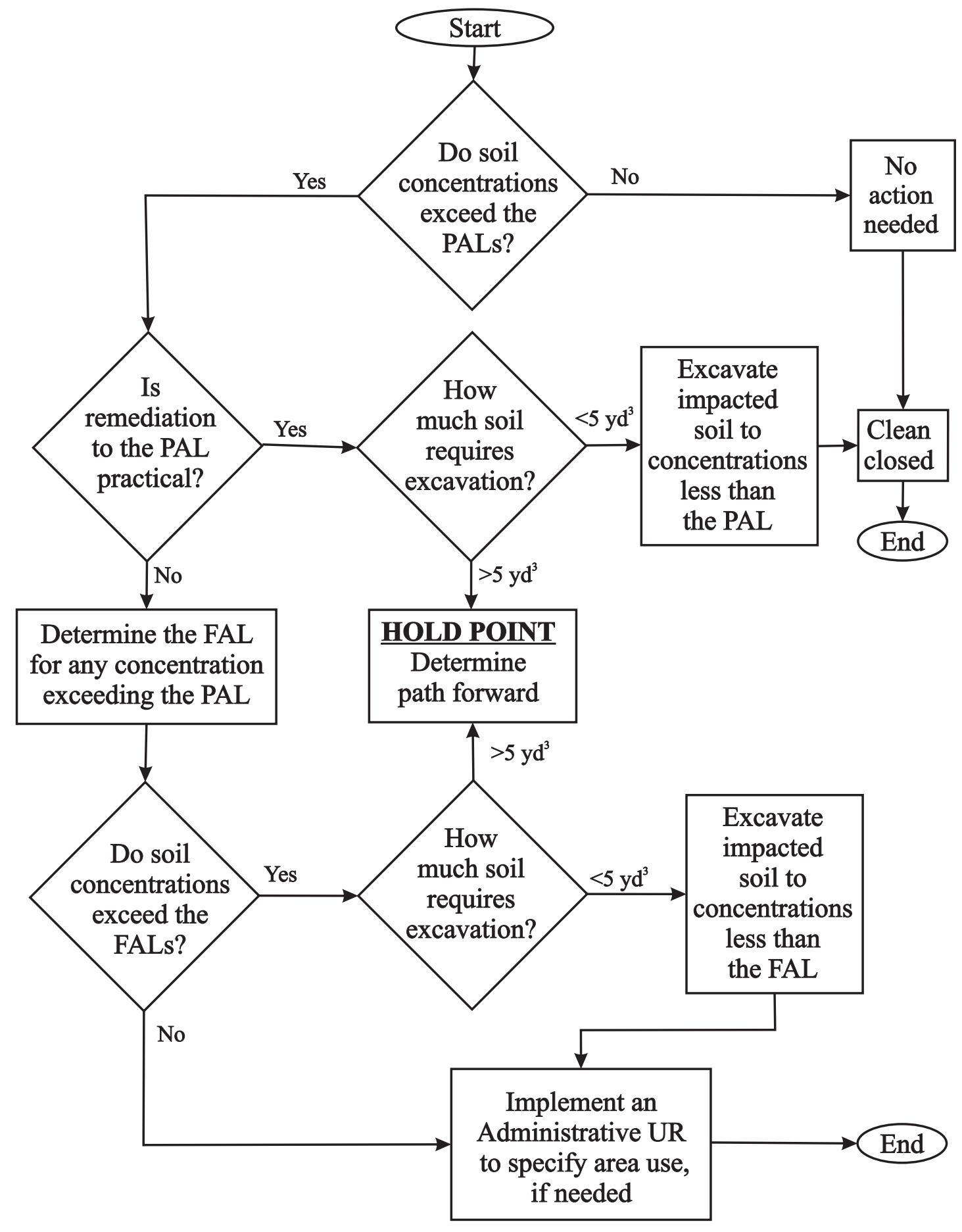

\section{FIGURE 7}

DECISION FLOWCHART FOR CASS 12-01-01 AND 12-01-02 


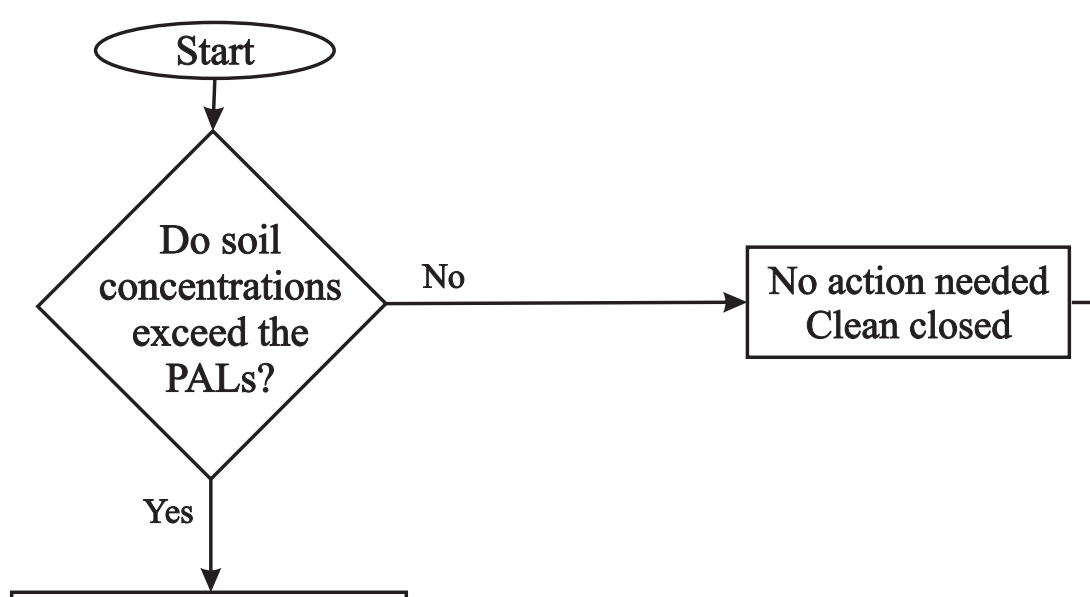

Determine the FAL

for any concentration exceeding the PAL

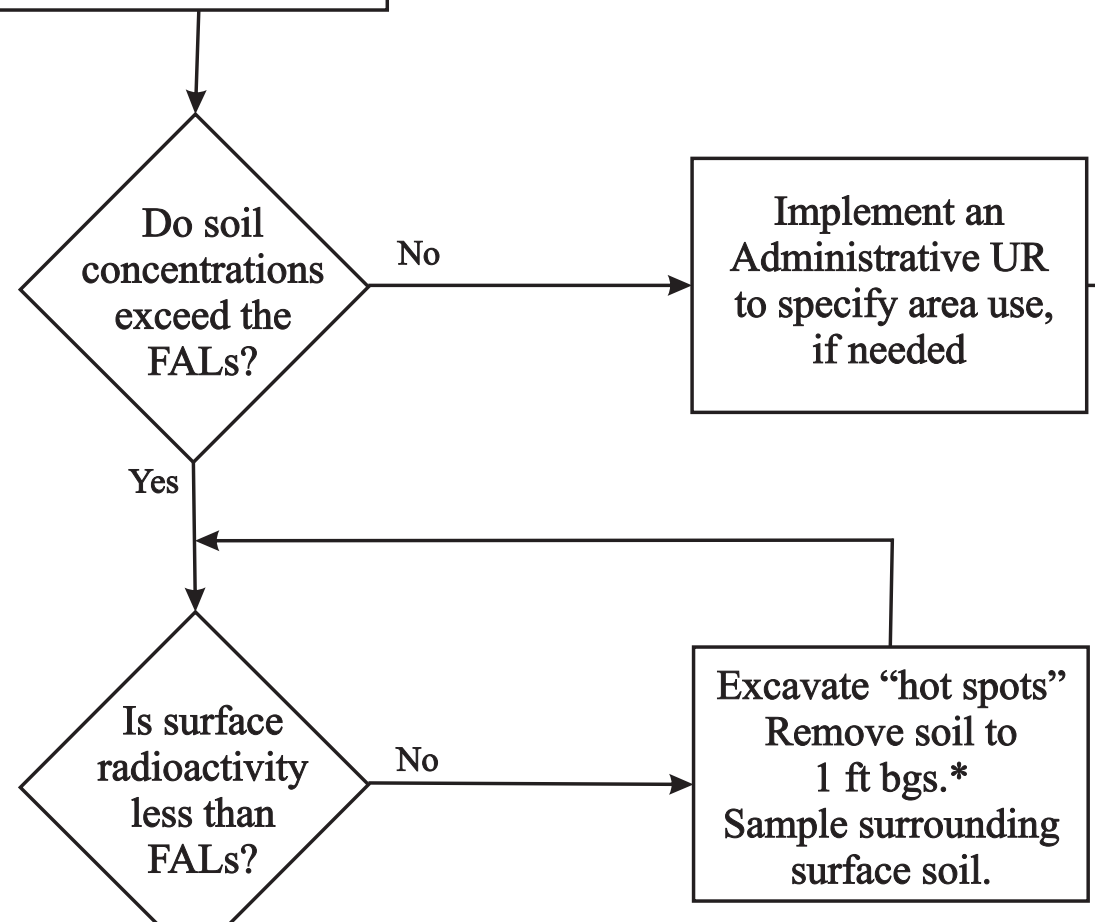

*HOLD POINT

If radioactivity presents

undue hazard to personnel,

stop excavating and

identify path forward $\quad$ Page 1 of 2

FIGURE 8

DECISION FLOWCHART FOR CAS 12-22-26 


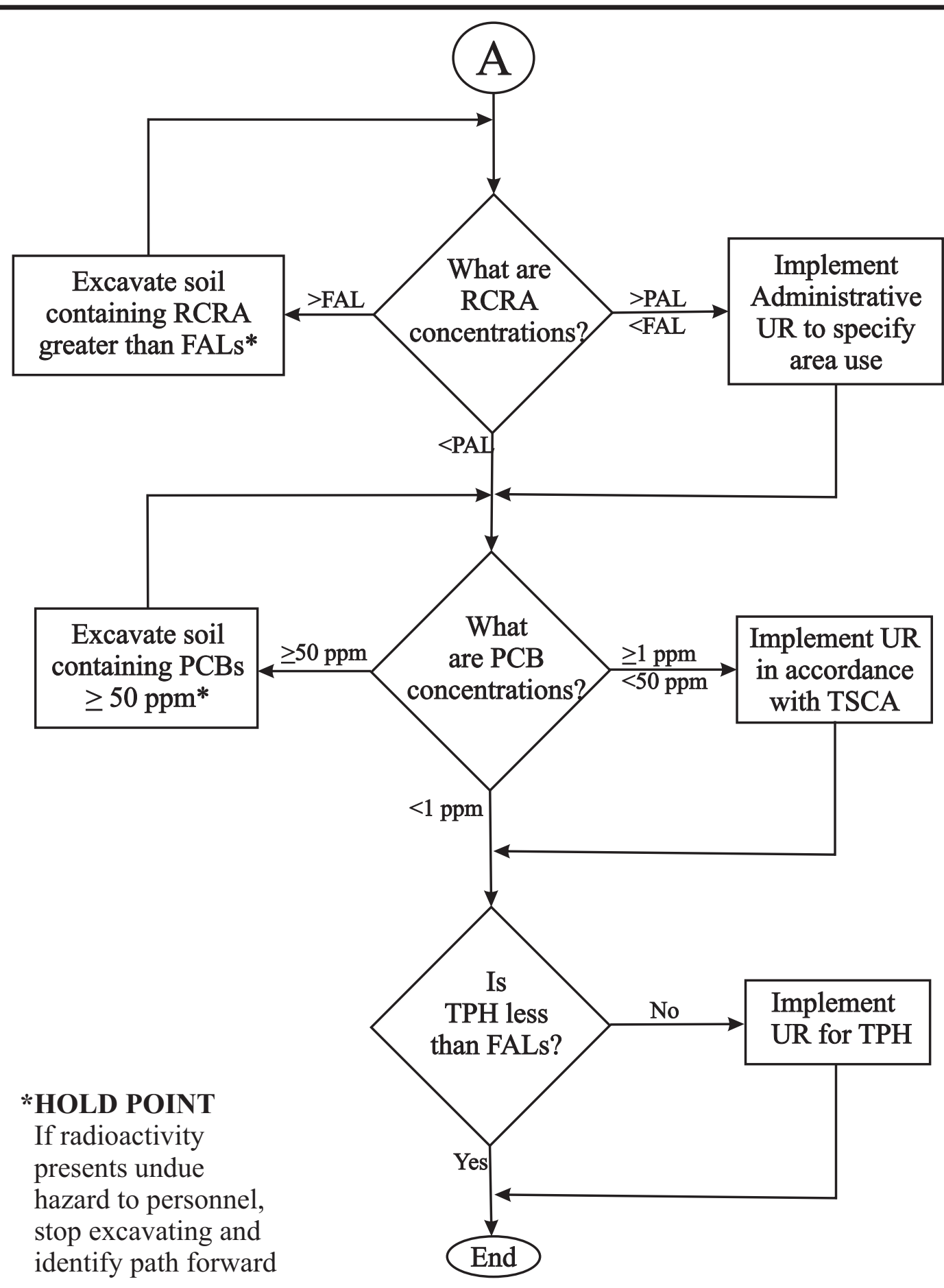

Page 2 of 2

FIGURE 8 (CONT'D)

DECISION FLOWCHART FOR CAS 12-22-26 


\subsection{RESUlTS OF THE DQO ANALYSIS}

\subsubsection{ACTION LEVEL DETERMINATION AND BASIS}

The PALs for CAU 121 will be identified based on the following:

- Chemicals - The chemical PALs are defined as the risk-based preliminary remediation goals for chemical constituents in industrial soils (EPA, 2004), with exceptions as described below.

- PCBs - The PAL for PCBs will be 1 ppm, as identified in Title 40 CFR Part 761.61 (CFR, 2006) for unrestricted use.

- TPH - The TPH PAL will be $100 \mathrm{mg} / \mathrm{kg}$, as is established in the NAC, Section 445A.2272, "Contamination of soil: Establishment of action levels," (NAC, 2006).

- Radioactivity - The PALs for radiological contaminants are based on the NCRP Report No. 129 recommended screening limits for construction, commercial, and industrial land-use scenarios (NCRP, 1999) scaled to $25 \mathrm{mrem} / \mathrm{yr}$ dose constraint (Murphy, 2004) and the generic guidelines for residual concentration of radionuclides in DOE Order 5400.5 (DOE, 1993). The radiological action level for solid media will be defined as the unrestrictedrelease criteria defined in the NV/YMP RadCon Manual (NNSA/NSO, 2004). Remaining radiological contamination, per Decision II of the decision rules, will be posted per the NV/YMP RadCon Manual (NNSA/NSO, 2004). For CAS 12-22-26, the PALs will be the greater of the levels described above, or the local area background levels, as determined through a sample collected from the local area but outside of the CAS boundary.

If results show that chemical or radiological concentrations exceed PALs, then FALs will be determined using the process identified in the "Industrial Sites Project Establishment of Final Action Levels" (NNSA/NSO, 2006). Closure actions to be taken at each site depend on the CAS-specific FALs.

\subsubsection{HYPOTHESIS TEST}

Only valid data from radiological surveys and laboratory analytical results will be used to determine if contamination is present. The null hypothesis is that soil below the ASTs in CASs 12-01-01 and 12-01-02 and the (former) drums in CAS 12-22-26 has not been impacted at concentrations above action levels by releases from these containers, while soil in the AST area at CAS 12-22-26 has been impacted with diesel at concentrations greater than $100 \mathrm{mg} / \mathrm{kg}$.

The two types of decision errors are false rejection (i.e., false positive) and false acceptance (i.e., false negative). A false rejection decision error would occur:

1. If contamination is determined to be present above the action levels at CASs 12-01-01, 12-01-02, and below drums at 12-22-26 when it actually is not, resulting in increased costs for unnecessary remediation and increased risk to human health by excavating in a URMA, and/or

2. If TPH is determined not to be present above the action levels below and around the CAS 12-22-26 AST when it is, resulting in the area not being use-restricted for TPH (although it remains posted as a URMA). 
A false acceptance (i.e., false negative) decision error would occur:

1. If contamination is determined to not be present above the action levels at CASs 12-01-01, 12-01-02, and the drum area of CAS 12-22-26 when it actually is, resulting in increased risk to human health and the environment by leaving impacted soil, and/or

2. If diesel concentrations are determined to be greater than the action level in the CAS 12-22-26 AST area but they are not, resulting in increased costs to establish the UR and for post-closure monitoring of the area.

\subsubsection{Statistical Model}

Individual sample results will be compared to action levels and statistical models will not apply for determining the actions at any of the CAU 121 CASs. CASs 12-01-01, 12-01-02, and the AST area of 12-22-26 will all be sampled at locations most likely impacted by releases from the tanks, as determined through biasing factors at each site.

The drum area of CAS 12-22-26 will be sampled at statistically determined locations because there are no biasing factors in this area. The size and configuration of the drum area was entered into the VSP statistical software program (PNNL, 2005). A sampling grid was provided by the program that should identify a $2 \frac{1}{2}$-ft "hot spot" within this area (approximate diameter of drum) to a 95-percent confidence level. Samples will be collected from the grid locations and results will be input back into the program to verify that this 95-percent confidence level is achieved.

\subsubsection{DESIGN DESCRIPTION/OPTION}

Biased (judgmental) samples will be collected, as summarized in Table 1. These locations were chosen based on process knowledge of the sites. Systematic radiological surveys will be conducted to identify radiological contamination and background concentrations. Where biasing factors are not present, samples will be collected from statistically determined sample locations designed to identify "hot spots" to a 95-percent confidence level.

\subsubsection{CSM}

Two CSMs are presented for CAU 121. The first CSM applies to CASs 12-01-01 and 12-01-02, and to the former drum area at CAS 12-22-26. This CSM assumes that the existing ASTs were deposited at their present location after they had been emptied, and that the drums did not release their contents. The alternate CSM assumes that contents of the ASTs (or drums) have been released to the environment. Because the ASTs do not appear to have been operational in their current location, any releases from these ASTs, or the drums, should have resulted in localized releases of limited quantities to the surface soil with limited migration into the subsurface soil. The primary and alternate CSMs for these CASs are presented in Figure 2.

The second CSM applies to the diesel AST of CAS 12-22-26. This CSM assumes that diesel has been released at both operational locations of the diesel AST as a result of spilling and overfilling when fueling locomotives from this AST. Because the site is a URMA, radioactive materials are assumed to be buried underneath this CAS. This CSM is depicted in Figure 3. The alternate CSM assumes that soil has not been impacted by diesel from the AST and is similar to the primary CSM for CASs 12-01-01 and 12-01-02. 
SAFER Plan - CAU 121

Section: Data Quality Objectives

Revision: 0

Date: June 2007

\section{THIS PAGE INTENTIONALLY LEFT BLANK}


CAU 121 Closure Report

Section: Appendix B

Revision: 0

Date: September 2008

\section{APPENDIX B}

\section{SAMPLE ANALYTICAL RESULTS}


CAU 121 Closure Report

Section: Appendix B

Revision: 0

Date: September 2008

\section{THIS PAGE INTENTIONALLY LEFT BLANK}




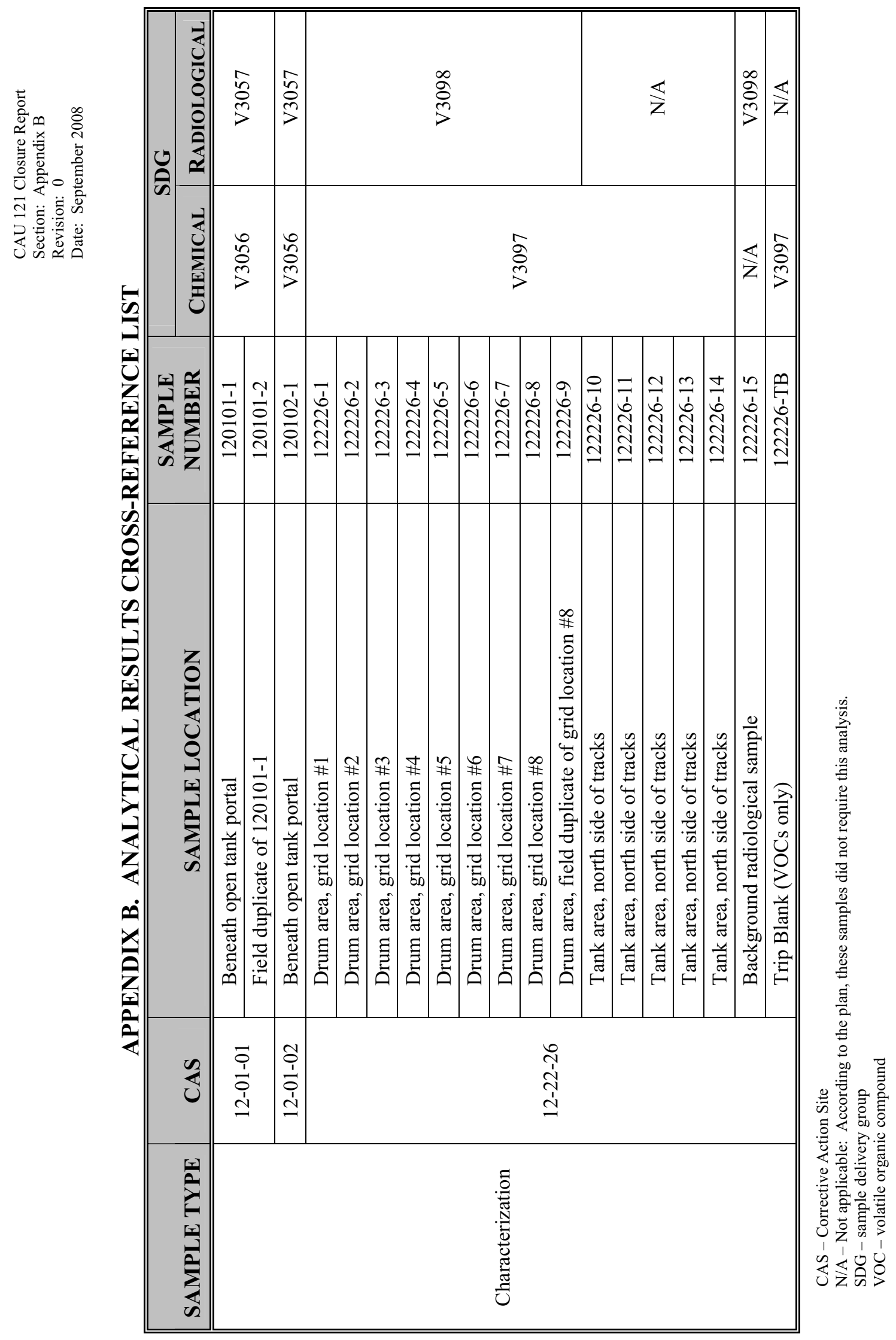




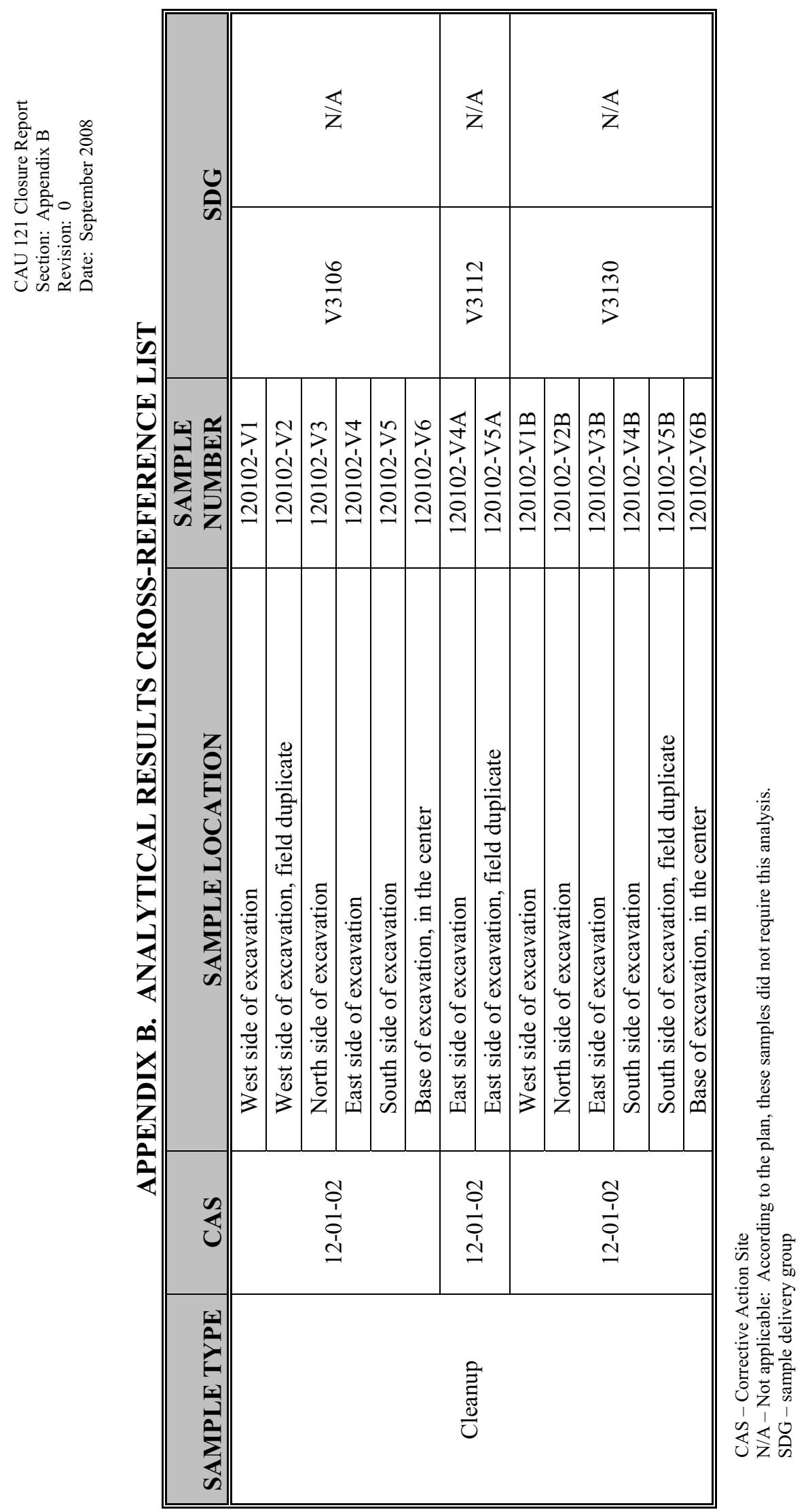


CAU 121 Closure Report

Section: Appendix B

Revision: 0

Date: September 2008

\section{Sample Delivery Group V3056}


CAU 121 Closure Report

Section: Appendix B

Revision: 0

Date: September 2008

\section{THIS PAGE INTENTIONALLY LEFT BLANK}




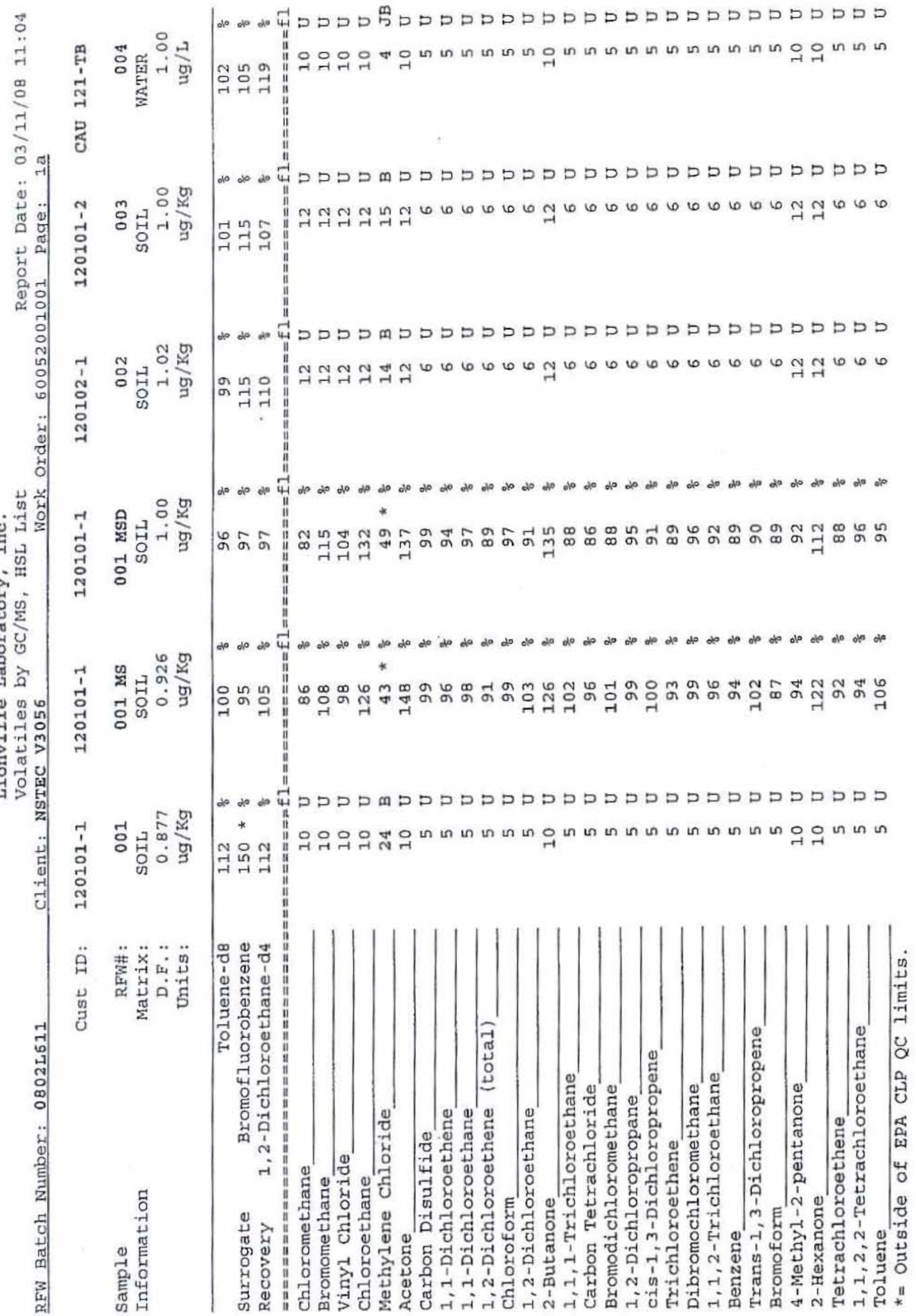




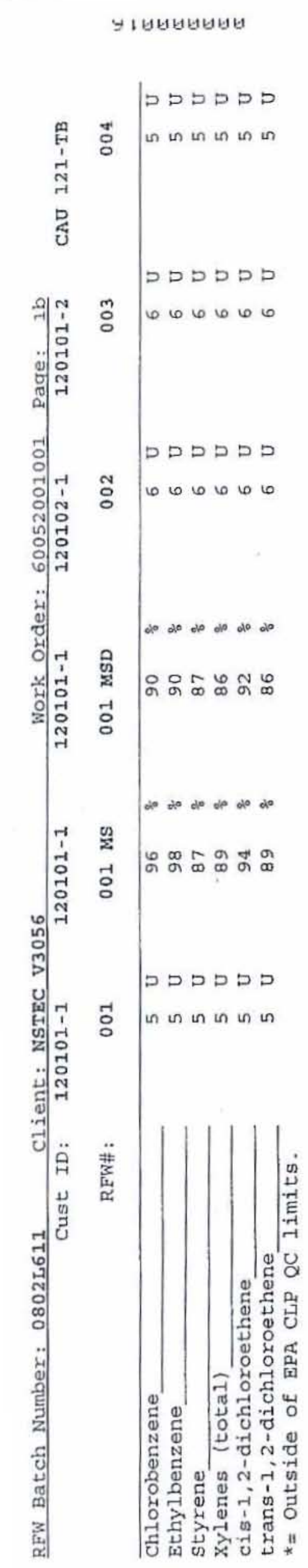




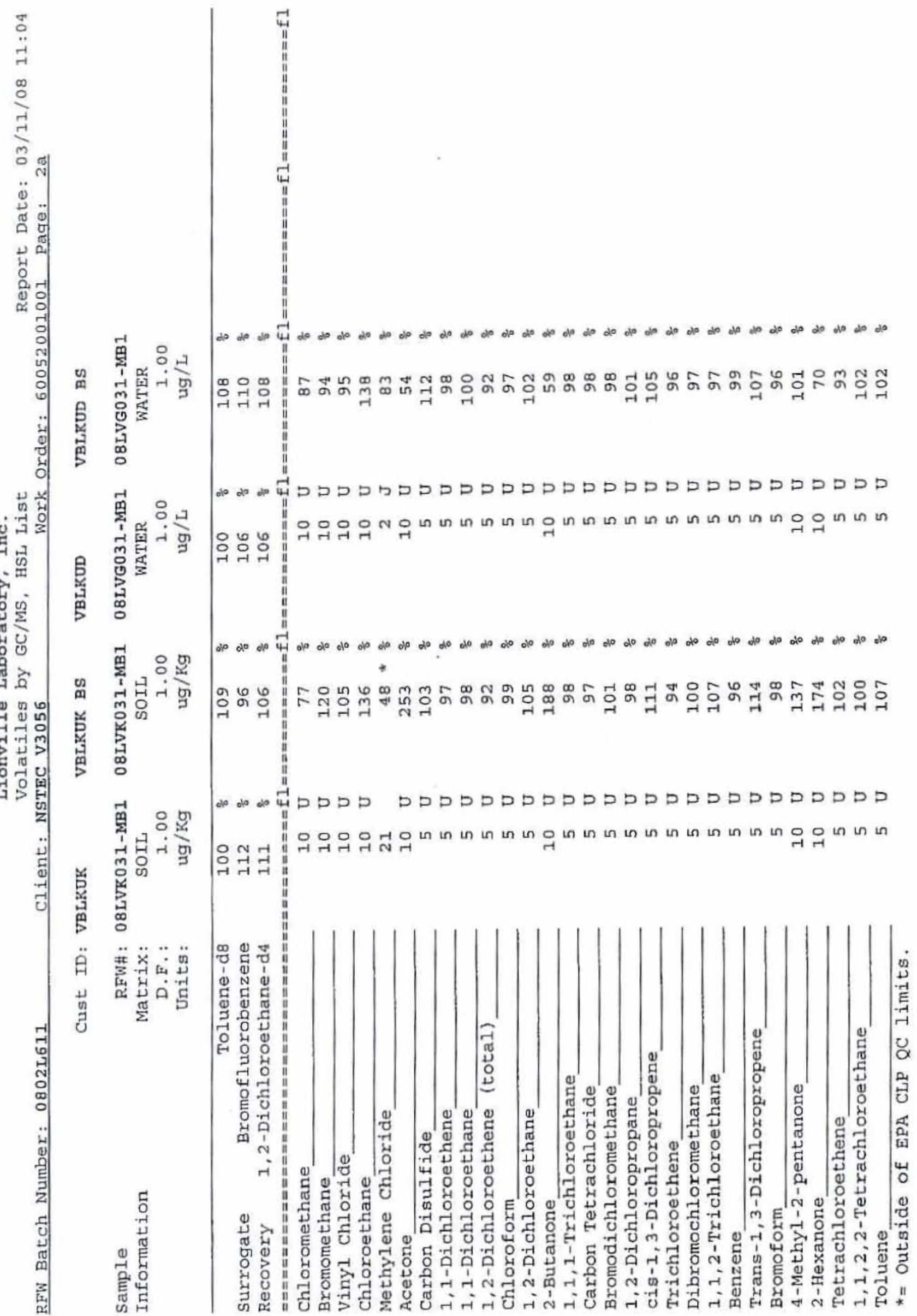




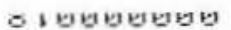

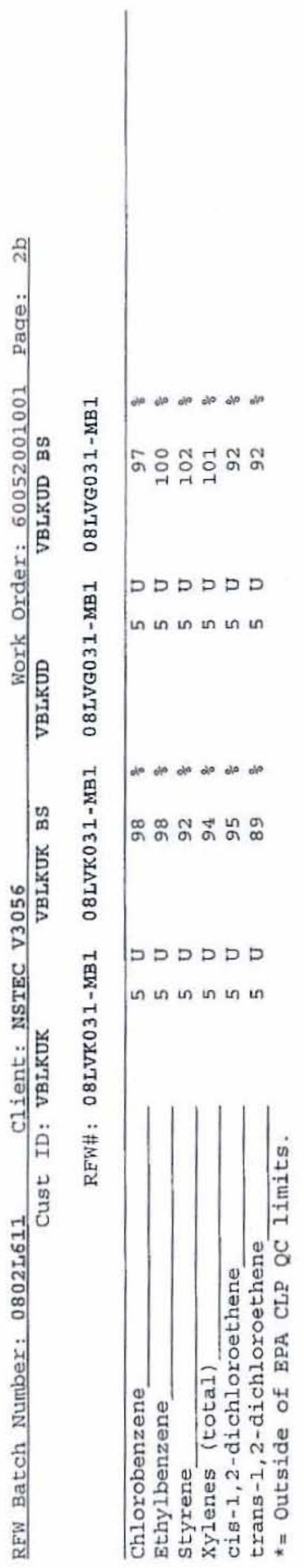




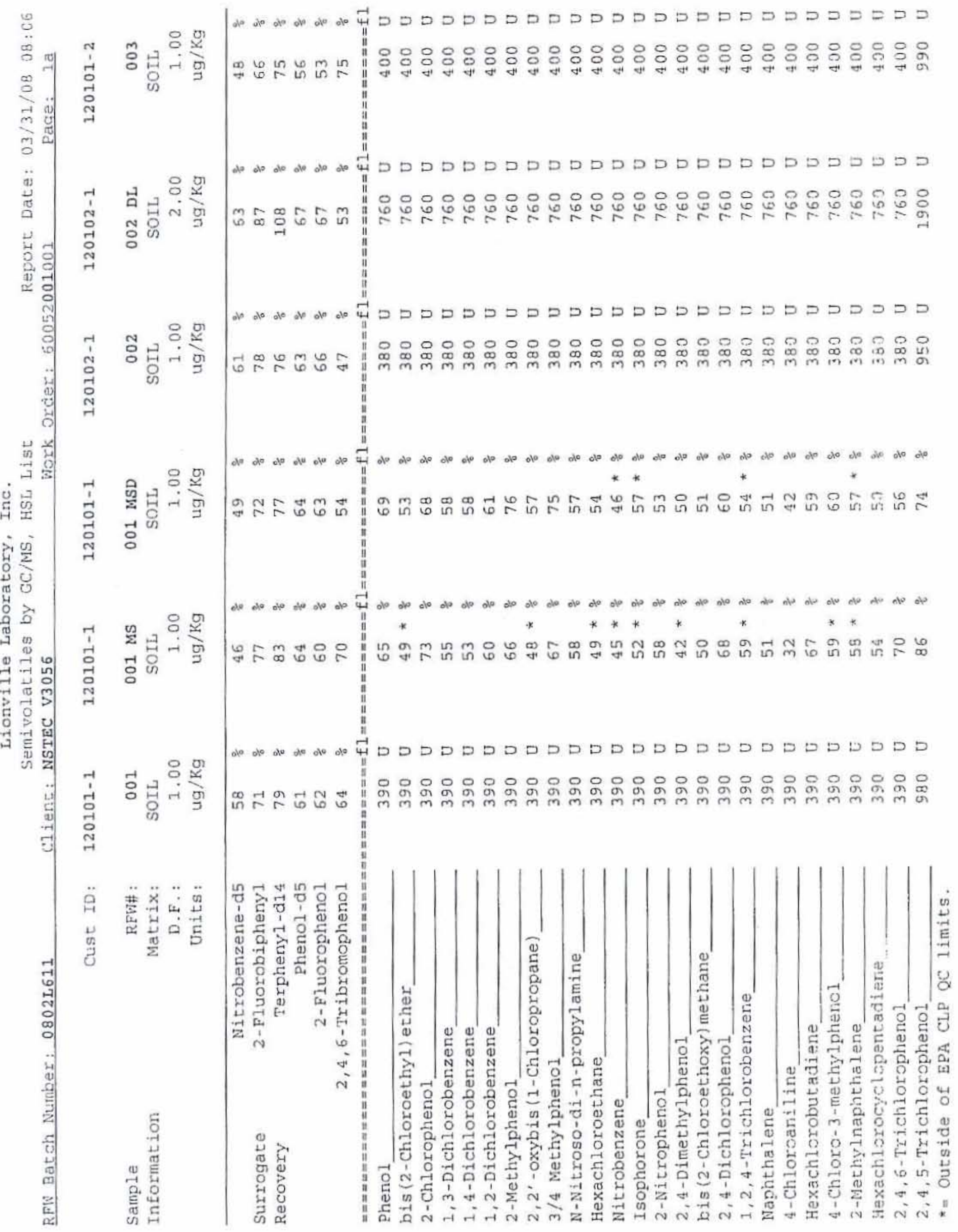




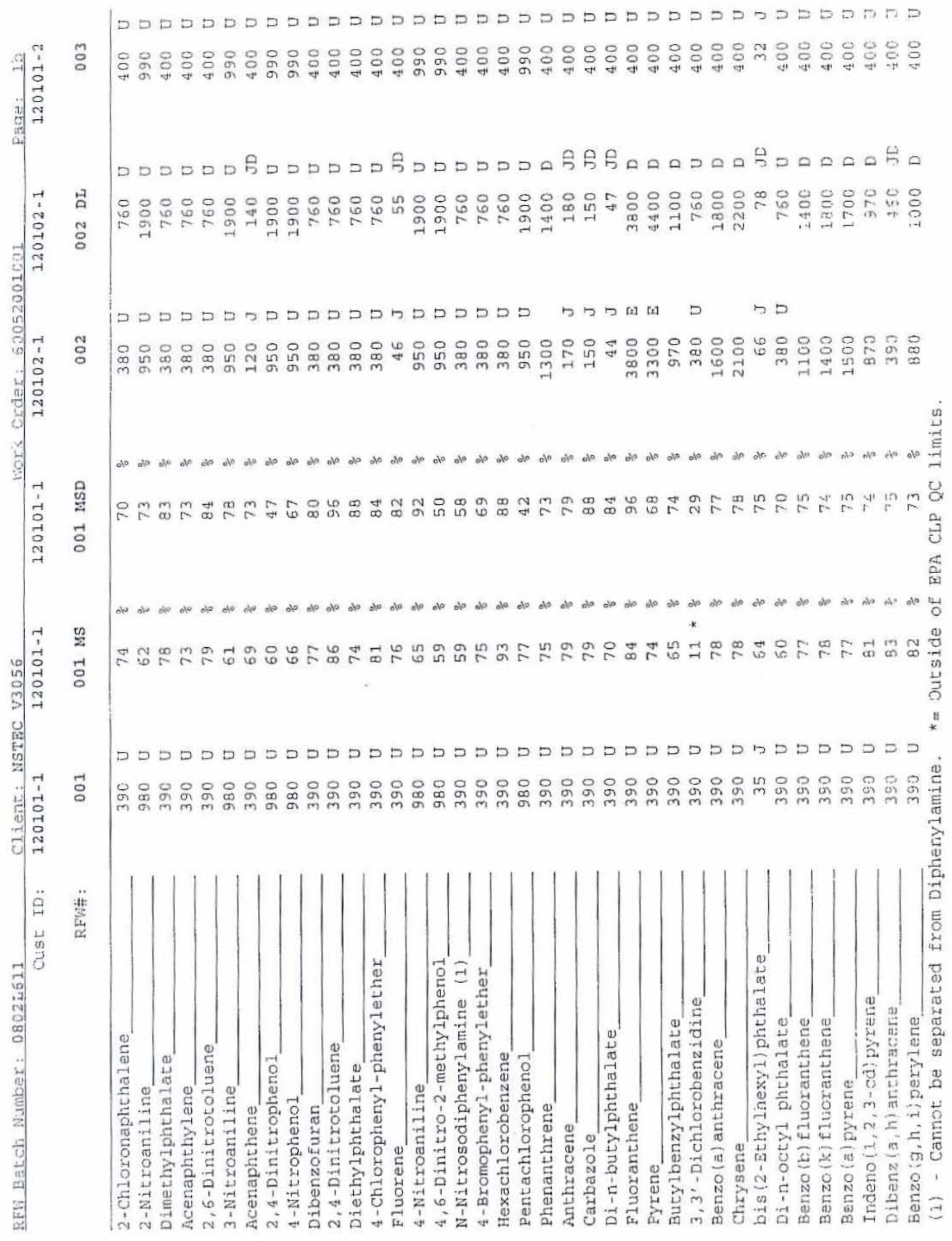




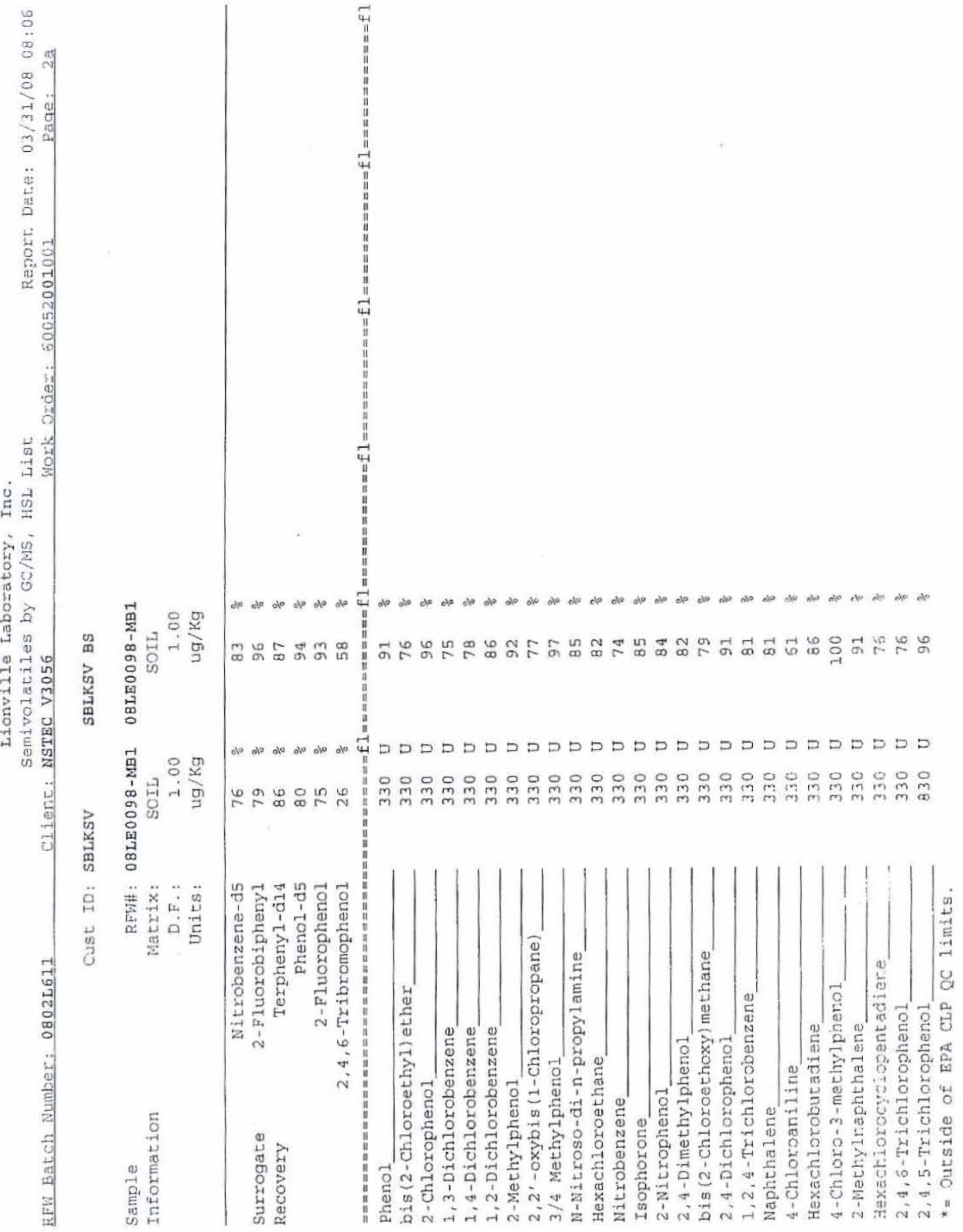




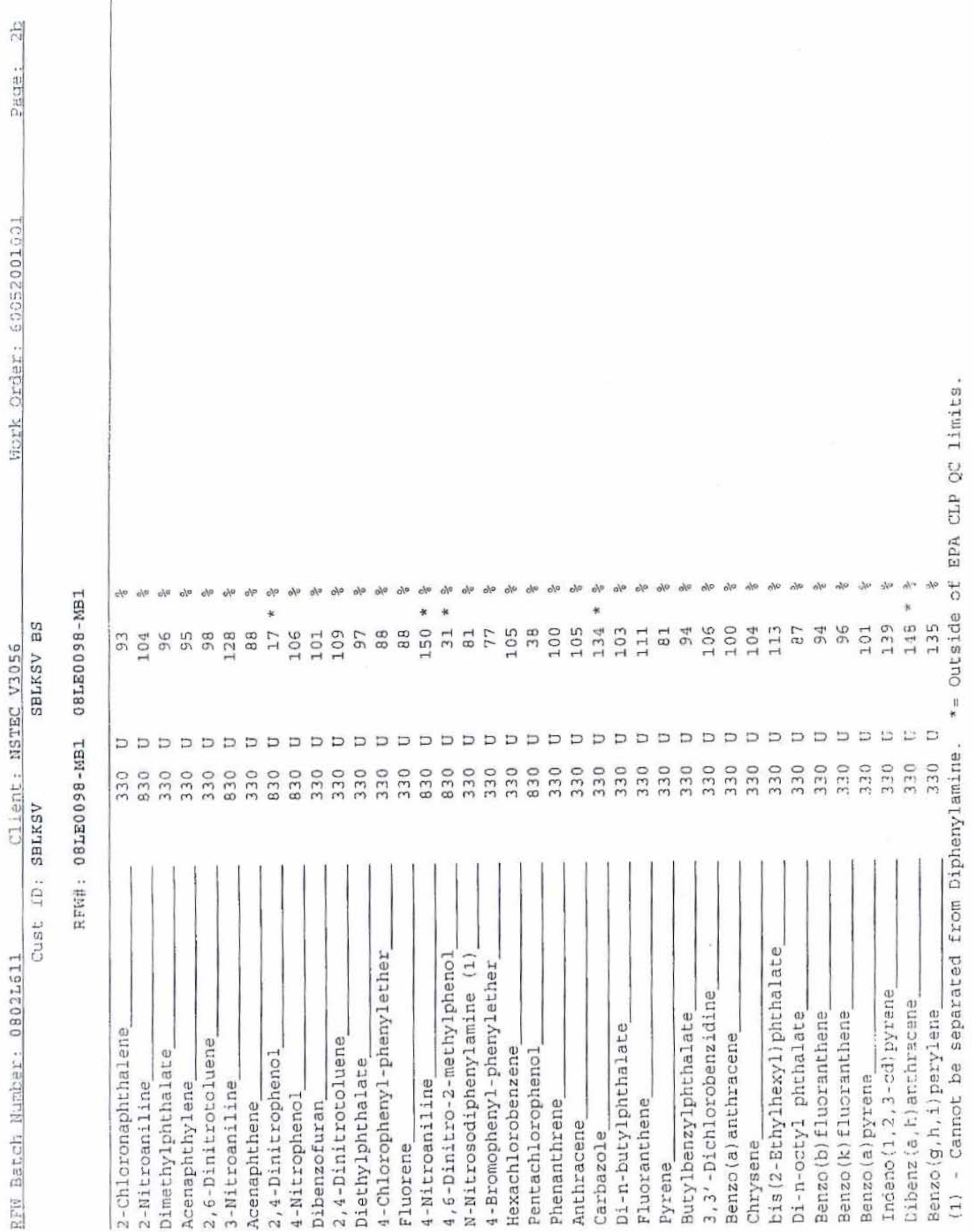


EPA SAMPLE NO.

1011

Lab Name: LIONVILIE LABORATORY

Lab Code: LVLI Matrix (soil/water): SoIL

Level (low/med): LOW

\% Solids: $\quad-84 \overline{.9}$

Contract: 60052

SAS No. :

Lab Sample ID: 08021611-001

Date Received: 02/15/08

Concentration Units (ug/L or $\mathrm{mg} / \mathrm{kg}$ dry weight): MG/KG

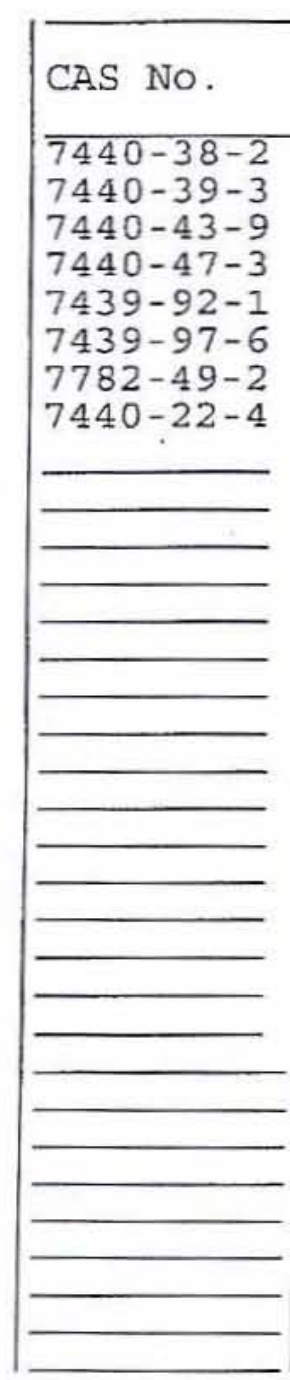

Color Before: Color After:

Comments :

120101-1

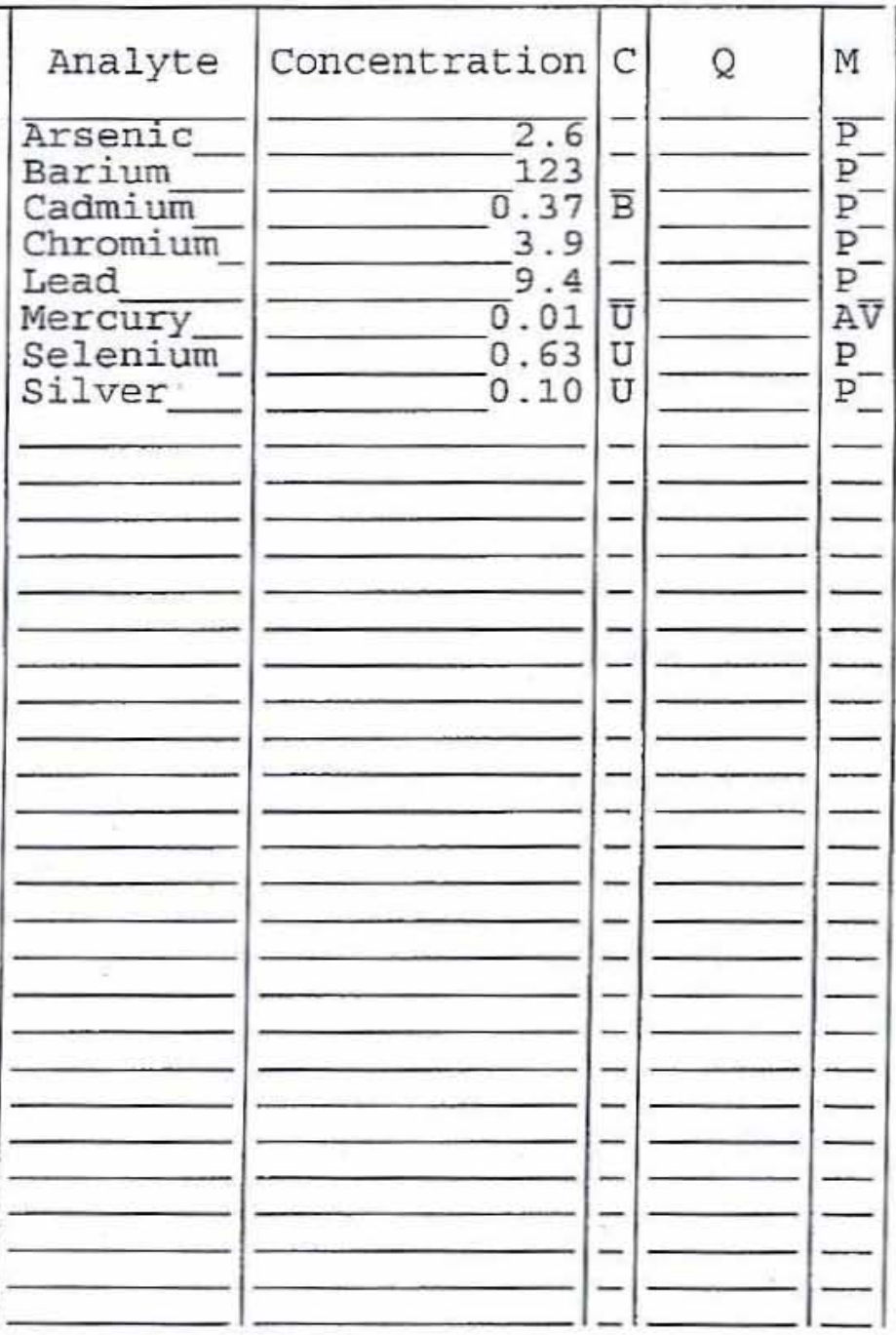

Clarity Before:

Texture: Clarity After:
Artifacts : 
U.S. EPA

1

INORGANIC ANALYSES DATA SHEET
EPA SAMPLE NO.

1021

Lab Name: LIONVILIE LABORATORY

Contract: 60052

Lab Code: LVLI

Matrix (soil/water): SOIL

Level (low/med): LOW

\% Solids :
SAS No. :

Lab Sample ID: 0802L611-002

Date Received: 02/15/08

Concentration Units (ug/L or $\mathrm{mg} / \mathrm{kg}$ dry weight): MG/KG

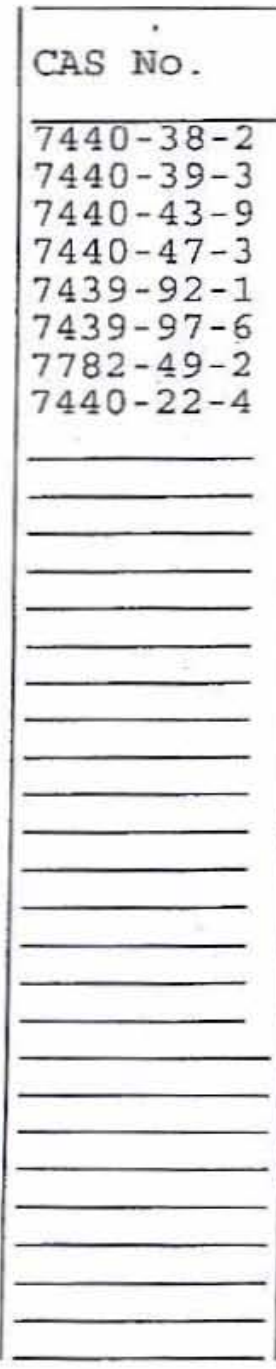

Color Before: Color After:

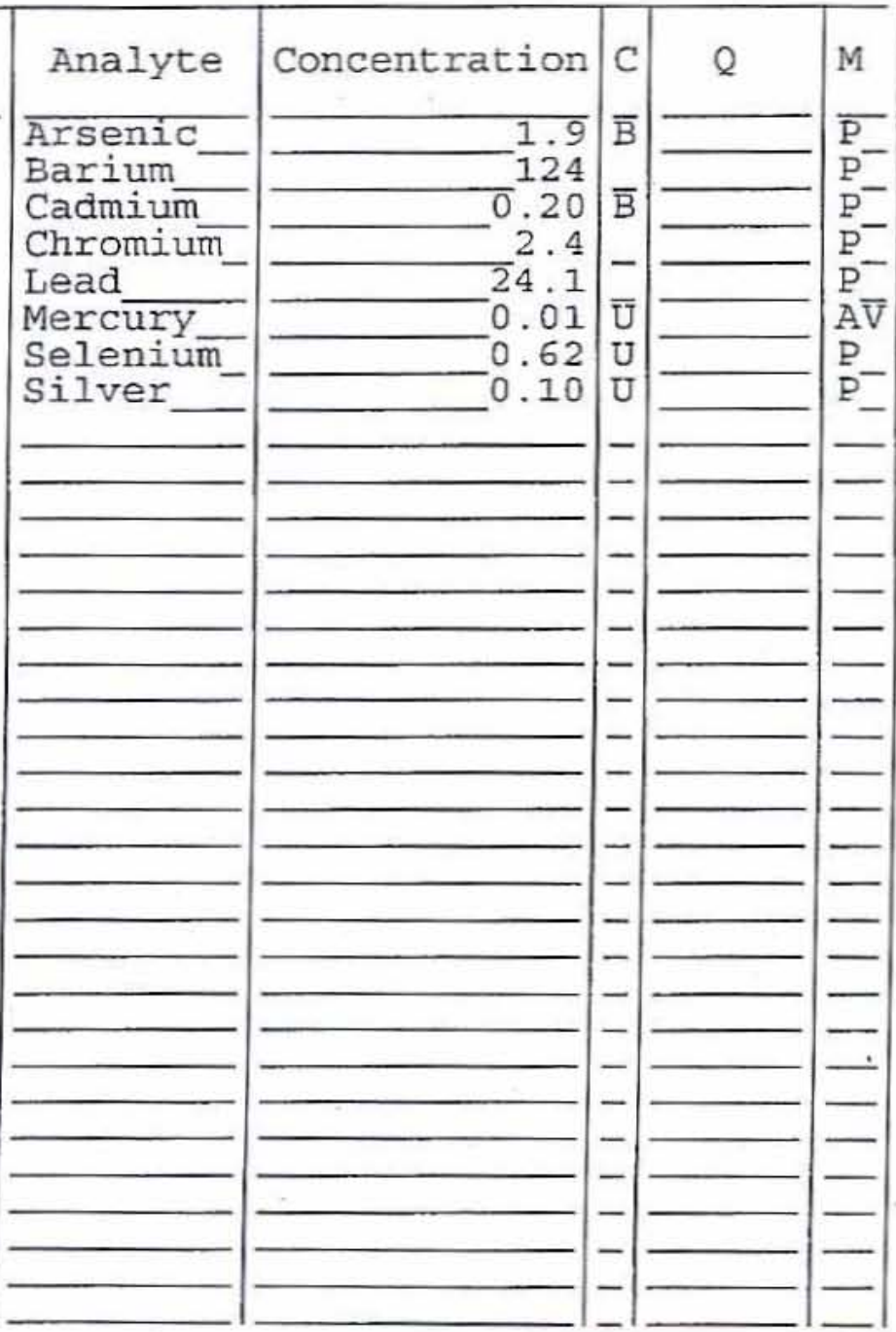

Clarity Before: Clarity After:
Texture:

Artifacts :

Comments:

120102-1 


\section{U.S. EPA}

1

INORGANIC ANALYSES DATA SHEET
BPA SAMPLE NO.

\section{2}

Lab Name: LIONVILLE LABORATORY

Contract: 60052

SAS NO.: SDG No.: V3056

Lab Code: LVLI Matrix (soil/water): SoIL_ Level (low/med): LOW $\%$ Solids :
Lab Sample ID: 0802L611-0̄03

Date Received: 02/15/08 $84 \overline{3}$

Concentration Units (ug/L or $\mathrm{mg} / \mathrm{kg}$ dry weight): MG/KG

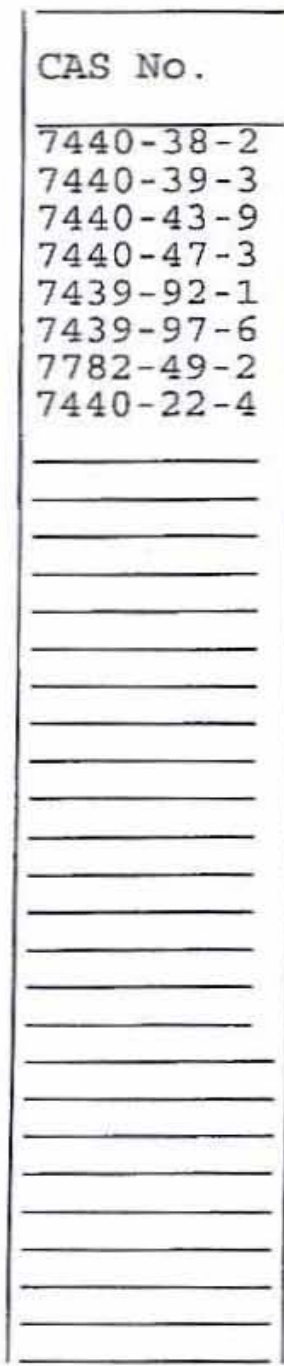

Color Before: Color After:

Comments :

120101-2

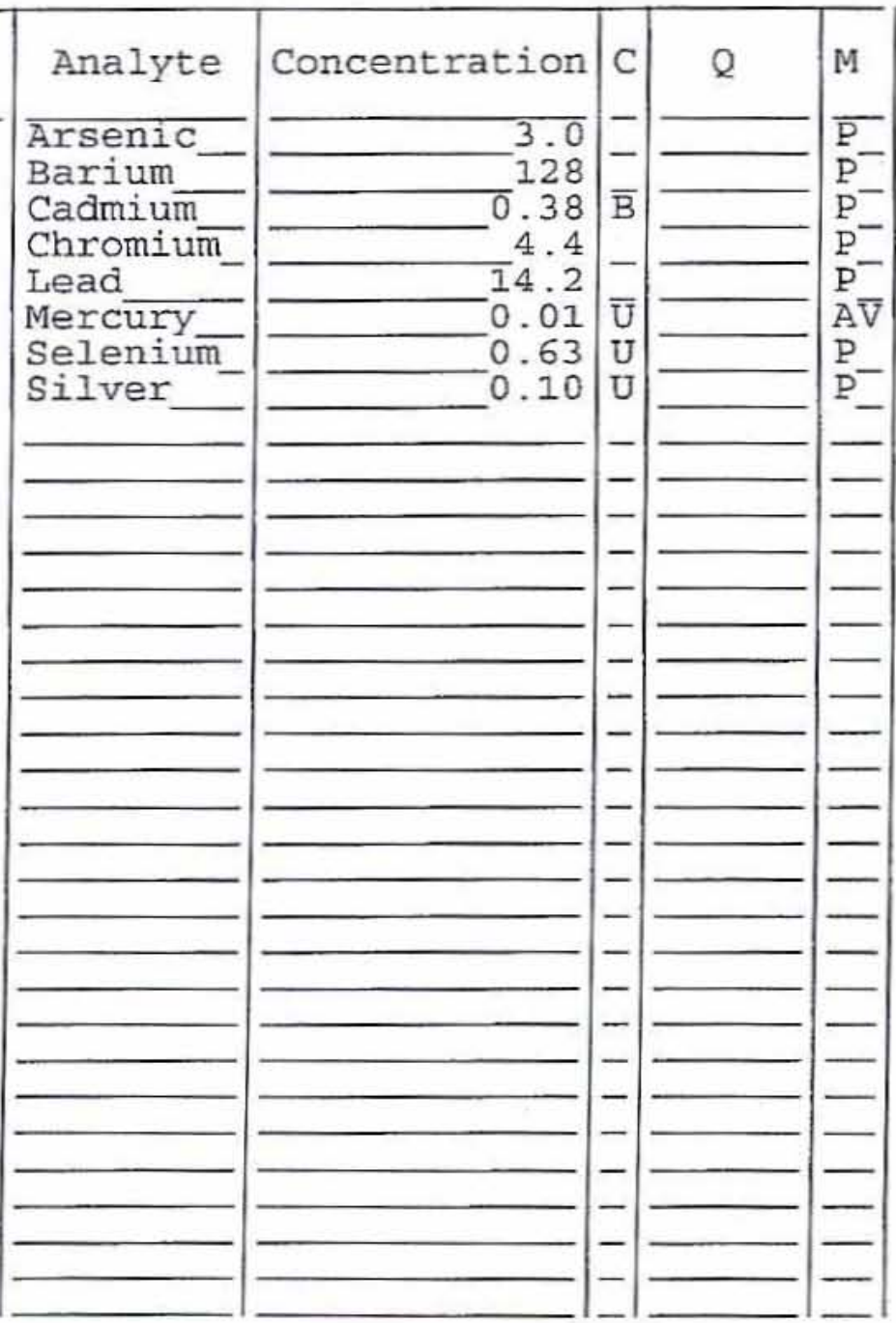

Clarity Before: Clarity After:
Texture:

Artifacts: 


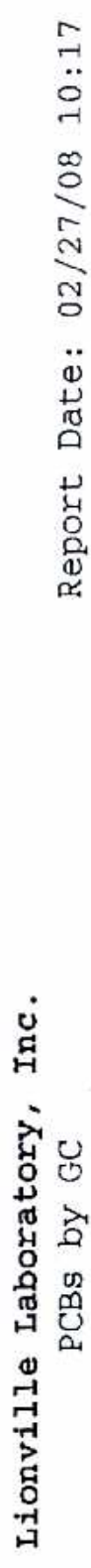

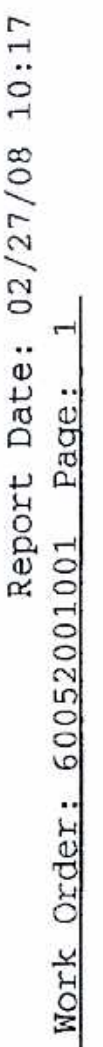

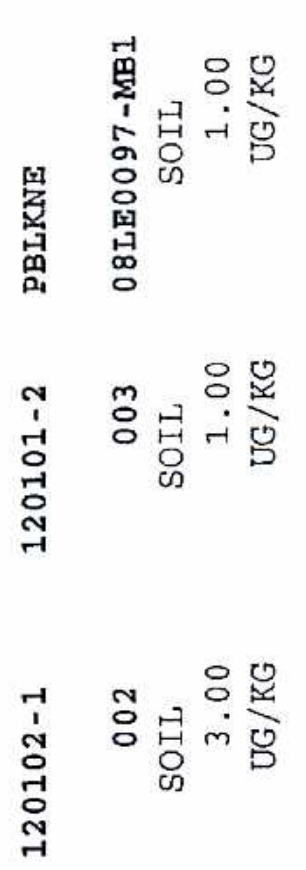

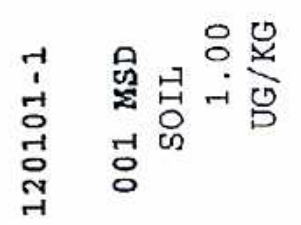

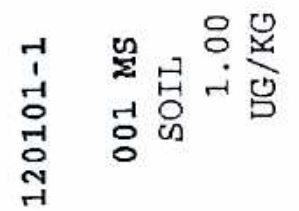

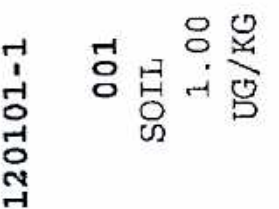

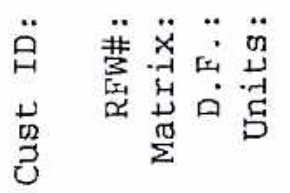

do do 芩口 $m m m m m m$

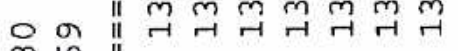
क<smiles>C=[Se]=[Fe]</smiles>

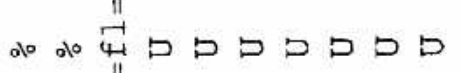

6666

in

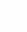

ロロロ

분 6

ก๊
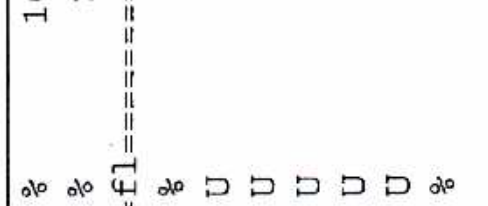

ம 660

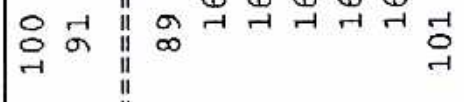

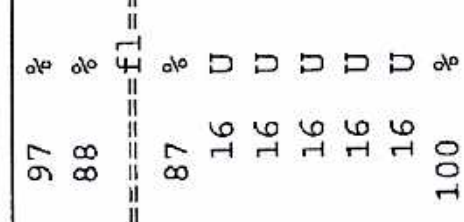

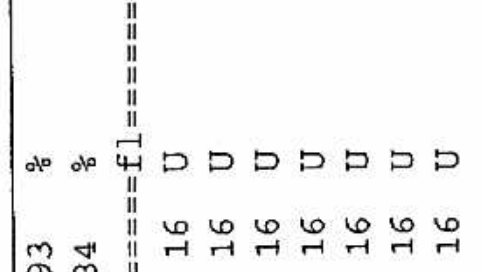

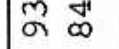

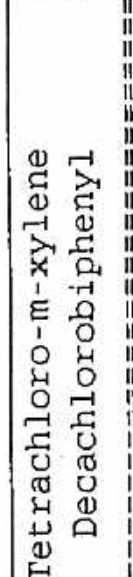

音

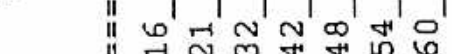

i

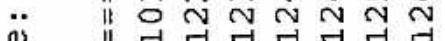

(1)

崩 II

ㅂ.

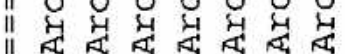

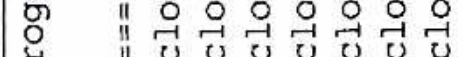

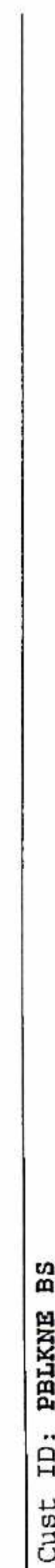




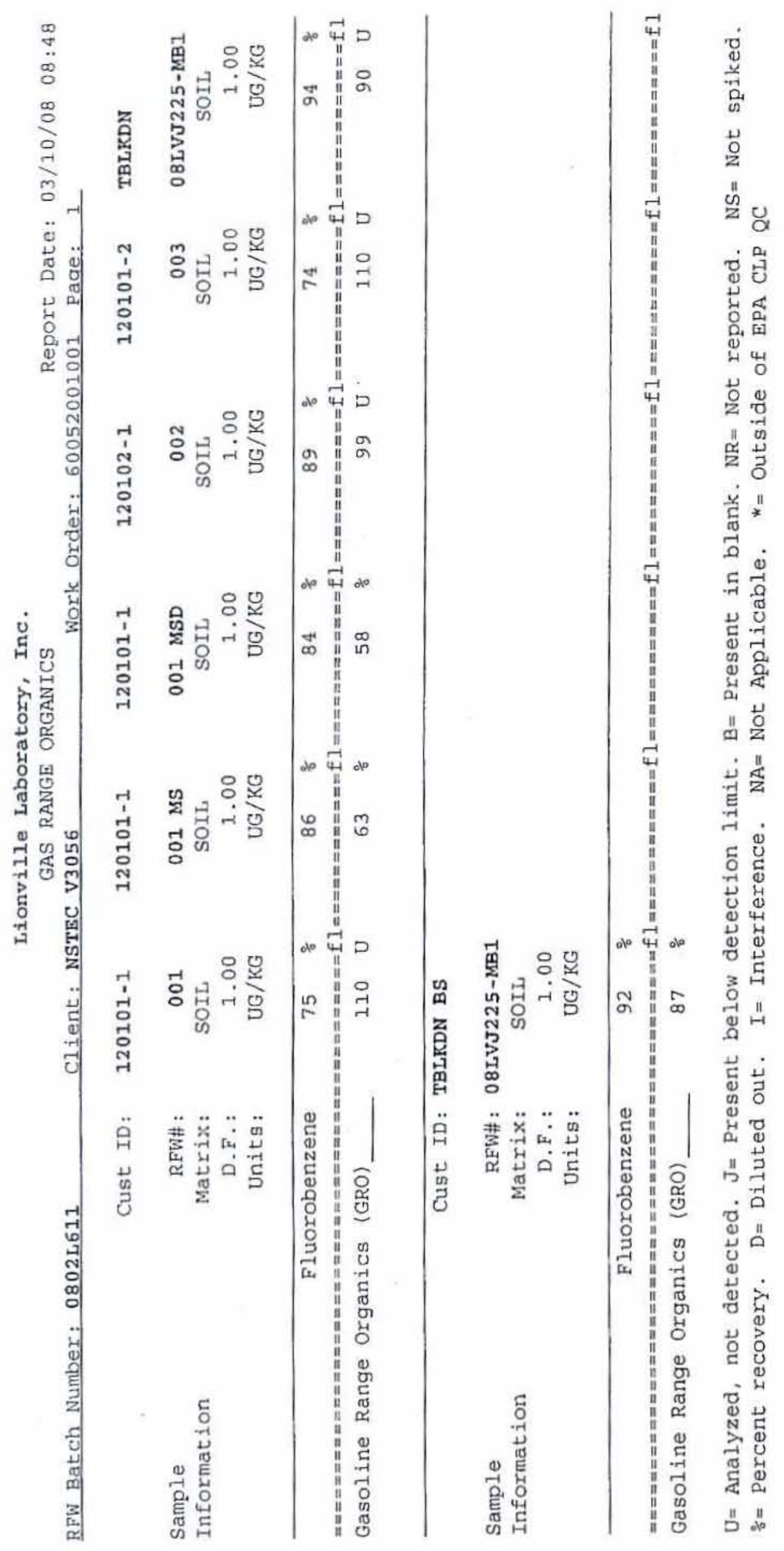




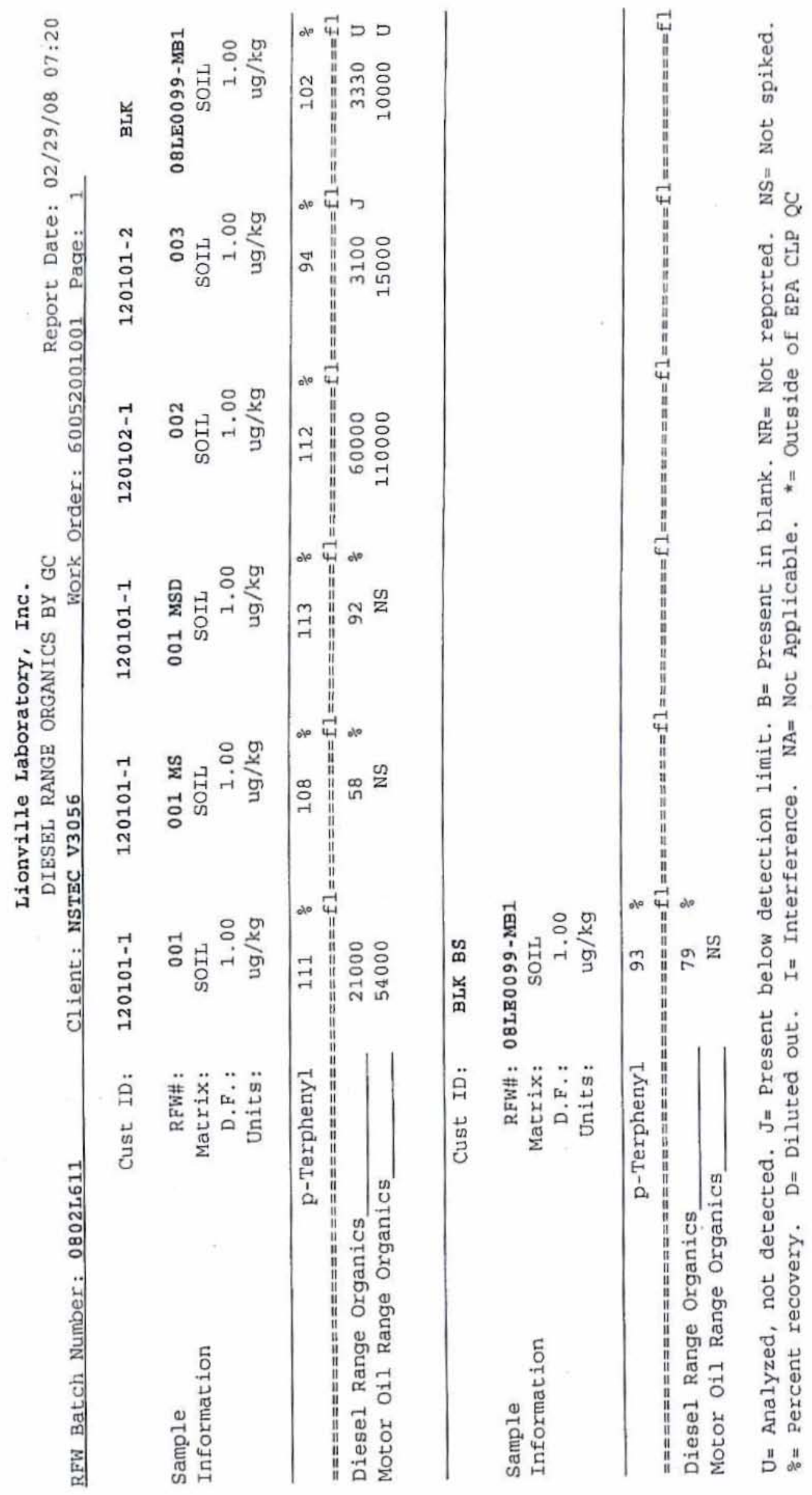




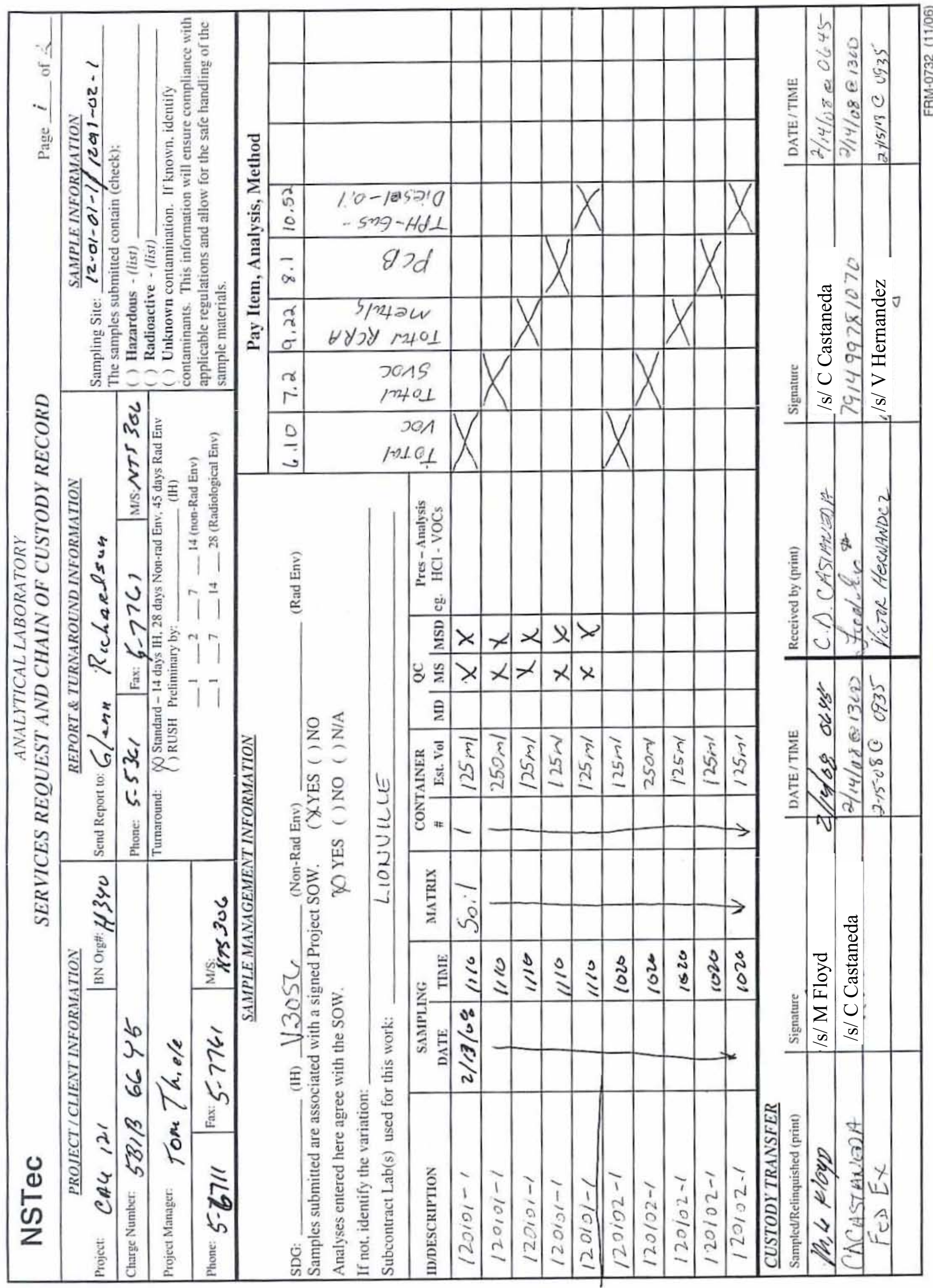




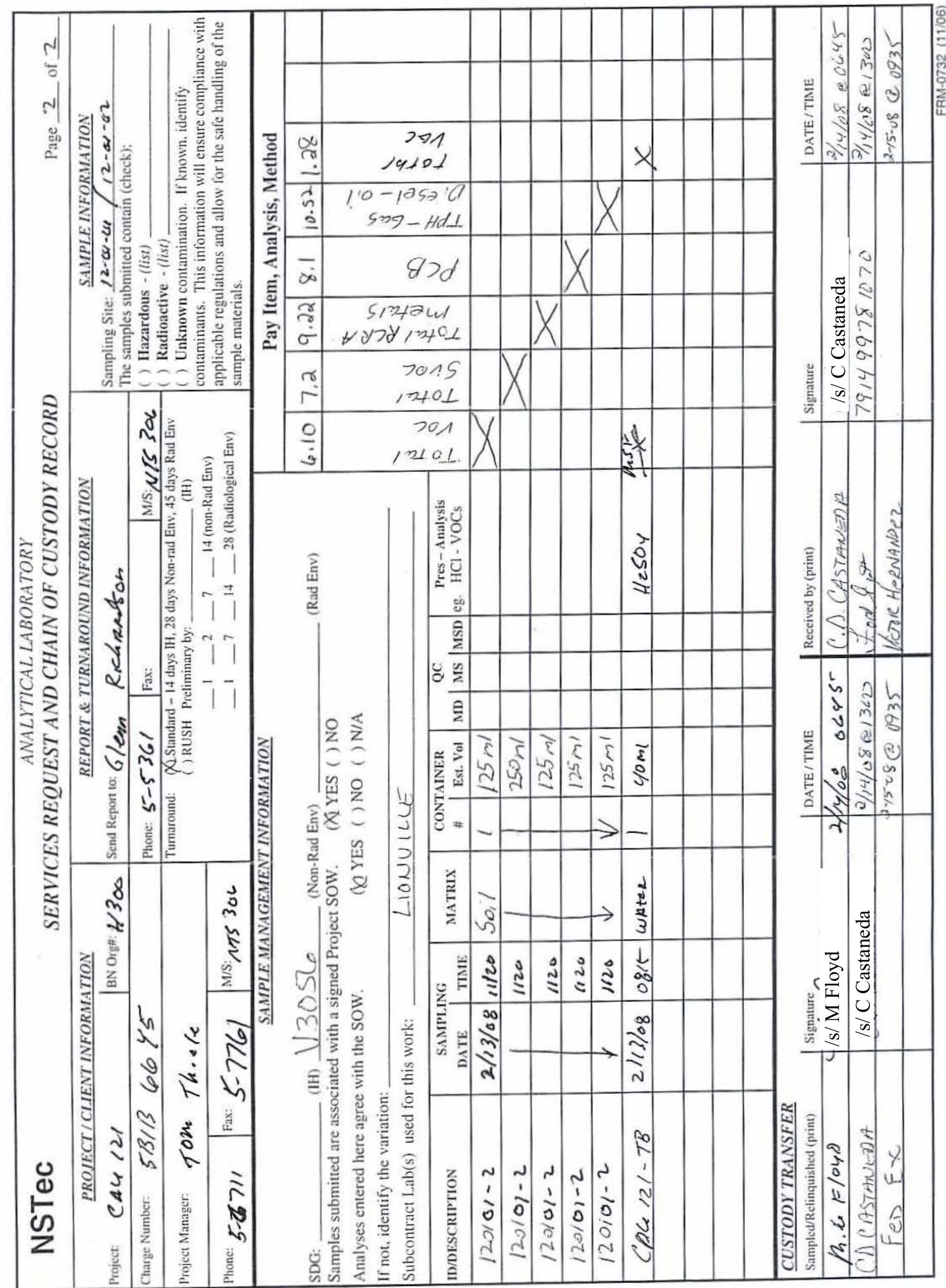


CAU 121 Closure Report

Section: Appendix B

Revision: 0

Date: September 2008

\section{Sample Delivery Group V3057}


CAU 121 Closure Report

Section: Appendix B

Revision: 0

Date: September 2008

\section{THIS PAGE INTENTIONALLY LEFT BLANK}



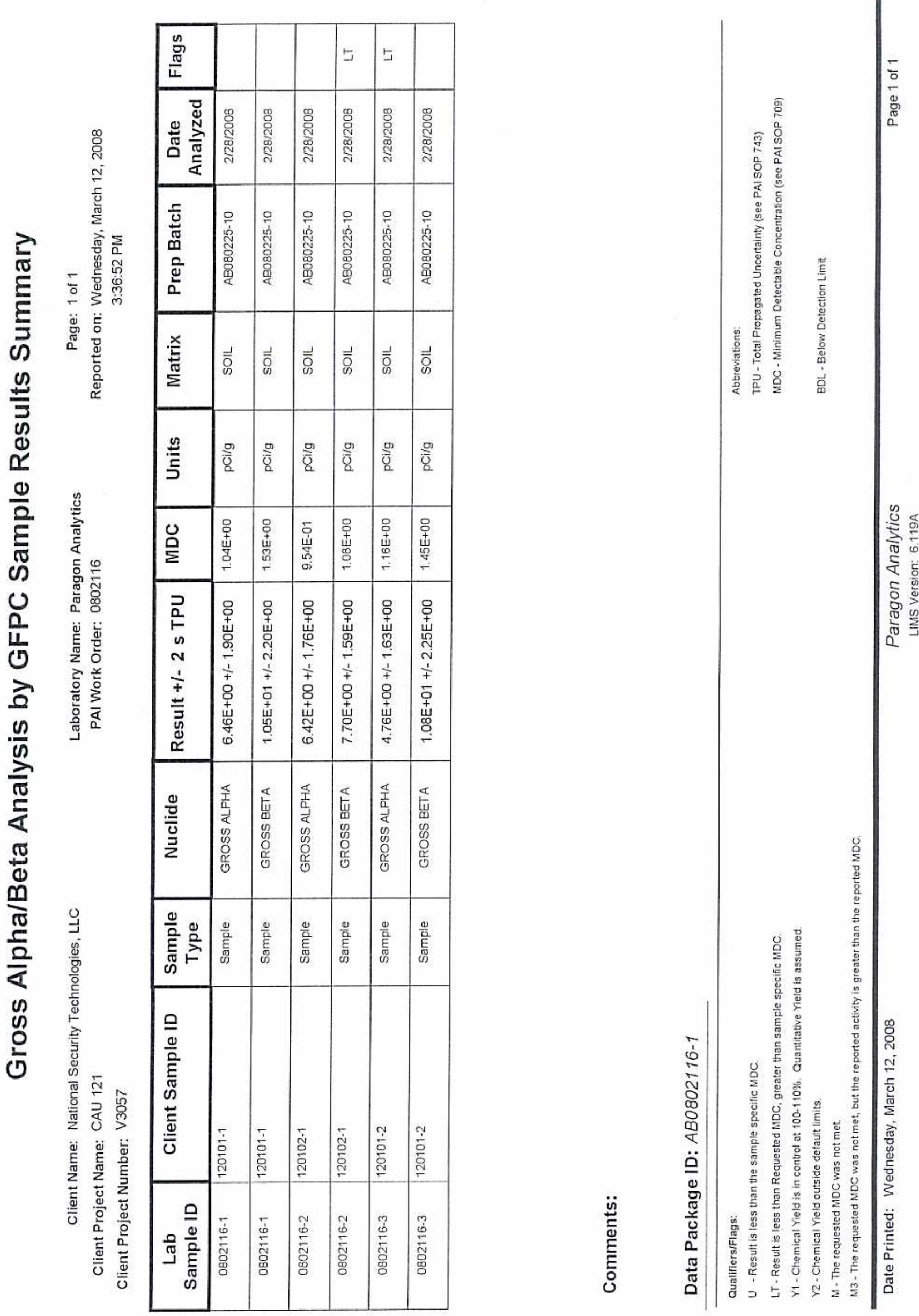


\title{
Gamma Spectroscopy Results
}

\author{
PAI 713 Rev 9 \\ Sample Results
}

Lab Name: Paragon Analytics

Work Order Number: 0802116

Client Name: National Security Technologies, LLC

ClientProject ID: CAU 121 V3057

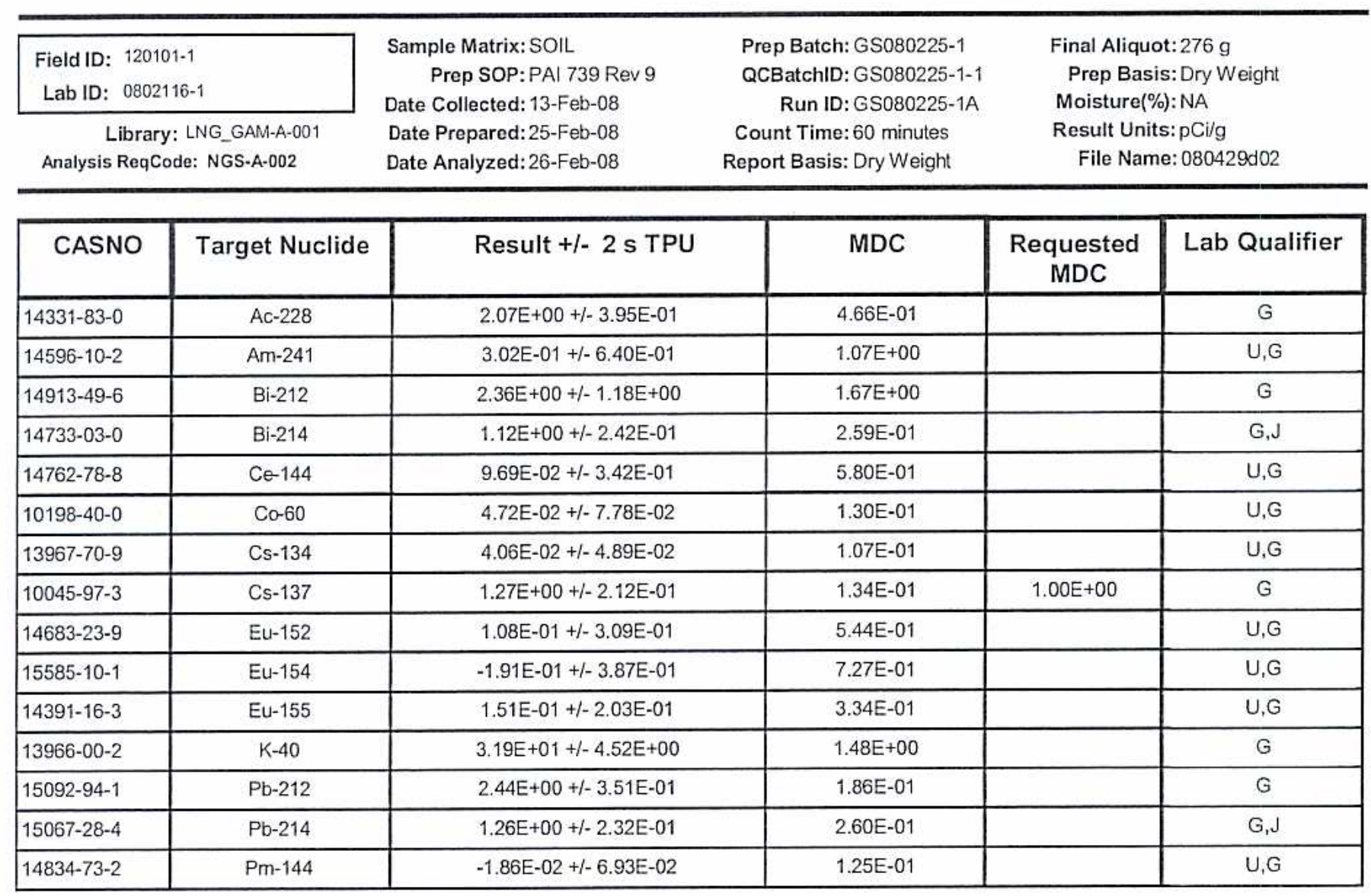

\section{Comments:}

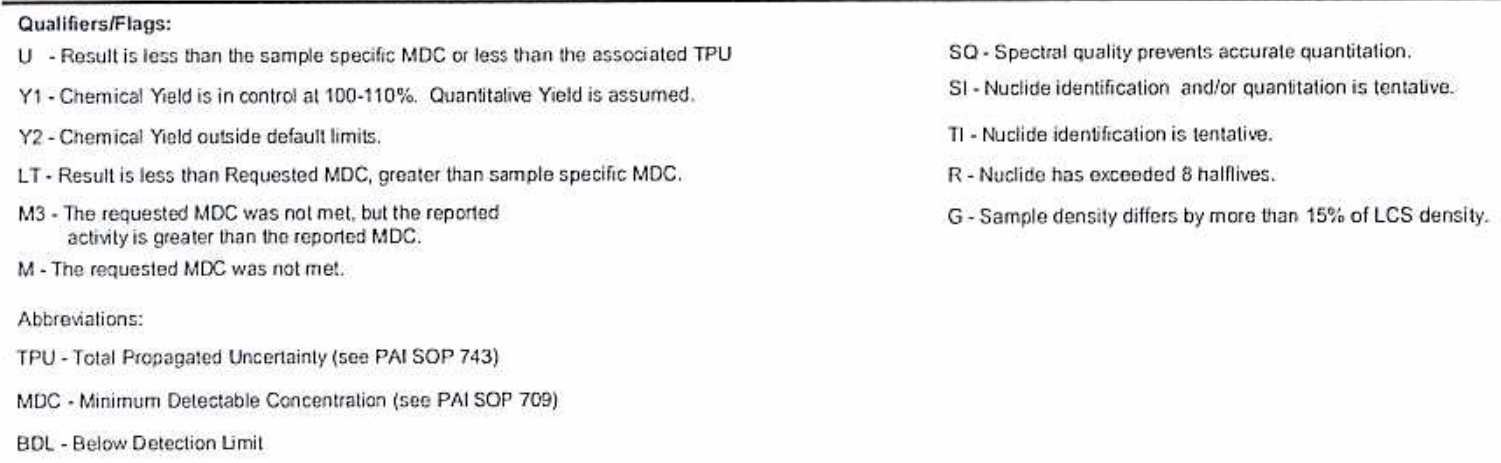




\title{
Gamma Spectroscopy Results
}

\author{
PAI 713 Rev 9 \\ Sample Results
}

Lab Name: Paragon Analytics

Work Order Number: 0802116

Client Name: National Security Technologies, LLC

ClientProject ID: CAU 121 V3057

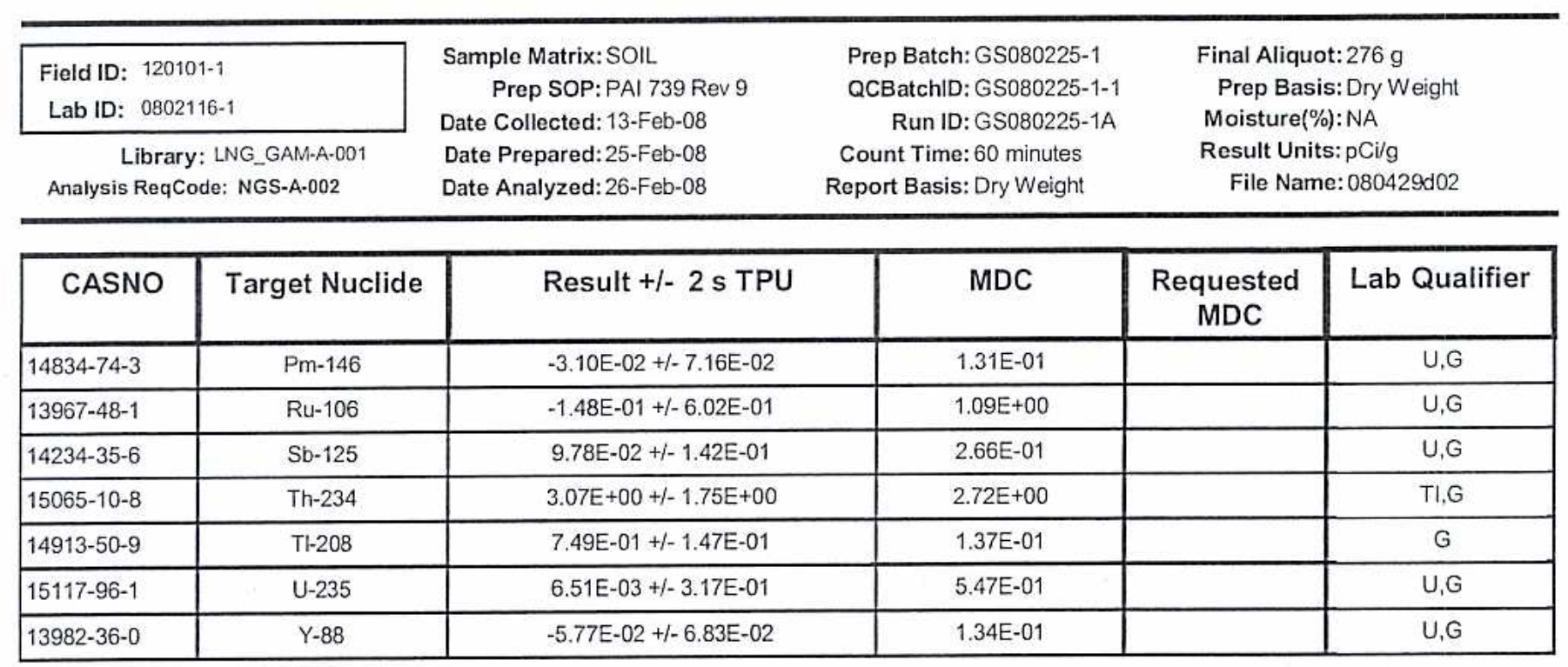

\section{Comments:}

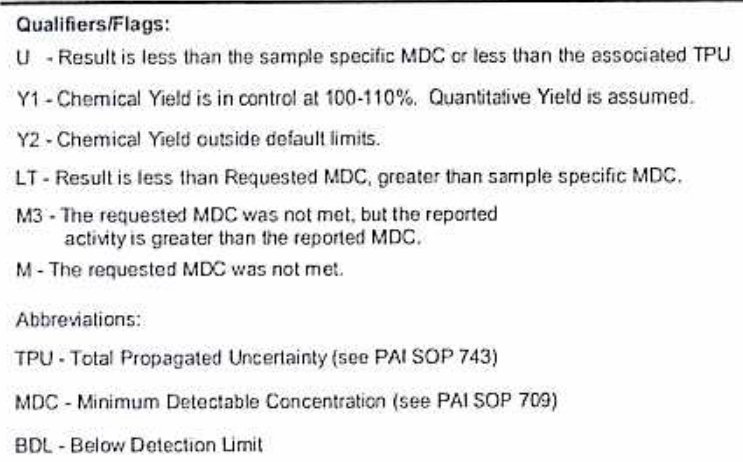

Data Package ID: GSS0802116-1

SQ-Spectral quality prevents accurate quantitation.

SI - Nuclide identification and/or quanbtation is tentative.

$\mathrm{TI}$ - Nuclide identification is tentative.

$R$ - Nuclide has exceeded 8 halfives.

G. Sample density differs by more than $15 \%$ of LCS density. 


\section{Gamma Spectroscopy Results}

\section{PAI 713 Rev 9 \\ Sample Results}

Lab Name: Paragon Analytics

Work Order Number: 0802116

Client Name: National Security Technologies, LLC

ClientProject ID: CAU 121 V3057

\begin{tabular}{|c|c|c|c|c|c|}
\hline \multicolumn{2}{|c|}{$\begin{array}{l}\text { Field ID: } 120101-2 \\
\text { Lab ID: } 0802116-3\end{array}$} & \multirow{2}{*}{$\begin{array}{l}\text { Sample Matrix: SOIL } \\
\quad \text { Prep SOP: PAI } 739 \text { Rev } 9 \\
\text { Date Collected: } 13-F e b-08 \\
\text { Date Prepared: } 25-F e b-08 \\
\text { Date Analyzed: } 26-F e b-08\end{array}$} & \multirow{2}{*}{$\begin{array}{l}\text { Prep Batch: GS080225-1 } \\
\text { QCBatchID: GS080225-1-1 } \\
\text { Run ID: GS080225-1A } \\
\text { Count Time: } 60 \text { minutes } \\
\text { Report Basis: Dry Weight }\end{array}$} & \multirow{2}{*}{\multicolumn{2}{|c|}{$\begin{array}{l}\text { Final Aliquot: } 273 \mathrm{~g} \\
\text { Prep Basis: Dry Weight } \\
\text { Moisture(\%): NA } \\
\text { Result Units: } \mathrm{pCi} / \mathrm{g} \\
\text { File Name: } 080433 \mathrm{~d} 10\end{array}$}} \\
\hline $\begin{array}{r}\text { Librar } \\
\text { Analysis ReqC }\end{array}$ & $\begin{array}{l}\text { LNG_GAM-A-001 } \\
\text { e: NGS-A-002 }\end{array}$ & & & & \\
\hline CASNO & Target Nuclide & Result $+/-2 \mathrm{~s}$ TPU & MDC & $\begin{array}{l}\text { Requested } \\
\text { MDC }\end{array}$ & Lab Qualifier \\
\hline $14331-83-0$ & Ac-228 & $2.38 E+00+/-4.37 E-01$ & 4.83E-01 & & G \\
\hline $14596-10-2$ & Am-241 & $8.97 \mathrm{E}-01+/-9.88 \mathrm{E}-01$ & $1.60 \mathrm{E}+00$ & & U,G \\
\hline $14913-49-6$ & $\mathrm{Bi}-212$ & $3.39 E+00+1-1.37 E+00$ & $1.83 E+00$ & & G \\
\hline $14733-03-0$ & $\mathrm{Bi}-214$ & $9.22 \mathrm{E}-01+/-2.29 \mathrm{E}-01$ & 2.79E-01 & & $G, J$ \\
\hline $14762-78-8$ & Ce-144 & $1.51 \mathrm{E}-01+/-3.62 \mathrm{E}-01$ & $6.10 \mathrm{E}-01$ & & $U, G$ \\
\hline $10198-40-0$ & $\mathrm{Co}-60$ & $-3.12 \mathrm{E}-02+/-7.22 \mathrm{E}-02$ & 1.40E-01 & & $U, G$ \\
\hline $13967-70-9$ & Cs-134 & $6.91 \mathrm{E}-02+/-6.93 \mathrm{E}-02$ & $1.11 \mathrm{E}-01$ & & U,G \\
\hline $10045-97-3$ & Cs-137 & $9.51 \mathrm{E}-01+/-1.77 \mathrm{E}-01$ & 1.33E-01 & $1.00 E+00$ & $L T, G$ \\
\hline $14683-23-9$ & Eu-152 & $4.72 \mathrm{E}-02+/-3.64 \mathrm{E}-01$ & $6.57 \mathrm{E}-01$ & & $U, G$ \\
\hline $15585-10-1$ & Eu-154 & $-1.92 \mathrm{E}-02+/-3.74 \mathrm{E}-01$ & $6.81 E-01$ & & $U, G$ \\
\hline $14391-16-3$ & Eu-155 & $1.98 \mathrm{E}-01+/-2.43 \mathrm{E}-01$ & 3.97E-01 & & U,G \\
\hline $13966-00-2$ & $K-40$ & $3.41 E+01+/-4.84 E+00$ & $1.45 E+00$ & & G \\
\hline $15092-94-1$ & $\mathrm{~Pb}-212$ & $2.66 \mathrm{E}+00+/-3.79 \mathrm{E}-01$ & 1.86E-01 & & G \\
\hline $15067-28-4$ & $\mathrm{~Pb}-214$ & $1.19 \mathrm{E}+00+/-2.27 \mathrm{E}-01$ & $2.52 \mathrm{E}-01$ & & G,J \\
\hline $14834-73-2$ & $\mathrm{Pm}-144$ & $7.09 \mathrm{E}-03+1-7.21 \mathrm{E}-02$ & 1.26E-01 & & U.G \\
\hline
\end{tabular}

\section{Comments:}

Data Package ID: GSS0802116-1 


\section{Gamma Spectroscopy Results \\ PAl 713 Rev 9 \\ Sample Results}

Lab Name: Paragon Analytics

Work Order Number: 0802116

Client Name: National Security Technologies, LLC

ClientProject ID: CAU 121 V3057

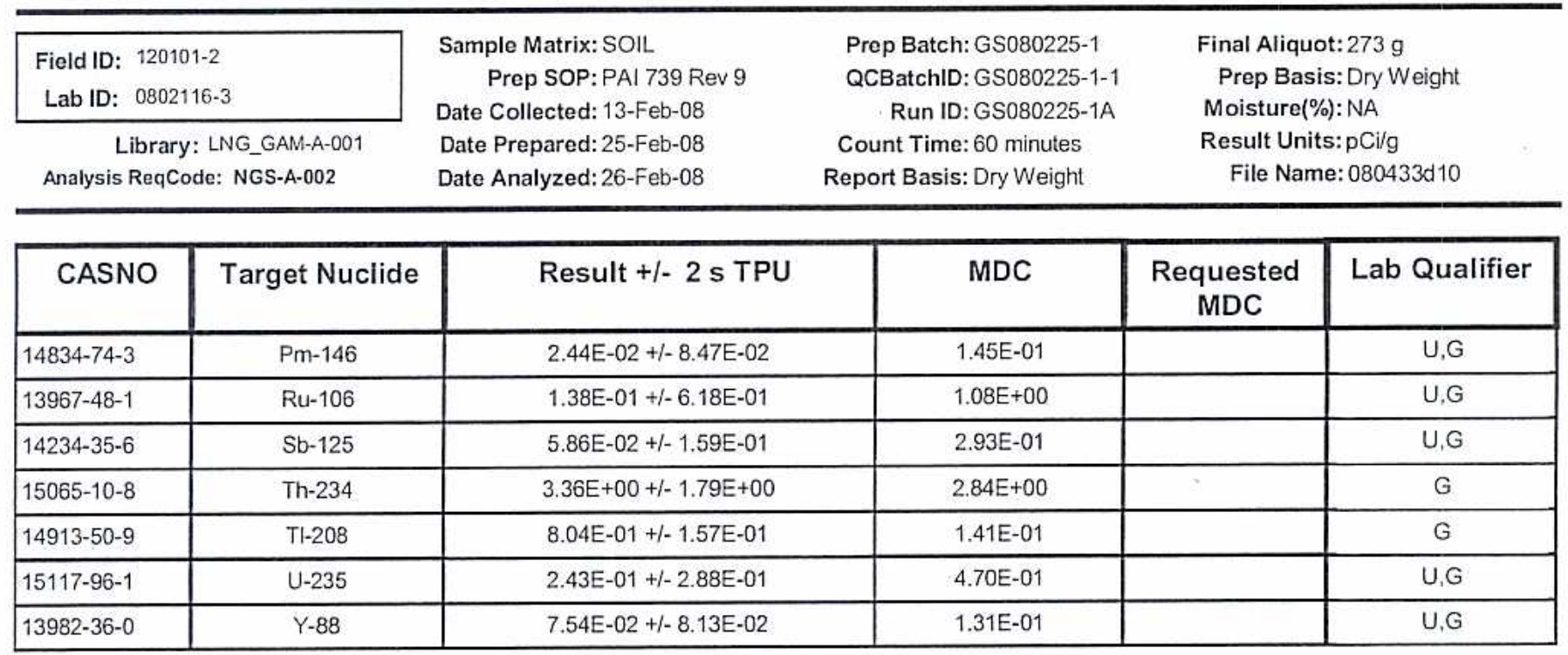

\section{Comments:}

\footnotetext{
Qualifiers/Flags:

$U$-Result is less than the sample specific MDC or less than the associated TPU

SQ - Spectral quality prevents accurate quantitation.

Y1 - Chemical Yield is in control at 100-110\%. Quantitative Yield is assumed.

$\mathrm{SI}$ - Nuclide identification and/or quantiation is tentative.

Y2 - Chemical Yield outside defautl limits.

$\pi$ - Nuclide identification is tentative.

LT - Result is less than Requested MDC, greater than sample specific MDC.

$R$ - Nuclide has exceeded 8 halfives.

M3 - The requested MDC was not mel, but the reported

G-Sample density differs by more than $15 \%$ of LCS density.

activity is greater than the reported $M D C$.

$M$ - The requested MDC was not met.

Abbreviations:

TPU - Total Propagated Uncertainty (see PAI SOP 743)

MDC - Minimum Detectable Concentration (see PAI SOP 709)

BDL - Below Detection Limit
}

Data Package ID: GSS0802116-1 


\section{Gamma Spectroscopy Results}

\section{PAl 713 Rev 9 \\ Sample Results}

Lab Name: Paragon Analytics

Work Order Number: 0802116

Client Name: National Security Technologies, LLC

ClientProject ID: CAU 121 V3057

\begin{tabular}{|c|c|c|c|c|c|}
\hline \multicolumn{2}{|c|}{$\begin{array}{l}\text { Field ID: } 120102-1 \\
\text { Lab ID: } 0802116-2 \\
\end{array}$} & \multirow{2}{*}{$\begin{array}{l}\text { Sample Matrix: SOIL } \\
\quad \text { Prep SOP: PAI } 739 \text { Rev } 9 \\
\text { Date Collected: } 13-F e b-08 \\
\text { Date Prepared: } 25-F e b-08 \\
\text { Date Analyzed: } 26-\text { Feb- } 08\end{array}$} & \multirow{2}{*}{$\begin{array}{l}\text { Prep Batch: GS080225-1 } \\
\text { QCBatchID: GS080225-1-1 } \\
\text { Run ID: GS080225-1A } \\
\text { Count Time: } 60 \text { minutes } \\
\text { Report Basis: Dry Weight }\end{array}$} & \multirow{2}{*}{\multicolumn{2}{|c|}{$\begin{array}{l}\text { Final Aliquot: } 305 \mathrm{~g} \\
\text { Prep Basis: Dry Weight } \\
\text { Moisture(\%): NA } \\
\text { Result Units: } \mathrm{pCi} / \mathrm{g} \\
\text { File Name: } 080547 \mathrm{~d} 08\end{array}$}} \\
\hline $\begin{array}{r}\text { Librar } \\
\text { Analysis ReqC }\end{array}$ & $\begin{array}{l}\text { LNG_GAM-A-001 } \\
\text { e: NGS-A-002 }\end{array}$ & & & & \\
\hline CASNO & Target Nuclide & Result +/- 2 s TPU & MDC & $\begin{array}{l}\text { Requested } \\
\text { MDC }\end{array}$ & Lab Qualifier \\
\hline $14331-83-0$ & Ac-228 & $2.04 E+00+/-3.67 E-01$ & 4.38E-01 & & G \\
\hline $14596-10-2$ & Am-241 & 7.36E-02 +/-1.19E-01 & $1.97 \mathrm{E}-01$ & & $U, G$ \\
\hline $14913-49-6$ & $\mathrm{Bi}-212$ & $2.37 E+00+1-1.06 E+00$ & $1.40 E+00$ & & G \\
\hline $14733-03-0$ & $\mathrm{Bi}-214$ & $1.17 \mathrm{E}+00+/-2.35 \mathrm{E}-01$ & $2.22 \mathrm{E}-01$ & & G,J \\
\hline $14762-78-8$ & $\mathrm{Ce}-144$ & $-2.89 \mathrm{E}-03+/-2.71 \mathrm{E}-01$ & $4.69 \mathrm{E}-01$ & & U,G \\
\hline $10198-40-0$ & Co-60 & $9.49 \mathrm{E}-03+/-5.70 \mathrm{E}-02$ & $1.04 \mathrm{E}-01$ & & U,G \\
\hline $13967-70-9$ & Cs-134 & $3.42 \mathrm{E}-02+/-4.39 \mathrm{E}-02$ & $9.11 \mathrm{E}-02$ & & $U, G$ \\
\hline $10045-97-3$ & Cs-137 & $1.96 \mathrm{E}-01+/-7.36 \mathrm{E}-02$ & 8.90E-02 & $1.00 \mathrm{E}+00$ & $L T, G$ \\
\hline $14683-23-9$ & Eu-152 & 2.35E-01+/-2.59E-01 & 4.09E-01 & & $U, G$ \\
\hline $15585-10-1$ & Eu-154 & $-2.75 \mathrm{E}-01+/-3.68 \mathrm{E}-01$ & 7.10E-01 & & U.G \\
\hline $14391-16-3$ & Eu-155 & $1.98 \mathrm{E}-01+/-1.57 \mathrm{E}-01$ & $2,48 \mathrm{E}-01$ & & U,G \\
\hline $13966-00-2$ & $K-40$ & 3.17E+01+i-4.46E+00 & $1.04 E+00$ & & G \\
\hline $15092-94-1$ & $\mathrm{~Pb}-212$ & $2.25 E+00+1-3.16 E-01$ & $1.40 \mathrm{E}-01$ & & G \\
\hline $15067-28-4$ & $\mathrm{~Pb}-214$ & $1.22 \mathrm{E}+00+/-2.12 \mathrm{E}-01$ & 2.04E-01 & & $\mathrm{G}, \mathrm{J}$ \\
\hline $14834-73-2$ & Pm-144 & $3.83 \mathrm{E}-02+/-5.76 \mathrm{E}-02$ & 9.57E-02 & & $U, G$ \\
\hline
\end{tabular}

\section{Comments:}

\footnotetext{
Qualifiers/Flags:

$U$ - Result is less than the sample specific MDC or less than the associated TPU

SQ- Spectral quality prevents accurate quantiation.

Y1 - Chemical Yield is in control at 100-110\%. Quanttative Yield is assumed.

SI - Nuclide identification and/or quantitation is tentative.

Y2. Chemical Yield outside defautt limits

LT - Result is less than Requested MDC, greater than sample specific MDC.

M3 - The requested MDC was not met, but the reported

Tf - Nuclide identification is tentative.

activity is greater than the reponed MDC.

$R$ - Nuclide has exceeded 8 halfives.

$M$ - The requested $M D C$ was not met.

Abbreviations:

TPU - Total Propagated Uncertainty (see PAI SOP 743)

MDC - Minimum Detectable Concentration (see PAI SOP 709)

BDL - Below Detection Limit
}

Data Package ID: GSS0802116-1 


\section{Gamma Spectroscopy Results \\ PAI 713 Rev 9 \\ Sample Results}

Lab Name: Paragon Analytics

Work Order Number: 0802116

Client Name: National Security Technologies, LLC

ClientProject ID: CAU 121 V3057

\begin{tabular}{|c|c|c|c|c|c|}
\hline \multicolumn{2}{|c|}{$\begin{array}{l}\text { Field ID: } 120102-1 \\
\text { Lab ID: } 0802116-2\end{array}$} & \multirow{2}{*}{$\begin{array}{l}\text { Sample Matrix: SOIL } \\
\quad \text { Prep SOP: PAI } 739 \text { Rev } 9 \\
\text { Date Collected: } 13-F e b-08 \\
\text { Date Prepared: } 25-F e b-08 \\
\text { Date Analyzed: } 26-F e b-08\end{array}$} & \multirow{2}{*}{$\begin{array}{l}\text { Prep Batch: GS080225-1 } \\
\text { QCBatchID: GS080225-1-1 } \\
\text { Run ID: GS080225-1A } \\
\text { Count Time: } 60 \text { minutes } \\
\text { Report Basis: Dry Weight }\end{array}$} & \multirow{2}{*}{\multicolumn{2}{|c|}{$\begin{array}{l}\text { Final Aliquot: } 305 \mathrm{~g} \\
\text { Prep Basis: Dry Weight } \\
\text { Moisture(\%): NA } \\
\text { Result Units: } \mathrm{pCi} / \mathrm{g} \\
\text { File Name: } 080547 \mathrm{~d} 08\end{array}$}} \\
\hline $\begin{array}{r}\text { Librar } \\
\text { Analysis ReqC }\end{array}$ & $\begin{array}{l}\text { LNG_GAM-A-001 } \\
\text { e: NGS-A-002 }\end{array}$ & & & & \\
\hline CASNO & Target Nuclide & Result +/- 2 s TPU & MDC & $\begin{array}{l}\text { Requested } \\
\text { MDC }\end{array}$ & Lab Qualifier \\
\hline $14834-74-3$ & Pm-146 & $6.22 \mathrm{E}-02+1-6.60 \mathrm{E}-02$ & $1.06 \mathrm{E}-01$ & & U,G \\
\hline $13967-48-1$ & Ru-106 & $-1.08 \mathrm{E}-01+/-5.26 \mathrm{E}-01$ & $9.57 \mathrm{E}-01$ & & U,G \\
\hline $14234-35-6$ & Sb-125 & 1.33E-01+/-1.25E-01 & $2.08 \mathrm{E}-01$ & & U,G \\
\hline $15065-10-8$ & Th-234 & $2.27 \mathrm{E}+00+/-7.92 \mathrm{E}-01$ & $1.53 E+00$ & & G \\
\hline $14913-50-9$ & TI-208 & 7.22E-01+/-1.39E-01 & $1.20 \mathrm{E}-01$ & & G \\
\hline $15117-96-1$ & U-235 & 1.64E-01+/-3.02E-01 & $5.03 E-01$ & & U,G \\
\hline $13982-36-0$ & $Y-88$ & $-1.22 \mathrm{E}-02+/-7.11 \mathrm{E}-02$ & 1.30E-01 & & $U, G$ \\
\hline
\end{tabular}

\section{Comments:}

\begin{tabular}{|c|c|}
\hline \multicolumn{2}{|l|}{ Qualifiers/Flags: } \\
\hline$U$-Result is less than the sample specific MDC or less than the associated TPU & SQ - Spectral quality prevents accurate quantitation. \\
\hline Y1 - Chemical Yield is in control at $100-110 \%$. Quantitative Yield is assumed. & SI - Nuclide identification andior quantitation is tentative. \\
\hline Y2-Chemical Yield outside default limits. & $\mathrm{Tl}$ - Nuclide identification is tentative. \\
\hline LT - Result is less than Requested MDC, greater than sample specific MDC. & R - Nuclide has exceeded 8 halflives. \\
\hline $\begin{array}{l}\text { M3 - The requested MDC was not met, but the reported } \\
\text { actinty is greater than the reported MDC. }\end{array}$ & G. Sample density differs by more than $15 \%$ of LCS density. \\
\hline
\end{tabular}

$M$ - The requested MDC was not met.

Abbreviations:

TPU - Total Propagated Uncertainty (see PAI SOP 743)

MDC - Minimum Detectable Concentration (see PAI SOP 709)

BDL - Below Detection Limit

Data Package ID: GSS0802116-1 


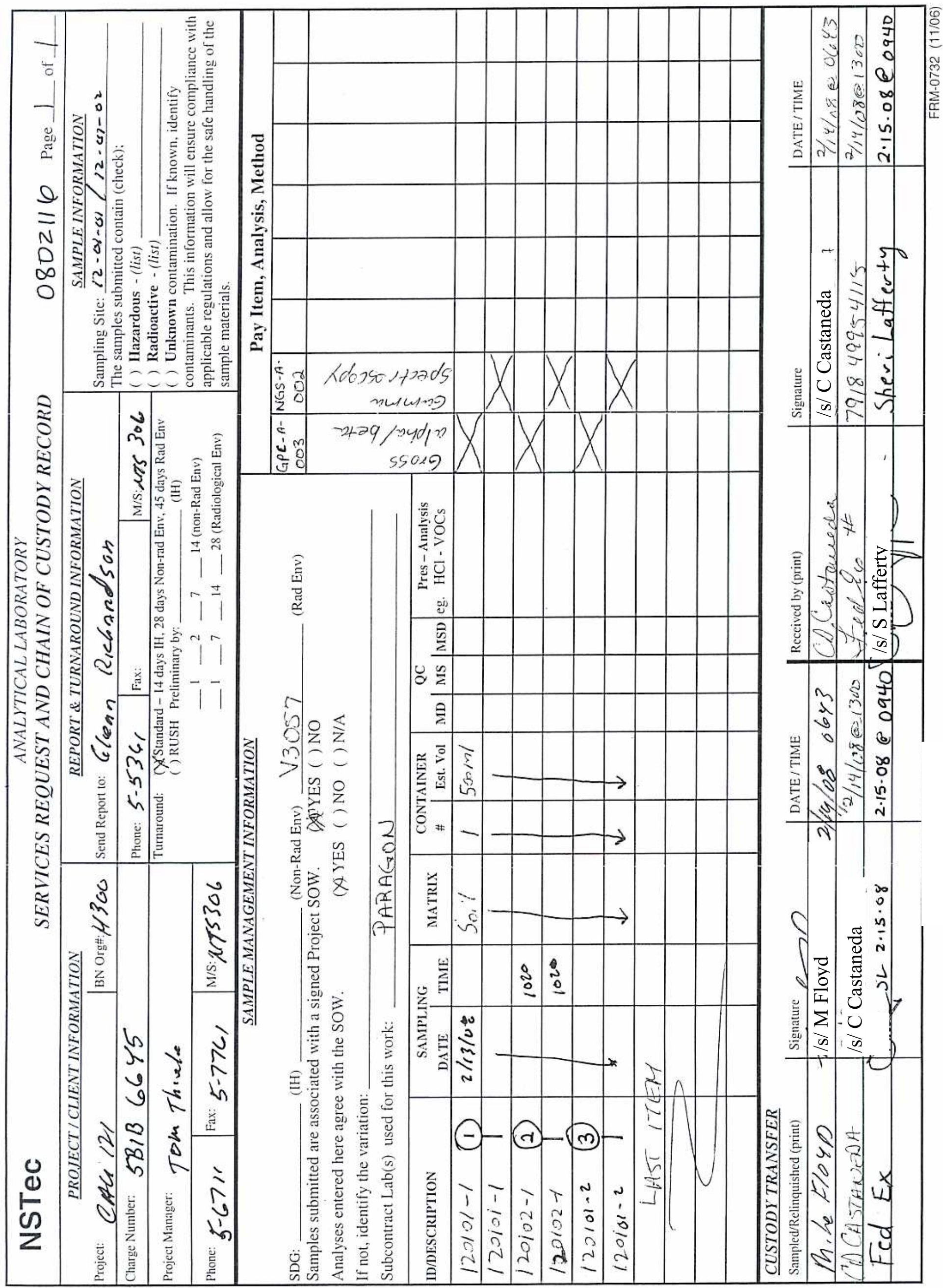


CAU 121 Closure Report

Section: Appendix B

Revision: 0

Date: September 2008

\section{Sample Delivery Group V3097}


CAU 121 Closure Report

Section: Appendix B

Revision: 0

Date: September 2008

\section{THIS PAGE INTENTIONALLY LEFT BLANK}




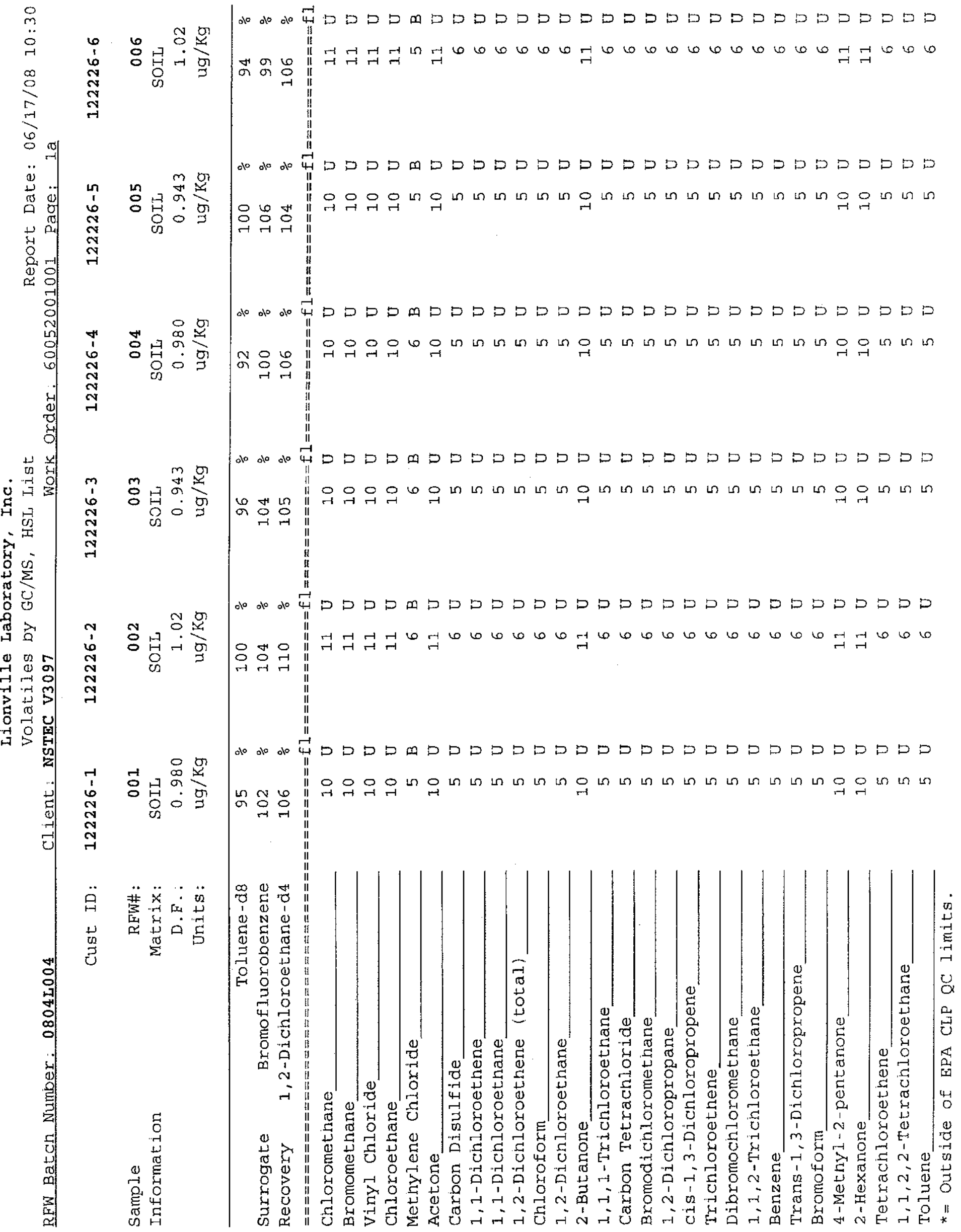


bh

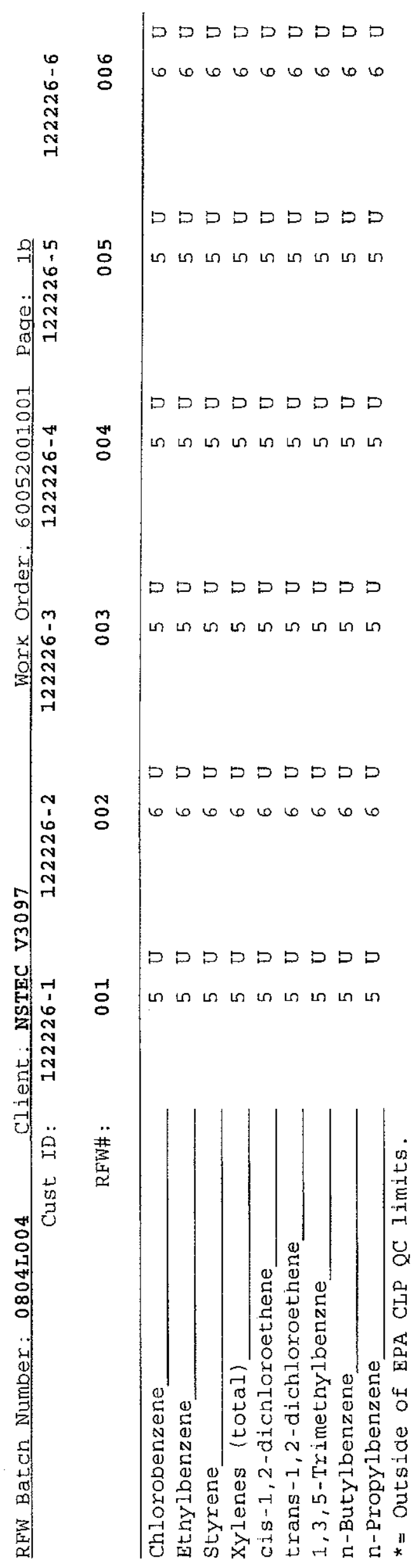




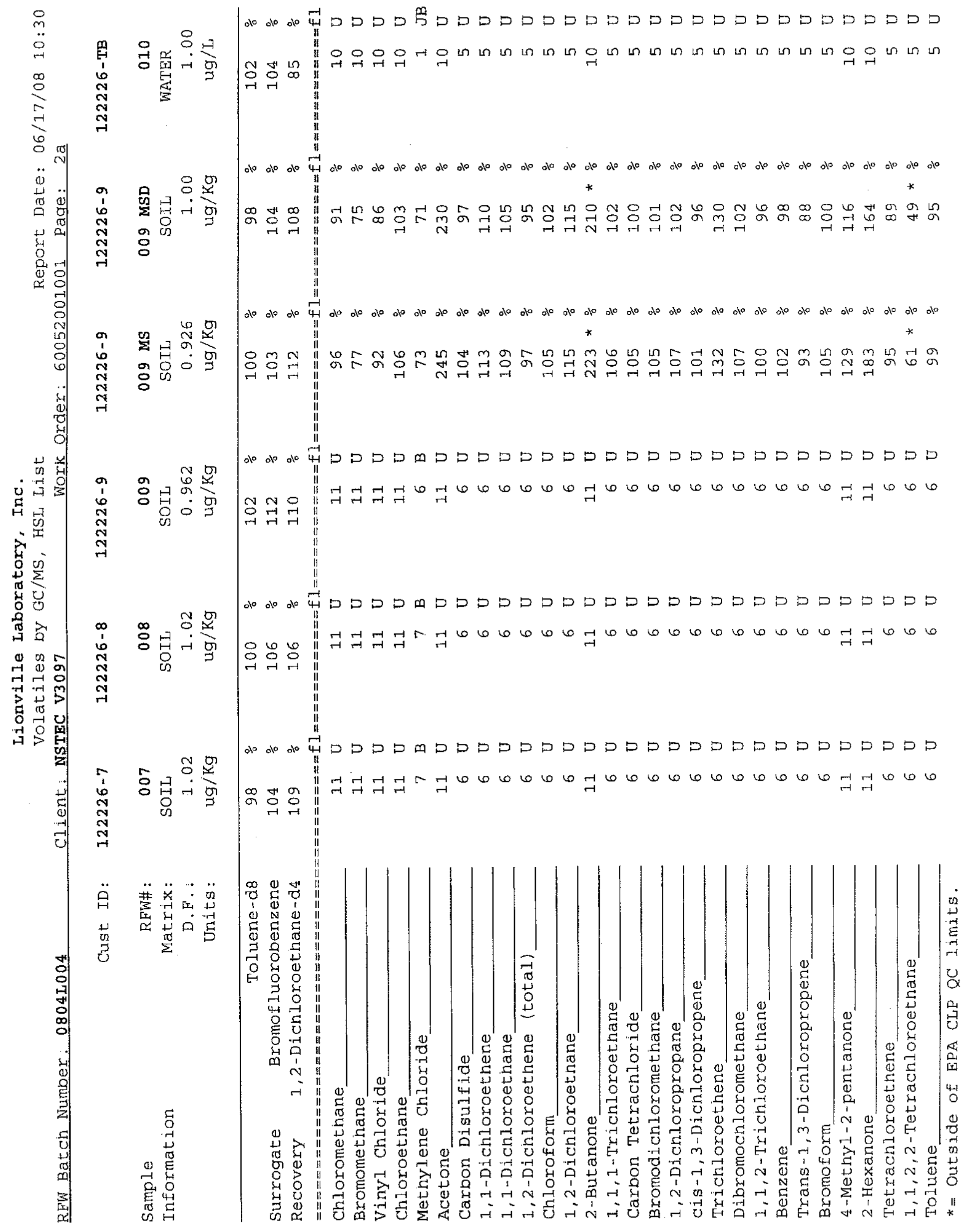




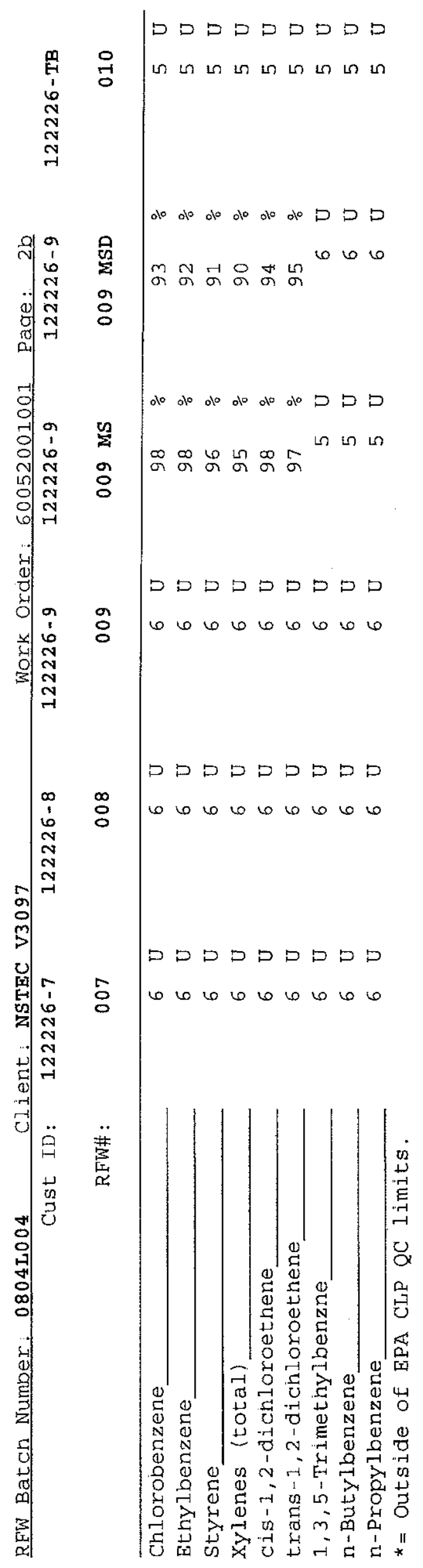




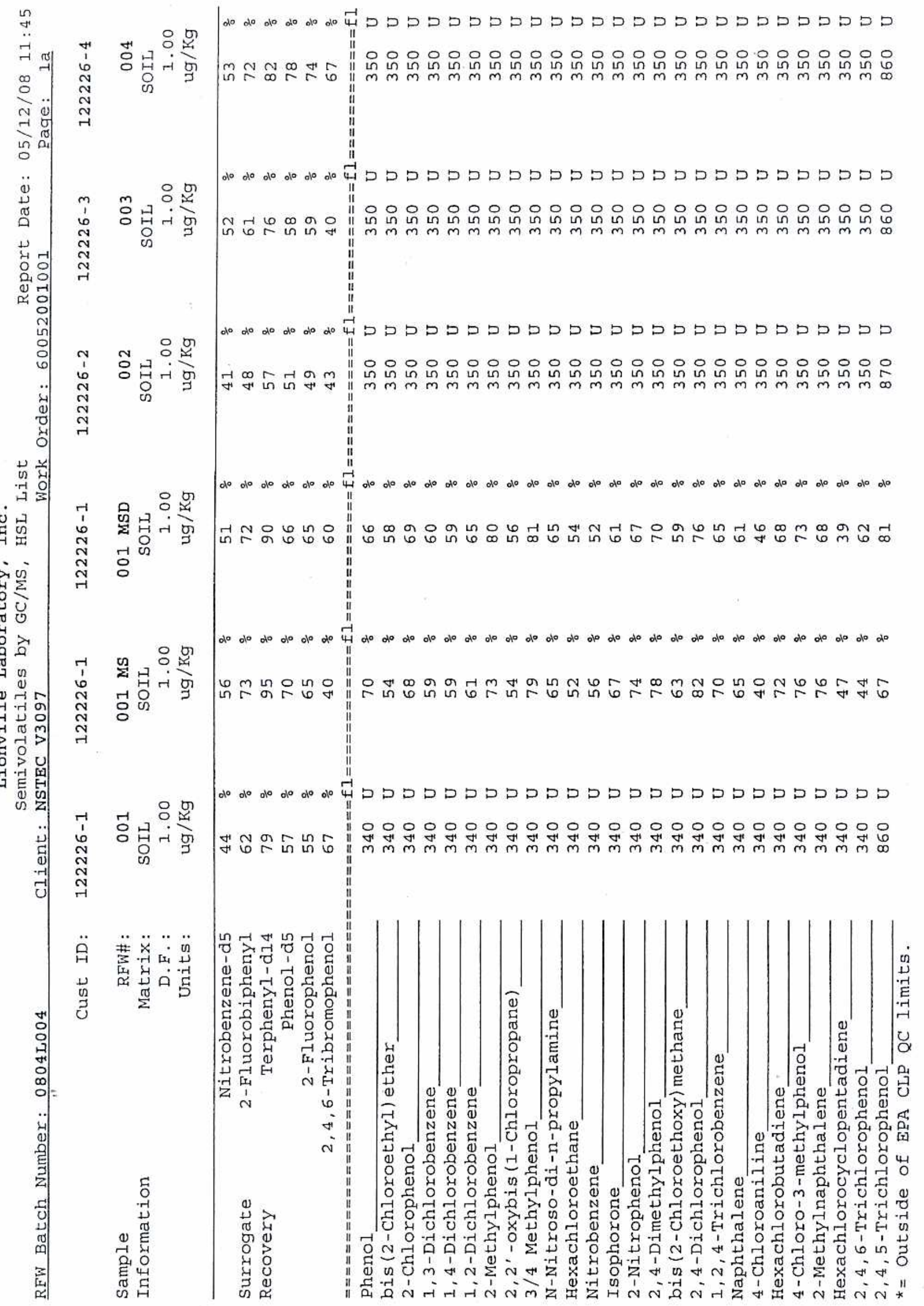




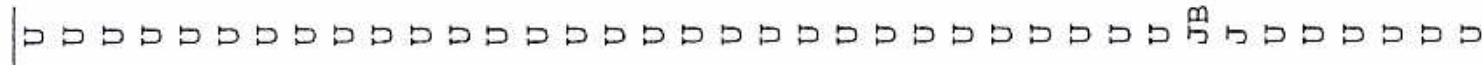

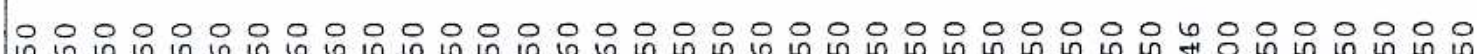

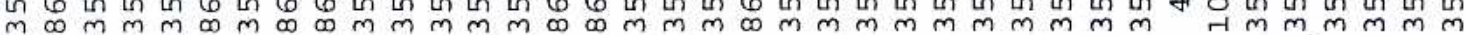

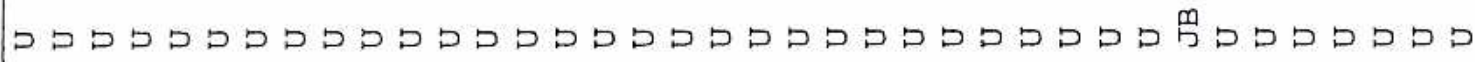

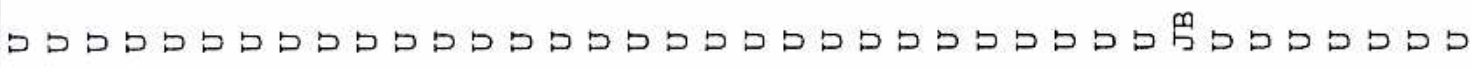

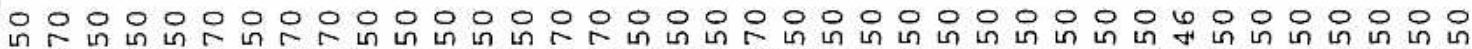

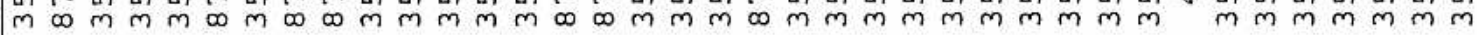

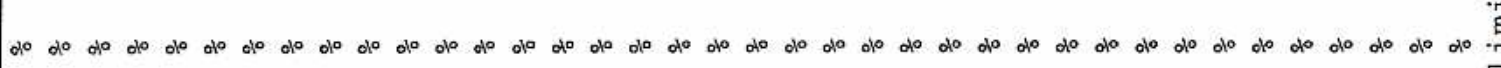
ザம 豆 r$$
\text { dio do do }
$$ 


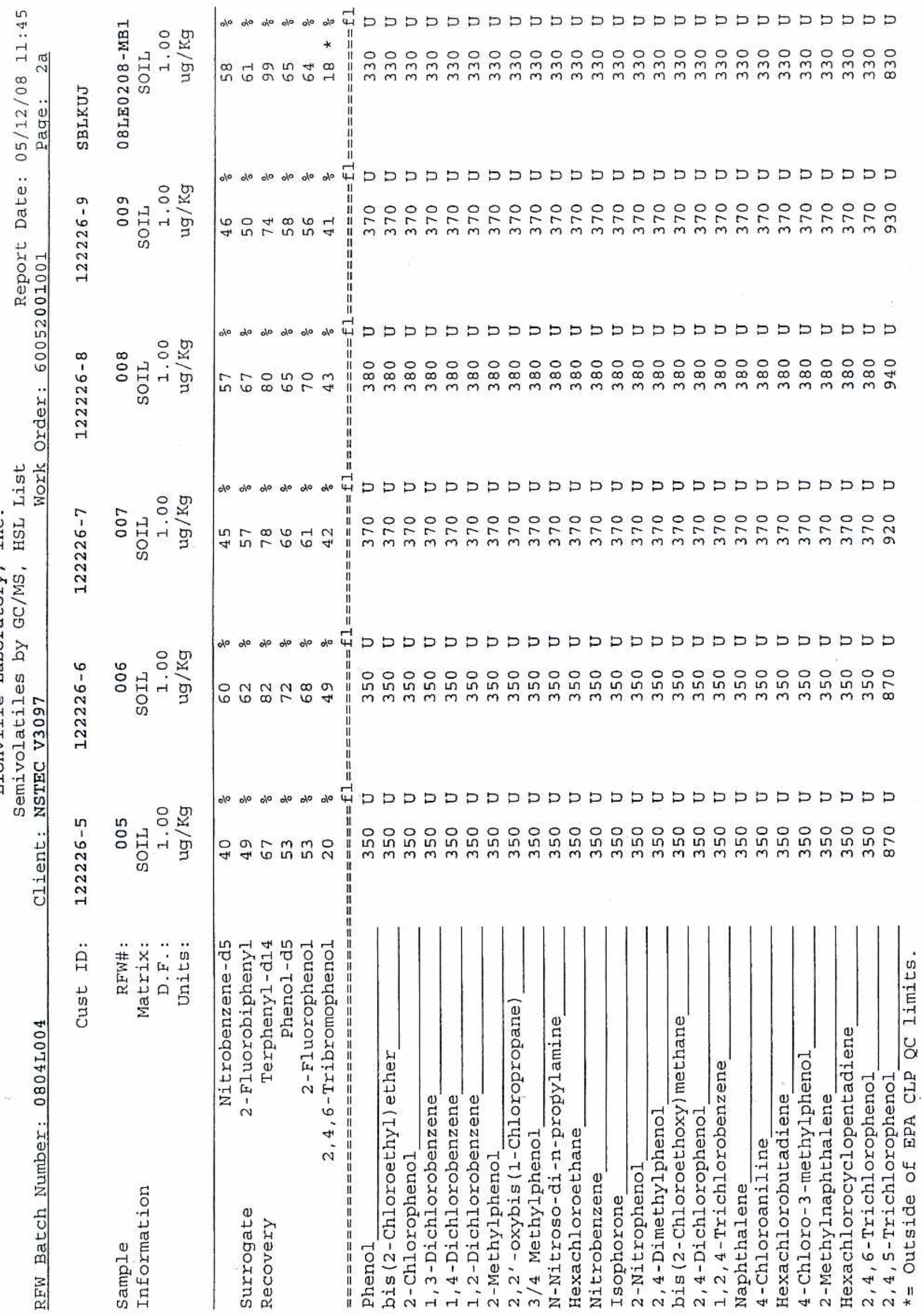




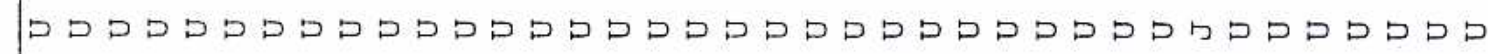

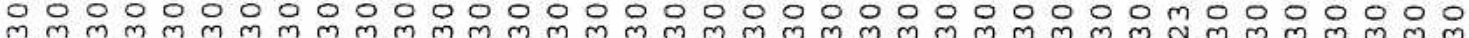

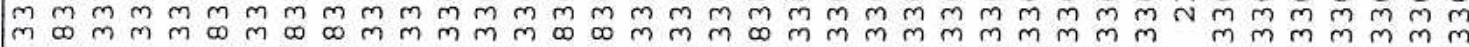

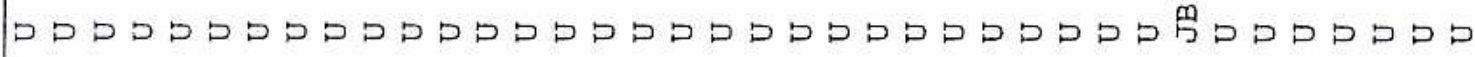

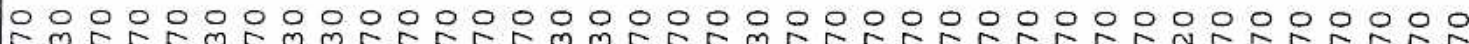

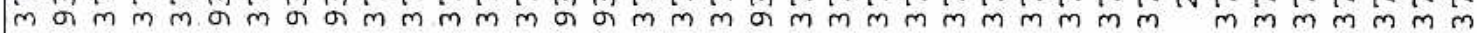

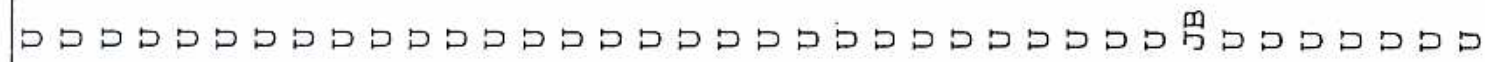

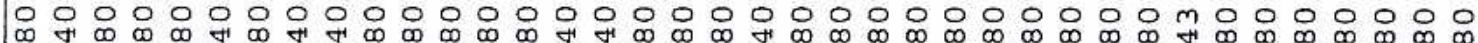
品

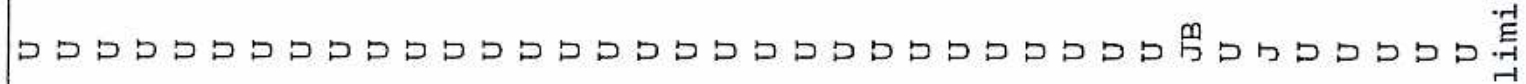

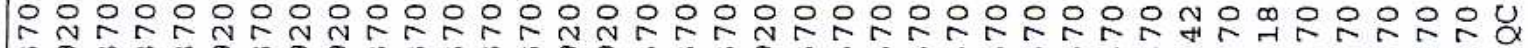
ma mmman

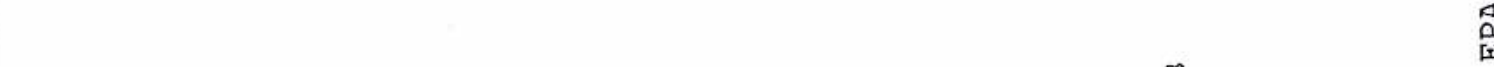

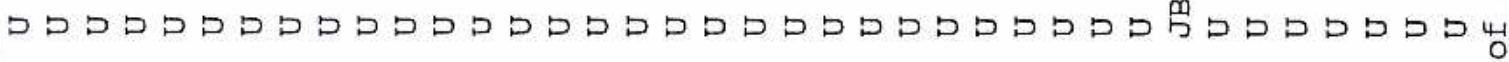

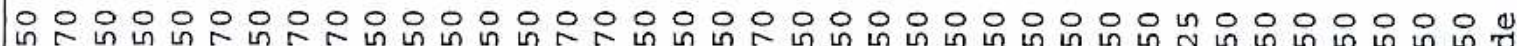

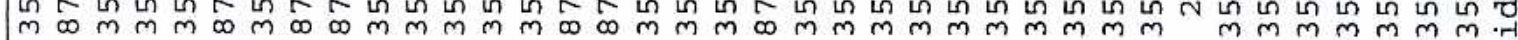

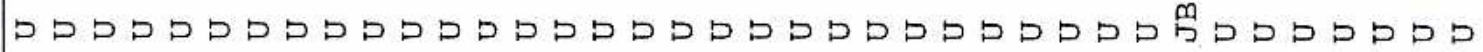
. 
1 INORGANIC ANALYSES DATA SHEET
EPA SAMPLE NO.

\section{1}

Contract: 60052

SAS NO.:

Lab Sample ID: 0804L004-0̄01

Date Received: 04/25/08
Lab Code: LVLI

Matrix (soil/water): SOIL

Level (low/med): LOW

\% Solids: $\quad-96 \overline{.8}$

Concentration Units (ug/L or $\mathrm{mg} / \mathrm{kg}$ dry weight): MG/KG

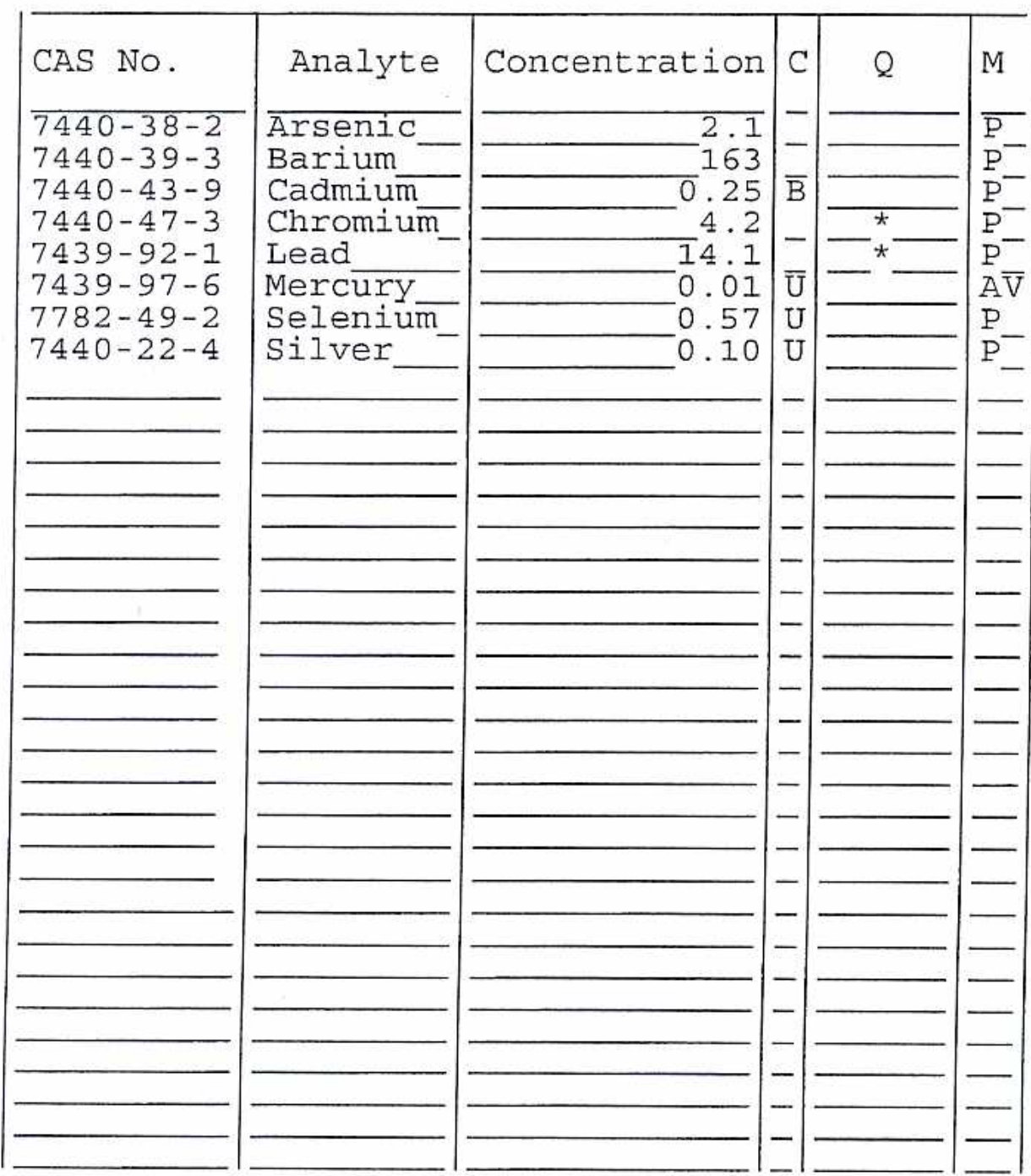

Clarity Before:

Clarity After:
Texture:

Artifacts:

Comments :

122226-1 
U.S. EPA

1

INORGANIC ANALYSES DATA SHEET
Lab Name: LIONVILLE_LABORATORY

Lab Code: LVLI

Matrix (soil/water): SOIL

Level (low/med): LOW

\% Solids:
Contract: 60052

SAS NO.:

SDG NO.: V3097

22262

Lab Sample ID: 0804L004-0̄02

Date Received: 04/25/08

Concentration Units (ug/L or $\mathrm{mg} / \mathrm{kg}$ dry weight): MG/KG

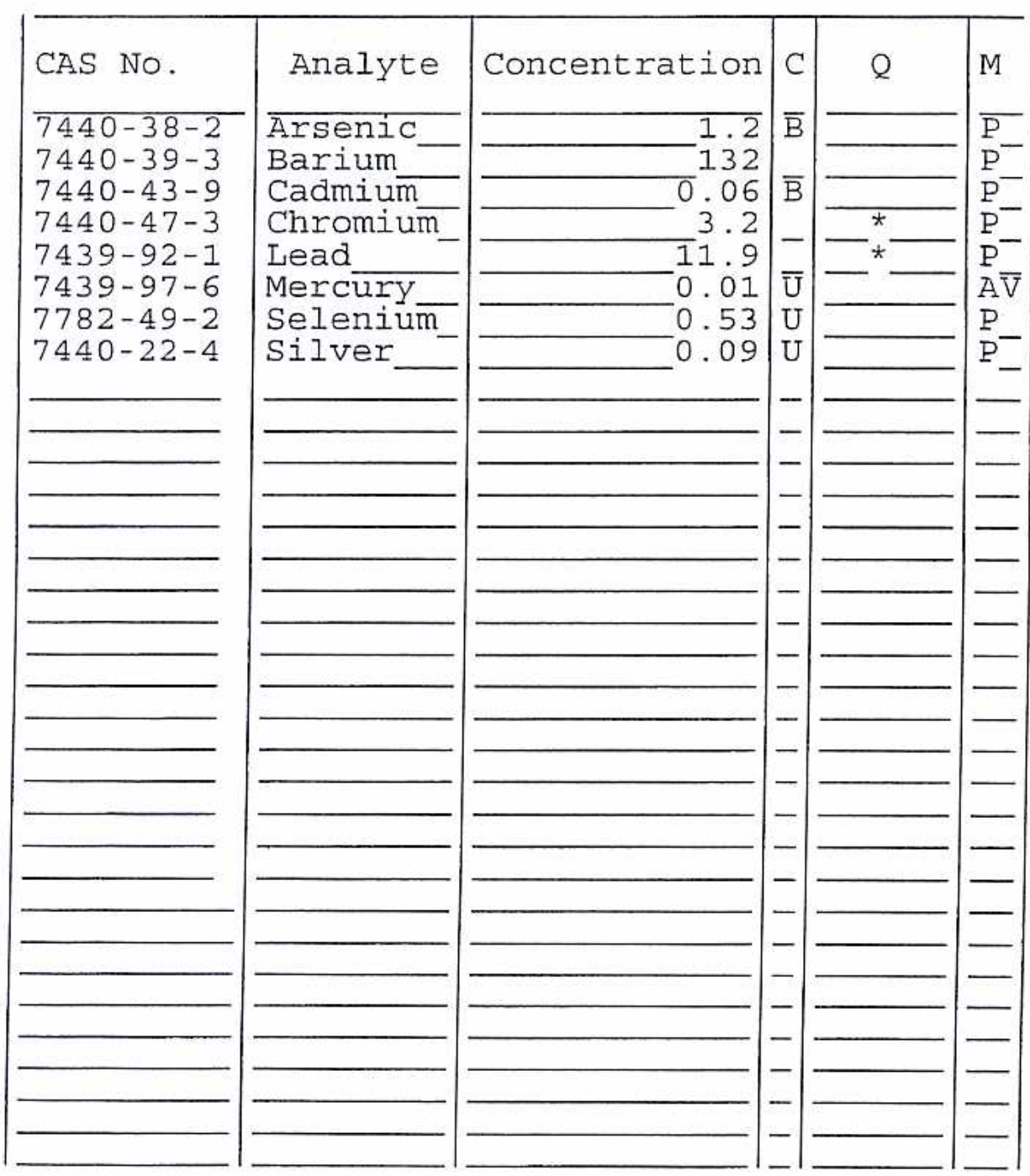

Color Before:

Clarity Before:

Clarity After:
Texture:

Artifacts:

\section{Comments:}

$122226-2$ 
1

INORGANIC ANALYSES DATA SHEET
EPA SAMPLE NO.

\section{3}

Contract: 60052 SAS NO.:

Lab Sample ID: 0804L004-0̄03

Date Received: 04/25/08
Lab Code: LVLI Matrix (soil/water): SOIL Level (low/med): \% Solids :

$$
\begin{array}{r}
\text { LOW } \\
-96.5
\end{array}
$$

Concentration Units (ug/L or $\mathrm{mg} / \mathrm{kg}$ dry weight): MG/KG

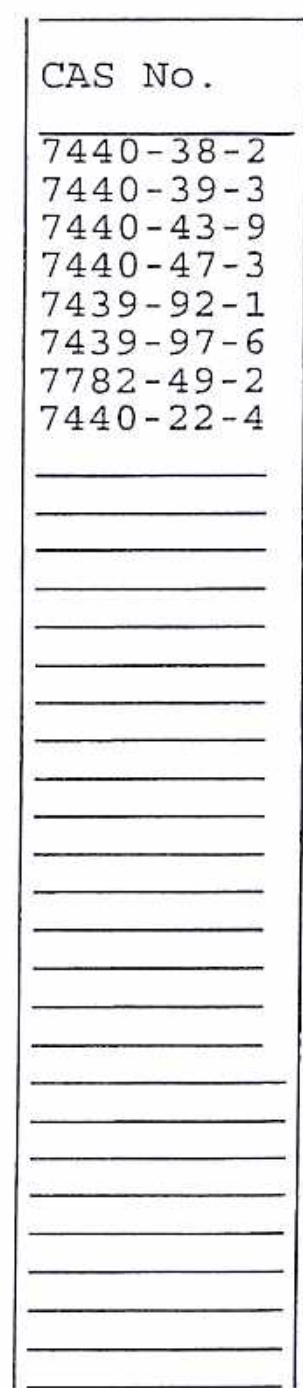

Color Before: Color After:

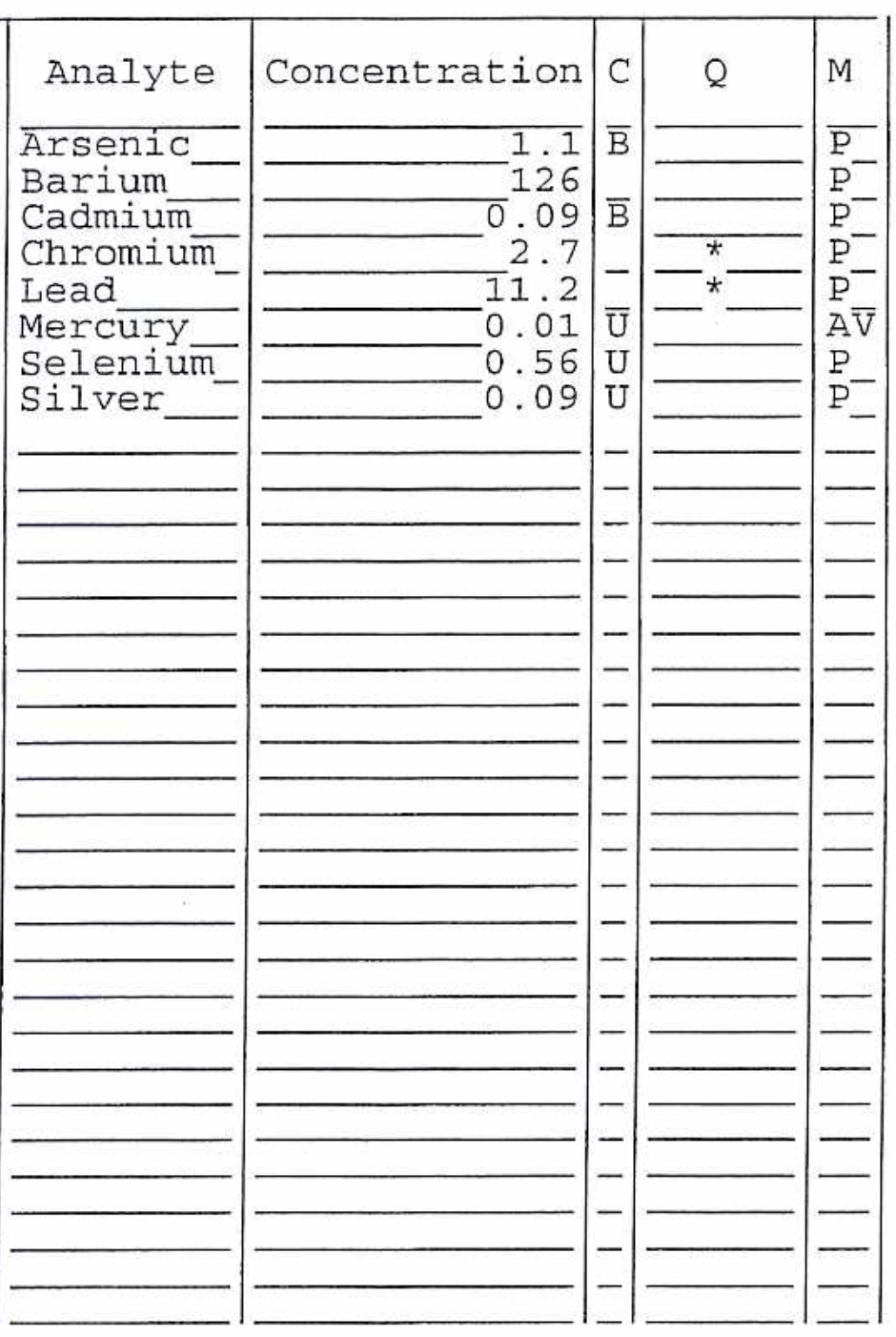

Clarity Before: Clarity After:
Texture: Artifacts:

Comments :

$122226-3$ 
EPA SAMPLE NO.

$$
22264
$$

Lab Name: LIONVILLE_LABORATORY

Lab Code: LVLI

Matrix (soil/water): SOIL

Level (low/med): LOW

$\div$ Solids:
Contract: 60052

SAS NO.:

Lab Sample ID: 0804L004-0̄04

Date Received: 04/25/08

Concentration Units (ug/L or $\mathrm{mg} / \mathrm{kg}$ dry weight): MG/KG

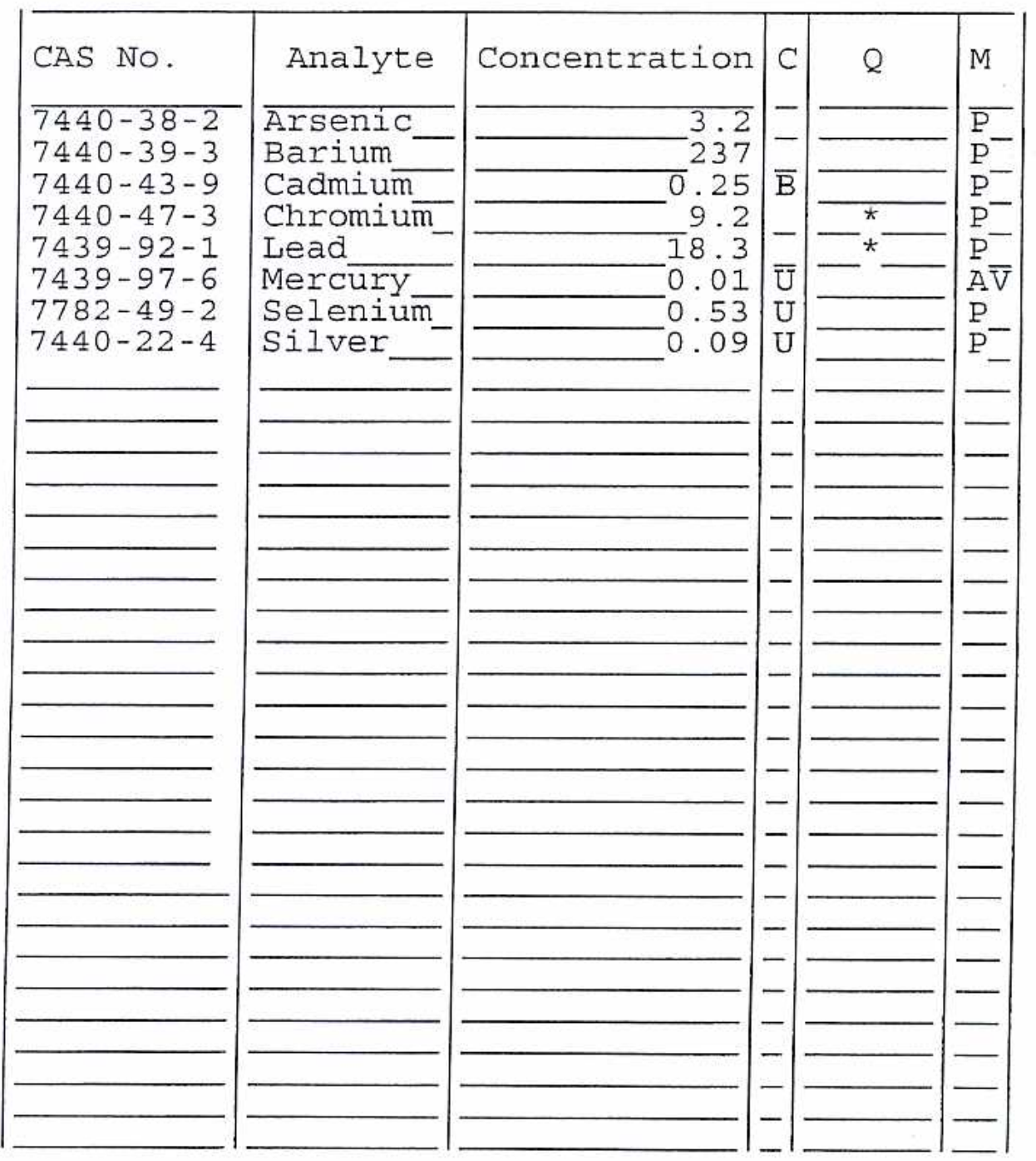

Color Before:

Color After:

Comments :

$122226-4$
Clarity Before:

Clarity After:
Texture:

Artifacts: 
U.S. EPA

\section{INORGANIC ANALYSES DATA SHEET}

Lab Name: LIONVILLE_LABORATORY

Lab Code: Case No.: NSTEC

Matrix (soil/water): SOIL

Level (low/med): LOW

: Solids :

LOW

EPA SAMPLE NO.

22265

Contract: 60052 SAS No.:

Lab Sample ID: 0804L004-0̄05

Date Received: 04/25/08

Concentration Units (ug/L or $\mathrm{mg} / \mathrm{kg}$ dry weight): MG/KG

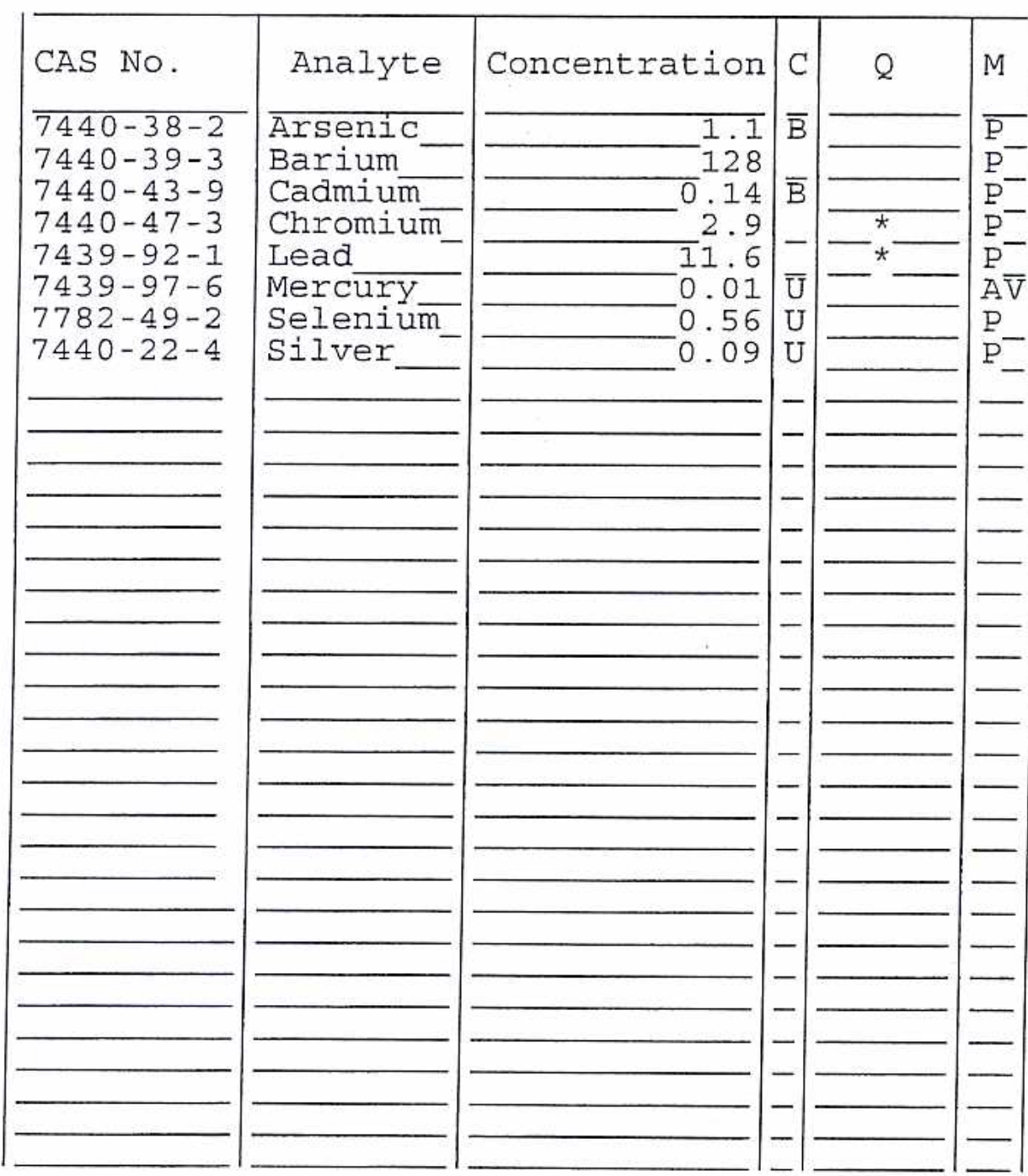

Color Before:

Color After:

Comments :

$122226-5$
Clarity Before:

Clarity After:
Texture:

Artifacts: 


\section{INORGANIC ANALYSES DATA SHEET}

Lab Name: LIONVILLE_LABORATORY

Lab Code: LVLI

Matrix (soil/water): SOIL

Level (low/med):

\% Solids :
Contract: 60052

SAS NO.:

Lab Sample ID: 0804L004-0̄06

LOW
-95.6

Date Received: 04/25/08
EPA SAMPLE NO.

22266

Concentration Units (ug/L or $\mathrm{mg} / \mathrm{kg}$ dry weight): MG/KG

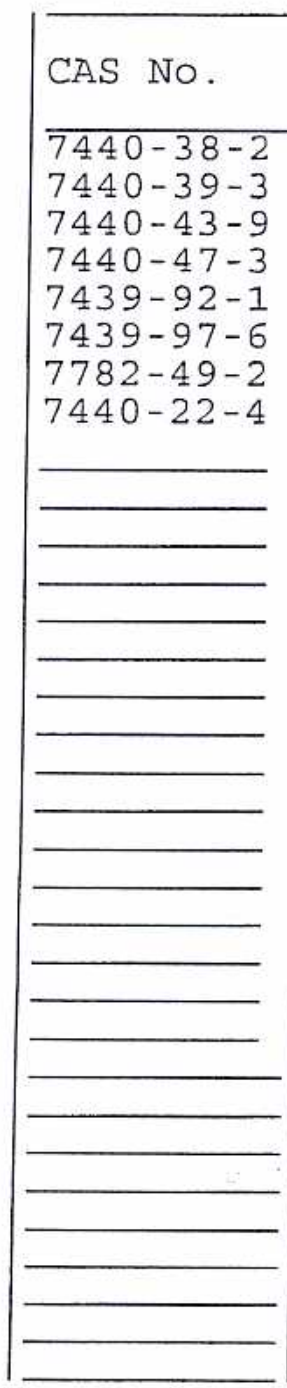

Color Before:

Color After:

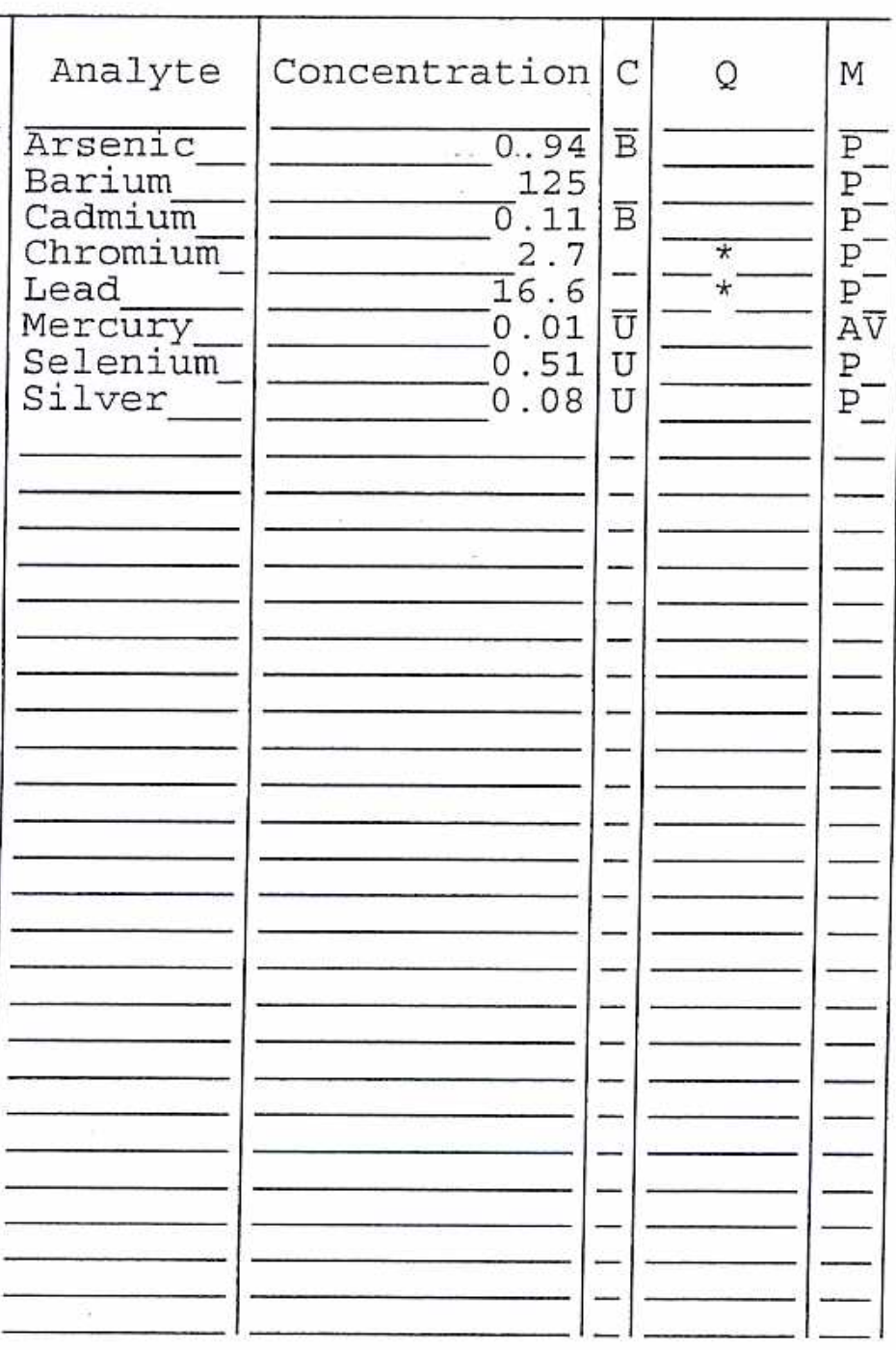

Clarity Before:

Clarity After:
Texture:

Artifacts:

\section{Comments :}

$122226-6$ 
1

INORGANIC ANALYSES DATA SHEET

EPA SAMPLE NO.

22267

Lab Name: LIONVILLE IAABORATORY

Lab code: IVLI Matrix (soil/water): SOIL Level (low/med): LOW \% Solids: $\quad$ $\quad 90 \overline{\overline{6}}$

Contract: 60052

SAS NO.:

SDG NO.: V3097

Lab Sample ID: 0804L004-0̄07

Date Received: 04/25/08

Concentration Units (ug/L or $\mathrm{mg} / \mathrm{kg}$ dry weight): MG/KG

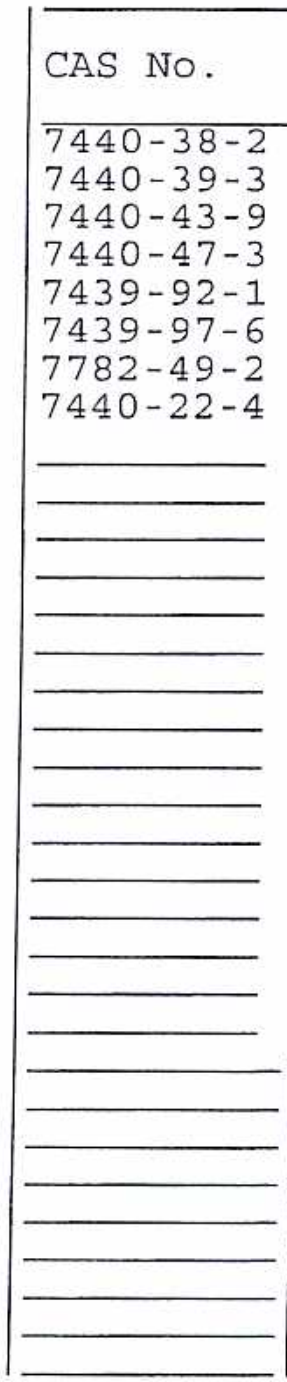

Color Before:

Color After:

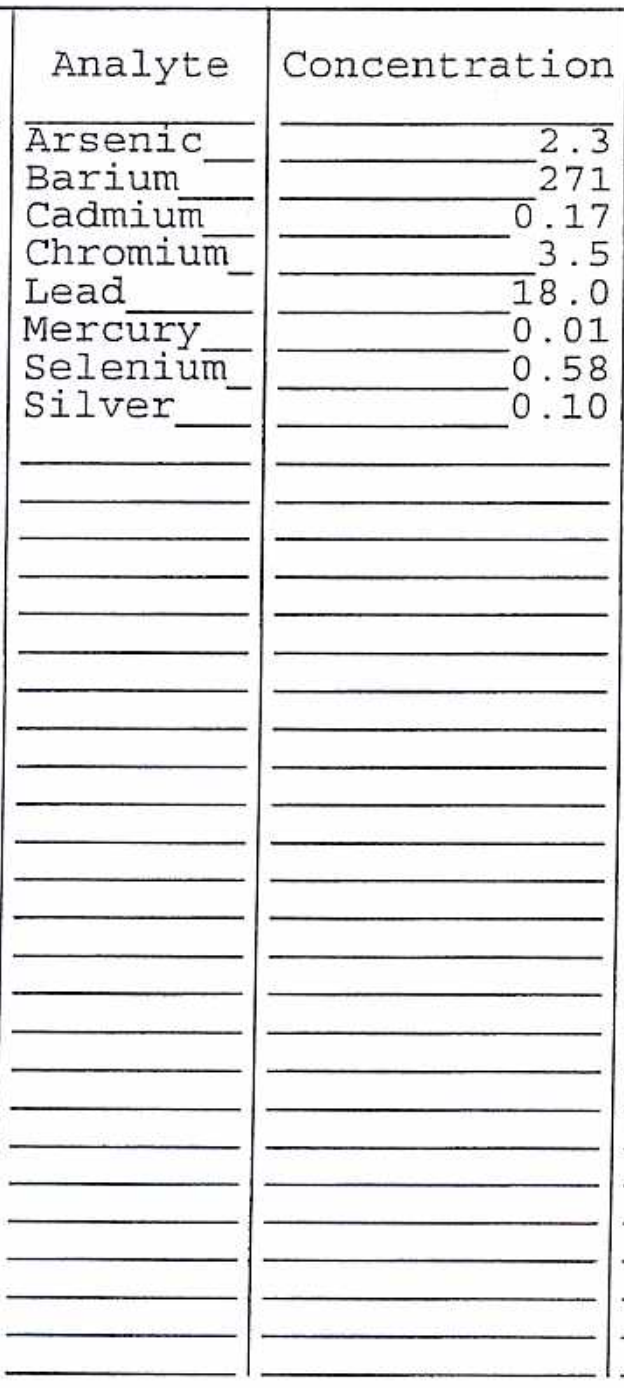

Clarity Before: Clarity After:

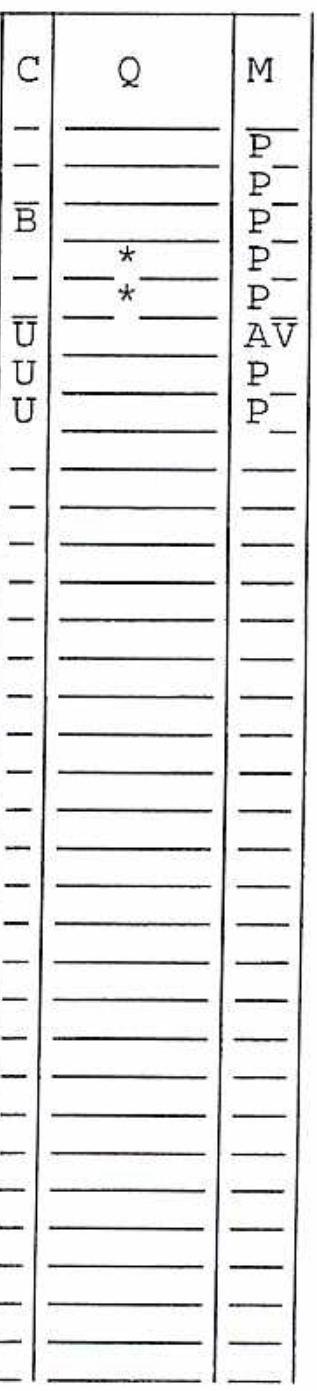

Texture: Artifacts :

Comments :

$122226-7$ 
EPA SAMPLE NO.

\section{8}

Lab Name: LIONVILLE LABORATORY

Contract: 60052

Lab Code: LVLI

Matrix (soil/water): SOIL

Level (low/med): LOW

: Solids :
SAS No. :

Lab Sample ID: 0804L004-0̄08

Date Received: 04/25/08

Concentration Units (ug/L or $\mathrm{mg} / \mathrm{kg}$ dry weight): MG/KG

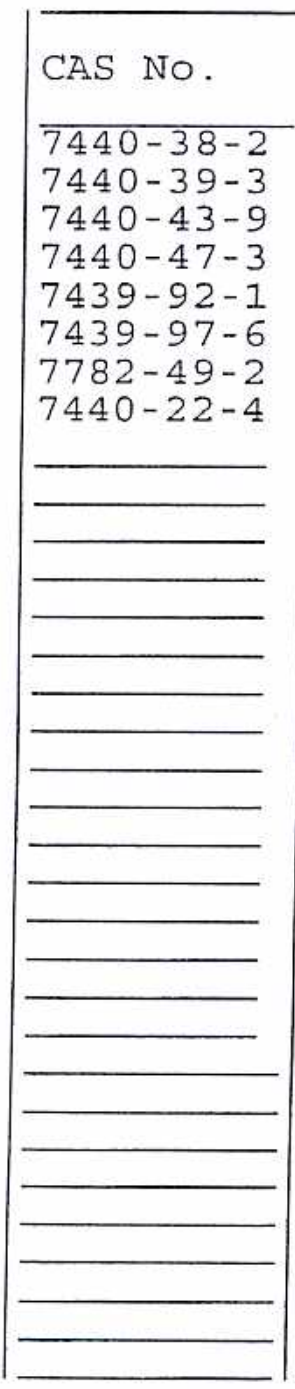

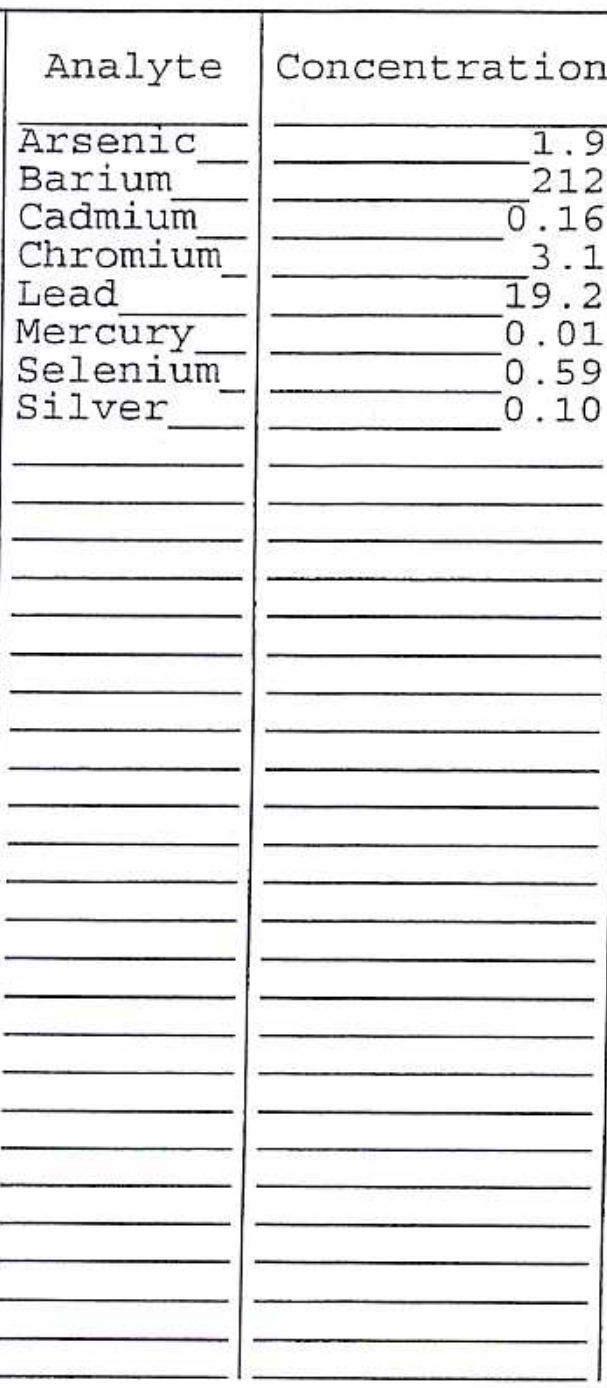

Clarity Before:

Clarity After:

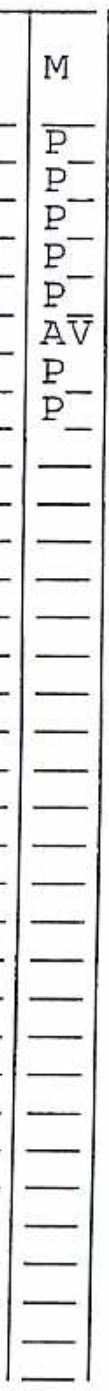

Texture : Artifacts:
Color Before:

Comments :

$122226-8$ 


\section{U.S. EPA}

1

INORGANIC ANALYSES DATA SHEET
EPA SAMPLE NO.

\section{9}

Lab Name: LIONVILLE_LABORATORY Lab Code: LVLI Matrix (soil/water): SOIL Level (low/med): LOW : Solids :
Contract: 60052

SAS No. :

SDG NO.: V3097

Lab Sample ID: 0804L004-0̄09 $-89 \overline{.8}$

Date Received: 04/25/08

Concentration Units (ug/L or $\mathrm{mg} / \mathrm{kg}$ dry weight): MG/KG

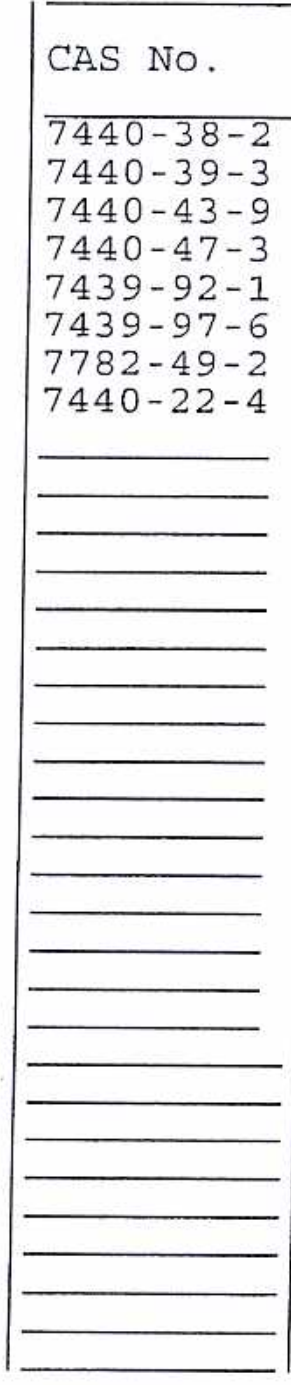

Color Before:

Color After:

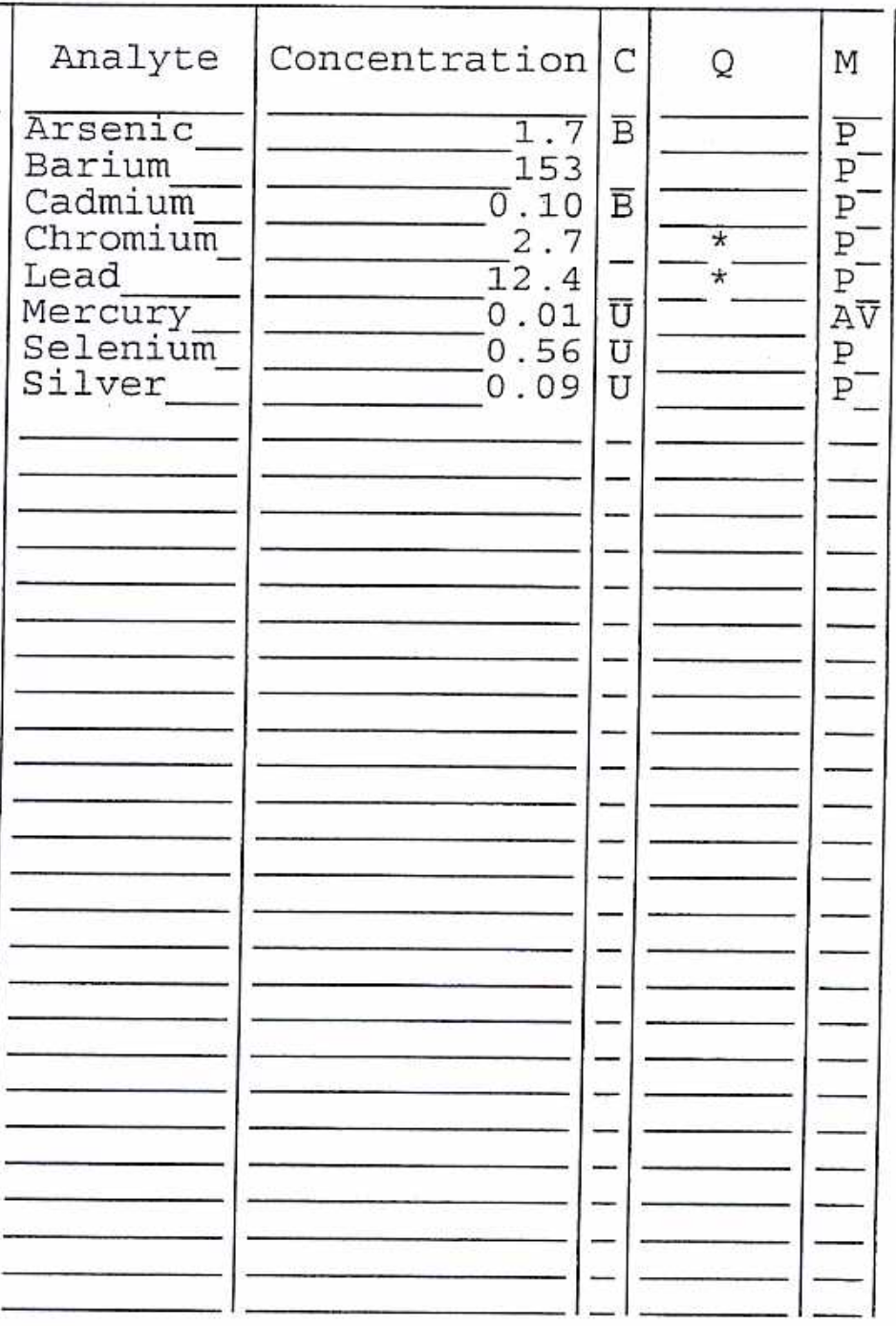

Clarity Before: Clarity After:
Texture:

Artifacts:

\section{Comments :}

122226-9 
$\stackrel{\sim}{N}$
$\ddot{r}$
$\infty$
$\stackrel{1}{0}$
$\stackrel{0}{0}$
$\stackrel{0}{0}$

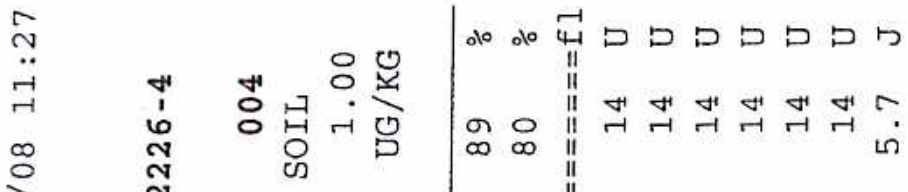$$
\text { i) }
$$

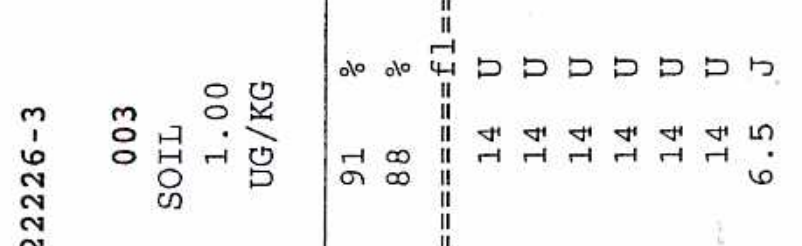

त्

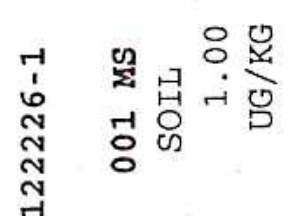

กิ

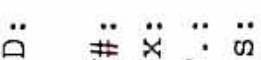
芝菜落

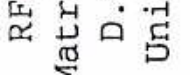

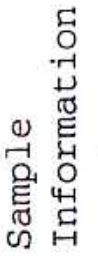

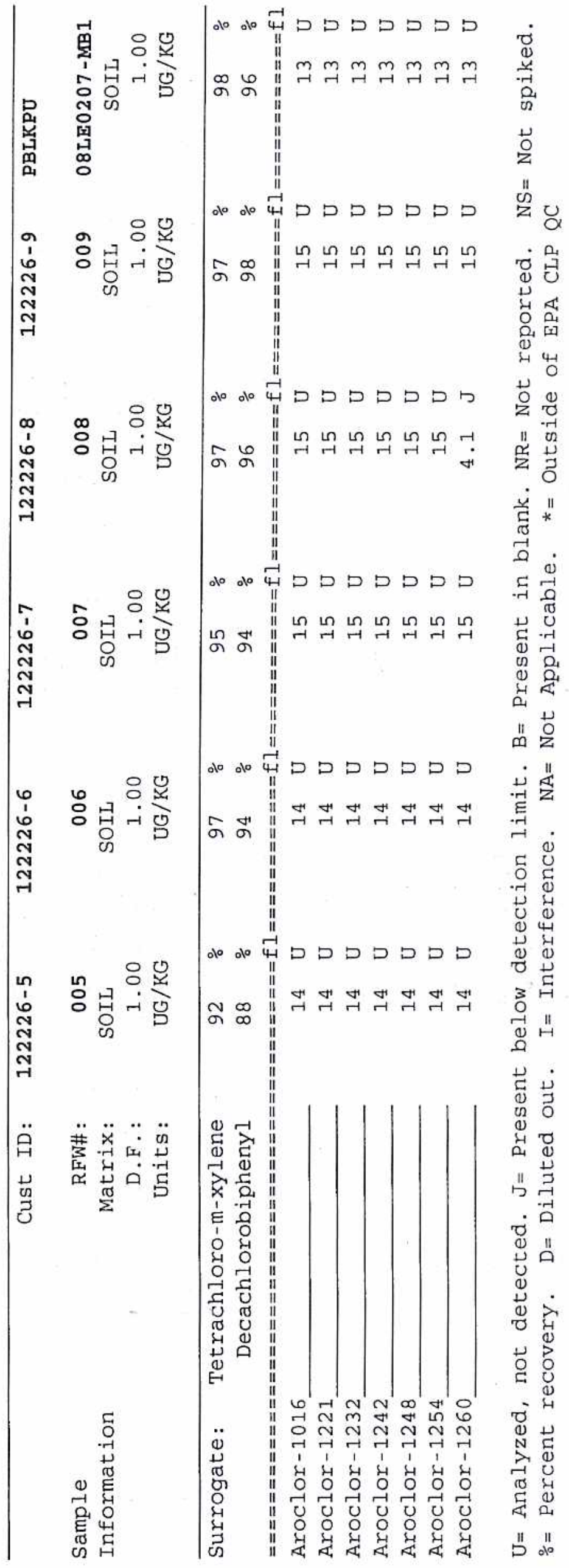


510000000

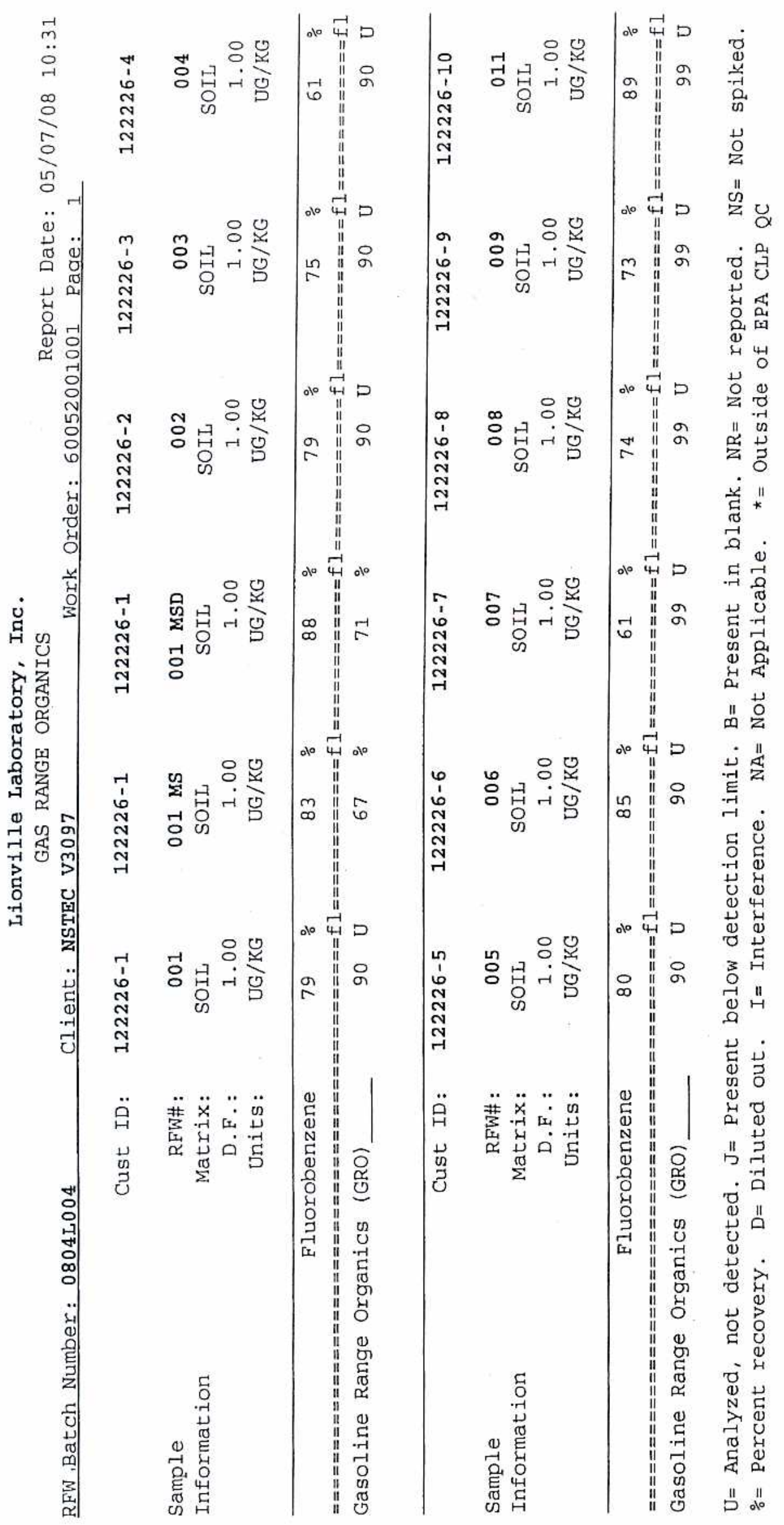




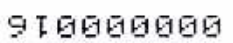

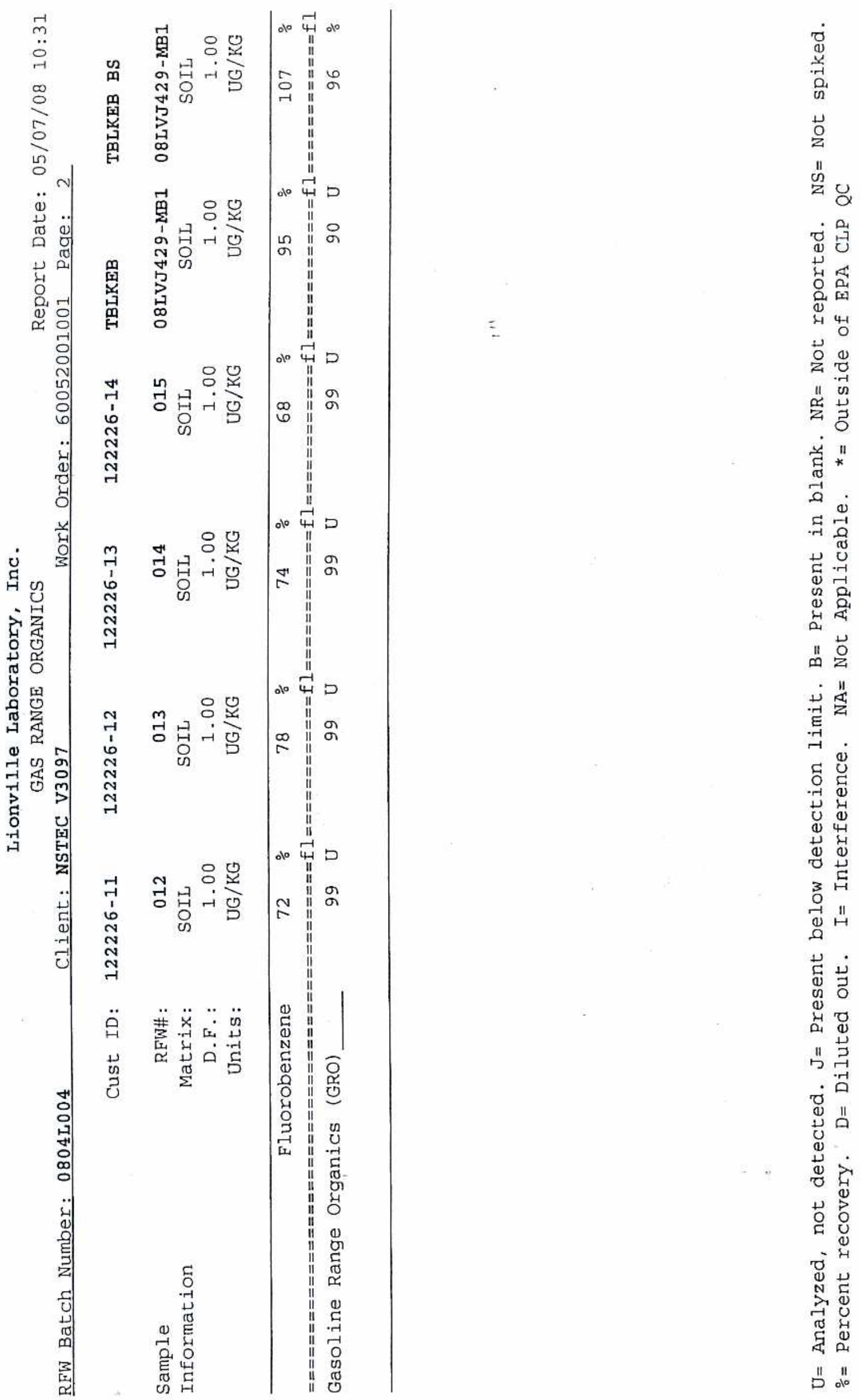


SI 969060日

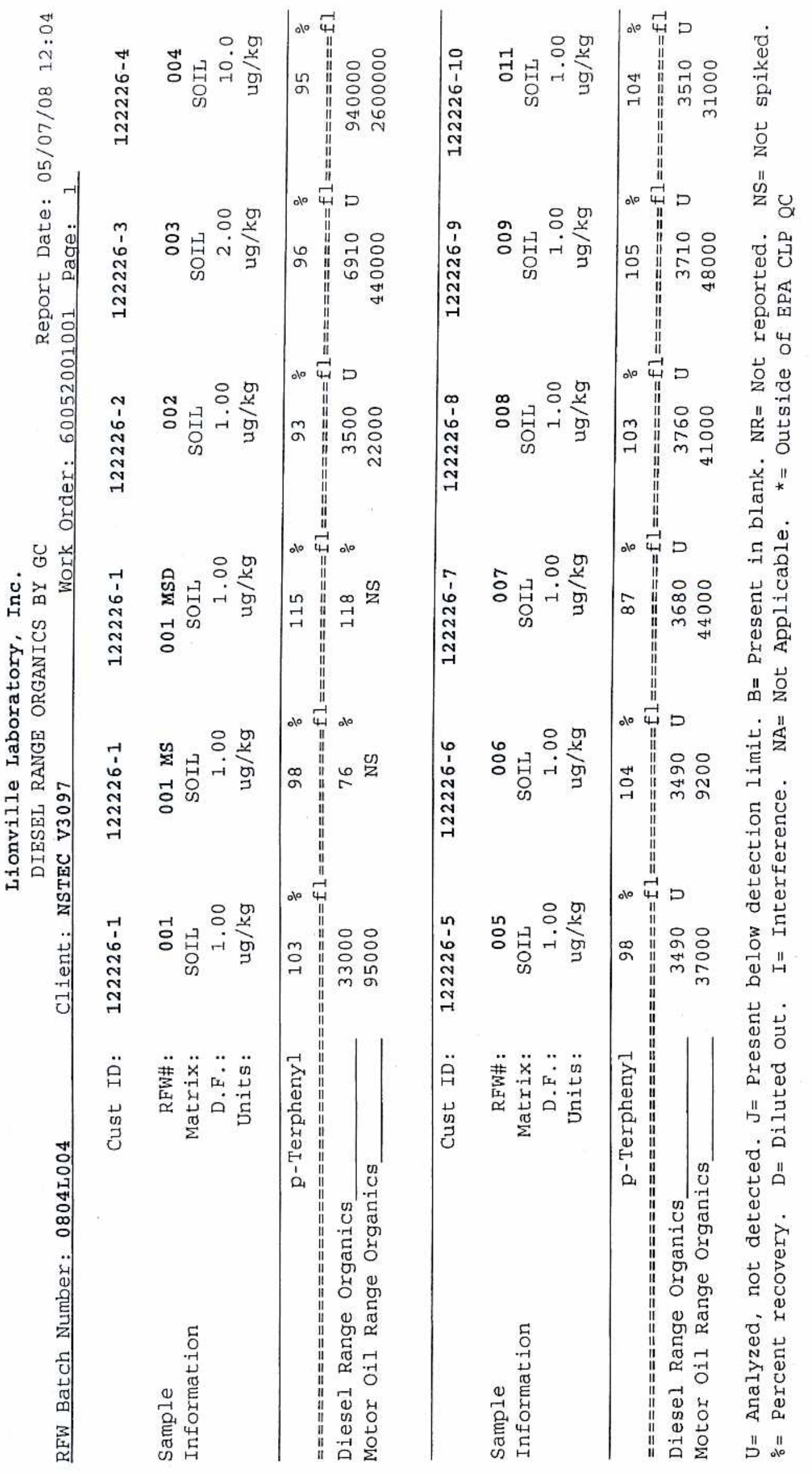


9 대년으

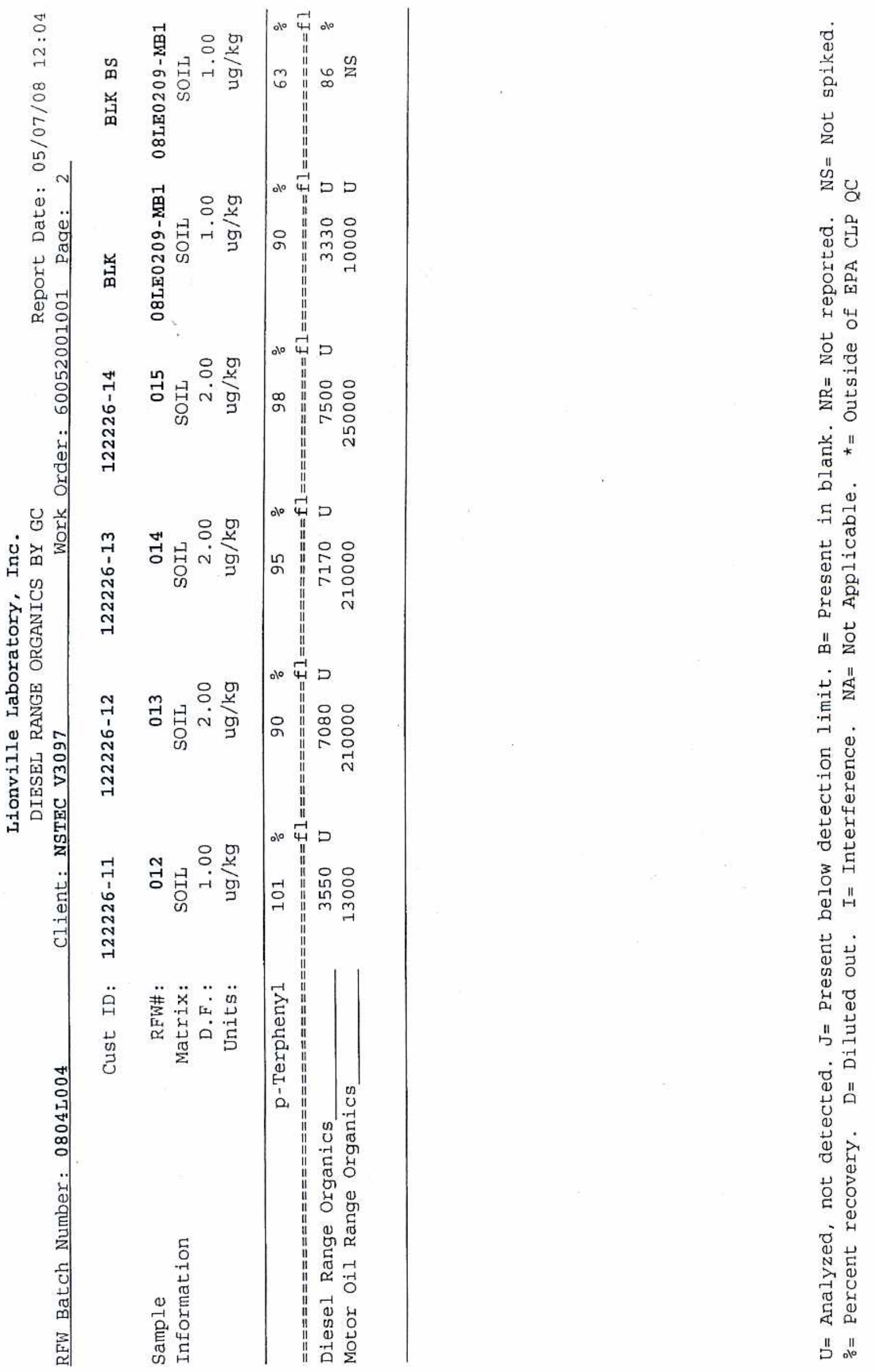




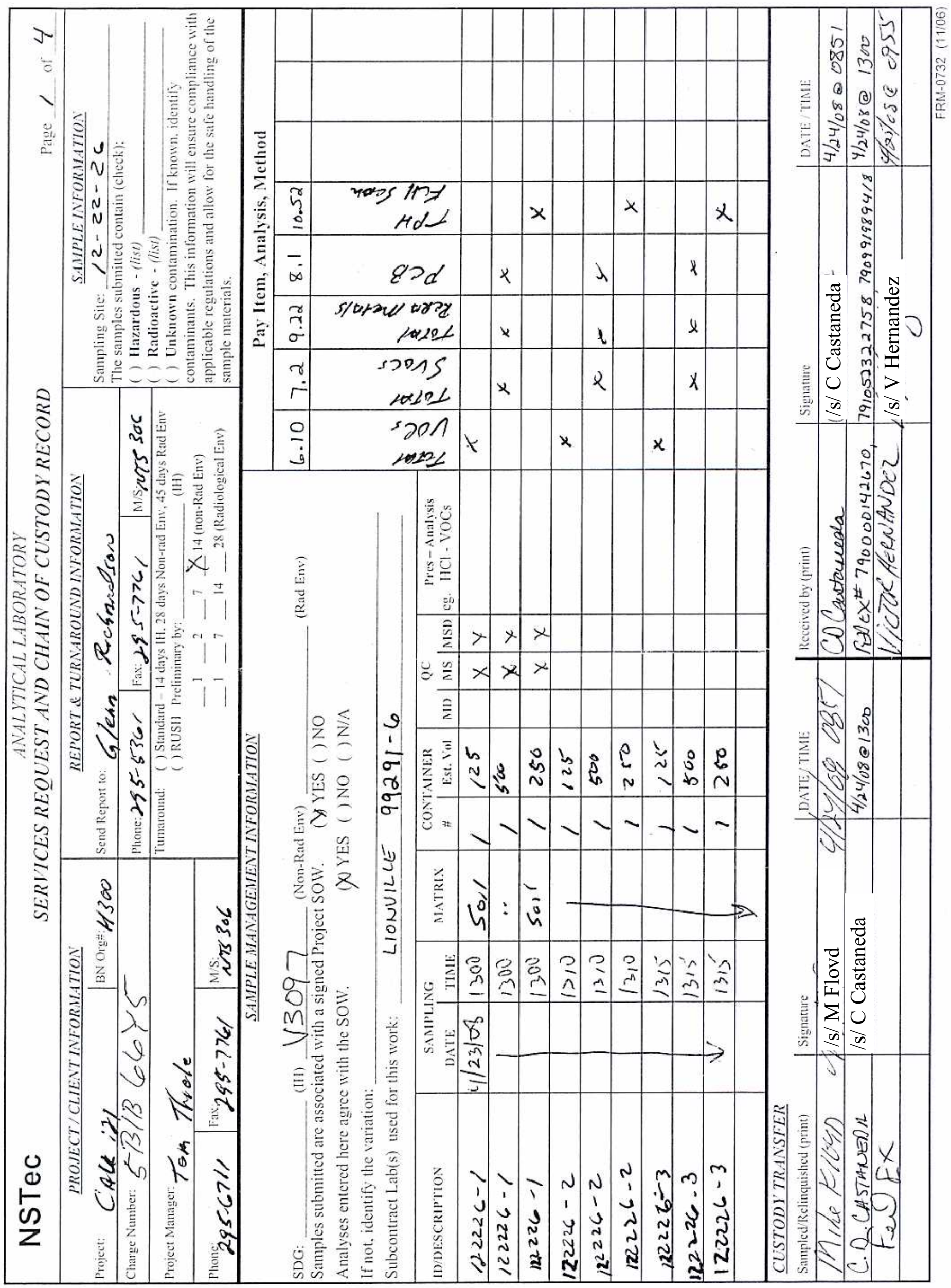




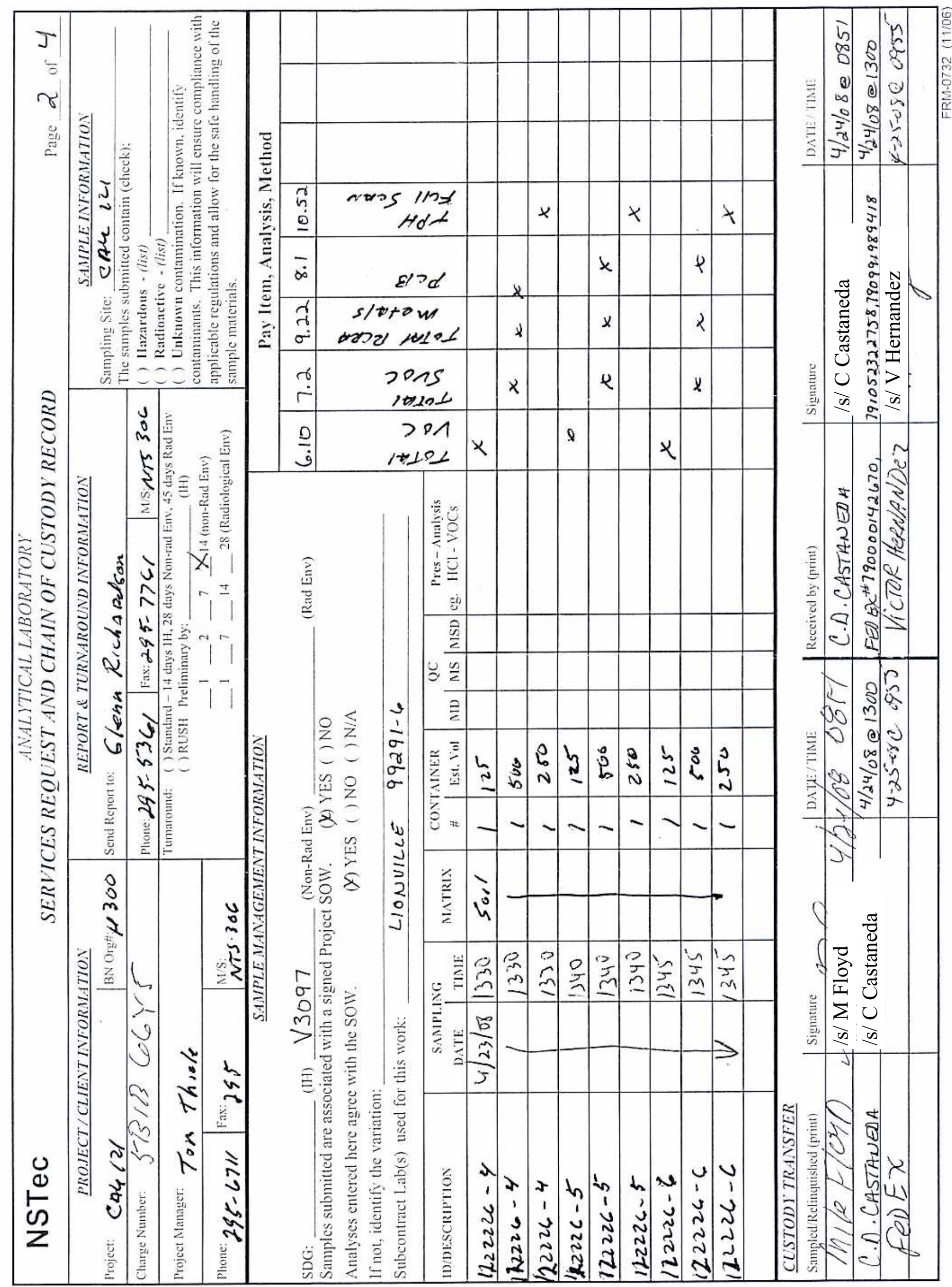




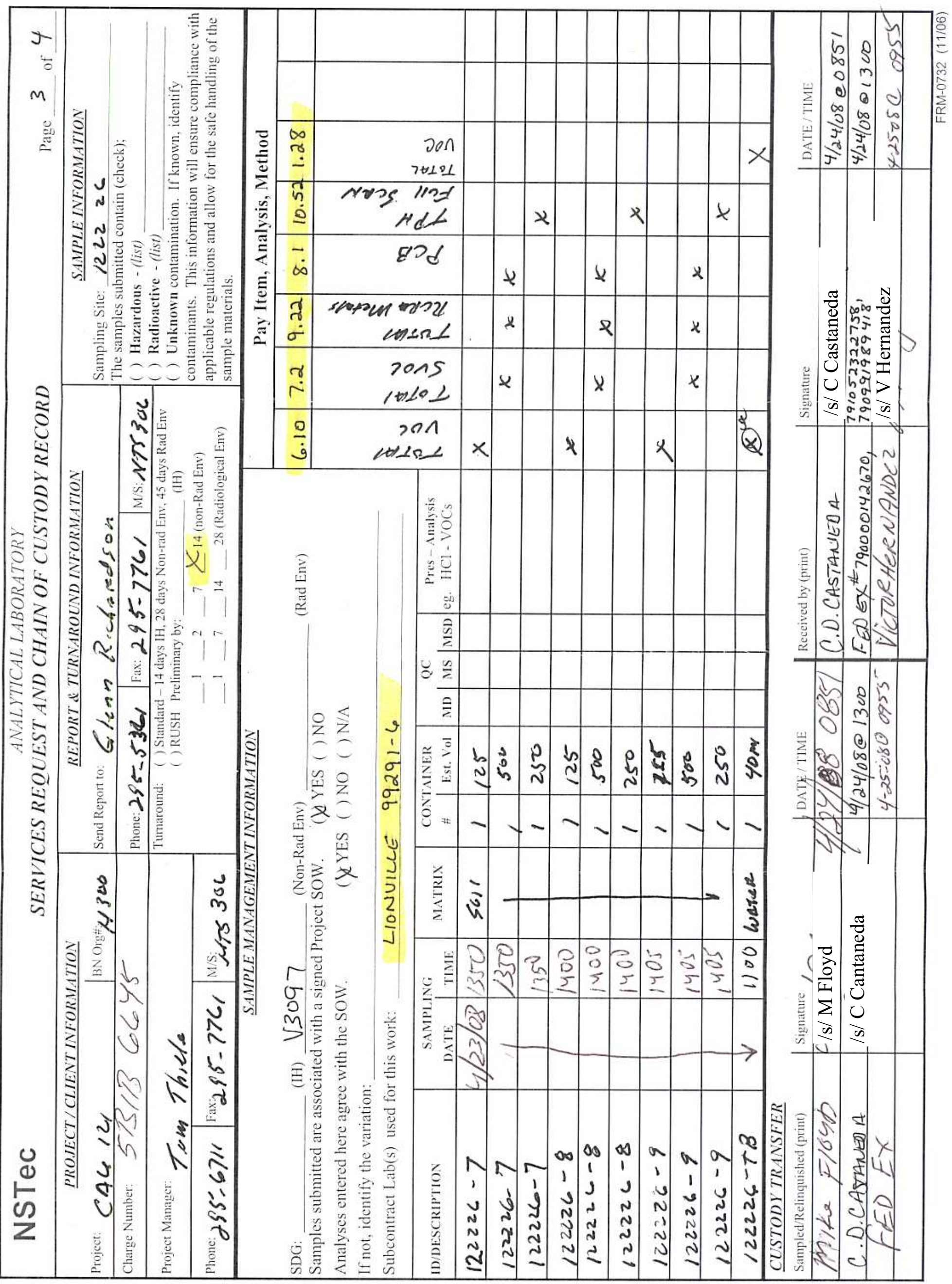


CAU 121 Closure Report

Section: Appendix B

Revision: 0

Date: September 2008

\section{Sample Delivery Group V3098}


CAU 121 Closure Report

Section: Appendix B

Revision: 0

Date: September 2008

\section{THIS PAGE INTENTIONALLY LEFT BLANK}



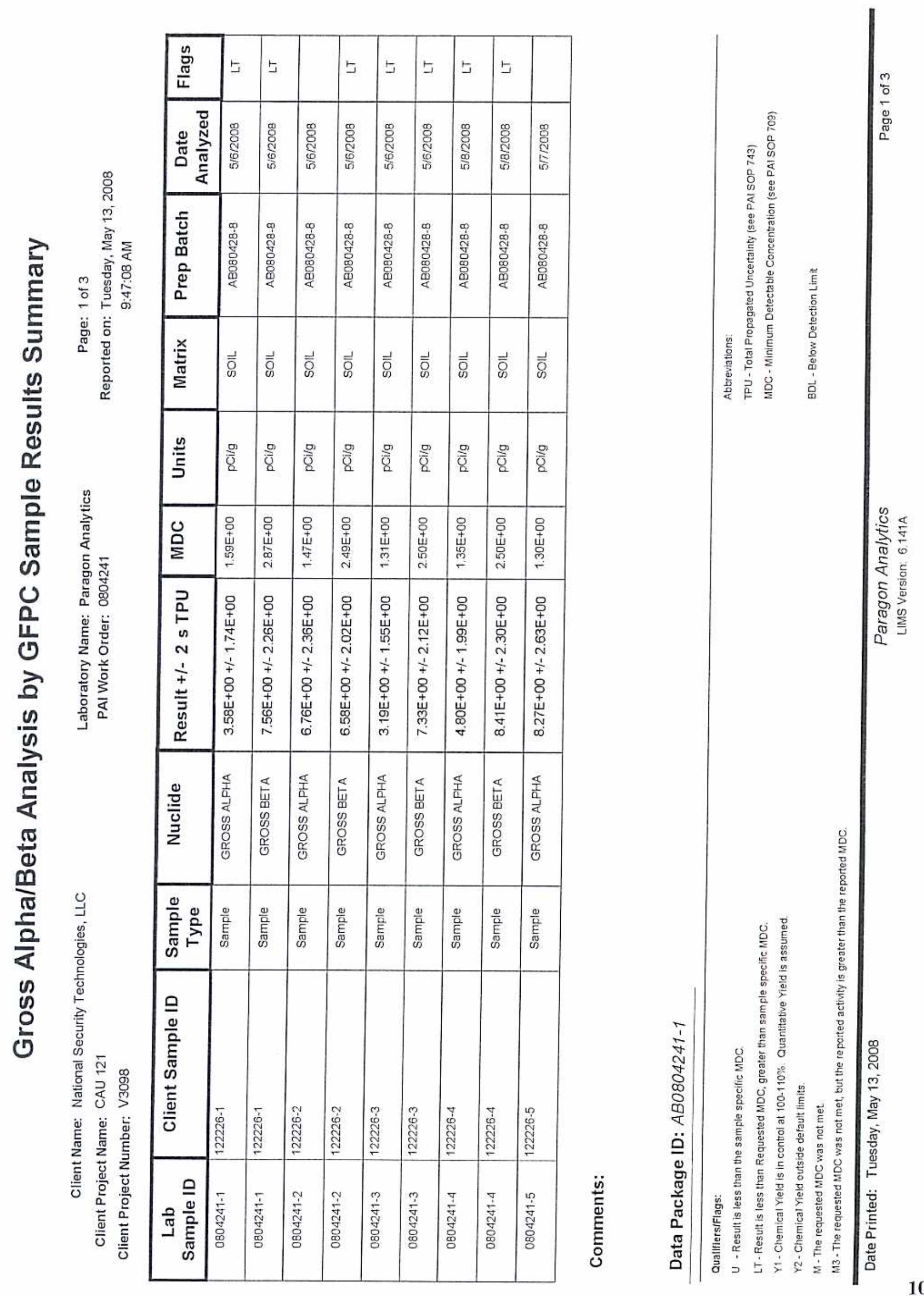

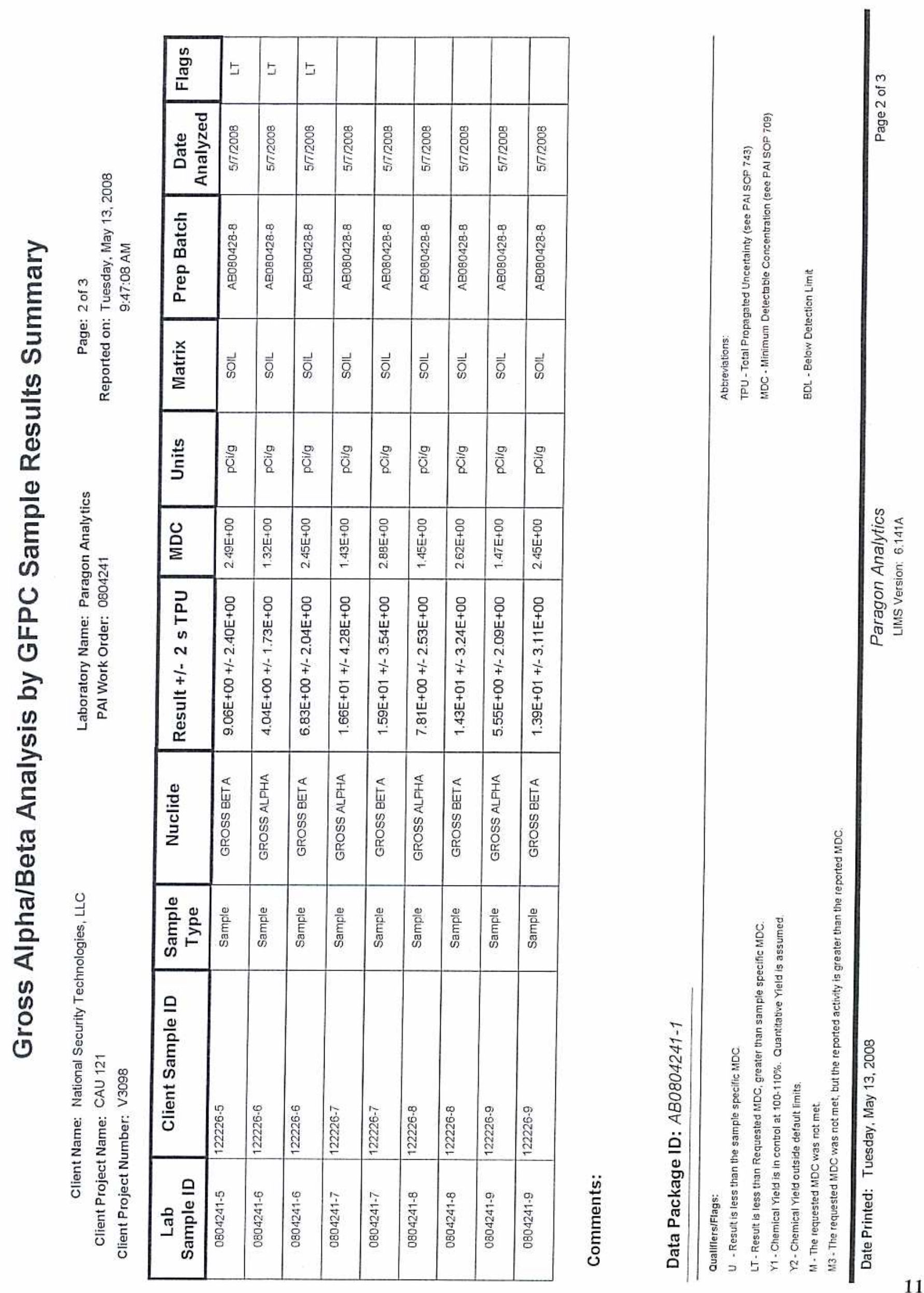

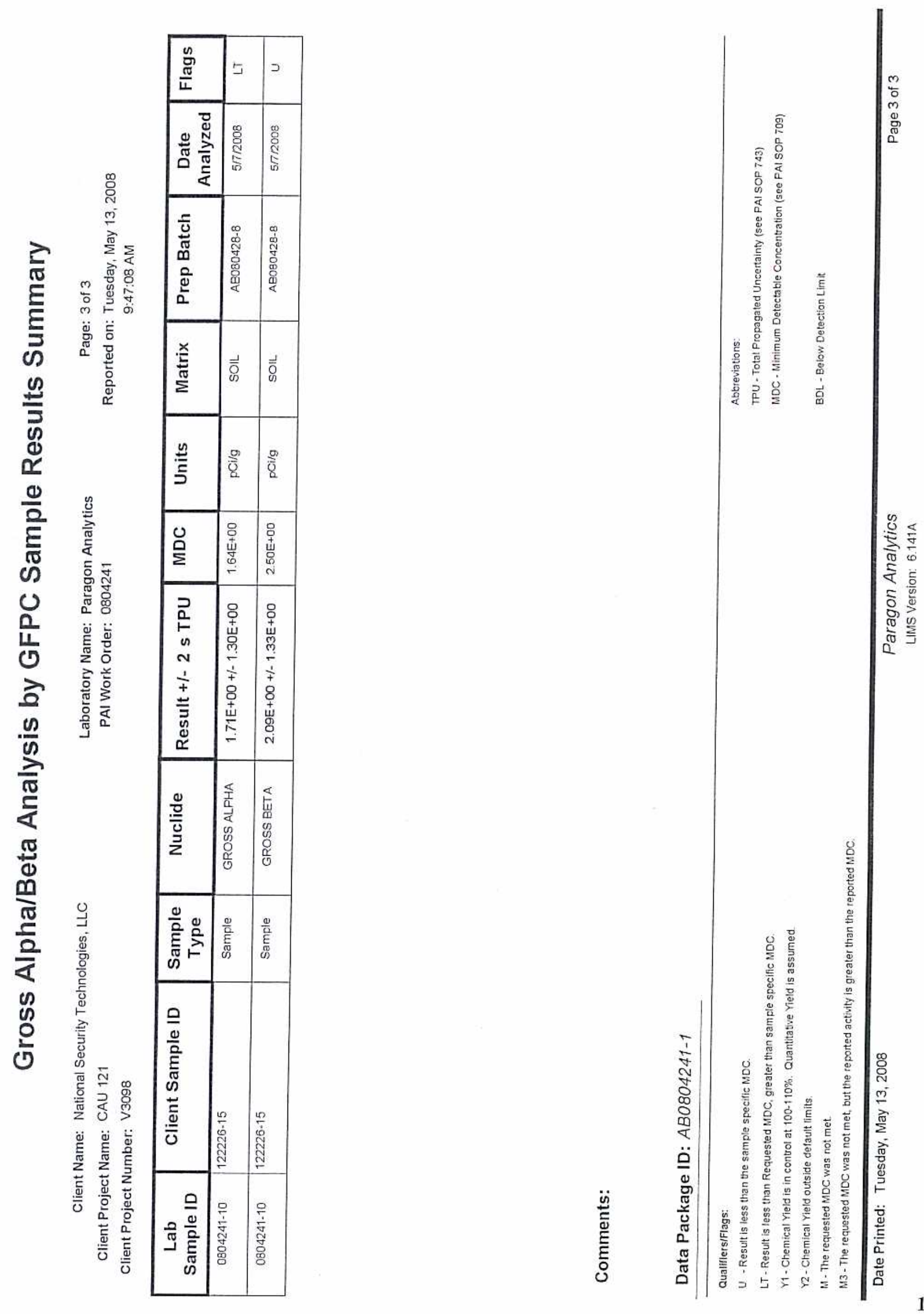


\section{Gamma Spectroscopy Results \\ PAl 713 Rev 9 \\ Duplicate Sample Results (DER)}

Lab Name: Paragon Analytics

Work Order Number: 0804241

Client Name: National Security Technologies, LLC

ClientProject ID: CAU 121 V3098

\begin{tabular}{|c|}
\hline $\begin{array}{l}\text { Field ID: } 122226-1 \\
\text { Lab ID: } \quad 0804241-1 D \text { DP }\end{array}$ \\
\hline
\end{tabular}

Library: LNG_GAM-A-001
Sample Matrix: SOIL

Prep SOP: PAI 739 Rev 9

Date Collected: 23-Apr-08

Date Prepared: 28-Apr-08

Date Analyzed: 29-Apr-08
Prep Batch: GS080428-1

QCBatchID: GS080428-1-1

Run ID: GS080428-1A

Count Time: 30 minutes

Report Basis:Dry Weight
Final Aliquot: $422 \mathrm{~g}$

Prep Basis: Dry Weight

Moisture(\%): NA

Result Units: $\mathrm{pCi} / \mathrm{g}$

File Name:080221d03

\begin{tabular}{|c|c|c|c|c|c|c|}
\hline CASNO & Analyte & $\begin{array}{c}\text { Sample } \\
\text { Result + } /-2 \text { S TPU }\end{array}$ & $\begin{array}{c}\text { Duplicate } \\
\text { Result +/- 2s TPU }\end{array}$ & DER & $\begin{array}{l}\text { Control } \\
\text { Limit }\end{array}$ & $\begin{array}{c}\text { Lab } \\
\text { Qualifiers }\end{array}$ \\
\hline $14331-83-0$ & $A C-228$ & 8.44E-01 +/-2.77E-01 & $8.71 \mathrm{E}-01+/-3.00 \mathrm{E}-01$ & 0.13 & 3 & G,TI \\
\hline $14596-10-2$ & Am-241 & 2.69E-01+/- 7.86E-01 & $6.47 \mathrm{E}-02+/-7.72 \mathrm{E}-01$ & 0.37 & 3 & $U, G$ \\
\hline $14733-03-0$ & $\mathrm{Bi}-214$ & 9.97E-01+/-2.54E-01 & $9.92 \mathrm{E}-01+/-2.37 \mathrm{E}-01$ & 0.03 & 3 & G,J \\
\hline $14762-78-8$ & $\mathrm{Ce}-144$ & $-3.53 \mathrm{E}-01+/-4.05 \mathrm{E}-01$ & $-8.29 \mathrm{E}-02+1-3.82 \mathrm{E}-01$ & 0.97 & 3 & U.G \\
\hline $10198-40-0$ & Co-60 & $-6.66 \mathrm{E}-02+1-8.06 \mathrm{E}-02$ & $-8.55 \mathrm{E}-02+/-7.55 \mathrm{E}-02$ & 0.34 & 3 & U,G \\
\hline $13967-70-9$ & Cs-134 & $1.00 \mathrm{E}-02+1-6.35 \mathrm{E}-02$ & $-1.31 \mathrm{E}-01+/-6.39 \mathrm{E}-02$ & 3.14 & 3 & $U, D, G$ \\
\hline $10045-97-3$ & Cs-137 & $1.10 \mathrm{E}-01+/-8.14 \mathrm{E}-02$ & $9.46 \mathrm{E}-02+1-7.92 \mathrm{E}-02$ & 0.26 & 3 & U,G \\
\hline $14683-23-9$ & Eu-152 & 1.58E-01 +/-2.75E-01 & $2.89 \mathrm{E}-01+/-3.02 \mathrm{E}-01$ & 0.64 & 3 & U,G \\
\hline $15585-10-1$ & Eu-154 & 1.31E-01 +/- 3.37E-01 & $-3.84 \mathrm{E}-02+1-3.66 \mathrm{E}-01$ & 0.68 & 3 & $U, G$ \\
\hline $14391-16-3$ & Eu-155 & $2.58 \mathrm{E}-01+/-2.64 \mathrm{E}-01$ & $1.94 \mathrm{E}-01+/-2.45 \mathrm{E}-01$ & 0.35 & 3 & U.G \\
\hline $13966-00-2$ & K-40 & $2.53 E+01+/-4.01 E+00$ & $2.65 E+01+1-4.12 E+00$ & 0.42 & 3 & $G$ \\
\hline $15092-94-1$ & $\mathrm{~Pb}-212$ & $9.65 \mathrm{E}-01+/-2.10 \mathrm{E}-01$ & $1.02 \mathrm{E}+00+/-2.11 \mathrm{E}-01$ & 0.39 & 3 & G \\
\hline $15067-28-4$ & $\mathrm{~Pb}-214$ & $1.07 \mathrm{E}+00+/-2.19 \mathrm{E}-01$ & $9.22 \mathrm{E}-01+1-2.09 \mathrm{E}-01$ & 0.99 & 3 & G.J \\
\hline $14834-73-2$ & $\mathrm{Pm} \cdot 144$ & $-2.15 \mathrm{E}-02+1-7.00 \mathrm{E}-02$ & $4.89 \mathrm{E}-03+/-6.84 \mathrm{E}-02$ & 0.54 & 3 & U,G \\
\hline $14834-74-3$ & $\mathrm{Pm} \cdot 146$ & $8.48 \mathrm{E}-02+i-8.09 \mathrm{E}-02$ & $2.80 \mathrm{E}-02+/-6.52 \mathrm{E}-02$ & 1.09 & 3 & U.G \\
\hline $13967-48-1$ & Ru-106 & $-2.46 \mathrm{E}-02+/-5.22 \mathrm{E}-01$ & $-3.33 \mathrm{E}-01+1-4.95 \mathrm{E}-01$ & 0.86 & 3 & U,G \\
\hline $14234-35-6$ & Sb-125 & $-6.09 \mathrm{E}-02+/-1.71 \mathrm{E}-01$ & $2.36 \mathrm{E}-02+/-1.68 \mathrm{E}-01$ & 0.71 & 3 & U,G \\
\hline
\end{tabular}

\section{Comments:}

\footnotetext{
Duplicate Qualifiers/Flags:

$U$-Result is less than the sample specific MDC.

$\mathrm{Y1}$. Chemical Yield is in control at $100-110 \%$. Quantitative yield is assumed

Y2. Chemical Yield outside default limits.
}

D - DER is greater than Control Limit of 3

LT - Result is less than Request MDC, greater than sample specific MDC

M- Requested MDC not met.

M3 - The requested MDC was not met, but the reported activity is greater than the reported MDC.

L- LCS Recovery below lower control limit.

H- LCS Recovery above upper control limit

P. LCS, Matrix Spike Recovery within control limits.

N-Matrix Spike Recovery outside control limits

\section{Abbreviations:}

TPU - Total Propagated Uncertainty (see PAI SOP 743)

DER - Duplicate Error Ratio (see PAISOP 715)

$\mathrm{BDL}$ - Below Detection Limit

NR - Not Reported

Data Package ID: GSS0804241-1 


\section{Gamma Spectroscopy Results \\ PAl 713 Rev 9 \\ Duplicate Sample Results (DER)}

Lab Name: Paragon Analytics

Work Order Number: 0804241

Client Name: National Security Technologies, LLC

ClientProject ID: CAU 121 V3098

\begin{tabular}{|c|c|c|c|c|c|c|}
\hline \multicolumn{2}{|c|}{$\begin{array}{l}\text { Field ID: } 122226-1 \\
\text { Lab ID: } 0804241-1 \text { DUP }\end{array}$} & $\begin{array}{l}\text { Sample Matrix: SOIL } \\
\quad \text { Prep SOP:PAl } 739 \text { Rev } 9 \\
\text { Date Collected: } 23-A p r-08 \\
\text { Date Prepared: } 28-A p r-08 \\
\text { Date Analyzed: } 29-A p r-08\end{array}$ & $\begin{array}{l}\text { Prep Batch: GS080428-1 } \\
\text { QCBatchID: GS080428-1-1 } \\
\text { Run ID: GS080428-1A } \\
\text { Count Time: } 30 \text { minutes } \\
\text { Report Basis: Dry Weight }\end{array}$ & \multicolumn{3}{|c|}{$\begin{array}{l}\text { Final Aliquot: } 422 \mathrm{~g} \\
\text { Prep Basis: Dry Weight } \\
\text { Moisture(\%): NA } \\
\text { Result Units: pCi/g } \\
\text { File Name: } 080221 \mathrm{~d} 03\end{array}$} \\
\hline CASNO & Analyte & $\begin{array}{c}\text { Sample } \\
\text { Result }+/-\quad 2 \text { S TPU }\end{array}$ & $\begin{array}{c}\text { Duplicate } \\
\text { Result }+/-2 \text { S TPU }\end{array}$ & DER & $\begin{array}{l}\text { Control } \\
\text { Limit }\end{array}$ & $\begin{array}{c}\text { Lab } \\
\text { Qualifiers }\end{array}$ \\
\hline $15065-10-8$ & Th-234 & $1.51 E+00+/-1.07 E+00$ & $5.68 \mathrm{E}-01+/-1.26 \mathrm{E}+00$ & 1.14 & 3 & U,G \\
\hline $14913-50-9$ & $\mathrm{Ti}-208$ & $3.24 \mathrm{E}-01+/-1.08 \mathrm{E}-01$ & $3.08 \mathrm{E}-01+/-1.03 \mathrm{E}-01$ & 0.21 & 3 & $G$ \\
\hline $15117-96-1$ & U-235 & 1.82E-01+/- 4.32E-01 & 1.13E-01+/-3.98E-01 & 0.23 & 3 & $U, G$ \\
\hline $13982-36-0$ & $Y-88$ & $-5.97 \mathrm{E}-03+/-8.17 \mathrm{E}-02$ & $-1.66 \mathrm{E}-02+/-7.65 \mathrm{E}-02$ & 0.19 & 3 & $U, G$ \\
\hline
\end{tabular}

\section{Comments:}

Duplicate Qualifiers/Flags:

$U$-Result is less than the sample specific MDC.

Y1 - Chemical Yield is in control at 100-110\%. Quantitative yield is assumed.

Y2 - Chemical Yield outside default limits.

D. DER is greater than Control Limit of 3

LT - Result is less than Request MDC, greater than sample specific MDC

$M$ - Requested MDC not met.

M3- The requested MDC was not met, but the reported

activity is greater than the reported MDC

L. LCS Recovery below lower control limit.

H. LCS Recovery above upper control limit.

P. LCS, Matrix Spike Recovery within control limits.

N-Matrix Spike Recovery outside control limits
Abbreviations:

TPU - Total Propagated Uncertainty (see PAI SOP 743)

DER - Duplicate Error Rato (see PAISOP 715)

BDL - Below Detection Limit

NR - Not Reported

Data Package ID: GSS0804241-1 


\section{Gamma Spectroscopy Results}

\section{PAI $713 \operatorname{Rev} 9$ \\ Sample Results}

Lab Name: Paragon Analytics

Work Order Number: 0804241

Client Name: National Security Technologies, LLC

ClientProject ID: CAU 121 V3098

\begin{tabular}{|c|c|c|c|c|c|}
\hline \multicolumn{2}{|c|}{$\begin{array}{l}\text { Field ID: } 122226-1 \\
\text { Lab ID: } 0804241-1\end{array}$} & \multirow{2}{*}{$\begin{array}{l}\text { Sample Matrix: SOIL } \\
\text { Prep SOP: PAI } 739 \text { Rev } 9 \\
\text { Date Collected: } 23-A p r-08 \\
\text { Date Prepared: } 28-A p r-08 \\
\text { Date Analyzed: } 29-A p r-08\end{array}$} & \multirow{2}{*}{$\begin{array}{r}\text { Prep Batch: GS080428-1 } \\
\text { QCBatchID: GS080428-1-1 } \\
\text { Run ID: GS080428-1A } \\
\text { Count Time: } 30 \text { minutes } \\
\text { Report Basis: Dry Weight }\end{array}$} & \multirow{2}{*}{\multicolumn{2}{|c|}{$\begin{array}{l}\text { Final Aliquot: } 413 \mathrm{~g} \\
\text { Prep Basis: Dry Weight } \\
\text { Moisture(\%): NA } \\
\text { Result Units: } \mathrm{pCi} / \mathrm{g} \\
\text { File Name: } 080220 \mathrm{~d} 03\end{array}$}} \\
\hline $\begin{array}{r}\text { Librar } \\
\text { Analysis ReqC }\end{array}$ & $\begin{array}{l}\text { LNG_GAM-A-001 } \\
\text { e: NGS-A-002 }\end{array}$ & & & & \\
\hline CASNO & Target Nuclide & Result +/- $2 \mathrm{~s}$ TPU & MDC & $\begin{array}{l}\text { Requested } \\
\text { MDC }\end{array}$ & Lab Qualifier \\
\hline $14331-83-0$ & Ac-228 & 8.44E-01 +/- 2.77E-01 & $5.07 E-01$ & & G \\
\hline $14596-10-2$ & Am-241 & $2.69 \mathrm{E}-01+/-7.86 \mathrm{E}-01$ & $1.33 \mathrm{E}+00$ & & U,G \\
\hline $14913-49-6$ & $\mathrm{Bi}-212$ & $1.91 E+00+/-1.08 E+00$ & $1.45 \mathrm{E}+00$ & & G,TI \\
\hline $14733-03-0$ & $\mathrm{Bi}-214$ & 9.97E-01 +/- 2.54E-01 & $2.78 \mathrm{E}-01$ & & $G, J$ \\
\hline $14762-78-8$ & $\mathrm{Ce}-144$ & $-3.53 E-01+/-4.05 E-01$ & $7.40 \mathrm{E}-01$ & & U,G \\
\hline $10198-40-0$ & Co-60 & $-6.66 \mathrm{E}-02+1-8.06 \mathrm{E}-02$ & $1.68 \mathrm{E}-01$ & & U,G \\
\hline $13967-70-9$ & Cs-134 & $1.00 \mathrm{E}-02+/-6.35 \mathrm{E}-02$ & 1.13E-01 & & U,G \\
\hline $10045-97-3$ & Cs-137 & $1.10 \mathrm{E}-01+/-8.14 \mathrm{E}-02$ & $1.23 \mathrm{E}-01$ & $1.00 E+00$ & U,G \\
\hline $14683-23-9$ & Eu-152 & $1.58 \mathrm{E}-01+/-2.75 \mathrm{E}-01$ & 4.73E-01 & & $U, G$ \\
\hline $15585-10-1$ & Eu-154 & $1.31 \mathrm{E}-01+/-3.37 \mathrm{E}-01$ & 5.97E-01 & & U,G \\
\hline $14391-16-3$ & Eu-155 & $2.58 \mathrm{E}-01+/-2.64 \mathrm{E}-01$ & $4.26 \mathrm{E}-01$ & & $U, G$ \\
\hline $13966-00-2$ & $K-40$ & $2.53 E+01+/-4.01 E+00$ & $1.42 E+00$ & & G \\
\hline $15092-94-1$ & $\mathrm{~Pb}-212$ & $9.65 \mathrm{E}-01+/-2.10 \mathrm{E}-01$ & 2.05E-01 & & G \\
\hline $15067-28-4$ & $\mathrm{~Pb}-214$ & $1.07 \mathrm{E}+00+/-2.19 \mathrm{E}-01$ & 2.31E-01 & & $G, J$ \\
\hline $14834-73-2$ & Pm-144 & $-2.15 \mathrm{E}-02+1-7.00 \mathrm{E}-02$ & $1.31 E-01$ & & U,G \\
\hline
\end{tabular}

\section{Comments:}

\footnotetext{
Qualifiers/Flags:

$U$-Result is less than the sample specific MDC or less than the associated TPU

Y1 - Chemical Yield is in control at 100-110\%. Quantitative Yield is assumed.

Y2 - Chemical Yield outside default limits.

LT - Result is less than Requested MDC, greater than sample specific MDC.

M3 - The requested MDC was not met, but the reported

activity is greater than the reported MDC.

$M$ - The requested MDC was not met.

Abbreviations:

TPU - Total Propagated Uncertainty (see PAI SOP 743)

MDC - Minimum Detectable Concentration (see PAI SOP 709)

BDL - Below Detection Limit
}

Data Package ID: GSS0804241-1

Date Printed: Tuesday, May 13, 2008 


\section{Gamma Spectroscopy Results}

\section{PAI 713 Rev 9 \\ Sample Results}

Lab Name: Paragon Analytics

Work Order Number: 0804241

Client Name: National Security Technologies, LLC

ClientProject ID: CAU 121 V3098

\begin{tabular}{|c|c|c|c|c|c|}
\hline \multicolumn{2}{|c|}{$\begin{array}{l}\text { Field ID: } 122226-1 \\
\text { Lab ID: } \quad 0804241-1\end{array}$} & \multirow{2}{*}{$\begin{array}{l}\text { Sample Matrix: SOIL } \\
\text { Prep SOP: PAI } 739 \text { Rev } 9 \\
\text { Date Collected: } 23-A p r-08 \\
\text { Date Prepared: } 28-A p r-08 \\
\text { Date Analyzed: } 29-A p r-08\end{array}$} & \multirow{2}{*}{$\begin{array}{r}\text { Prep Batch: GS080428-1 } \\
\text { QCBatchID: GS080428-1-1 } \\
\text { Run ID: GS080428-1A } \\
\text { Count Time: } 30 \text { minutes } \\
\text { Report Basis: Dry Weight }\end{array}$} & \multirow{2}{*}{\multicolumn{2}{|c|}{$\begin{array}{l}\text { Final Aliquot: } 413 \mathrm{~g} \\
\text { Prep Basis: Dry Weight } \\
\text { Moisture(\%): NA } \\
\text { Result Units: pCi } / \mathrm{g} \\
\text { File Name: } 080220 \mathrm{~d} 03\end{array}$}} \\
\hline $\begin{array}{r}\text { Libra } \\
\text { Analysis Req }\end{array}$ & $\begin{array}{l}\text { LNG_GAM-A-001 } \\
\text { e: NGS-A-002 }\end{array}$ & & & & \\
\hline CASNO & Target Nuclide & Result +/- 2 s TPU & MDC & $\begin{array}{c}\text { Requested } \\
\text { MDC }\end{array}$ & Lab Qualifier \\
\hline $14834-74-3$ & Pm-146 & $8.48 \mathrm{E}-02+/-8.09 \mathrm{E}-02$ & 1.27E-01 & & $U, G$ \\
\hline $13967-48-1$ & Ru-106 & $-2.46 \mathrm{E}-02+/-5.22 \mathrm{E}-01$ & $9.76 \mathrm{E}-01$ & & $U, G$ \\
\hline $14234-35-6$ & $\mathrm{Sb}-125$ & $-6.09 \mathrm{E}-02+/-1.71 \mathrm{E}-01$ & $3.20 \mathrm{E}-01$ & & $\cup, G$ \\
\hline $15065-10-8$ & Th-234 & $1.51 E+00+/-1.07 E+00$ & $1.65 \mathrm{E}+00$ & & U,G \\
\hline $14913-50-9$ & TI-208 & $3.24 \mathrm{E}-01+/-1.08 \mathrm{E}-01$ & 1.30E-01 & & G \\
\hline $15117-96-1$ & U-235 & 1.82E-01+/-4.32E-01 & $7.28 \mathrm{E}-01$ & & U,G \\
\hline $13982-36-0$ & $Y-88$ & $-5.97 \mathrm{E}-03+/-8.17 \mathrm{E}-02$ & $1.52 E-01$ & & U,G \\
\hline
\end{tabular}

\section{Comments:}

\footnotetext{
Qualifiers/Flags:

$U$ - Result is less than the sample specific MDC or less than the associated TPU

$Y_{1}$ - Chemical Yield is in control at 100-110\%. Quantitative Yield is assumed.

Y2 - Chemical Yield outside default limits.

LT - Result is less than Requested MDC, greater than sample specific MDC.

M3 - The requested MDC was not met, but the reported

activity is greater than the reported MDC

$M$ - The requested MDC was not met.
}

Abbreviations:

TPU - Total Propagated Uncertainty (see PAI SOP 743)

MDC - Minimum Detectable Concentration (see PAI SOP 709)

BDL - Below Detection Limit

\section{Data Package ID: GSS0804241-1}




\title{
Gamma Spectroscopy Results
}

\author{
PAI 713 Rev 9 \\ Sample Results
}

Lab Name: Paragon Analytics

Work Order Number: 0804241

Client Name: National Security Technologies, LLC

ClientProject ID: CAU 121 V3098

\begin{tabular}{|c|c|c|c|c|c|}
\hline \multicolumn{2}{|c|}{ 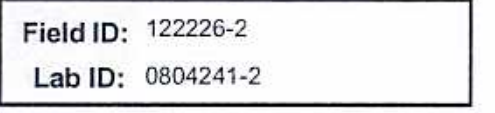 } & $\begin{array}{l}\text { Sample Matrix: SOIL } \\
\text { Prep SOP: PAI } 739 \text { Rev } 9 \\
\text { Date Collected: } 23-A p r-08 \\
\text { Date Prepared: } 28-A p r-08 \\
\text { Date Analyzed: } 29-A p r-08\end{array}$ & $\begin{array}{l}\text { Prep Batch: GS080428-1 } \\
\text { QCBatchID: GS080428-1-1 } \\
\text { Run ID: GS080428-1A } \\
\text { Count Time: } 30 \text { minutes } \\
\text { Report Basis: Dry Weight }\end{array}$ & \multicolumn{2}{|c|}{$\begin{array}{l}\text { Final Aliquot: } 388 \mathrm{~g} \\
\text { Prep Basis: Dry Weight } \\
\text { Moisture(\%): NA } \\
\text { Result Units: } \mathrm{pCi} / \mathrm{g} \\
\text { File Name: } 080222 \mathrm{~d} 03\end{array}$} \\
\hline CASNO & Target Nuclide & Result +/- 2 s TPU & MDC & $\begin{array}{c}\text { Requested } \\
\text { MDC }\end{array}$ & Lab Qualifier \\
\hline $14331-83-0$ & Ac-228 & $9.18 \mathrm{E}-01+/-3.55 \mathrm{E}-01$ & $6.61 \mathrm{E}-01$ & & $\mathrm{G}, \mathrm{TI}$ \\
\hline $14596-10-2$ & Am-241 & $-8.44 \mathrm{E}-02+/-7.52 \mathrm{E}-01$ & $1.32 \mathrm{E}+00$ & & $U, G$ \\
\hline $14913-49-6$ & $\mathrm{Bi}-212$ & $2.68 \mathrm{E}+00+/-1.23 \mathrm{E}+00$ & $1.50 \mathrm{E}+00$ & & $\mathrm{G}, \mathrm{TI}$ \\
\hline $14733-03-0$ & $\mathrm{Bi}-214$ & $1.08 \mathrm{E}+00+/-2.65 \mathrm{E}-01$ & 2.32E-01 & & $G, J$ \\
\hline $14762-78-8$ & $\mathrm{Ce}-144$ & $3.75 E-02+/-3.82 E-01$ & $6.64 E-01$ & & $U, G$ \\
\hline $10198-40-0$ & Co-60 & $-4.61 \mathrm{E}-02+/-7.77 \mathrm{E}-02$ & $1.61 \mathrm{E}-01$ & & $U, G$ \\
\hline $13967-70-9$ & Cs-134 & $4.10 \mathrm{E}-02+/-6.29 \mathrm{E}-02$ & $1.05 \mathrm{E}-01$ & & $U, G$ \\
\hline $10045-97-3$ & Cs-137 & $-5.72 \mathrm{E}-02+/-7.16 \mathrm{E}-02$ & 1.44E-01 & 1.00E+00 & $U, G$ \\
\hline $14683-23-9$ & Eu-152 & $2.28 \mathrm{E}-01+/-3.78 \mathrm{E}-01$ & $6.41 \mathrm{E}-01$ & & $U, G$ \\
\hline $15585-10-1$ & Eu-154 & $2.14 \mathrm{E}-01+/-4.02 \mathrm{E}-01$ & $6.90 \mathrm{E}-01$ & & U,G \\
\hline $14391-16-3$ & Eu-155 & 1.38E-01+/-2.61E-01 & 4.36E-01 & & U.G \\
\hline $13966-00-2$ & $\mathrm{~K}-40$ & $2.68 \mathrm{E}+01+/-4.26 \mathrm{E}+00$ & $1.50 \mathrm{E}+00$ & & G \\
\hline $15092-94-1$ & $\mathrm{~Pb}-212$ & $8.97 \mathrm{E}-01+/-2.01 \mathrm{E}-01$ & 1.93E-01 & & G \\
\hline $15067-28-4$ & $\mathrm{~Pb}-214$ & $9.95 \mathrm{E}-01+/-2.16 \mathrm{E}-01$ & $2.46 \mathrm{E}-01$ & & $\mathrm{G}, \mathrm{J}$ \\
\hline $14834-73-2$ & $P m-144$ & $-5.10 \mathrm{E}-02+/-6.83 \mathrm{E}-02$ & 1.36E-01 & & U.G \\
\hline
\end{tabular}

\section{Comments:}

\begin{tabular}{ll}
\hline Qualifiers/Flags: & SQ-Spectral quality prevents accurate quantitation. \\
U - Result is less than the sample specific MDC or less than the associated TPU & SI - Nuclide identification and/or quantitation is tentative. \\
Y1 - Chemical Yield is in control at 100-110\%. Quantitative Yield is assumed. & TI - Nuclide identification is tentative. \\
Y2 - Chemical Yield outside default limits. & R - Nuclide has exceeded 8 halflives, \\
LT - Result is less than Requested MDC, greater than sample specific MDC. & G - Sample density differs by more than $15 \%$ of LCS density. \\
M3 - The requested MDC was not met, but the reported & activity is greater than the reported MDC.
\end{tabular}

$M$ - The requested MDC was not met.

Abbreviations:

TPU - Total Propagated Uncertainty (see PAI SOP 743)

MDC - Minimum Detectable Concentration (see PAI SOP 709)

BDL - Below Detection Limit

Data Package ID: GSS0804241-1

Date Printed: Tuesday, May 13, 2008 


\title{
Gamma Spectroscopy Results
}

\author{
PAI 713 Rev 9 \\ Sample Results
}

Lab Name: Paragon Analytics

Work Order Number: 0804241

Client Name: National Security Technologies, LLC

ClientProject ID: CAU $121 \mathrm{~V} 3098$

\begin{tabular}{|c|c|c|c|c|c|}
\hline \multicolumn{2}{|c|}{$\begin{aligned} \text { Field ID: } & 122226-2 \\
\text { Lab ID: } & 0804241-2\end{aligned}$} & \multirow{2}{*}{$\begin{array}{l}\text { Sample Matrix: SOIL } \\
\text { Prep SOP: PAI } 739 \text { Rev } 9 \\
\text { Date Collected: } 23-A p r-08 \\
\text { Date Prepared: } 28-A p r-08 \\
\text { Date Analyzed: } 29-A p r-08\end{array}$} & \multirow{2}{*}{$\begin{array}{l}\text { Prep Batch: GS080428-1 } \\
\text { QCBatchID: GS080428-1-1 } \\
\text { Run ID: GS080428-1A } \\
\text { Count Time: } 30 \text { minutes } \\
\text { Report Basis: Dry Weight }\end{array}$} & \multirow{2}{*}{\multicolumn{2}{|c|}{$\begin{array}{l}\text { Final Aliquot: } 388 \mathrm{~g} \\
\text { Prep Basis: Dry Weight } \\
\text { Moisture(\%): NA } \\
\text { Result Units: } \mathrm{pCi} / \mathrm{g} \\
\text { File Name: } 080222 \mathrm{~d} 03\end{array}$}} \\
\hline $\begin{array}{r}\text { Libra } \\
\text { Analysis Req }\end{array}$ & $\begin{array}{l}\text { LNG_GAM-A-001 } \\
\text { e: NGS-A-002 }\end{array}$ & & & & \\
\hline CASNO & Target Nuclide & Result +/- 2 s TPU & MDC & $\begin{array}{c}\text { Requested } \\
\text { MDC }\end{array}$ & Lab Qualifier \\
\hline $14834-74-3$ & $\mathrm{Pm}-146$ & $6.35 \mathrm{E}-02+/-8.38 \mathrm{E}-02$ & $1.38 \mathrm{E}-01$ & & $U, G$ \\
\hline $13967-48-1$ & $\mathrm{Ru}-106$ & $1.35 \mathrm{E}-01+/-5.45 \mathrm{E}-01$ & 9.77E-01 & & U,G \\
\hline $14234-35-6$ & Sb-125 & $-1.23 \mathrm{E}-01+/-1.84 \mathrm{E}-01$ & $3.54 \mathrm{E}-01$ & & U,G \\
\hline $15065-10-8$ & Th-234 & 3.27E-01+/-1.52E +00 & $2.59 E+00$ & & U,G \\
\hline $14913-50-9$ & TI-208 & $2.94 \mathrm{E}-01+/-1.08 \mathrm{E}-01$ & $1.28 \mathrm{E}-01$ & & G \\
\hline $15117-96-1$ & U-235 & 1.10E-01 +/- 4.13E-01 & 7.06E-01 & & $U, G$ \\
\hline $13982-36-0$ & $Y-88$ & $-1.06 \mathrm{E}-02+/-7.99 \mathrm{E}-02$ & $1.51 \mathrm{E}-01$ & & $U, G$ \\
\hline
\end{tabular}

\section{Comments:}

\footnotetext{
Qualifiers/Flags:

$U$-Result is less than the sample specific MDC or less than the associated TPU

SQ - Spectral quality prevents accurate quantitation.

Y1 - Chemical Yield is in control at 100-110\%. Quantitative Yield is assumed,

$\mathrm{SI}$ - Nuclide identification and/or quantitation is tentative.

Y2 - Chemical Yield outside default limits

$\mathrm{T}$ - Nuclide identification is tentative.

LT - Result is less than Requested MDC, greater than sample specific MDC.

$\mathrm{R}$ - Nuclide has exceeded 8 halfilives.

M3 - The requested MDC was not met, but the reported activity is greater than the reported MDC.

G. Sample density differs by more than $15 \%$ of LCS density.

$M$ - The requested $M D C$ was not met.

Abbreviations:

TPU - Total Propagated Uncertainty (see PAI SOP 743)

MDC - Minimum Detectable Concentration (see PAI SOP 709)

$\mathrm{BDL}$ - Below Detection Limit
}

Data Package ID: GSS0804241-1

Date Printed: Tuesday, May 13, 2008 


\section{Gamma Spectroscopy Results}

\section{PAl 713 Rev 9 \\ Sample Results}

Lab Name: Paragon Analytics

Work Order Number: 0804241

Client Name: National Security Technologies, LLC

ClientProject ID: CAU $121 \mathrm{~V} 3098$

\begin{tabular}{|c|c|c|c|c|c|}
\hline \multicolumn{2}{|c|}{$\begin{array}{l}\text { Field ID: } 122226-3 \\
\text { Lab ID: } 0804241-3\end{array}$} & \multirow{3}{*}{$\begin{array}{l}\text { Sample Matrix: SOIL } \\
\quad \text { Prep SOP: PAI } 739 \text { Rev } 9 \\
\text { Date Collected: } 23-A p r-08 \\
\text { Date Prepared: } 28-A p r-08 \\
\text { Date Analyzed: } 29-A p r-08\end{array}$} & \multirow{3}{*}{$\begin{array}{r}\text { Prep Batch: GS080428-1 } \\
\text { QCBatchID: GS080428-1-1 } \\
\text { Run ID: GS080428-1A } \\
\text { Count Time: } 30 \text { minutes } \\
\text { Report Basis: Dry Weight }\end{array}$} & \multirow{3}{*}{\multicolumn{2}{|c|}{$\begin{array}{l}\text { Final Aliquot: } 407 \mathrm{~g} \\
\text { Prep Basis: Dry Weight } \\
\text { Moisture(\%): NA } \\
\text { Result Units: } p \mathrm{Ci} / \mathrm{g} \\
\text { File Name: } 080223 \mathrm{~d} 03\end{array}$}} \\
\hline \multirow{2}{*}{\multicolumn{2}{|c|}{$\begin{array}{l}\text { Library: LNG_GAM-A-001 } \\
\text { Analysis ReqCode: NGS-A-002 }\end{array}$}} & & & & \\
\hline & & & & & \\
\hline CASNO & Target Nuclide & Result +/- $2 \mathrm{~s}$ TPU & MDC & $\begin{array}{l}\text { Requested } \\
\text { MDC }\end{array}$ & Lab Qualifier \\
\hline $14331-83-0$ & Ac-228 & $8.73 \mathrm{E}-01+/-2.82 \mathrm{E}-01$ & $5.02 E-01$ & & G \\
\hline $14596-10-2$ & Am-241 & $-5.64 \mathrm{E}-01+/-8.02 \mathrm{E}-01$ & $1.45 E+00$ & & U,G \\
\hline $14733-03-0$ & $\mathrm{Bi}-214$ & 8.12E-01+/- 2.39E-01 & $2.56 \mathrm{E}-01$ & & $\mathrm{G}, \mathrm{J}$ \\
\hline $14762-78-8$ & $\mathrm{Ce}-144$ & $-2.27 E-01+/-4.15 E-01$ & 7.46E-01 & & U,G \\
\hline $10198-40-0$ & Co-60 & $-6.64 \mathrm{E}-02+1-7.62 \mathrm{E}-02$ & 1.63E-01 & & U,G \\
\hline $13967-70-9$ & Cs-134 & $4.07 \mathrm{E}-03+/-5.89 \mathrm{E}-02$ & $1.07 \mathrm{E}-01$ & & $U, G$ \\
\hline $10045-97-3$ & Cs-137 & $-2.98 \mathrm{E}-02+1-7.82 \mathrm{E}-02$ & $1.48 \mathrm{E}-01$ & $1.00 E+00$ & U,G \\
\hline $14683-23-9$ & Eu-152 & $2.59 \mathrm{E}-01+/-3.37 \mathrm{E}-01$ & $5.50 \mathrm{E}-01$ & & U,G \\
\hline $15585-10-1$ & Eu-154 & $2.65 \mathrm{E}-02+1-4.00 \mathrm{E}-01$ & 7.37E-01 & & U,G \\
\hline $14391-16-3$ & Eu-155 & 1.41E-01+/- 2.40E-01 & $4.00 \mathrm{E}-01$ & & $U, G$ \\
\hline $13966-00-2$ & $K-40$ & $2.41 E+01+/-3.88 E+00$ & $1.34 E+00$ & & G \\
\hline $15092-94-1$ & $\mathrm{~Pb}-212$ & $8.72 \mathrm{E}-01+/-2.07 \mathrm{E}-01$ & 2.21E-01 & & G \\
\hline $15067-28-4$ & $\mathrm{~Pb}-214$ & $1.01 \mathrm{E}+00+/-2.14 \mathrm{E}-01$ & $2.40 E-01$ & & $\mathrm{G}, \mathrm{J}$ \\
\hline $14834-73-2$ & $\mathrm{Pm}-144$ & $-4.42 \mathrm{E}-02+/-7.05 \mathrm{E}-02$ & $1.37 \mathrm{E}-01$ & & U.G \\
\hline $14834-74-3$ & $\mathrm{Pm}-146$ & $5.32 \mathrm{E}-02+/-8.47 \mathrm{E}-02$ & $1.42 E-01$ & & U,G \\
\hline
\end{tabular}

\section{Comments:}

\footnotetext{
Qualifiers/Flags:

$U$ - Result is less than the sample specific MDC or less than the associated TPU

$Y_{1}$ - Chemical Yieid is in control at 100-110\%. Quantitative Yield is assumed.

Y2 - Chemical Yield outside default limits.

LT - Result is less than Requested MDC, greater than sample specific MDC.

M3 - The requested MDC was not met, but the reported

activity is greater than the reported MDC

$M$ - The requested MDC was not met.

Abbrevations:

TPU - Total Propagated Uncertainty (see PAI SOP 743)

MDC - Minimum Detectable Concentration (see PAI SOP 709)

BDL - Below Detection Limit
}

Data Package ID: GSS0804241-1 


\title{
Gamma Spectroscopy Results
}

\author{
PAl 713 Rev 9 \\ Sample Results
}

Lab Name: Paragon Analytics

Work Order Number: 0804241

Client Name: National Security Technologies, LLC

ClientProject ID: CAU $121 \mathrm{~V} 3098$

\begin{tabular}{|c|c|c|c|c|c|}
\hline \multicolumn{2}{|c|}{$\begin{array}{l}\text { Field ID: } 122226-3 \\
\text { Lab ID: } 0804241-3 \\
\end{array}$} & \multirow{3}{*}{$\begin{array}{l}\text { Sample Matrix: SOIL } \\
\quad \text { Prep SOP: PAI } 739 \text { Rev } 9 \\
\text { Date Collected: } 23-A p r-08 \\
\text { Date Prepared: } 28-A p r-08 \\
\text { Date Analyzed: } 29-A p r-08\end{array}$} & \multirow{3}{*}{$\begin{array}{r}\text { Prep Batch: GS080428-1 } \\
\text { QCBatchID: GS080428-1-1 } \\
\text { Run ID: GS080428-1A } \\
\text { Count Time: } 30 \text { minutes } \\
\text { Report Basis: Dry Weight }\end{array}$} & \multirow{3}{*}{\multicolumn{2}{|c|}{$\begin{array}{l}\text { Final Aliquot: } 407 \mathrm{~g} \\
\text { Prep Basis: Dry Weight } \\
\text { Moisture(\%): NA } \\
\text { Result Units: } p \mathrm{Ci} / \mathrm{g} \\
\text { File Name: } 080223 \mathrm{~d} 03\end{array}$}} \\
\hline \multirow{2}{*}{\multicolumn{2}{|c|}{$\begin{array}{l}\text { Library: LNG_GAM-A-001 } \\
\text { Analysis ReqCode: NGS-A-002 }\end{array}$}} & & & & \\
\hline & & & & & \\
\hline CASNO & Target Nuclide & Result $+/-2$ s TPU & MDC & $\begin{array}{l}\text { Requested } \\
\text { MDC }\end{array}$ & Lab Qualifier \\
\hline $13967-48-1$ & Ru-106 & 3.33E-02 +/- 5.81E-01 & $1.06 \mathrm{E}+00$ & & U,G \\
\hline $14234-35-6$ & Sb-125 & 1.36E-01+/-1.90E-01 & $3.15 E-01$ & & $U, G$ \\
\hline $15065-10-8$ & Th-234 & 1.14E+00 +/-1.54E+00 & $2.54 \mathrm{E}+00$ & & U,G \\
\hline $14913-50-9$ & TI-208 & $2.92 \mathrm{E}-01+/-9.39 \mathrm{E}-02$ & $9.24 \mathrm{E}-02$ & & G \\
\hline $15117-96-1$ & $U-235$ & $3.04 \mathrm{E}-01+/-4.13 \mathrm{E}-01$ & $6.79 E-01$ & & $U, G$ \\
\hline $13982-36-0$ & $Y-88$ & $-4.30 \mathrm{E}-02+/-8.36 \mathrm{E}-02$ & 1.63E-01 & & $U, G$ \\
\hline
\end{tabular}

\section{Comments:}

\footnotetext{
Qualifiers/Flags:

$U$ - Result is less than the sample specific MDC or less than the associated TPU

$\mathrm{Y}_{1}$ - Chemical Yield is in control at $100-110 \%$. Quantitative Yield is assumed.

Y2 - Chemical Yield outside default limits.

LT - Result is less than Requested MDC, greater than sample specific MDC.

M3 - The requested MDC was not met, but the reported activity is greater than the reported MDC.

$M$ - The requested $M D C$ was not met.

Abbreviations:

TPU - Total Propagated Uncertainty (see PAI SOP 743)

MDC - Minimum Detectable Concentration (see PAI SOP 709)

$\mathrm{BDL}$ - Below Detection Limit
}

Data Package ID: GSS0804241-1 


\title{
Gamma Spectroscopy Results
}

\author{
PAI 713 Rev 9 \\ Sample Results
}

Lab Name: Paragon Analytics

Work Order Number: 0804241

Client Name: National Security Technologies, LLC

ClientProject ID: CAU 121 V3098

\begin{tabular}{|c|c|c|c|c|c|}
\hline \multicolumn{2}{|c|}{$\begin{array}{l}\text { Field ID: } 122226-4 \\
\text { Lab ID: } \quad 0804241-4 \\
\end{array}$} & $\begin{array}{l}\text { Sample Matrix: SOIL } \\
\quad \text { Prep SOP: PAI } 739 \text { Rev } 9 \\
\text { Date Collected: } 23-A p r-08 \\
\text { Date Prepared: } 28-A p r-08 \\
\text { Date Analyzed: } 29-A p r-08\end{array}$ & $\begin{array}{l}\text { Prep Batch: GS080428-1 } \\
\text { QCBatchID: GS080428-1-1 } \\
\text { Run ID: GS080428-1A } \\
\text { Count Time: } 30 \text { minutes } \\
\text { Report Basis: Dry Weight }\end{array}$ & \multicolumn{2}{|c|}{$\begin{array}{l}\text { Final Aliquot: } 392 \mathrm{~g} \\
\text { Prep Basis: Dry Weight } \\
\text { Moisture(\%): NA } \\
\text { Result Units: pCi/g } \\
\text { File Name: } 080772 \mathrm{~d} 06\end{array}$} \\
\hline CASNO & Target Nuclide & Result +/- $2 \mathrm{~s}$ TPU & MDC & $\begin{array}{c}\text { Requested } \\
\text { MDC }\end{array}$ & Lab Qualifier \\
\hline $14331-83-0$ & Ac-228 & $1.01 \mathrm{E}+00+1-3.21 \mathrm{E}-01$ & $5.92 \mathrm{E}-01$ & & G \\
\hline $14596-10-2$ & $A m-241$ & $3.74 \mathrm{E}-01+/-1.23 \mathrm{E}+00$ & $2.11 \mathrm{E}+00$ & & U,G \\
\hline $14733-03-0$ & $\mathrm{Bi}-214$ & $8.49 \mathrm{E}-01+/-2.30 \mathrm{E}-01$ & $2.45 \mathrm{E}-01$ & & $\mathrm{G}, \mathrm{J}$ \\
\hline $14762-78-8$ & $\mathrm{Ce}-144$ & $2.17 \mathrm{E}-01+/-4.19 \mathrm{E}-01$ & 7.04E-01 & & $U, G$ \\
\hline $10198-40-0$ & Co-60 & $2.38 \mathrm{E}-02+/-7.62 \mathrm{E}-02$ & 1.38E-01 & & U,G \\
\hline $13967-70-9$ & Cs-134 & $-1.84 \mathrm{E}-02+/-6.58 \mathrm{E}-02$ & $1.24 \mathrm{E}-01$ & & U,G \\
\hline $10045-97-3$ & Cs-137 & $4.85 \mathrm{E}-01+/-1.35 \mathrm{E}-01$ & 1.27E-01 & $1.00 E+00$ & LT,G \\
\hline $14683-23-9$ & Eu-152 & $-1.18 \mathrm{E}-01+/-3.44 \mathrm{E}-01$ & 7.14E-01 & & U,G \\
\hline $15585-10-1$ & Eu-154 & $-5.11 \mathrm{E}-01+/-4.67 \mathrm{E}-01$ & $9.76 \mathrm{E}-01$ & & U,G \\
\hline $14391-16-3$ & Eu-155 & $8.96 \mathrm{E}-02+/-2.90 \mathrm{E}-01$ & 4.96E-01 & & U,G \\
\hline $13966-00-2$ & $\mathrm{~K}-40$ & $2.50 E+01+/-4.13 E+00$ & $1.71 \mathrm{E}+00$ & & $\mathrm{G}$ \\
\hline $15092-94-1$ & $\mathrm{~Pb}-212$ & $1.19 E+00+/-2.45 E-01$ & $2.28 \mathrm{E}-01$ & & $G$ \\
\hline $15067-28-4$ & $\mathrm{~Pb}-214$ & $7.40 \mathrm{E}-01+/-1.84 \mathrm{E}-01$ & $2.26 \mathrm{E}-01$ & & $G, J$ \\
\hline $14834-73-2$ & $\mathrm{Pm}-144$ & $-4.93 \mathrm{E}-02+1-6.95 \mathrm{E}-02$ & $1.38 \mathrm{E}-01$ & & U,G \\
\hline $14834-74-3$ & Pm-146 & 1.54E-02 +/- 7.36E-02 & $1.31 \mathrm{E}-01$ & & $U, G$ \\
\hline
\end{tabular}

\section{Comments:}

\footnotetext{
Qualifiers/Flags:

$U$ - Result is less than the sample specific MDC or less than the associated TPU

$\mathrm{Y}_{1}$ - Chemical Yield is in control at 100-110\%. Quantitative Yield is assumed.

Y2 - Chemical Yield outside default limits.

$L T$ - Result is less than Requested MDC, greater than sample specific MDC.

M3 - The requested MDC was not met, but the reported

activity is greater than the reported MDC.

$M$ - The requested $M D C$ was not met.
}

Abbreviations:

TPU - Total Propagated Uncertainty (see PAI SOP 743)

MDC - Minimum Detectable Concentration (see PAI SOP 709)

BDL - Below Detection Limit

Data Package ID: GSS0804241-1 


\title{
Gamma Spectroscopy Results
}

\author{
PAI 713 Rev 9 \\ Sample Results
}

Lab Name: Paragon Analytics

Work Order Number: 0804241

Client Name: National Security Technologies, LLC

ClientProject ID: CAU 121 V3098

\begin{tabular}{|c|c|c|c|c|c|}
\hline \multicolumn{2}{|c|}{$\begin{array}{l}\text { Field ID: } 122226-4 \\
\text { Lab ID: } 0804241-4\end{array}$} & \multirow{2}{*}{$\begin{array}{l}\text { Sample Matrix: SOIL } \\
\text { Prep SOP: PAI } 739 \text { Rev } 9 \\
\text { Date Collected: } 23-A p r-08 \\
\text { Date Prepared: } 28-A p r-08 \\
\text { Date Analyzed: } 29-A p r-08\end{array}$} & \multirow{2}{*}{$\begin{array}{l}\text { Prep Batch: GS080428-1 } \\
\text { QCBatchID: GS080428-1-1 } \\
\text { Run ID: GS080428-1A } \\
\text { Count Time: } 30 \text { minutes } \\
\text { Report Basis: Dry Weight }\end{array}$} & \multirow{2}{*}{\multicolumn{2}{|c|}{$\begin{array}{l}\text { Final Aliquot: } 392 \mathrm{~g} \\
\text { Prep Basis: Dry Weight } \\
\text { Moisture(\%): NA } \\
\text { Result Units: pCi/g } \\
\text { File Name: } 080772 \mathrm{~d} 06\end{array}$}} \\
\hline $\begin{array}{l}\text { Libra } \\
\text { Analysis Req }\end{array}$ & LNG_GAM-A-001 & & & & \\
\hline CASNO & Target Nuclide & Result +/- 2 s TPU & MDC & $\begin{array}{c}\text { Requested } \\
\text { MDC }\end{array}$ & Lab Qualifier \\
\hline $13967-48-1$ & Ru-106 & $-2.77 \mathrm{E}-01+/-7.67 \mathrm{E}-01$ & $1.43 E+00$ & & U,G \\
\hline $14234-35-6$ & Sb-125 & $-2.14 \mathrm{E}-02+/-1.68 \mathrm{E}-01$ & $3.10 \mathrm{E}-01$ & & U.G \\
\hline $15065-10-8$ & Th-234 & $-7.42 \mathrm{E}-01+/-1.76 \mathrm{E}+00$ & $3.12 \mathrm{E}+00$ & & U.G \\
\hline $14913-50-9$ & TI-208 & $3.40 \mathrm{E}-01+/-1.16 \mathrm{E}-01$ & 1.33E-01 & & G \\
\hline $15117-96-1$ & $U-235$ & $0 \mathrm{E}+00+/-4.05 \mathrm{E}-01$ & 7.11E-01 & & U,G \\
\hline $13982-36-0$ & $Y-88$ & $-4.51 \mathrm{E}-02+/-8.47 \mathrm{E}-02$ & 1.67E-01 & & U,G \\
\hline
\end{tabular}

\section{Comments:}

\footnotetext{
Qualifiers/Flags:

$U$ - Result is less than the sample specific MDC or less than the associated TPU

$\mathrm{Y}_{1}$ - Chemical Yield is in control at 100-110\%. Quantitative Yield is assumed.

Y2 - Chemical Yield outside default limits.

LT - Result is less than Requested MDC, greater than sample specific MDC.

M3 - The requested MDC was not met, but the reported activity is greater than the reported MDC.

$M$ - The requested MDC was not met.

Abbreviations:

TPU - Total Propagated Uncertainty (see PAI SOP 743)

MDC - Minimum Detectable Concentration (see PAI SOP 7C9)

BDL - Below Detection Limit
}

SQ-Spectral quality prevents accurate quantitation.

Data Package ID: GSS0804241-1 


\title{
Gamma Spectroscopy Results
}

\author{
PAI 713 Rev 9 \\ Sample Results
}

Lab Name: Paragon Analytics

Work Order Number: 0804241

Client Name: National Security Technologies, LLC

ClientProject ID: CAU 121 V3098

\begin{tabular}{|c|c|c|c|c|c|}
\hline \multicolumn{2}{|c|}{$\begin{array}{l}\text { Field ID: } 122226-5 \\
\text { Lab ID: } 0804241-5\end{array}$} & $\begin{array}{l}\text { Sample Matrix: SOIL } \\
\text { Prep SOP: PAI } 739 \text { Rev } 9 \\
\text { Date Collected: } 23-A p r-08 \\
\text { Date Prepared: } 28-A p r-08 \\
\text { Date Analyzed: } 29-A p r-08\end{array}$ & $\begin{array}{r}\text { Prep Batch: GS080428-1 } \\
\text { QCBatchID: GS080428-1-1 } \\
\text { Run ID: GS080428-1A } \\
\text { Count Time: } 30 \text { minutes } \\
\text { Report Basis: Dry Weight }\end{array}$ & \multicolumn{2}{|c|}{$\begin{array}{l}\text { Final Aliquot: } 378 \mathrm{~g} \\
\text { Prep Basis: Dry Weight } \\
\text { Moisture(\%): NA } \\
\text { Result Units: } p C i / g \\
\text { File Name: } 080892 \mathrm{~d} 08\end{array}$} \\
\hline CASNO & Target Nuclide & Result +/- 2 s TPU & MDC & $\begin{array}{c}\text { Requested } \\
\text { MDC }\end{array}$ & Lab Qualifier \\
\hline $14331-83-0$ & Ac-228 & $9.93 E-01+/-2.87 E-01$ & $3.78 \mathrm{E}-01$ & & G \\
\hline $14596-10-2$ & Am-241 & 1.16E-02 +/- 1.21E-01 & 2.11E-01 & & $U, G$ \\
\hline $14913-49-6$ & $\mathrm{Bi}-212$ & $1.81 \mathrm{E}+00+/-9.62 \mathrm{E}-01$ & $1.19 E+00$ & & G \\
\hline $14733-03-0$ & $\mathrm{Bi}-214$ & $9.60 \mathrm{E}-01+/-2.43 \mathrm{E}-01$ & 2.07E-01 & & $G, J$ \\
\hline $14762-78-8$ & $\mathrm{Ce}-144$ & $2.98 \mathrm{E}-02+/-3.16 \mathrm{E}-01$ & 5.53E-01 & & U,G \\
\hline $10198-40-0$ & Co-60 & $3.06 \mathrm{E}-02+/-7.81 \mathrm{E}-02$ & 1.39E-01 & & $U, G$ \\
\hline $13967-70-9$ & Cs-134 & $0 E+00+/-5.86 E-02$ & $1.08 \mathrm{E}-01$ & & U,G \\
\hline $10045-97-3$ & Cs-137 & $2.12 \mathrm{E}-01+/-1.01 \mathrm{E}-01$ & $1.32 \mathrm{E}-01$ & $1.00 E+00$ & LT,G \\
\hline $14683-23-9$ & Eu-152 & 7.59E-02 +/- 3.04E-01 & $5.70 \mathrm{E}-01$ & & U,G \\
\hline $15585-10-1$ & Eu-154 & $3.41 \mathrm{E}-02+/-3.27 \mathrm{E}-01$ & $6.19 \mathrm{E}-01$ & & U,G \\
\hline $14391-16-3$ & Eu-155 & $1.36 \mathrm{E}-01+/-1.50 \mathrm{E}-01$ & $2.43 \mathrm{E}-01$ & & U,G \\
\hline $13966-00-2$ & $\mathrm{~K}-40$ & $2.78 E+01+/-4.41 E+00$ & $1.50 \mathrm{E}+00$ & & G \\
\hline $15092-94-1$ & $\mathrm{~Pb}-212$ & $8.93 \mathrm{E}-01+/-1.82 \mathrm{E}-01$ & $1.51 \mathrm{E}-01$ & & G \\
\hline $15067-28-4$ & $\mathrm{~Pb}-214$ & $1.13 \mathrm{E}+00+/-2.19 \mathrm{E}-01$ & 2.34E-01 & & G,J \\
\hline $14834-73-2$ & Pm-144 & $3.76 \mathrm{E}-02+/-6.10 \mathrm{E}-02$ & $1.03 \mathrm{E}-01$ & & U.G \\
\hline
\end{tabular}

\section{Comments:}

\footnotetext{
Qualifiers/Flags:

$U$ - Result is less than the sample specific MDC or less than the associated TPU

Y1 - Chemical Yield is in control at $100-110 \%$. Quantitative Yield is assumed.

Y2 - Chemical Yield outside default limits.

LT - Result is less than Requested MDC, greater than sample specific MDC.

M3 - The requested MDC was not met, but the reported activity is greater than the reported MDC.

$M$ - The requested MDC was not met.

Abbreviations:

TPU - Total Propagated Uncertainty (see PAI SOP 743)

MDC - Minimum Detectable Concentration (see PAI SOP 709)

BDL - Below Detection Limit
}

Data Package ID: GSS0804241-1 


\title{
Gamma Spectroscopy Results
}

\author{
PAI 713 Rev 9 \\ Sample Results
}

Lab Name: Paragon Analytics

Work Order Number: 0804241

Client Name: National Security Technologies, LLC

ClientProject ID: CAU 121 V3098

\begin{tabular}{|c|c|c|c|c|c|}
\hline \multicolumn{2}{|c|}{$\begin{array}{l}\text { Field ID: } 122226-5 \\
\text { Lab ID: } 0804241-5\end{array}$} & \multirow{2}{*}{$\begin{array}{l}\text { Sample Matrix: SOIL } \\
\text { Prep SOP: PAI } 739 \text { Rev } 9 \\
\text { Date Collected: } 23-A p r-08 \\
\text { Date Prepared: } 28-A p r-08 \\
\text { Date Analyzed: } 29-A p r-08\end{array}$} & \multirow{2}{*}{$\begin{array}{r}\text { Prep Batch: GS080428-1 } \\
\text { QCBatchID: GS080428-1-1 } \\
\text { Run ID: GS080428-1A } \\
\text { Count Time: } 30 \text { minutes } \\
\text { Report Basis: Dry Weight }\end{array}$} & \multirow{2}{*}{\multicolumn{2}{|c|}{$\begin{array}{l}\text { Final Aliquot: } 378 \mathrm{~g} \\
\text { Prep Basis: Dry Weight } \\
\text { Moisture(\%): NA } \\
\text { Result Units: } \mathrm{pCi} / \mathrm{g} \\
\text { File Name: } 080892 \mathrm{~d} 08\end{array}$}} \\
\hline \multicolumn{2}{|c|}{$\begin{array}{l}\text { Library: LNG_GAM-A-001 } \\
\text { Analysis ReqCode: NGS-A-002 }\end{array}$} & & & & \\
\hline CASNO & Target Nuclide & Result +/- 2 s TPU & MDC & $\begin{array}{c}\text { Requested } \\
\text { MDC }\end{array}$ & Lab Qualifier \\
\hline $14834-74-3$ & Pm-146 & 3.93E-02 +1- $6.41 \mathrm{E}-02$ & $1.08 \mathrm{E}-01$ & & U,G \\
\hline $13967-48-1$ & Ru-106 & 1.30E-01 +/- 5.54E-01 & $9.95 E-01$ & & $U, G$ \\
\hline $14234-35-6$ & Sb-125 & 1.54E-01 +/- 1.44E-01 & 2.24E-01 & & $U, G$ \\
\hline $15065-10-8$ & Th-234 & 1.36E+00 +/- 7.71E-01 & $1.45 \mathrm{E}+00$ & & U,G \\
\hline $14913-50-9$ & TH-208 & $3.08 \mathrm{E}-01+/-1.10 \mathrm{E}-01$ & $1.28 \mathrm{E}-01$ & & $G$ \\
\hline $15117-96-1$ & U-235 & $6.13 \mathrm{E}-02+/-3.27 \mathrm{E}-01$ & 5.67E-01 & & $U, G$ \\
\hline $13982-36-0$ & $Y-88$ & $-5.01 \mathrm{E}-02+/-7.32 \mathrm{E}-02$ & $1.50 \mathrm{E}-01$ & & U,G \\
\hline
\end{tabular}

\section{Comments:}

Qualifiers/Flags:

$U$ - Result is less than the sample specific MDC or less than the associated TPU

Y1 - Chemical Yield is in control at 100-110\%. Quantitative Yield is assumed.

Y2 - Chemical Yield outside default limits.

LT - Result is less than Requested MDC, greater than sample specific MDC.

M3 - The requested MDC was not met, but the reported

activity is greater than the reported MDC.

$M$ - The requested MDC was not met.

Abbreviations:

TPU - Total Propagated Uncertainty (see PAI SOP 743)

MDC - Minimum Detectable Concentration (see PAI SOP 709)

BDL - Below Detection Limit

Data Package ID: GSS0804241-1
SQ-Spectral quality prevents accurate quantitation.

SI - Nuclide identification and/or quantitation is tentative.

$\mathrm{Tl}$ - Nuclide identification is tentative.

$R$ - Nuclide has exceeded 8 halflives.

G. Sample density differs by more than $15 \%$ of LCS density. 


\title{
Gamma Spectroscopy Results
}

\author{
PAI 713 Rev 9 \\ Sample Results
}

Lab Name: Paragon Analytics

Work Order Number: 0804241

Client Name: National Security Technologies, LLC

ClientProject ID: CAU 121 V3098

\begin{tabular}{|c|c|c|c|c|c|}
\hline \multicolumn{2}{|c|}{$\begin{array}{l}\text { Field ID: } 122226-6 \\
\text { Lab ID: } 0804241-6\end{array}$} & \multirow{2}{*}{$\begin{array}{l}\text { Sample Matrix: SOIL } \\
\text { Prep SOP: PAI } 739 \text { Rev } 9 \\
\text { Date Collected: } 23-A p r-08 \\
\text { Date Prepared: } 28-A p r-08 \\
\text { Date Analyzed: } 29-A p r-08\end{array}$} & \multirow{2}{*}{$\begin{array}{l}\text { Prep Batch: GS080428-1 } \\
\text { QCBatchID: GS080428-1-1 } \\
\text { Run ID: GS080428-1A } \\
\text { Count Time: } 30 \text { minutes } \\
\text { Report Basis: Dry Weight }\end{array}$} & \multirow{2}{*}{\multicolumn{2}{|c|}{$\begin{array}{l}\text { Final Aliquot: } 385 \mathrm{~g} \\
\text { Prep Basis: Dry Weight } \\
\text { Moisture(\%): NA } \\
\text { Result Units: pCi/g } \\
\text { File Name: } 080568 \mathrm{~d} 09\end{array}$}} \\
\hline $\begin{array}{l}\text { Librar } \\
\text { Analysis Req }\end{array}$ & $\begin{array}{l}\text { LNG_GAM-A-001 } \\
\text { e: NGS-A-002 }\end{array}$ & & & & \\
\hline CASNO & Target Nuclide & Result +/- 2 s TPU & MDC & $\begin{array}{l}\text { Requested } \\
\text { MDC }\end{array}$ & Lab Qualifier \\
\hline $14331-83-0$ & Ac-228 & $1.10 \mathrm{E}+00+/-3.74 \mathrm{E}-01$ & 5.93E-01 & & $\mathrm{G}, \mathrm{TI}$ \\
\hline $14596-10-2$ & $\mathrm{Am}-241$ & 1.31E-01+/-1.24E-01 & $1.97 \mathrm{E}-01$ & & U,G \\
\hline $14733-03-0$ & $\mathrm{Bi}-214$ & $1.07 \mathrm{E}+00+/-2.95 \mathrm{E}-01$ & $2.84 \mathrm{E}-01$ & & $G, J$ \\
\hline $14762-78-8$ & $\mathrm{Ce}-144$ & $-3.31 \mathrm{E}-01+/-3.08 \mathrm{E}-01$ & 5.94E-01 & & U.G \\
\hline $10198-40-0$ & $\mathrm{Co}-60$ & $-1.04 \mathrm{E}-02+/-8.06 \mathrm{E}-02$ & 1.65E-01 & & U,G \\
\hline $13967-70-9$ & Cs-134 & $6.84 \mathrm{E}-02+/-7.85 \mathrm{E}-02$ & $1.26 \mathrm{E}-01$ & & U.G \\
\hline $10045-97-3$ & Cs-137 & 1.49E-01 +/- $9.98 \mathrm{E}-02$ & $1.43 \mathrm{E}-01$ & $1.00 \mathrm{E}+00$ & $L T, G$ \\
\hline $14683-23-9$ & Eu-152 & $1.56 \mathrm{E}-01+/-4.03 \mathrm{E}-01$ & 7.33E-01 & & $U, G$ \\
\hline $15585-10-1$ & Eu-154 & $-1.34 \mathrm{E}-01+/-5.45 \mathrm{E}-01$ & $1.05 \mathrm{E}+00$ & & U.G \\
\hline $14391-16-3$ & Eu-155 & $-1.33 \mathrm{E}-02+/-1.58 \mathrm{E}-01$ & $2.82 \mathrm{E}-01$ & & U,G \\
\hline $13966-00-2$ & $\mathrm{~K}-40$ & $3.17 \mathrm{E}+01+/-5.25 \mathrm{E}+00$ & $1.86 \mathrm{E}+00$ & & G \\
\hline $15092-94-1$ & $\mathrm{~Pb}-212$ & $1.20 \mathrm{E}+00+1-2.36 \mathrm{E}-01$ & $1.81 \mathrm{E}-01$ & & G \\
\hline $15067-28-4$ & $\mathrm{~Pb}-214$ & $9.32 \mathrm{E}-01+/-2.06 \mathrm{E}-01$ & 1.99E-01 & & $\mathrm{G}, \mathrm{J}$ \\
\hline $14834-73-2$ & $\mathrm{Pm}-144$ & $3.70 \mathrm{E}-03+/-8.04 \mathrm{E}-02$ & $1.47 \mathrm{E}-01$ & & U,G \\
\hline $14834-74-3$ & $\mathrm{Pm}-146$ & $1.68 \mathrm{E}-02+/-7.62 \mathrm{E}-02$ & 1.37E-01 & & U,G \\
\hline
\end{tabular}

\section{Comments:}

\footnotetext{
Qualifiers/Flags:

$U$ - Result is less than the sample specific MDC or less than the associated TPU

Y1 - Chemical Yield is in control at 100-110\%. Quantitative Yield is assumed.

Y2 - Chemical Yield outside default limits.

LT - Result is less than Requested MDC, greater than sample specific MDC.

M3 - The requested MDC was not met, but the reported

activity is greater than the reported MDC.

$M$ - The requested MDC was not met.
}

Abbreviations:

TPU - Total Propagated Uncertainty (see PAI SOP 743)

MDC - Minimum Detectable Concentration (see PAI SOP 709)

BDL - Below Detection Limit

Data Package ID: GSS0804241-1

Date Printed:Tuesday, May 13, 2008 


\section{Gamma Spectroscopy Results}

\section{PAI 713 Rev 9 \\ Sample Results}

Lab Name: Paragon Analytics

Work Order Number: 0804241

Client Name: National Security Technologies, LLC

ClientProject ID: CAU $121 \mathrm{~V} 3098$

\begin{tabular}{|c|c|c|c|c|c|}
\hline \multicolumn{2}{|c|}{$\begin{array}{l}\text { Field ID: }{ }^{122226-6} \\
\text { Lab ID: } 0804241-6\end{array}$} & \multirow{2}{*}{$\begin{array}{l}\text { Sample Matrix: SOIL } \\
\text { Prep SOP: PAI } 739 \text { Rev } 9 \\
\text { Date Collected: } 23-A p r-08 \\
\text { Date Prepared: } 28-A p r-08 \\
\text { Date Analyzed: } 29-A p r-08\end{array}$} & \multirow{2}{*}{$\begin{array}{l}\text { Prep Batch: GS080428-1 } \\
\text { QCBatchID: GS080428-1-1 } \\
\text { Run ID: GS080428-1A } \\
\text { Count Time: } 30 \text { minutes } \\
\text { Report Basis: Dry Weight }\end{array}$} & \multirow{2}{*}{\multicolumn{2}{|c|}{$\begin{array}{l}\text { Final Aliquot: } 385 \mathrm{~g} \\
\text { Prep Basis: Dry Weight } \\
\text { Moisture(\%): NA } \\
\text { Result Units: } \mathrm{pCi} / \mathrm{g} \\
\text { File Name: } 080568 \mathrm{~d} 09\end{array}$}} \\
\hline $\begin{array}{r}\text { Librar } \\
\text { Analysis ReqC }\end{array}$ & $\begin{array}{l}\text { LNG_GAM-A-001 } \\
\text { le: NGS-A-002 }\end{array}$ & & & & \\
\hline CASNO & Target Nuclide & Result +/- $2 \mathrm{~s}$ TPU & MDC & $\begin{array}{c}\text { Requested } \\
\text { MDC }\end{array}$ & Lab Qualifier \\
\hline $13967-48-1$ & Ru-106 & $-3.78 E-01+/-6.76 E-01$ & $1.35 \mathrm{E}+00$ & & $U, G$ \\
\hline $14234-35-6$ & Sb-125 & $-7.25 \mathrm{E}-02+/-1.79 \mathrm{E}-01$ & $3.44 \mathrm{E}-01$ & & $U, G$ \\
\hline $15065-10-8$ & Th-234 & $1.61 \mathrm{E}+00+/-7.34 \mathrm{E}-01$ & $1.34 \mathrm{E}+00$ & & G \\
\hline $14913-50-9$ & TI-208 & $3.16 \mathrm{E}-01+/-1.14 \mathrm{E}-01$ & 1.24E-01 & & G \\
\hline $15117-96-1$ & U-235 & $3.10 \mathrm{E}-01+/-3.29 \mathrm{E}-01$ & 5.29E-01 & & $U, G$ \\
\hline $13982-36-0$ & $Y-88$ & $4.86 \mathrm{E}-02+/-7.96 \mathrm{E}-02$ & 1.35E-01 & & $U, G$ \\
\hline
\end{tabular}

\section{Comments:}

\footnotetext{
Qualifiers/Flags:

$U$ - Result is less than the sample specific MDC or less than the associated TPU

SQ-Spectral quality prevents accurate quantitation.

Y1 - Chemical Yield is in control at 100-110\%. Quantitative Yield is assumed.

SI - Nuclide identification and/or quantitation is tentative.

Y2 - Chemiçal Yield outside default limits.

$\mathrm{TI}$ - Nuclide identification is tentative.

$L T$ - Result is less than Requested MDC, greater than sample specific MDC.

$R$ - Nuclide has exceeded 8 halflives.

M3 - The requested MDC was not met, but the reported activity is greater than the reported MDC.

$M$ - The requested MDC was not met.

Abbreviations:

TPU - Total Propagated Uncertainty (see PAI SOP 743)

MDC - Minimum Detectable Concentration (see PAI SOP 709)

BDL - Below Detection Limit
}

Data Package ID: GSS0804241-1 


\title{
Gamma Spectroscopy Results
}

\author{
PAI 713 Rev 9 \\ Sample Results
}

Lab Name: Paragon Analytics

Work Order Number: 0804241

Client Name: National Security Technologies, LLC

ClientProject ID: CAU 121 V3098

\begin{tabular}{|c|c|c|c|c|c|}
\hline \multicolumn{2}{|c|}{$\begin{array}{l}\text { Field ID: } 122226-7 \\
\text { Lab ID: } 0804241-7\end{array}$} & \multirow{2}{*}{$\begin{array}{l}\text { Sample Matrix: SOIL } \\
\text { Prep SOP: PAI } 739 \text { Rev } 9 \\
\text { Date Collected: } 23-A p r-08 \\
\text { Date Prepared: } 28-A p r-08 \\
\text { Date Analyzed: } 29-A p r-08\end{array}$} & \multirow{2}{*}{$\begin{array}{l}\text { Prep Batch: GS080428-1 } \\
\text { QCBatchID: GS080428-1-1 } \\
\text { Run ID: GS080428-1A } \\
\text { Count Time: } 30 \text { minutes } \\
\text { Report Basis: Dry Weight }\end{array}$} & \multirow{2}{*}{\multicolumn{2}{|c|}{$\begin{array}{l}\text { Final Aliquot: } 284 \mathrm{~g} \\
\text { Prep Basis: Dry Weight } \\
\text { Moisture(\%): NA } \\
\text { Result Units: } \mathrm{pCi} / \mathrm{g} \\
\text { File Name: } 080734 \mathrm{~d} 10\end{array}$}} \\
\hline $\begin{array}{r}\text { Libra } \\
\text { Analysis Req }\end{array}$ & $\begin{array}{l}\text { LNG_GAM-A-001 } \\
\text { e: NGS-A-002 }\end{array}$ & & & & \\
\hline CASNO & Target Nuclide & Result $+/-2$ s TPU & MDC & $\begin{array}{l}\text { Requested } \\
\text { MDC }\end{array}$ & Lab Qualifier \\
\hline $14331-83-0$ & Ac-228 & $2.30 \mathrm{E}+00+/-6.04 \mathrm{E}-01$ & $6.64 \mathrm{E}-01$ & & $\mathrm{G}, \mathrm{TI}$ \\
\hline $14596-10-2$ & Am-241 & $2.20 \mathrm{E}+00+/-1.38 \mathrm{E}+00$ & $2.07 \mathrm{E}+00$ & & G \\
\hline $14733-03-0$ & Bi-214 & 7.87E-01 +/-3.00E-01 & $3.80 \mathrm{E}-01$ & & $G, J$ \\
\hline $14762-78-8$ & $\mathrm{Ce}-144$ & 7.14E-02 +/- 5.90E-01 & $1.02 \mathrm{E}+00$ & & $U, G$ \\
\hline $10198-40-0$ & $\mathrm{Co}-60$ & $-2.98 \mathrm{E}-02+/-9.77 \mathrm{E}-02$ & 1.97E-01 & & U,G \\
\hline $13967-70-9$ & Cs-134 & $-2.28 \mathrm{E}-02+/-1.07 \mathrm{E}-01$ & 1.95E-01 & & U,G \\
\hline $10045-97-3$ & Cs-137 & $1.05 E+01+/-1.34 E+00$ & 2.32E-01 & $1.00 E+00$ & $G$ \\
\hline $14683-23-9$ & Eu-152 & $3.95 \mathrm{E}-01+/-4.78 \mathrm{E}-01$ & 7.67E-01 & & U,G \\
\hline $15585-10-1$ & Eu-154 & $-3.68 \mathrm{E}-03+/-5.61 \mathrm{E}-01$ & $1.04 \mathrm{E}+00$ & & U,G \\
\hline $14391-16-3$ & Eu-155 & 1.69E-01 +/-3.81E-01 & $6.44 \mathrm{E}-01$ & & U,G \\
\hline $13966-00-2$ & $\mathrm{~K}-40$ & $3.37 E+01+/-5.44 E+00$ & $1.90 E+00$ & & G \\
\hline $15092-94-1$ & $\mathrm{~Pb}-212$ & $2.44 \mathrm{E}+00+/-4.19 \mathrm{E}-01$ & $3.09 \mathrm{E}-01$ & & G \\
\hline $15067-28-4$ & $\mathrm{~Pb}-214$ & $9.90 \mathrm{E}-01+/-3.04 \mathrm{E}-01$ & 5.09E-01 & & $G, J$ \\
\hline $14834-73-2$ & $\mathrm{Pm}-144$ & $-3.24 \mathrm{E}-02+/-7.81 \mathrm{E}-02$ & $1.53 \mathrm{E}-01$ & & U.G \\
\hline $14834-74-3$ & $\mathrm{Pm}-146$ & $1.20 \mathrm{E}-01+/-1.86 \mathrm{E}-01$ & $3.09 E-01$ & & U.G \\
\hline
\end{tabular}

\section{Comments:}

\footnotetext{
Qualifiers/Flags:

$U$ - Result is less than the sample specific MDC or less than the associated TPU

Y1 - Chemical Yield is in control at $100-110 \%$. Quantitative Yield is assumed.

Y2 - Chemical Yield outside default limits.

$L T$ - Result is less than Requested MDC, greater than sample specific MDC.

M3 - The requested MDC was not met, but the reported activity is greater than the reported MDC.

$M$ - The requested MDC was not met.

Abbreviations:

TPU - Total Propagated Uncertainty (see PAI SOP 743)

MDC - Minimum Detectable Concentration (see PAI SOP 709)

BDL - Below Detection Limit
}

Data Package ID: GSS0804241-1

SQ-Spectral quality prevents accurate quantitation.

SI-Nuclide identification and/or quantitation is tentative.

$\mathrm{TI}$ - Nuclide identification is tentative.

$R$ - Nuclide has exceeded 8 halflives.

G. Sample density differs by more than $15 \%$ of LCS density. 


\title{
Gamma Spectroscopy Results
}

\author{
PAI 713 Rev 9 \\ Sample Results
}

Lab Name: Paragon Analytics

Work Order Number: 0804241

Client Name: National Security Technologies, LLC

ClientProject ID: CAU $121 \mathrm{~V} 3098$

\begin{tabular}{|c|c|c|c|c|c|}
\hline \multicolumn{2}{|c|}{$\begin{array}{l}\text { Field ID: }{ }^{122226-7} \\
\text { Lab ID: } 0804241-7\end{array}$} & \multirow{2}{*}{$\begin{array}{l}\text { Sample Matrix: SOIL } \\
\text { Prep SOP: PAI } 739 \text { Rev } 9 \\
\text { Date Collected: } 23-A p r-08 \\
\text { Date Prepared: } 28-A p r-08 \\
\text { Date Analyzed: } 29-A p r-08\end{array}$} & \multirow{2}{*}{$\begin{array}{r}\text { Prep Batch: GS080428-1 } \\
\text { QCBatchID: GS080428-1-1 } \\
\text { Run ID: GS080428-1A } \\
\text { Count Time: } 30 \text { minutes } \\
\text { Report Basis: Dry Weight }\end{array}$} & \multirow{2}{*}{\multicolumn{2}{|c|}{$\begin{array}{l}\text { Final Aliquot: } 284 \mathrm{~g} \\
\text { Prep Basis: Dry Weight } \\
\text { Moisture(\%): NA } \\
\text { Result Units: } \mathrm{pCi} / \mathrm{g} \\
\text { File Name: } 080734 \mathrm{~d} 10\end{array}$}} \\
\hline $\begin{array}{r}\text { Librar } \\
\text { Analysis ReqC }\end{array}$ & $\begin{array}{l}\text { LNG_GAM-A-001 } \\
\text { le: NGS-A-002 }\end{array}$ & & & & \\
\hline CASNO & Target Nuclide & Result $+/-2$ s TPU & MDC & $\begin{array}{c}\text { Requested } \\
\text { MDC }\end{array}$ & Lab Qualifier \\
\hline $13967-48-1$ & Ru-106 & $-3.04 \mathrm{E}-01+/-8.70 \mathrm{E}-01$ & $1.65 \mathrm{E}+00$ & & U,G \\
\hline $14234-35-6$ & Sb-125 & $-2.68 \mathrm{E}-01+/-3.25 \mathrm{E}-01$ & $6.07 \mathrm{E}-01$ & & U,G \\
\hline $15065-10-8$ & Th-234 & $3.90 \mathrm{E}+00+/-2.48 \mathrm{E}+00$ & $3.83 E+00$ & & $\mathrm{G}, \mathrm{TI}$ \\
\hline $14913-50-9$ & TI-208 & 7.35E-01 +/-1.94E-01 & $2.16 \mathrm{E}-01$ & & G \\
\hline $15117-96-1$ & U-235 & $-6.70 \mathrm{E}-02+/-6.23 \mathrm{E}-01$ & $1.09 \mathrm{E}+00$ & & $\cup, G$ \\
\hline $13982-36-0$ & $\mathrm{Y}-88$ & $6.04 \mathrm{E}-03+/-1.08 \mathrm{E}-01$ & 1.97E-01 & & U,G \\
\hline
\end{tabular}

\section{Comments:}

\footnotetext{
Qualifiers/Flags:

$U$ - Result is less than the sample specific MDC or less than the associated TPU

$Y_{1}$ - Chemical Yield is in control at $100-110 \%$. Quantitative Yield is assumed.

Y2 - Chemical Yield outside default limits

LT - Result is less than Requested MDC, greater than sample specific MDC

M3 - The requested MDC was not met, but the reported activity is greater than the reported MDC

$M$ - The requested MDC was not met.

Abbreviations:

TPU - Total Propagated Uncertainty (see PAI SOP 743)

MDC - Minimum Detectable Concentration (see PAI SOP 709)

BDL - Below Detection Limit
}

Data Package ID: GSS0804241-1
SQ-Spectral quality prevents accurate quantitation.
SI - Nuclide identification and/or quantitation is tentative.
$\mathrm{TI}$ - Nuclide identification is tentative.
$R$ - Nuclide has exceeded 8 halflives.
G - Sample density differs by more than $15 \%$ of LCS density.

Date Printed: Tuesday, May 13, 2008 


\section{Gamma Spectroscopy Results \\ PAI 713 Rev 9 \\ Sample Results}

Lab Name: Paragon Analytics

Work Order Number: 0804241

Client Name: National Security Technologies, LLC

ClientProject ID: CAU 121 V3098

\begin{tabular}{|c|}
\hline Field ID: $122226-8$ \\
\hline Lab ID: $0804241-8$ \\
\hline
\end{tabular}

Library: LNG_GAM-A-001

Analysis ReqCode: NGS-A-002
Sample Matrix: SOIL

Prep SOP:PAl 739 Rev 9

Date Collected: 23-Apr-08

Date Prepared: 28-Apr-08

Date Analyzed: 29-Apr-08
Prep Batch: GS080428-1

QCBatchID: GS080428-1-1

Run ID: GS080428-1A

Count Time: 30 minutes

Report Basis: Dry Weight
Final Aliquot: $290 \mathrm{~g}$

Prep Basis: Dry Weight

Moisture(\%): NA

Result Units: pCi/g

File Name: $080777 \mathrm{~d} 02$

\begin{tabular}{|c|c|c|c|c|c|}
\hline CASNO & Target Nuclide & Result + $/-2 \mathrm{~s}$ TPU & MDC & $\begin{array}{c}\text { Requested } \\
\text { MDC }\end{array}$ & Lab Qualifier \\
\hline $14331-83-0$ & Ac-228 & $1.65 \mathrm{E}+00+/-4.38 \mathrm{E}-01$ & 7.34E-01 & & G \\
\hline $14596-10-2$ & Am-241 & $6.21 \mathrm{E}-01+/-9.86 \mathrm{E}-01$ & $1.64 \mathrm{E}+00$ & & U,G \\
\hline $14733-03-0$ & $\mathrm{Bi}-214$ & $9.46 \mathrm{E}-01+/-2.91 \mathrm{E}-01$ & 3.21E-01 & & G,J \\
\hline $14762-78-8$ & $\mathrm{Ce}-144$ & $6.88 \mathrm{E}-02+/-4.70 \mathrm{E}-01$ & 8.14E-01 & & U,G \\
\hline $14093-03-9$ & Co-56 & $4.01 \mathrm{E}-01+/-2.28 \mathrm{E}-01$ & 3.14E-01 & & $\mathrm{G}, \mathrm{TI}$ \\
\hline $10198-40-0$ & Co-60 & $-5.65 E-02+/-9.53 E-02$ & $1.98 \mathrm{E}-01$ & & U,G \\
\hline $13967-70-9$ & Cs-134 & $4.15 \mathrm{E}-02+/-9.17 \mathrm{E}-02$ & $1.57 \mathrm{E}-01$ & & U,G \\
\hline $10045-97-3$ & Cs-137 & $7.65 E+00+1-1.00 E+00$ & $2.14 \mathrm{E}-01$ & $1.00 \mathrm{E}+00$ & G \\
\hline $14683-23-9$ & Eu-152 & $1.46 \mathrm{E}-01+/-4.35 \mathrm{E}-01$ & $7.86 \mathrm{E}-01$ & & U,G \\
\hline $15585-10-1$ & Eu-154 & $4.48 \mathrm{E}-02+/-5.46 \mathrm{E}-01$ & $9.98 \mathrm{E}-01$ & & U,G \\
\hline $14391-16-3$ & Eu-155 & $1.05 E-01+/-3.31 E-01$ & $5.64 \mathrm{E}-01$ & & U,G \\
\hline $13966-00-2$ & $\mathrm{~K}-40$ & $3.05 E+01+/-4.90 E+00$ & $1.45 \mathrm{E}+00$ & & G \\
\hline $15092-94-1$ & $\mathrm{~Pb}-212$ & $2.31 \mathrm{E}+00+/-3.91 \mathrm{E}-01$ & 2.85E-01 & & G \\
\hline $15067-28-4$ & $\mathrm{~Pb}-214$ & 1.11E+00 +/-2.79E-01 & 3.73E-01 & & $G, J$ \\
\hline $14834-73-2$ & $\mathrm{Pm}-144$ & $-6.66 \mathrm{E}-02+1-9.41 \mathrm{E}-02$ & $1.82 \mathrm{E}-01$ & & U,G \\
\hline
\end{tabular}

\section{Comments:}

\footnotetext{
Qualifiers/Flags:

$U$-Result is less than the sample specific MDC or less than the associated TPU

Y1 - Chemical Yield is in control at 100-110\%. Quantitative Yield is assumed.

Y2-Chemical Yield outside default limits.

LT - Result is less than Requested MDC, greater than sample specific MDC

M3 - The requested MDC was not met, but the reported activity is greater than the reported MDC.

$M$ - The requested $M D C$ was not met.

Abbreviations:

TPU - Total Propagated Uncertainty (see PAI SOP 743)

MDC - Minimum Detectable Concentration (see PAI SOP 709)

BDL - Below Detection Limit
}

\section{Data Package ID: GSS0804241-1}

SQ-Spectral quality prevents accurate quantitation.

SI - Nuclide identification and/or quantitation is tentative.

$\mathrm{Tl}$ - Nuclide identification is tentative

$R$ - Nuclide has exceeded 8 halfives.

G-Sample density differs by more than $15 \%$ of LCS density. 


\title{
Gamma Spectroscopy Results
}

\author{
PAI 713 Rev 9 \\ Sample Results
}

Lab Name: Paragon Analytics

Work Order Number: 0804241

Client Name: National Security Technologies, LLC

ClientProject ID: CAU 121 V3098

\begin{tabular}{|c|c|c|c|c|c|}
\hline \multicolumn{2}{|c|}{$\begin{array}{l}\text { Field ID: } 122226-8 \\
\text { Lab ID: } 0804241-8\end{array}$} & $\begin{array}{l}\text { Sample Matrix: SOIL } \\
\text { Prep SOP: PAI } 739 \text { Rev } 9 \\
\text { Date Collected: } 23-A p r-08 \\
\text { Date Prepared: } 28-A p r-08 \\
\text { Date Analyzed: } 29-A p r-08\end{array}$ & $\begin{array}{l}\text { Prep Batch: GS080428-1 } \\
\text { QCBatchID: GS080428-1-1 } \\
\text { Run ID: GS080428-1A } \\
\text { Count Time: } 30 \text { minutes } \\
\text { Report Basis: Dry Weight }\end{array}$ & \multicolumn{2}{|c|}{$\begin{array}{l}\text { Final Aliquot: } 290 \mathrm{~g} \\
\text { Prep Basis: Dry Weight } \\
\text { Moisture(\%): NA } \\
\text { Result Units: pCi/g } \\
\text { File Name: } 080777 \mathrm{~d} 02\end{array}$} \\
\hline CASNO & Target Nuclide & Result +/- $2 \mathrm{~s}$ TPU & MDC & $\begin{array}{c}\text { Requested } \\
\text { MDC }\end{array}$ & Lab Qualifier \\
\hline $14834-74-3$ & $P m-146$ & $2.20 \mathrm{E}-02+/-1.49 \mathrm{E}-01$ & 2.60E-01 & & U,G \\
\hline $13967-48-1$ & Ru-106 & $-2.65 \mathrm{E}-01+/-8.28 \mathrm{E}-01$ & $1.56 \mathrm{E}+00$ & & U,G \\
\hline $14234-35-6$ & Sb-125 & $-1.63 \mathrm{E}-03+/-2.65 \mathrm{E}-01$ & $4.72 \mathrm{E}-01$ & & U,G \\
\hline $15065-10-8$ & Th-234 & $2.29 \mathrm{E}+00+/-2.07 \mathrm{E}+00$ & $3.33 E+00$ & & $U, G$ \\
\hline $14913-50-9$ & TI-208 & $6.40 \mathrm{E}-01+/-1.85 \mathrm{E}-01$ & $2.09 \mathrm{E}-01$ & & G \\
\hline $15117-96-1$ & U-235 & $4.96 \mathrm{E}-01+/-5.02 \mathrm{E}-01$ & 8.07E-01 & & U,G \\
\hline $13982-36-0$ & $Y-88$ & 1.07E-04+/- $9.30 \mathrm{E}-02$ & $1.73 \mathrm{E}-01$ & & $\mathrm{U}, \mathrm{G}$ \\
\hline
\end{tabular}

\section{Comments:}

\section{Qualifiers/Flags:}

$U$-Result is less than the sample specific MDC or less than the associated TPU

$\mathrm{Y}_{1}$ - Chemical Yield is in control at $100-110 \%$. Quantitative Yield is assumed.

Y2 - Chemical Yield outside default limits.

LT - Result is less than Requested MDC, greater than sample specific MDC.

M3 - The requested MDC was not met, but the reported activity is greater than the reported MDC.

$M$ - The requested MDC was not met.

Abbreviations:

TPU - Total Propagated Uncertainty (see PAI SOP 743)

MDC - Minimum Detectable Concentration (see PAI SOP 709)

BDL - Below Detection Limit

Data Package ID: GSS0804241-1
SQ - Spectral quality prevents accurate quantitation.

SI - Nuclide identification and/or quantitation is tentative.

$\mathrm{TI}$ - Nuclide identification is tentative.

$R$ - Nuclide has exceeded 8 halflives.

G - Sample density differs by more than $15 \%$ of LCS density. 


\title{
Gamma Spectroscopy Results
}

\author{
PAI 713 Rev 9 \\ Sample Results
}

Lab Name: Paragon Analytics

Work Order Number: 0804241

Client Name: National Security Technologies, LLC

ClientProject ID: CAU 121 V3098

\begin{tabular}{|l|}
\hline Field ID: $122226-9$ \\
Lab ID: $0804241-9$ \\
\hline
\end{tabular}

Library: LNG_GAM-A-001

Analysis ReqCode: NGS-A-002
Sample Matrix: SOIL

Prep SOP: PAI 739 Rev 9

Date Collected: 23-Apr-08

Date Prepared: 28-Apr-08

Date Analyzed: 29-Apr-08
Prep Batch: GS080428-1

QCBatchID: GS080428-1-1

Run ID: GS080428-1A

Count Time: 30 minutes

Report Basis: Dry Weight
Final Aliquot: $295 \mathrm{~g}$

Prep Basis: Dry Weight

Moisture(\%): NA

Result Units: pCi/g

File Name: $080224 \mathrm{~d} 03$

\begin{tabular}{|c|c|c|c|c|c|}
\hline CASNO & Target Nuclide & Result $+/-2$ s TPU & MDC & $\begin{array}{c}\text { Requested } \\
\text { MDC }\end{array}$ & Lab Qualifier \\
\hline $14331-83-0$ & Ac-228 & $1.76 \mathrm{E}+00+/-4.67 \mathrm{E}-01$ & $6.65 \mathrm{E}-01$ & & G \\
\hline $14596-10-2$ & Am-241 & $8.88 \mathrm{E}-01+/-1.31 \mathrm{E}+00$ & $2.17 \mathrm{E}+00$ & & $U, G$ \\
\hline $14913-49-6$ & $\mathrm{Bi}-212$ & $3.15 E+00+/-1.67 E+00$ & $2.24 \mathrm{E}+00$ & & $\mathrm{G}, \mathrm{TI}$ \\
\hline $14733-03-0$ & $\mathrm{Bi}-214$ & $9.00 E-01+/-3.16 E-01$ & 3.85E-01 & & G,J \\
\hline $14762-78-8$ & $\mathrm{Ce}-144$ & $-8.57 \mathrm{E}-02+/-6.54 \mathrm{E}-01$ & $1.14 \mathrm{E}+00$ & & U,G \\
\hline $10198-40-0$ & Co-60 & $1.04 \mathrm{E}-01+/-8.71 \mathrm{E}-02$ & $1.22 \mathrm{E}-01$ & & $U, G$ \\
\hline $13967-70-9$ & Cs-134 & $-3.65 \mathrm{E}-02+/-1.05 \mathrm{E}-01$ & $1.94 \mathrm{E}-01$ & & U.G \\
\hline $10045-97-3$ & Cs-137 & $7.37 E+00+1-9.77 E-01$ & $2.01 \mathrm{E}-01$ & $1.00 \mathrm{E}+00$ & G \\
\hline $14683-23-9$ & Eu-152 & 2.64E-01+/-4.21E-01 & $7.12 \mathrm{E}-01$ & & U,G \\
\hline $15585-10-1$ & Eu-154 & $-6.22 \mathrm{E}-02+/-4.96 \mathrm{E}-01$ & $9.53 E-01$ & & U,G \\
\hline $14391-16-3$ & Eu-155 & 1.27E-01 +/-3.93E-01 & $6.66 \mathrm{E}-01$ & & U,G \\
\hline $13966-00-2$ & $\mathrm{~K}-40$ & $3.13 \mathrm{E}+01+/-5.09 \mathrm{E}+00$ & $1.71 \mathrm{E}+00$ & & G \\
\hline $15092-94-1$ & $\mathrm{~Pb}-212$ & $2.25 E+00+/-4.06 E-01$ & 3.35E-01 & & G \\
\hline $15067-28-4$ & $\mathrm{~Pb}-214$ & $9.83 \mathrm{E}-01+/-2.86 \mathrm{E}-01$ & 4.06E-01 & & G,J \\
\hline $14834-73-2$ & $\mathrm{Pm}-144$ & $-6.10 \mathrm{E}-02+/-9.57 \mathrm{E}-02$ & $1.86 \mathrm{E}-01$ & & U,G \\
\hline
\end{tabular}

\section{Comments:}

\footnotetext{
Qualifiers/Flags:

$U$ - Result is less than the sample specific MDC or less than the associated TPU

Y1 - Chemical Yield is in control at 100-110\%. Quantitative Yield is assumed.

Y2 - Chemical Yield outside default limits.

$L T$ - Result is less than Requested MDC, greater than sample specific MDC.

M3 - The requested MDC was not met, but the reported activity is greater than the reported MDC.

$M$ - The requested MDC was not met.

Abbrevations:

TPU - Total Propagated Uncertainty (see PAI SOP 743)

MDC - Minimum Detectable Concentration (see PAI SOP 709)

BDL - Below Detection Limit
}

Data Package ID: GSS0804241-1

SQ-Spectral quality prevents accurate quantitation.

SI - Nuclide identification and/or quantitation is tentative.

$\mathrm{Tl}$ - Nuclide identification is tentative.

$R$ - Nuclide has exceeded 8 halflives.

G - Sample density differs by more than $15 \%$ of LCS density. 


\title{
Gamma Spectroscopy Results
}

\author{
PAI 713 Rev 9 \\ Sample Results
}

Lab Name: Paragon Analytics

Work Order Number: 0804241

Client Name: National Security Technologies, LLC

ClientProject ID: CAU 121 V3098

\begin{tabular}{|l|}
\hline Field ID: $122226-9$ \\
Lab ID: $0804241-9$ \\
\hline
\end{tabular}

Library: LNG_GAM-A-001

Analysis ReqCode: NGS-A-002
Sample Matrix: SOIL

Prep SOP: PAI 739 Rev 9

Date Collected: 23-Apr-08

Date Prepared: 28-Apr-08

Date Analyzed:29-Apr-08
Prep Batch: GS080428-1

QCBatchID: GS080428-1-1

Run ID: GS080428-1A

Count Time: 30 minutes

Report Basis: Dry Weight
Final Aliquot: $295 \mathrm{~g}$

Prep Basis: Dry Weight

Moisture(\%): NA

Result Units: $\mathrm{pCi} / \mathrm{g}$

File Name: $080224 \mathrm{~d} 03$

\begin{tabular}{|c|c|c|c|c|c|}
\hline CASNO & Target Nuclide & Result +/- 2 s TPU & MDC & $\begin{array}{c}\text { Requested } \\
\text { MDC }\end{array}$ & Lab Qualifier \\
\hline $14834-74-3$ & $\mathrm{Pm}-146$ & $7.76 \mathrm{E}-02+/-1.82 \mathrm{E}-01$ & 3.07E-01 & & U,G \\
\hline $13967-48-1$ & Ru-106 & $-3.56 \mathrm{E}-01+/-8.81 \mathrm{E}-01$ & $1.68 \mathrm{E}+00$ & & U,G \\
\hline $14234-35-6$ & Sb-125 & $2.13 \mathrm{E}-01+/-3.34 \mathrm{E}-01$ & $6.03 E-01$ & & U,G \\
\hline $15065-10-8$ & Th-234 & $2.09 E+00+/-2.23 E+00$ & $3.62 E+00$ & & U,G \\
\hline $14913-50-9$ & TI-208 & $7.79 \mathrm{E}-01+/-1.97 \mathrm{E}-01$ & $1.90 \mathrm{E}-01$ & & G \\
\hline $15117-96-1$ & U-235 & $5.73 \mathrm{E}-01+/-6.43 \mathrm{E}-01$ & $1.04 \mathrm{E}+00$ & & U,G \\
\hline $13982-36-0$ & $\mathrm{Y}-88$ & $1.92 \mathrm{E}-02+/-1.08 \mathrm{E}-01$ & $1.94 \mathrm{E}-01$ & & U,G \\
\hline
\end{tabular}

\section{Comments:}

\section{Qualifiers/Flags:}

$U$ - Result is less than the sample specific MDC or less than the associated TPU

$\mathrm{Y}_{1}$ - Chemical Yield is in control at $100-110 \%$. Quantitative Yield is assumed.

Y2 - Chemical Yield outside default limits.

LT - Result is less than Requested MDC, greater than sample specific MDC.

M3 - The requested MDC was not met, but the reported activity is greater than the reported MDC

$M$ - The requested MDC was not met.

Abbreviations:

TPU - Total Propagated Uncertainty (see PAI SOP 743)

MDC - Minimum Detectable Concentration (see PAI SOP 709)

BDL - Below Detection Limit

Data Package ID: GSS0804241-1
SQ-Spectral quality prevents accurate quantitation.

SI - Nuclide identification and/or quantitation is tentative.

$\mathrm{TI}$ - Nuclide identification is tentative.

$R$ - Nuclide has exceeded 8 halflives.

G - Sample density differs by more than $15 \%$ of LCS density. 


\title{
Gamma Spectroscopy Results
}

\author{
PAl 713 Rev 9 \\ Sample Results
}

Lab Name: Paragon Analytics

Work Order Number: 0804241

Client Name: National Security Technologies, LLC

ClientProject ID: CAU $121 \mathrm{~V} 3098$

\begin{tabular}{|c|c|c|c|c|c|}
\hline \multicolumn{2}{|c|}{$\begin{aligned} & \text { Field ID: } 122226-15 \\
& \text { Lab ID: } 0804241-10 \\
&\end{aligned}$} & \multirow{2}{*}{$\begin{array}{l}\text { Sample Matrix: SOIL } \\
\quad \text { Prep SOP: PAI } 739 \text { Rev } 9 \\
\text { Date Collected: } 23-A p r-08 \\
\text { Date Prepared: } 28-A p r-08 \\
\text { Date Analyzed: } 29-A p r-08\end{array}$} & \multirow{2}{*}{$\begin{array}{l}\text { Prep Batch: GS080428-1 } \\
\text { QCBatchID: GS080428-1-1 } \\
\text { Run ID: GS080428-1A } \\
\text { Count Time: } 30 \text { minutes } \\
\text { Report Basis: Dry Weight }\end{array}$} & \multirow{2}{*}{\multicolumn{2}{|c|}{$\begin{array}{l}\text { Final Aliquot: } 456 \mathrm{~g} \\
\text { Prep Basis: Dry Weight } \\
\text { Moisture(\%): NA } \\
\text { Result Units: pCi/g } \\
\text { File Name: } 080735 \mathrm{~d} 04\end{array}$}} \\
\hline $\begin{array}{r}\text { Librar } \\
\text { Analysis ReqC }\end{array}$ & $\begin{array}{l}\text { LNG_GAM-A-001 } \\
\text { e: NGS-A-002 }\end{array}$ & & & & \\
\hline CASNO & Target Nuclide & Result +/- $2 \mathrm{~s}$ TPU & MDC & $\begin{array}{c}\text { Requested } \\
\text { MDC }\end{array}$ & Lab Qualifier \\
\hline $14331-83-0$ & Ac-228 & $3.95 \mathrm{E}-01+/-2.10 \mathrm{E}-01$ & 3.87E-01 & & $\mathrm{TI}$ \\
\hline $14596-10-2$ & Am-241 & $-5.47 \mathrm{E}-02+/-2.76 \mathrm{E}-01$ & 5.14E-01 & & $\mathrm{U}$ \\
\hline $14733-03-0$ & $\mathrm{Bi}-214$ & 4.34E-01+/- 1.60E-01 & 1.80E-01 & & $\mathrm{J}$ \\
\hline $14762-78-8$ & $\mathrm{Ce}-144$ & $7.53 \mathrm{E}-02+/-2.01 \mathrm{E}-01$ & $3.47 \mathrm{E}-01$ & & U \\
\hline $10198-40-0$ & Co-60 & 7.05E-03 +/- 3.73E-02 & 7.59E-02 & & $U$ \\
\hline $13967-70-9$ & Cs-134 & $-3.35 \mathrm{E}-02+/-3.44 \mathrm{E}-02$ & 7.72E-02 & & $u$ \\
\hline $10045-97-3$ & Cs-137 & 4.33E-01+/- 1.12E-01 & 8.64E-02 & $1.00 \mathrm{E}+00$ & LT \\
\hline 14683-23-9 & Eu-152 & $7.03 \mathrm{E}-02+/-1.99 \mathrm{E}-01$ & $3.78 \mathrm{E}-01$ & & $U$ \\
\hline $15585-10-1$ & Eu-154 & $9.26 \mathrm{E}-02+/-2.39 \mathrm{E}-01$ & 4.35E-01 & & $\mathrm{U}$ \\
\hline $14391-16-3$ & Eu-155 & $5.77 \mathrm{E}-03+/-1.18 \mathrm{E}-01$ & $2.12 \mathrm{E}-01$ & & $U$ \\
\hline $13966-00-2$ & $K-40$ & $8.80 E+00+/-1.98 E+00$ & $1.28 \mathrm{E}+00$ & & \\
\hline $15092-94-1$ & $\mathrm{~Pb}-212$ & $5.10 \mathrm{E}-01+/-1.37 \mathrm{E}-01$ & $1.51 \mathrm{E}-01$ & & \\
\hline $15067-28-4$ & $\mathrm{~Pb}-214$ & 4.12E-01 +/- 1.22E-01 & $1.68 \mathrm{E}-01$ & & $\mathrm{~J}$ \\
\hline $14834-73-2$ & $\mathrm{Pm}-144$ & $3.90 \mathrm{E}-02+/-5.32 \mathrm{E}-02$ & 8.77E-02 & & $\mathrm{U}$ \\
\hline $14834-74-3$ & $P m-146$ & $-4.23 \mathrm{E}-02+1-5.96 \mathrm{E}-02$ & 1.19E-01 & & $\mathrm{U}$ \\
\hline
\end{tabular}

\section{Comments:}

\footnotetext{
Qualifiers/Flags:

$U$ - Result is less than the sample specific MDC or less than the associated TPU

Y1 - Chemical Yield is in control at 100-110\%. Quantitative Yield is assumed.

Y2 - Chemical Yield outside default limits.

LT - Result is less than Requested MDC, greater than sample specific MDC.

M3 - The requested MDC was not met, but the reported

activity is greater than the reported MDC.

$M$ - The requested MDC was not met.
}

Abbreviations:

TPU - Total Propagated Uncertainty (see PAI SOP 743)

MDC - Minimum Detectable Concentration (see PAI SOP 709)

BDL - Below Detection Limit

Data Package ID: GSS0804241-1

SQ - Spectral quality prevents accurate quantitation.

$\mathrm{SI}$ - Nuclide identification and/or quantitation is tentative.

$\mathrm{Tl}$ - Nuclide identification is tentative.

$R$ - Nuclide has exceeded 8 halflives.

G - Sample density differs by more than $15 \%$ of LCS density 


\section{Gamma Spectroscopy Results}

\section{PAI 713 Rev 9 \\ Sample Results}

Lab Name: Paragon Analytics

Work Order Number: 0804241

Client Name: National Security Technologies, LLC

ClientProject ID: CAU 121 V3098

\begin{tabular}{|c|c|c|c|c|c|}
\hline \multicolumn{2}{|c|}{$\begin{array}{l}\text { Field ID: } 122226-15 \\
\text { Lab ID: } 0804241-10 \\
\end{array}$} & \multirow{3}{*}{$\begin{array}{l}\text { Sample Matrix: SOIL } \\
\quad \text { Prep SOP: PAI } 739 \text { Rev } 9 \\
\text { Date Collected: } 23-A p r-08 \\
\text { Date Prepared: } 28-A p r-08 \\
\text { Date Analyzed: } 29-A p r-08\end{array}$} & \multirow{3}{*}{$\begin{array}{r}\text { Prep Batch: GS080428-1 } \\
\text { QCBatchID: GS080428-1-1 } \\
\text { Run ID: GS080428-1A } \\
\text { Count Time: } 30 \text { minutes } \\
\text { Report Basis: Dry Weight }\end{array}$} & \multirow{3}{*}{\multicolumn{2}{|c|}{$\begin{array}{l}\text { Final Aliquot: } 456 \mathrm{~g} \\
\text { Prep Basis: Dry Weight } \\
\text { Moisture(\%): NA } \\
\text { Result Units: pCi/g } \\
\text { File Name: } 080735 \mathrm{~d} 04\end{array}$}} \\
\hline \multirow{2}{*}{\multicolumn{2}{|c|}{$\begin{array}{l}\text { Library: LNG_GAM-A-001 } \\
\text { Analysis ReqCode: NGS-A-002 }\end{array}$}} & & & & \\
\hline & & & & & \\
\hline CASNO & Target Nuclide & Result +/- 2 s TPU & MDC & $\begin{array}{l}\text { Requested } \\
\text { MDC }\end{array}$ & Lab Qualifier \\
\hline $13967-48-1$ & Ru-106 & $7.64 \mathrm{E}-02+/-3.90 \mathrm{E}-01$ & $7.19 \mathrm{E}-01$ & & $\mathrm{U}$ \\
\hline $14234-35-6$ & Sb-125 & 1.09E-01 +/- 1.18E-01 & $1.88 \mathrm{E}-01$ & & $\mathrm{U}$ \\
\hline $15065-10-8$ & Th-234 & $-7.21 \mathrm{E}-01+/-7.60 \mathrm{E}-01$ & $1.43 E+00$ & & $U$ \\
\hline $14913-50-9$ & TI-208 & 1.47E-01 +/- 7.17E-02 & $9.29 \mathrm{E}-02$ & & \\
\hline $15117-96-1$ & U-235 & $-7.39 \mathrm{E}-02+/-2.18 \mathrm{E}-01$ & 4.02E-01 & & $\mathrm{U}$ \\
\hline $13982-36-0$ & Y-88 & $-1.69 \mathrm{E}-02+/-5.40 \mathrm{E}-02$ & 1.10E-01 & & $\mathrm{U}$ \\
\hline
\end{tabular}

\section{Comments:}

\footnotetext{
Qualifiers/Flags:

$U$ - Result is less than the sample specific MDC or less than the associated TPU

Y1 - Chemical Yield is in control at 100-110\%. Quantitative Yield is assumed.

Y2 - Chemical Yield outside default limits.

LT - Result is less than Requested MDC, greater than sample specific MDC.

M3 - The requested MDC was not met, but the reported

activity is greater than the reported MDC.

$M$ - The requested $M D C$ was not met.

Abbrevations:

TPU - Total Propagated Uncertainty (see PAI SOP 743)

MDC - Minimum Detectable Concentration (see PAI SOP 709)

BDL - Below Detection Limit
}

SQ - Spectral quality prevents accurate quantitation.

SI - Nuclide identification and/or quantitation is tentative.

$\mathrm{Tl}$ - Nuclide identification is tentative.

$R$ - Nuclide has exceeded 8 halflives.

G - Sample density differs by more than $15 \%$ of LCS density.

Data Package ID: GSS0804241-1

Date Printed: Tuesday, May 13, 2008 


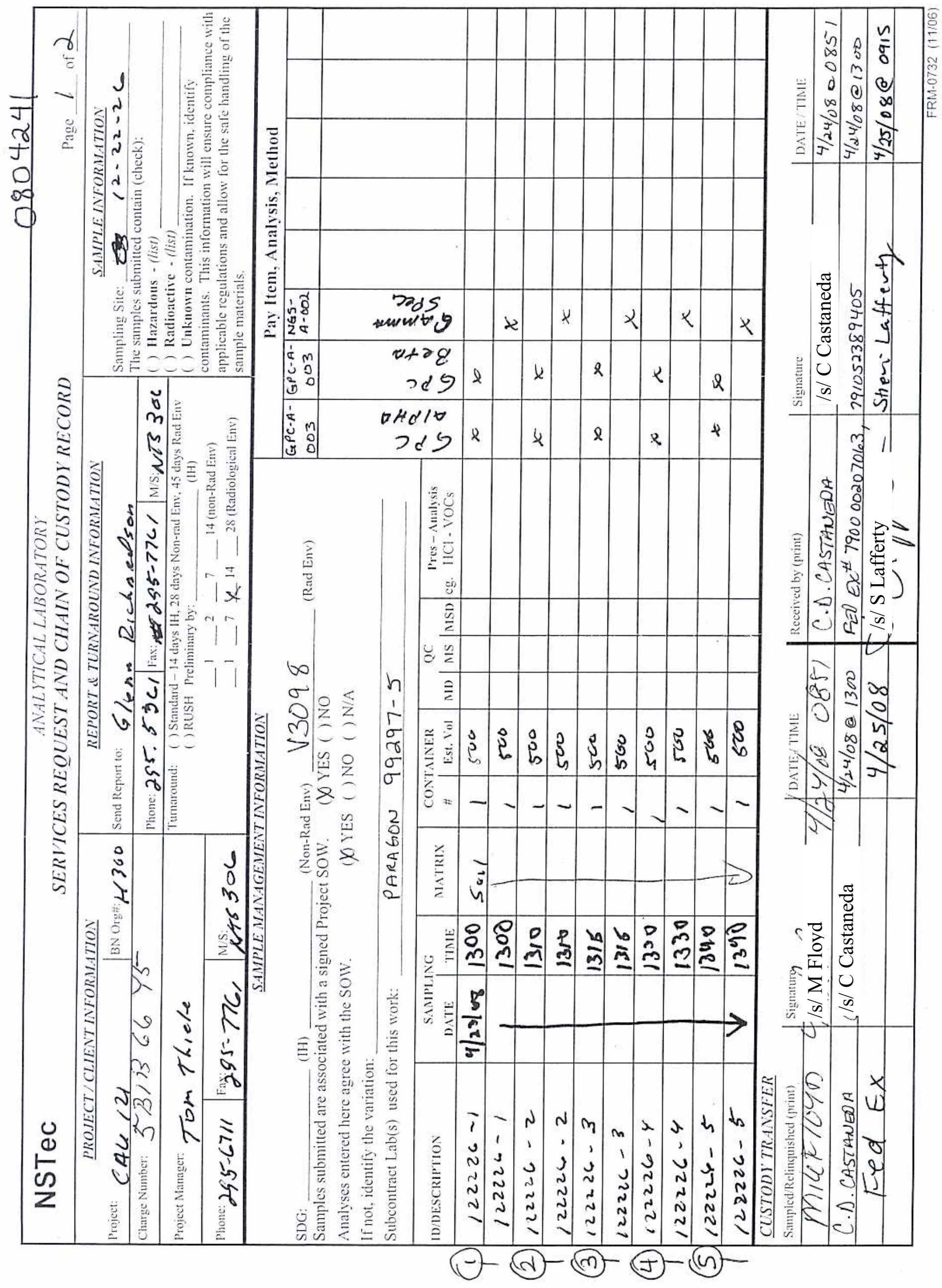




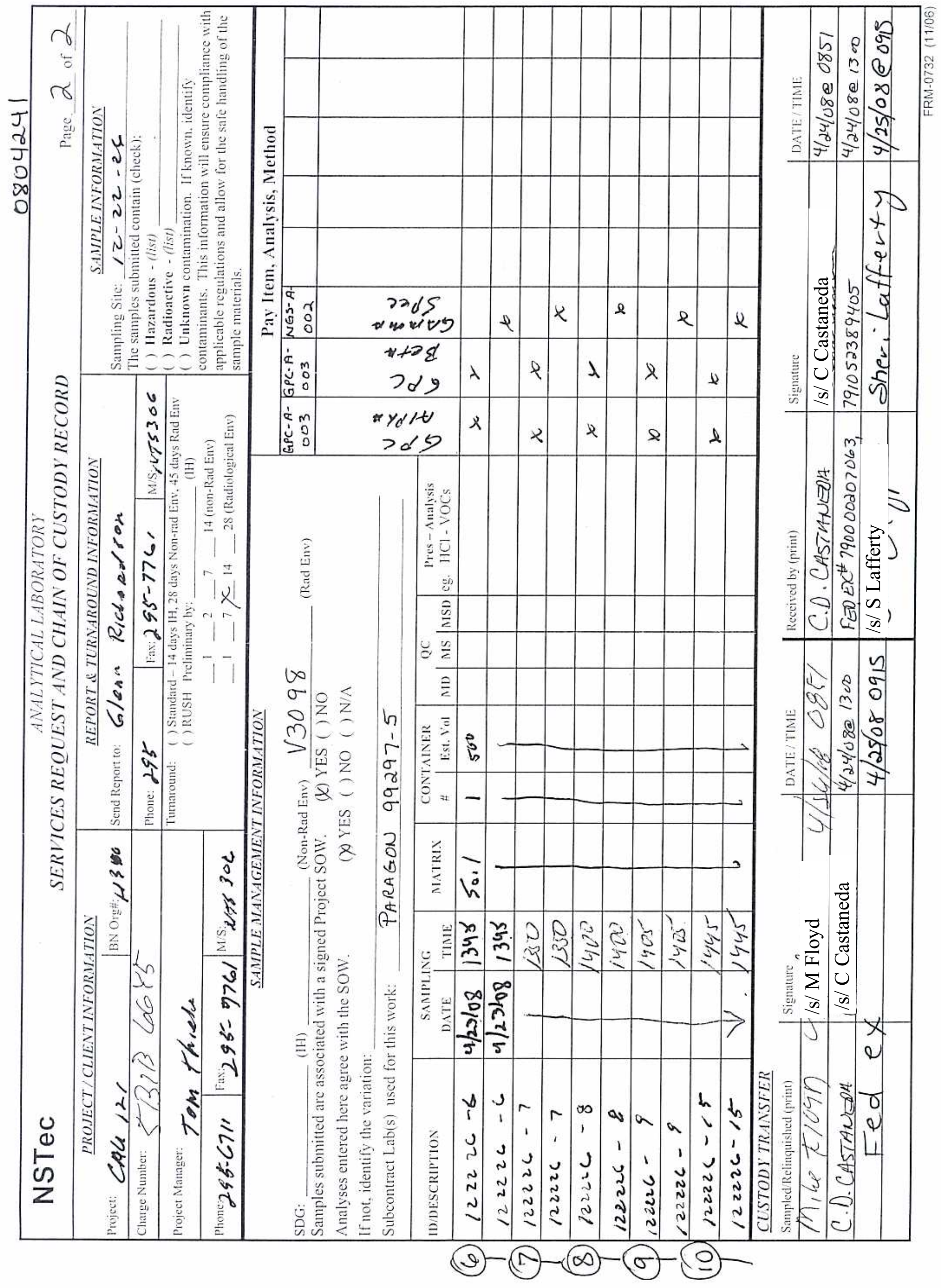


CAU 121 Closure Report

Section: Appendix B

Revision: 0

Date: September 2008

\section{THIS PAGE INTENTIONALLY LEFT BLANK}


CAU 121 Closure Report

Section: Appendix B

Revision: 0

Date: September 2008

\section{Sample Delivery Group V3106}


CAU 121 Closure Report

Section: Appendix B

Revision: 0

Date: September 2008

\section{THIS PAGE INTENTIONALLY LEFT BLANK}




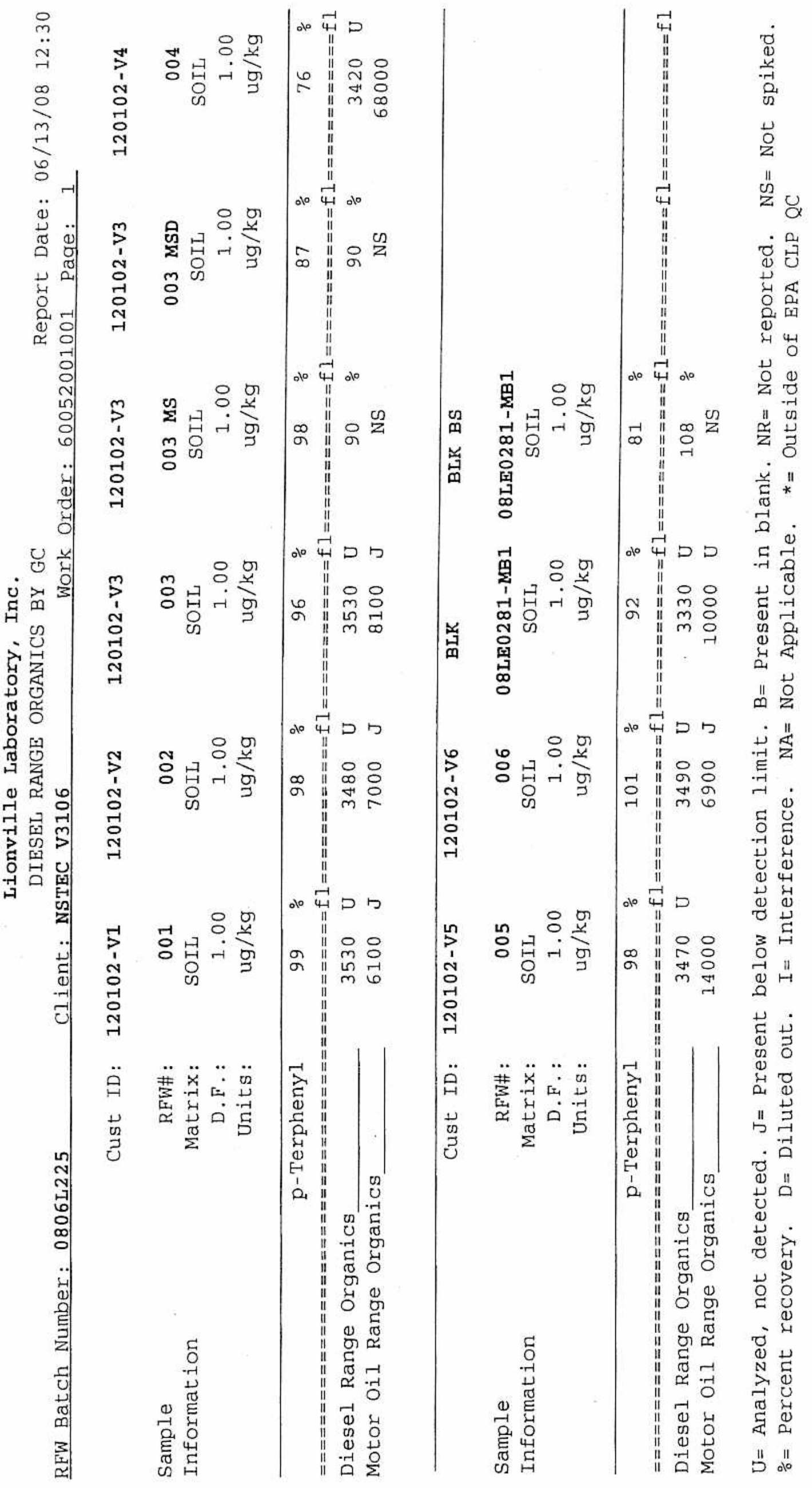




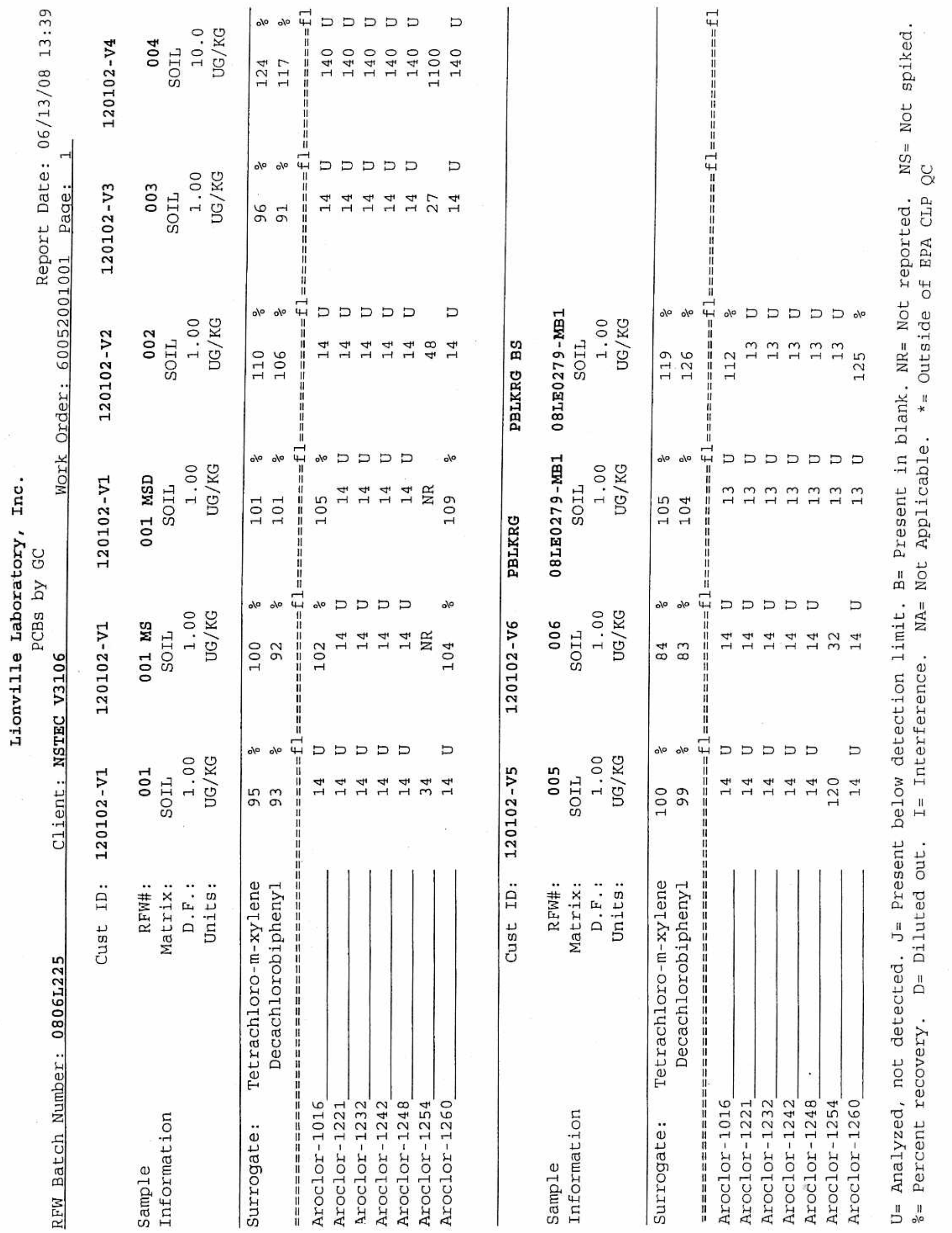




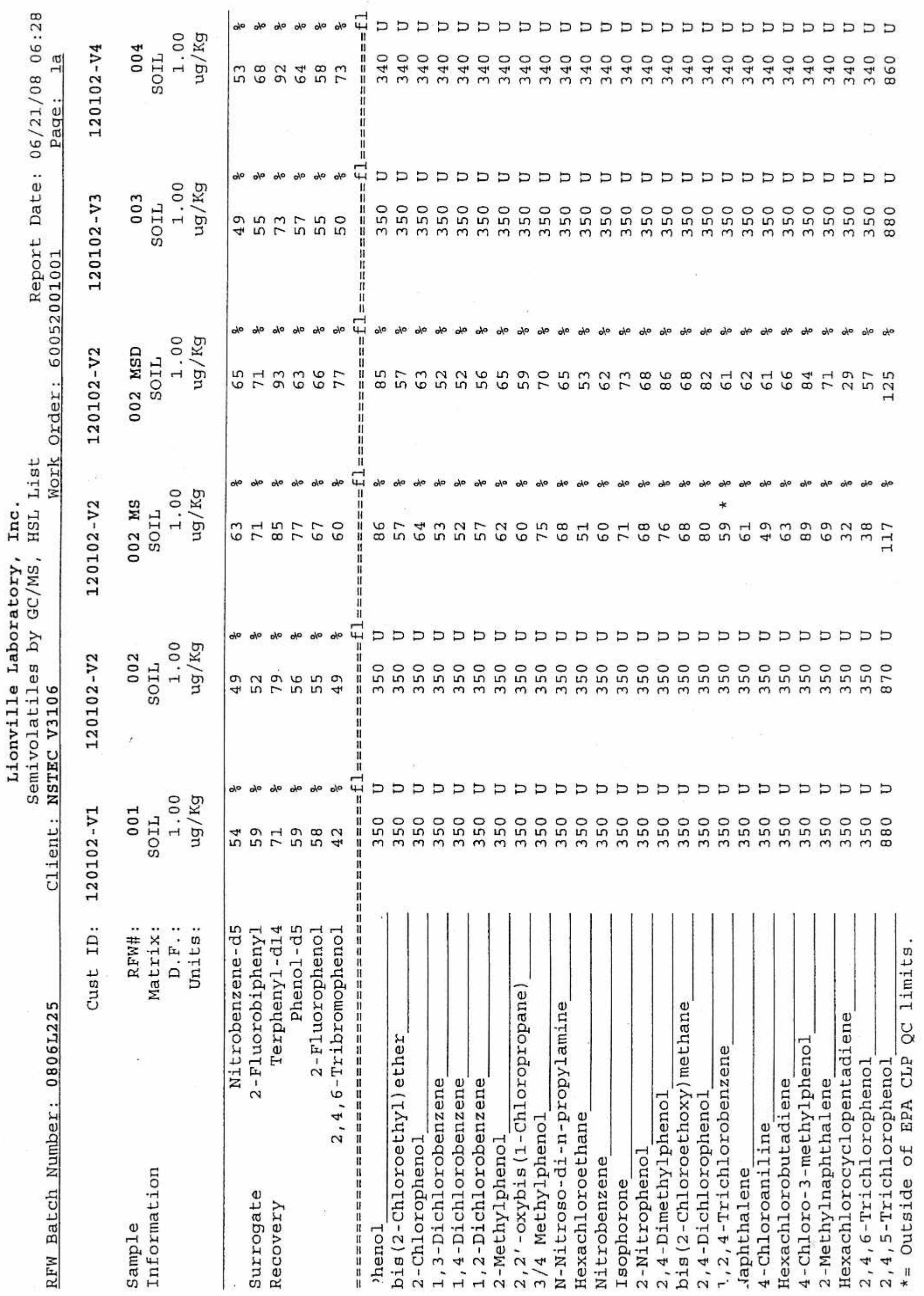




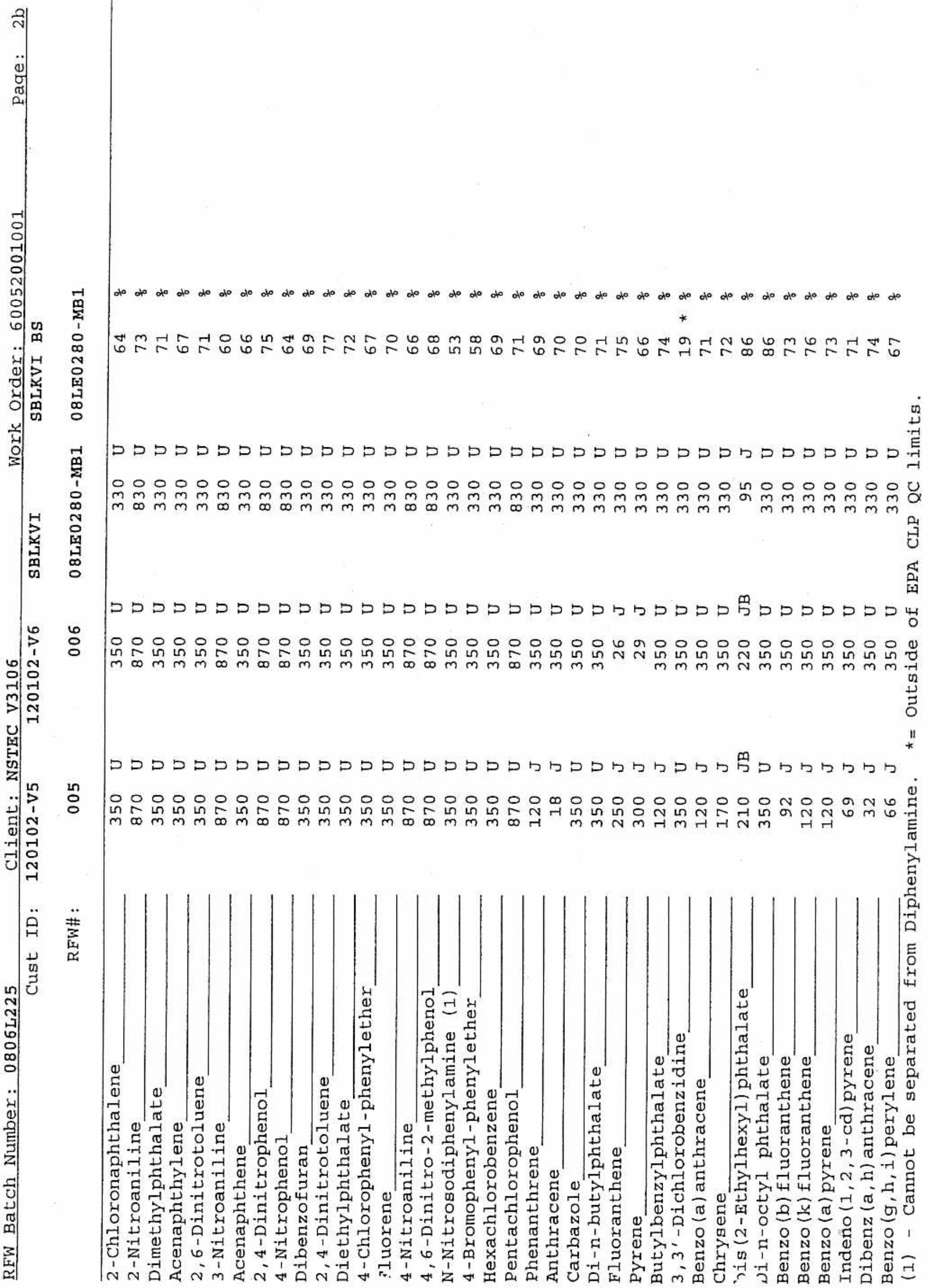




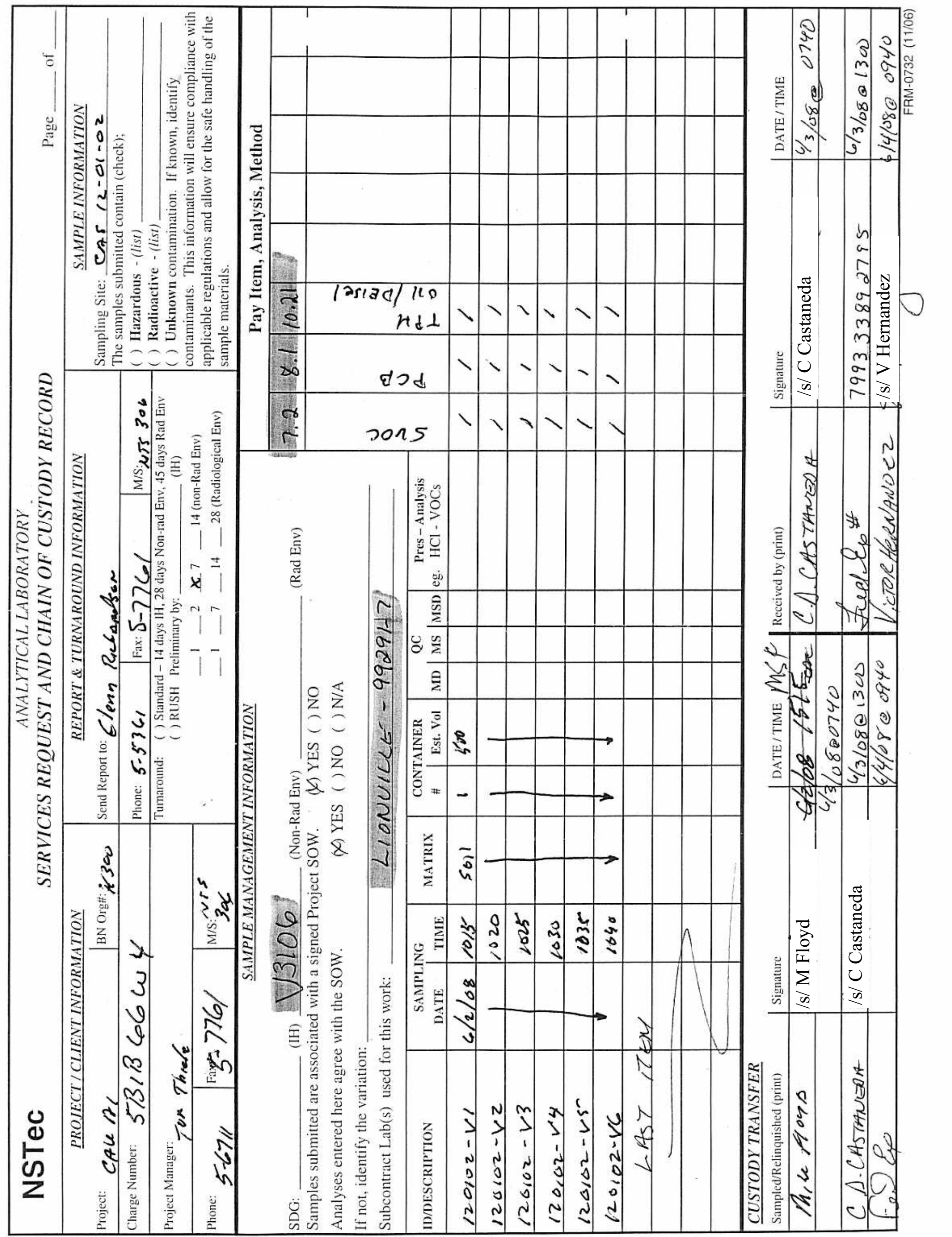


CAU 121 Closure Report

Section: Appendix B

Revision: 0

Date: September 2008

\section{THIS PAGE INTENTIONALLY LEFT BLANK}


CAU 121 Closure Report

Section: Appendix B

Revision: 0

Date: September 2008

Sample Delivery Group V3112 
CAU 121 Closure Report

Section: Appendix B

Revision: 0

Date: September 2008

\section{THIS PAGE INTENTIONALLY LEFT BLANK}




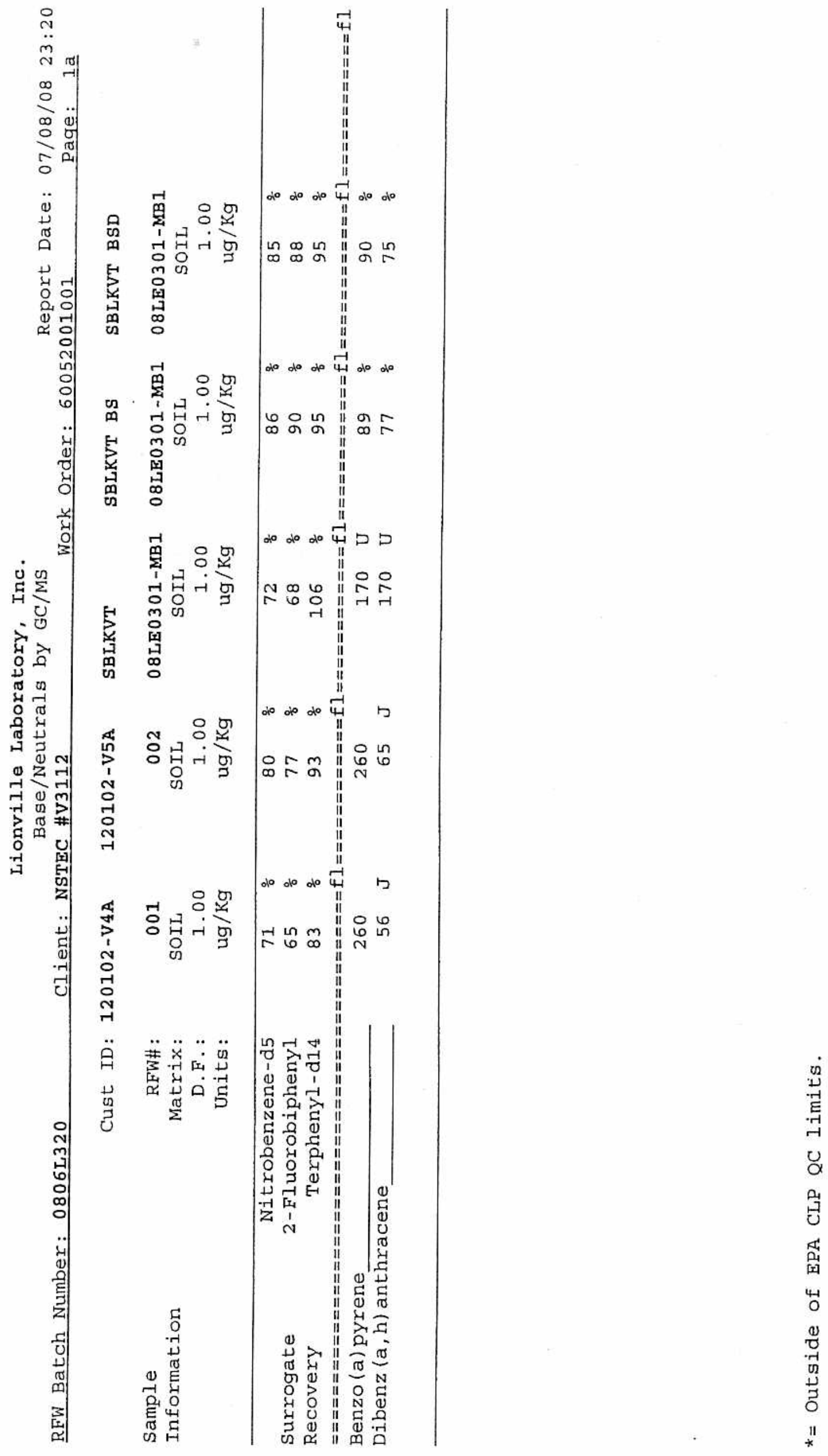




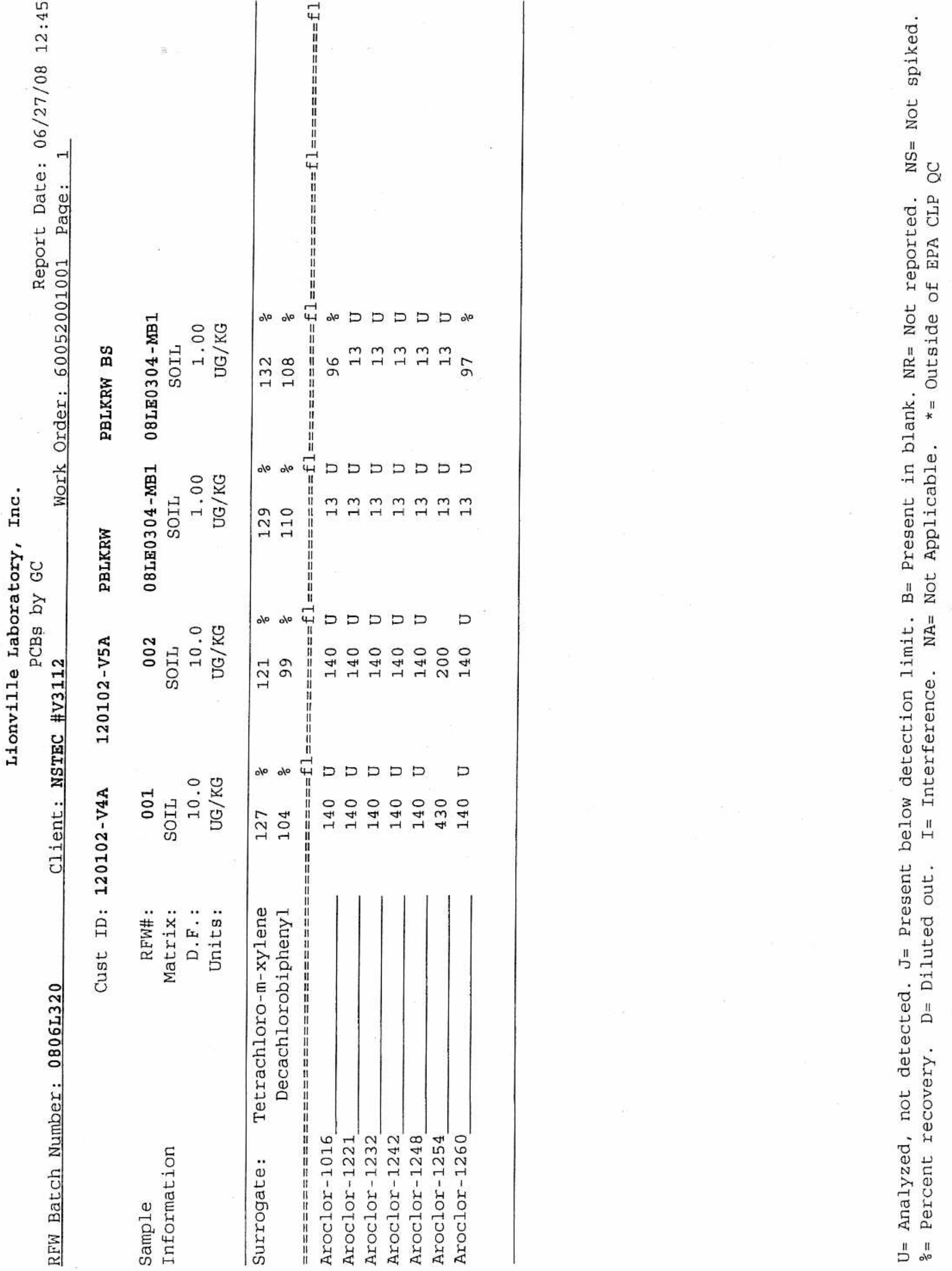




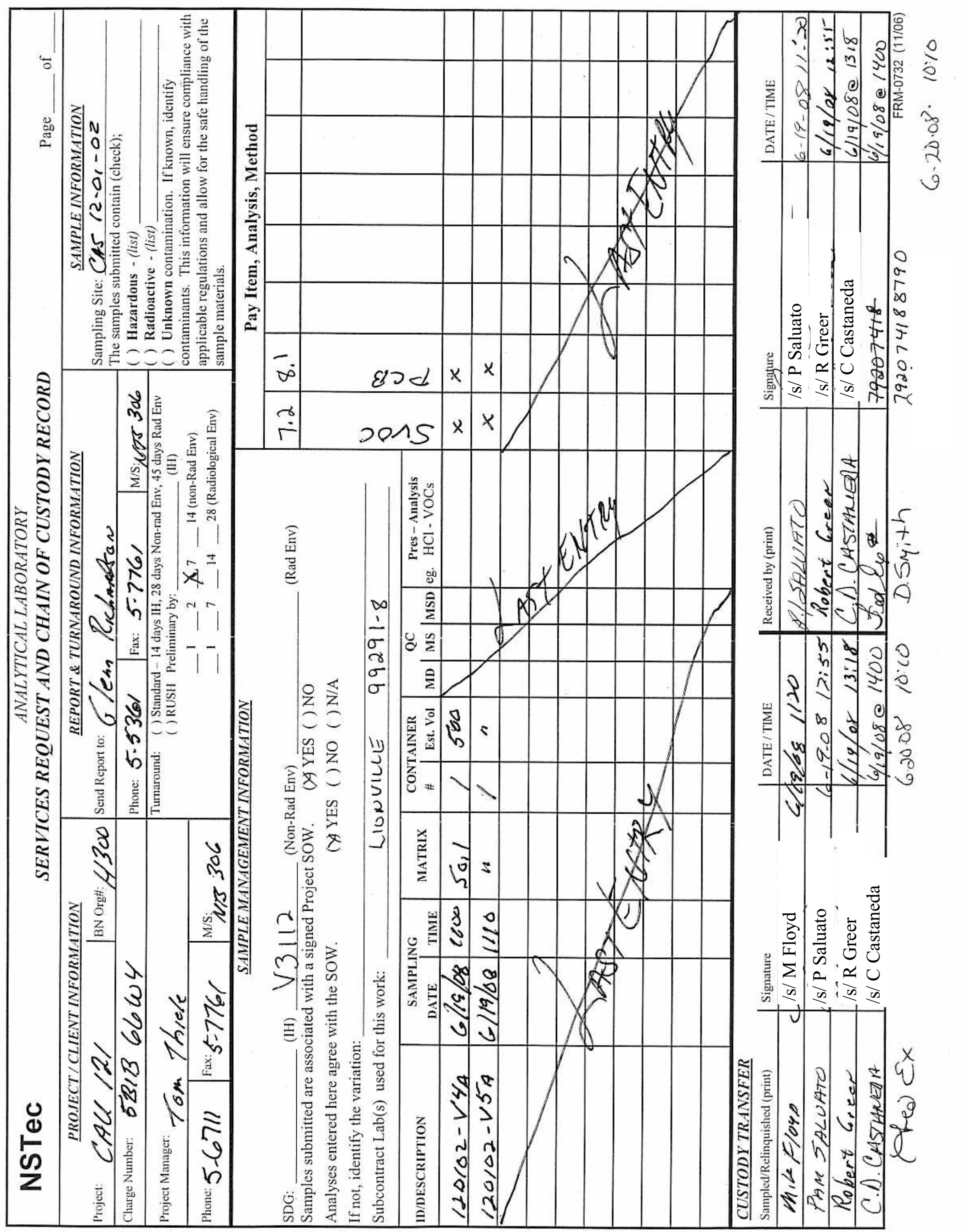


CAU 121 Closure Report

Section: Appendix B

Revision: 0

Date: September 2008

\section{THIS PAGE INTENTIONALLY LEFT BLANK}


CAU 121 Closure Report

Section: Appendix B

Revision: 0

Date: September 2008

\section{Sample Delivery Group V3130}


CAU 121 Closure Report

Section: Appendix B

Revision: 0

Date: September 2008

\section{THIS PAGE INTENTIONALLY LEFT BLANK}




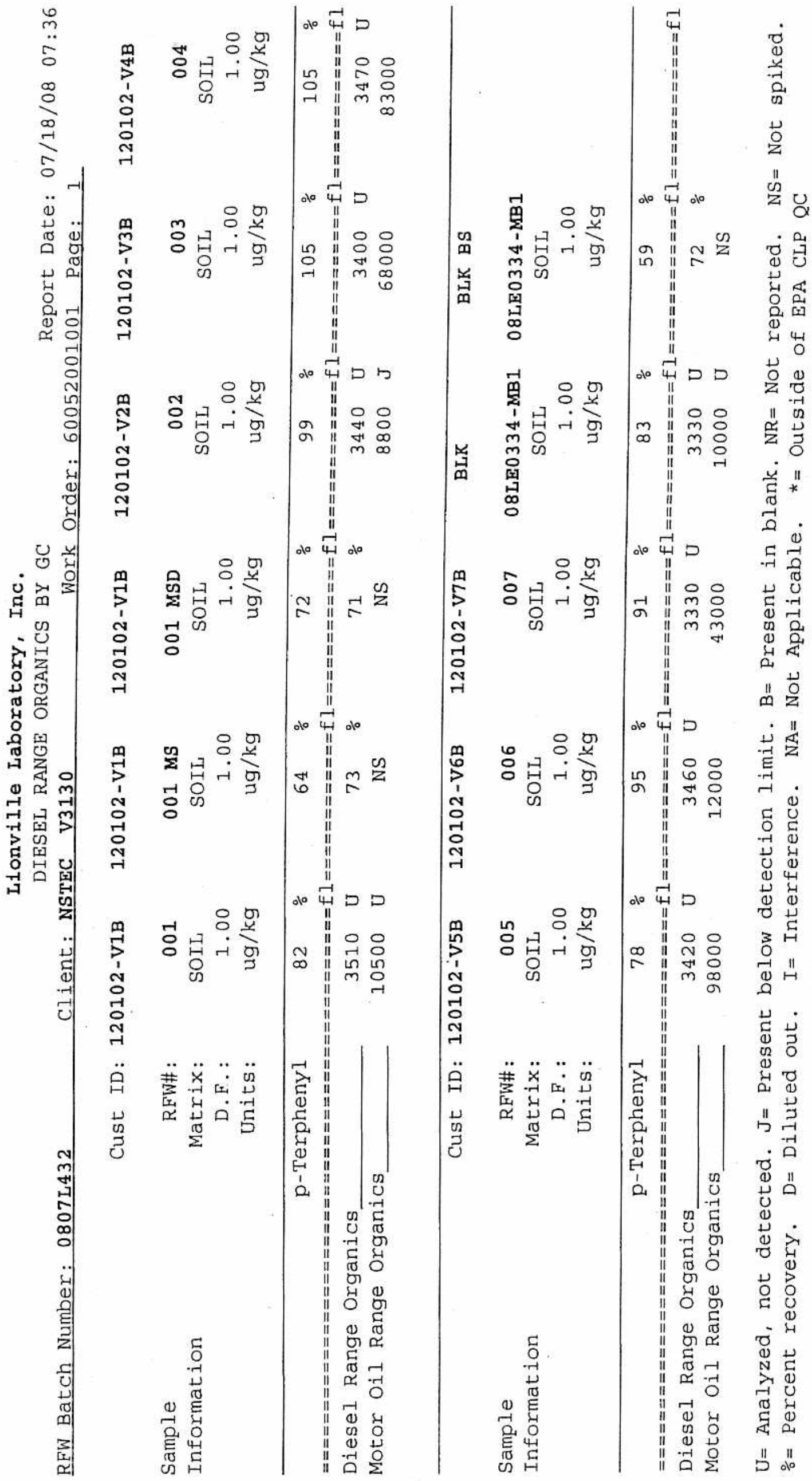




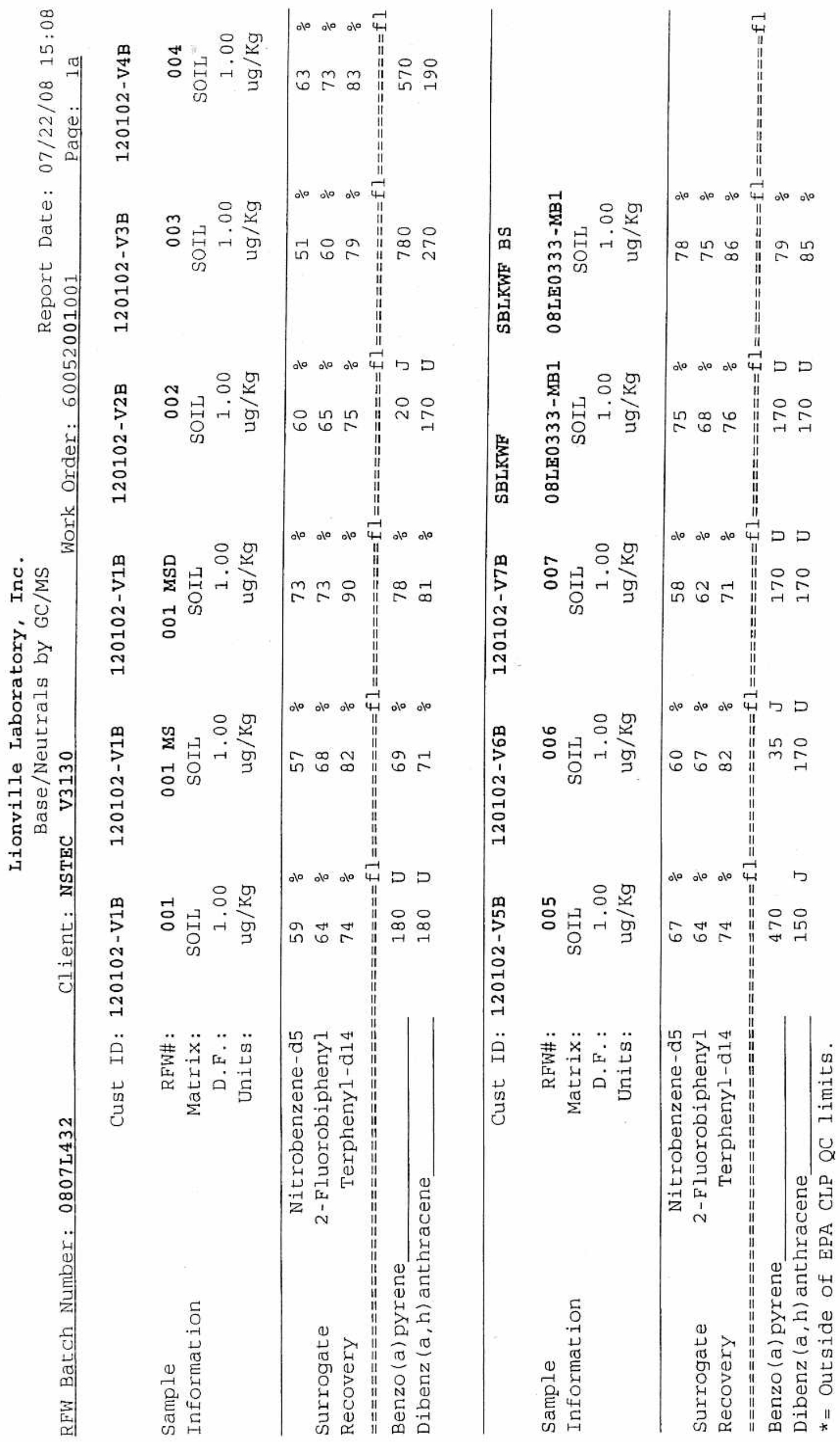


CAU 121 Closure Report

Section: Appendix B

Revision: 0

Date: September 2008

\section{THIS PAGE INTENTIONALLY LEFT BLANK}


CAU 121 Closure Report

Section: Appendix C

Revision: 0

Date: September 2008

\section{APPENDIX C}

\section{WASTE DISPOSITION DOCUMENTATION}


CAU 121 Closure Report

Section: Appendix C

Revision: 0

Date: September 2008

\section{THIS PAGE INTENTIONALLY LEFT BLANK}




\section{Tank Disposition}

- Corrective Action Sites 12-01-01 and 12-01-02, Aboveground Storage Tanks - Corrective Action Site 12-22-26, Drums; 2 AST's 
CAU 121 Closure Report

Section: Appendix C

Revision: 0

Date: September 2008

THIS PAGE INTENTIONALLY LEFT BLANK 
For waste characterization, approval, and/or assistance, contact Solid Waste Operation (SWO) at 5-7898.

\section{REQUIRED: WASTE GERERATOR INFORMATION}

(This form is for rolloffs, dump trucks, and other onsite disposal of materials.)

Waste Generator: MIKE FLOYD

Phone Number: $5-6653$

Location / Origin: CAU $121 / /$ area 12 camp

Waste Category: (check one)

Waste Type: $\square$ NTS

(check one)

$\square$ Non-Putrescible

Pollution Prevention Category: (check one)

Pollution Prevention Category: (check one)

Method of Characterization: (check one)

Prohibited Waste at all three

NTS landfills:

Additional Prohibited Waste

at the Area 9 U10C Landfill:

\section{Radioactive waste; RCRA waste; Hazardous waste; Free liquids,
levels, and Medical wastes (needles, sharps, bloody clothing).}

Sewage Sludge, Animal carcasses, Wet garbage (food waste); and Friable asbestos

\begin{tabular}{lll}
$\square$ Commercial & $\square$ Industrial \\
$\square$ Putrescrible & $\square$ FFACO-onsite & $\square$ WAC Exception \\
$\square$ Asbestos Containing Material & $\square$ FFACO-offsite & $\square$ Historic DOE/NV \\
$\square$ Environmental management & $\square$ Defense Projects \\
\hline Clean-Up & $\square$ YMP \\
\hline Sampling \& Analysis & $\square$ Process Knowledge $\square$ Contents
\end{tabular}

REQUIRED: WASTE CONTENTS ALLOWABLE WASTES

Check all allowable wastes that are contained within this load:

NOTE: Waste disposal at the Area 6 Hydrocarbon Landfill must have come into contact with petroleum hydrocarbons or coolants, such as: gasoline (no benzene, lead); jet fuel; diesel fuel; lubricants and hydraulics; kerosene; asphaltic petroleum hydrocarbon; and ethylene glycol.
Acceptable waste at any NTS landfill:
$\square$ Paper
$\square$ Soil
$\square$ Wood
$\square$ Cloth
$\square$ Rocks / unaltered geologic materials
$\square$ Rubber (excluding tires)
$\square$ Insulation (non-Asbestosform)
Plastic $\square$ Wire
Cable

\begin{abstract}
Cloth
\end{abstract}
carpet,

Achict

Additional waste accepted at the Area 23 Mercury Landfill: $\square$ Office Waste

$\square$ Asbestos

Friable

$\triangle$ Non-Friable (contact SWO if regulated load)

Food Waste

Quantity:

\section{Additional waste accepted at the Area 9 U10c Landfill:}

$\square$ Non-friable asbestos

$\square$ Light ballasts (contact SWO)

$\square$ Hydrocarbons (contact SWO)
Drained automobiles and military vehicles

Drained fuel filters (gas \& diesel)

Other
Solid fractions from sand/oil/water

Deconned Underground and Above Ground Tanks

Additional waste accepted at the Area 6 Hydrocarbon Landfill:
$\square$ Septic sludge
$\square$ Rags
$\square$ Drained fuel filters (gas \& diesel)
Soil
$\square$ Sludge from sand/oil/water separators
REQUIRED: WASTE GENERATOR SIGNATURE
Crushed non-teme plated oil filters PCBs below 50 parts per million

Initials: (if initialed, no radiological clearance is necessary.)

The above mentioned waste was generated outside of a Controlled Waste Management Area (CWMA) and to the best of my knowledge, does not contain radiological materials.

To the best of my knowledge, the waste described above contains only those mate site. I have verified this through the waste characterization method identified abov prohibited and allowable waste items. I have contacted Property Management and is approved for disposal in the landfill.

Print Name: Mike Floyd

Signature: ( /s/ Mike Floyd

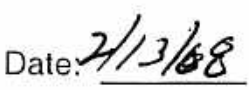

Radiological Survey Release for Waste Disposal RCT Initials

This container/load meets the criteria for no

P- This container/load meets the criteria for Radicon Manual Table 4.2 release limits. This container/load is exempt from survey due to process kngwledge and origin.

SIGNATURE: _ /S/ B H DATE: ${ }^{2-13-00}$

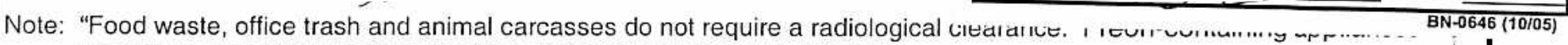
must have signed removal certification statement with Load Verification." 
NSTec

Form

\section{SWO USE (Select One) AREA \\ For wasta charactertzation aph \\ ब9 \\ $\triangle$ LANDFILL}

\section{This form REQUIRED: WASTE GERERATOR INFORMATION}

Waste Generator: GLENN RICHARASON Location / Drigin: CAU 121. Waste Category: (check one)

Waste Type: $\square$ NTS

(oheck ona)

$\square$ Non-Futresclble

Pollution Prevantion Category: (check one)

Polluklon Prevention Category: (check one) Method of Characterizatlon: (check one)

Prohlblted Waste at all three

NTS landfilis:

Additional Prohlblted Waste at the Area 9 U10C Landfill:

$$
\begin{aligned}
& \text { Radioactive waste; RCRA waste; Hazardous waste; Free liquids, PCBs above TSCA regulatory } \\
& \text { levels, and Medical wastes (needles, sherps, bloody clothing). }
\end{aligned}
$$

Phone Number: $5-5361$

\section{REQUIRED: WASTE CONTENTS ALLOWABLE WASTES}

NOTE: Waste disposal at the Area coolants, such as: gasoline (no benzene, lead) must have come into contact with petroleum hydrocarbons or petraleum hydrocarbon; and ethylene glycol.

\section{Acceptable waste at any NTS landfill:}
$\square$ Asphalt
$\square$ Metal
$\square$ Wood
$\square$ Soll
$\square$ Rocks / unaltered geologic materials
$\square$ Rubber (excluding tires)
$\square$ Plastic
$\square$ Cable
$\square$ Cloth
$\square$ Insulation (non-Asbestosform)

\section{Industria \\ $凶$ FFACO-onsite}

$\square$ Asbsstos Comtalning Materia

FACO-OFstte

$\square$ Historic DOE/NV

$\square$ Manufactured items: (swamp coolers, fumiture, rugs, carpet, electronic components, PPE, atc.)

Additional waste accepted at the Area 23 Mercury Landfill: $\square$ Office Waste $\square$ Food Waste $\square$ Asbestos $\square$ Frlable $\square$ Non-Friable (contact SWo If regulated load) Quantity:

Addlitonal Waste accepted at the Area 8 W10c Landfil:

$\square$ Non-friable asbestos

$\square$ Light bailasts (contact swo)

$\square$ Dralned automobiles and military vehicles

Hydrocarbons (contact swo)

Drained fuel filters (gas \& diesel)

Other Empty svo-gal desed temk Ground Tanks

Solid fractions from sand/oll/water

Deconned Underground and Alrove

Additional waste accepted at the Araa 6 Hydrocarbon Landfill:
$\square$ Septlc sludge $\square$ Rags
Plants
$\square$ Soil
$\square$ Drained fuel filters (gas \& diesel)
$\square$ Sludge from sand/ali/water separators
REQUIRED; WASTE GENERA?

Initials: (if initialed, no radialogical clearance is necossary.)

The above mentioned waste was generated outside of a Controlled Wa knowiedgo, does not contaln radiologlcel materlals.

To the best of my knowledge, the waste described above contains anly site. I have verified this through the waste charactorization method ide prohibited and allowable waste itoms. I have contactad Property Mana is approved for dlopozin in the landfill.

Radiological Survey Release for Waste Disposal RCT Initials

\section{Crusherd non-teme plated oil filters} PCBs below 50 parts per million

\section{Empty containers}

Demolition debris

Cement \& concrete

Anlmal Carcasses

Print Nama: GLENN EICHORASOSL?

Signature: _/s/ G Richardson

Note: "Food waste, offlce trash' '

must have signed removal certificalion stasses do not require a radlólogical clearance. Freon-containing appliances SWO IJSE ONLY

Load Weight (net from scale qr estimate): $1,500 . \begin{gathered}4-17-08 \\ \text { Signature of Certifieg: /s/ D Bickford }\end{gathered}$ djalogiçal Release Stickar" here. Onsite use only.

This container/load meets the criteria for no added man-made radioactive material This container/load meets the criteria for Radcon Manual Table 4.2 release limits. This container/loagh is exempt from survey due to process knowledge and origin.

SIGNATURE: See original

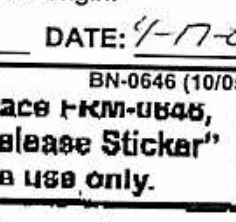


CAU 121 Closure Report

Section: Appendix C

Revision: 0

Date: September 2008

\section{Excavated Soil Disposition}

Corrective Action Site 12-01-02, Aboveground Storage Tank 
CAU 121 Closure Report

Section: Appendix C

Revision: 0

Date: September 2008

\section{THIS PAGE INTENTIONALLY LEFT BLANK}




\begin{tabular}{|llllll}
\hline SWO USE (Select One) & AREA & $\square 23$ & $\square 6$ & Q 9 & $\square$ LANDFILL
\end{tabular}

For waste characterization, approval, and/or assistance, contact Solid Waste Operation (SWO) at 5-7898. REQUIRED: WASTE GERERATOR INFORMATION

(This form is for rolloffs, dump trucks, and other onsite disposal of materials.)

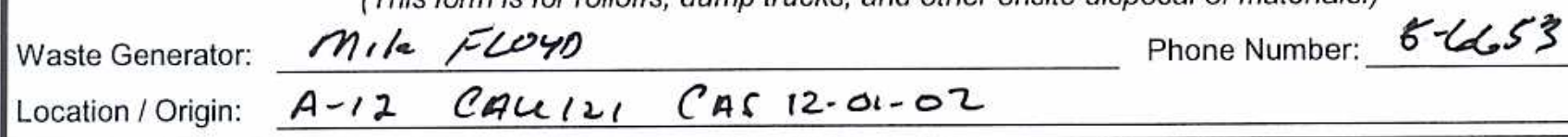

Waste Category: (check one)

Waste Type: $\otimes$ NTS $\square$ Commercial

$\triangle$ Industrial

(check one)

$\square$ Non-Putrescible

$\square$ Putrescrible

FFACO-onsite

WAC Exception

Pollution Prevention Category: (check one)

Pollution Prevention Category: (check one)

$\square$ Asbestos Containing Material

FFACO-offsite

Historic DOE/NV

Environmental management

$\square$ Defense Projects
$\square$ Routine

$\triangle$ Clean-Up

Method of Characterization: (check one) \ Sampling \& Analysis

TSE Process Knowledge

YMP

NTS landfills: levels, and Medical wastes (needles, sharps, bloody clothing).

Additional Prohibited Waste at the Area 9 U10C Landfill:

Sewage Sludge, Animal carcasses, Wet garbage (food waste); and Friable asbestos

\section{REQUIRED: WASTE CONTENTS ALLOWABLE WASTES}

Check all allowable wastes that are contained within this load:

NOTE: Waste disposal at the Area 6 Hydrocarbon Landfill must have come into contact with petroleum hydrocarbons or coolants, such as: gasoline (no benzene, lead); jet fuel; diesel fuel; lubricants and hydraulics; kerosene; asphaltic petroleum hydrocarbon; and ethylene glycol.

Acceptable waste at any NTS landfill: $\square$ Paper

$\square$ Asphalt $\square$ Metal $\square$ Wood $\square$ Soil

$\square$ Rocks / unaltered geologic materials

$\square$ Empty containers

S Plastic

Plastic $\square$ Wire $\square$ Cable $\square$ Cloth $\square$ Insulation (non-Asbestosform)
Manufactured items: (swamp coolers, furniture, rugs, carpet, electronic components, PPE, etc.)

Plastic $\square$ Wire $\square$ Cable $\square$ Cloth $\square$ Insulation (non-Asbestosform)
Manufactured items: (swamp coolers, furniture, rugs, carpet, electronic components, PPE, etc.)

$\square$ Rubber (excluding tires)

$\square$ Demolition debris

Additional waste accepted at the Area 23 Mercury Landfill: $\quad \square$ Office Waste $\square$ Food Waste $\square$ Animal Carcasses
Asbestos
Friable
Non-Friable (contact SWO if regulated load)
Quantity:

Additional waste accepted at the Area 9 U10c Landfill:

$\begin{array}{ll}\square \text { Non-friable asbestos } & \square \text { Drained automobiles and military vehicles } \\ \square \text { Light ballasts (contact SWO) } & \square \text { Drained fuel filters (gas \& diesel) } \\ \square \text { Hydrocarbons (contact SWO) } & \square \text { Other }\end{array}$
Solid fractions from sand/oil/water

Deconned Underground and Above Ground Tanks

Additional waste accepted at the Area 6 Hydrocarbon Landfill:
$\square$ Septic sludge
$\square$ Rags
$\square$ Drained fuel filters (gas \& diesel)
Crushed non-teme plated oil filters
Plants
Soil
Sludge from sand/oil/water separators
PCBs below 50 parts per million

Initials: (if initialed, no radiological clearance is necessary.)

The above mentioned waste was generated outside of a Controlled Was knowledge, does not contain radiological materials.

To the best of my knowledge, the waste described above contains only site. I have verified this through the waste characterization method ider prohibited and allowable waste items. I have contacted Property Manag is approved for disposal in the landfill.

Print Name: M/L Flcy?

Signature: /s/M Floyd
Radiological Survey Release for Waste Disposal RCT Initials

This container/load meets the criteria for no
added man-made radioactive material
This container/load meets the criteria for
Radcon Manual Table 4.2 release limits.
This container/load is exempt from survey
due to progess knowledge and origin.

SIGNATURE see original

$$
=\frac{\text { DATE: } \frac{5-29+88}{B N-0646(10 / 05)}}{106}
$$

Note: "Food waste, office trash and animal carcasses do not require a radiological clearance. Freon-containing appliances must have signed removal certification statement with Load Verification."

SWO USE ONLY

Load Weight (net from scale of estimate):
$5-29-08$

Signature of Certifier: /s/ D Bickford
If applicable, place FRM-0646,

"Radiological Release Sticker" here. Onsite use only. 


\section{$\begin{array}{llllll}\text { SWO USE (Select One) } & \text { AREA } & \square 23 & \square 6 & \square 9 & \square \text { LANDFILL }\end{array}$}

For waste characterization, approval, and/or assistance, contact Solid Waste Operation (SWO) at 5-7898.

REQUIRED: WASTE GERERATOR INFORMATION

(This form is for rolloffs, dump trucks, and other onsite disposal of materials.)

Waste Generator: MIKE FLOYD

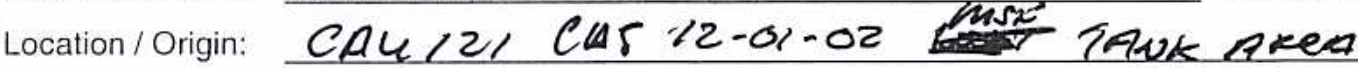

Waste Category: (check one)

$\square$ Commercial $\triangle$ Industrial

Waste Type: $\square$ NTS

$\square$ Putrescrible

$\triangle$ FFACO-onsite

WAC Exception

(check one)

$\square$ Non-Putrescible

$\square$ Asbestos Containing Material

$\square$ FFACO-offsite

Historic DOE/NV

Pollution Prevention Category: (check one)

Pollution Prevention Category: (check one)

Method of Characterization: (check one)

$\triangle$ Environmental management

$\triangle$ Clean-Up

Prohibited Waste at all three Radioactive waste; RCRA waste; Hazardous waste; Free liquids, PCBs above TSCA regulatory NTS landfills:

Additional Prohibited Waste

at the Area 9 U10C Landfill:

levels, and Medical wastes (needles, sharps, bloody clothing).

Sewage Sludge, Animal carcasses, Wet garbage (food waste); and Friable asbestos

\section{REQUIRED: WASTE CONTENTS ALLOWABLE WASTES}

Check all allowable wastes that are contained within this load:

NOTE: Waste disposal at the Area 6 Hydrocarbon Landfill must have come into contact with petroleum hydrocarbons or coolants, such as: gasoline (no benzene, lead); jet fuel; diesel fuel; lubricants and hydraulics; kerosene; asphaltic petroleum hydrocarbon; and ethylene glycol.
Acceptable waste at any NTS landfill:
$\square$ Paper
Rocks / unaltered geologic materials
Empty containers
$\square$ Asphalt $\square$ Metal $\square$ Wood $\square$ Soil
$\square$ Rubber (excluding tires)
Plastic
$\square$ Cable
$\square$ Cloth
Insulation (non-Asbestosform)
Demolition debris
Cement \& concrete

Manufactured items: (swamp coolers, furniture, rugs, carpet, electronic components, PPE, etc.)

Additional waste accepted at the Area 23 Mercury Landfill: $\quad \square$ Office Waste

Food Waste

Animal Carcasses

$\square$ Asbestos

Friable

Non-Friable (contact SWO if regulated load)

Quantity:

Additional waste accepted at the Area 9 U10c Landfill:

$\square$ Non-friable asbestos

Drained automobiles and military vehicles

Solid fractions from sand/oil/water

$\square$ Light ballasts (contact SWO)

Drained fuel filters (gas \& diesel)

Deconned Underground and Above

[E. Hydrocarbons (contact SWO) Other

Ground Tanks

Additional waste accepted at the Area 6 Hydrocarbon Landfill:

$\square$ Septic sludge $\square$ Rags $\square$ Drained fuel filters (gas \& diesel)

Plants $\square$ Soil $\square$ Sludge from sand/oil/water separators REQUIRED: WASTE GENER/

Initials: (if initialed, no radiological clearance is necessary.)

The above mentioned waste was generated outside of a Controlled W: knowledge, does not contain radiological materials.

To the best of my knowledge, the waste described above contains onl site. I have verified this through the waste characterization method id prohibited and allowable waste items. I have contacted Property Man is approved for disposal in the landfill.

Radiological Survey Release for Waste Disposal RCT Initials

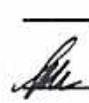

This container/load meets the criteria for no added man-made radioactive material This container/load meets the criteria for Radcon Manual Table 4.2 release limits. This container/load is exempt from survey due to proçess knowledge and origin.

SIGNATURE: see original DATE: $6-2-0 q$ BN-0646(10/05) !nt

Print Name: Mike Floy

Signature: /s/ M Floyd

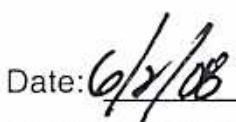

If applicable, place FRM-0646,

"Radiological Release Sticker" here. Onsite use only.

Note: "Food waste, office trash and animal carcasses do not require a radiological clearance. Freon-containing appliances must have signed removal certification statement with Load Verification." 
SWO USE (Select One) AREA

23

$\square 6$

凶9

$\triangle$ LANDFILL

For waste characterization, approval, and/or assistance, contact Solid Waste Operation (SWO) at 5-7898.

REQUIRED: WASTE GERERATOR INFORMATION

(This form is for rolloffs, dump trucks, and other onsite disposal of materials.)

Waste Generator: MIKE FLOYD

Phone Number: 5-6653

Location / Origin: $\quad$ CAU 121 // CAS 12-01-02 // AREA 12

Waste Category: (check one)

$\square$ Commercial

$\bigotimes$ Industrial

Waste Type: \ NTS

$\square$ Putrescrible

$\triangle$ FFACO-onsite

WAC Exception

(check one)

$\square$ Non-Putrescible

$\square$ Asbestos Containing Material

FFACO-offsite Historic DOE/NV

Pollution Prevention Category: (check one)

Pollution Prevention Category: (check one)

Method of Characterization: (check one)

$\triangle$ Environmental management

$凶$ Clean-Up

Prohibited Waste at all three

NTS landfills:

\ Sampling \& Analysis

$\square$ Defense Projects

YMP

Additional Prohibited Waste

at the Area 9 U10C Landfill:

Radioactive waste; RCRA waste; Hazardous waste; Free liquids,
levels, and Medical wastes (needles, sharps, bloody clothing).

Sewage Sludge, Animal carcasses, Wet garbage (food waste); and Friable asbestos

\section{REQUIRED: WASTE CONTENTS ALLOWABLE WASTES}

Check all allowable wastes that are contained within this load:

NOTE: Waste disposal at the Area 6 Hydrocarbon Landfill must have come into contact with petroleum hydrocarbons or coolants, such as: gasoline (no benzene, lead); jet fuel; diesel fuel; lubricants and hydraulics; kerosene; asphaltic petroleum hydrocarbon; and ethylene glycol.

Acceptable waste at any NTS landfill: $\quad \square$ Paper $\quad \square$ Rocks / unaltered geologic materials

$\square$ Asphalt $\square$ Metal $\square$ Wood $\quad \square$ Soil $\square$ Rubber (excluding tires)
Plastic
Wire
Cable
$\square$ Cloth
$\square$ Insulation (non-Asbestosform)

$\square$ Empty containers

$\square$ Demolition debris

$\square$ Cement \& concrete

Manufactured items: (swamp coolers, furniture, rugs, carpet, electronic components, PPE, etc.)

Additional waste accepted at the Area 23 Mercury Landfill: $\square$ Office Waste

$\square$ Asbestos

$\square$ Friable

$\square$ Non-Friable (contact SWO if regulated load)

Food Waste

Animal Carcasses

Additional waste accepted at the Area 9 U10c Landfill:
$\square$ Non-friable asbestos
Drained automobiles and military vehicles
Light ballasts (contact SWO)
Drained fuel filters (gas \& diesel)
Hydrocarbons (contact SWO)
Other $\mathrm{PCB}<2 \mathrm{PPM}$

Quantity:

\section{Additional waste accepted at the Area 6 Hydrocarbon Landfill:}

\begin{tabular}{|c|c|c|c|}
\hline Septic sludge & Rags & Drained fuel filters (gas \& diesel) & Crushed non-teme plated oil filters \\
\hline Plants & Soil & Sludge from sand/oil/water separators & PCBs below 50 parts per million \\
\hline
\end{tabular}

Initials: (if initialed, no radiological clearance is necessary.)

The above mentioned waste was generated outside of a Controlled Waste Management Area (CWMA) and to the best of my knowledge, does not contain radiological materials.

To the best of my knowledge, the waste described above contains only those materia site. I have verified this through the waste characterization method identified above : prohibited and allowable waste items. I have contacted Property Management and hi is approved for disposal in the landfill.

Print Name: Mike Floyd

Signature: / /s/ M Floyd

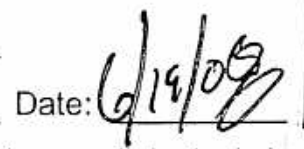

Solid fractions from sand/oil/water

Deconned Underground and Above Ground Tanks

Note: "Food waste, office trash and animal carcasses do not require a radiological cle. must have signed removal certification statement with Load Verification."

\section{SWO USE ONLY}

Load Weight (net frona-scale or estimate):
$6 / 19 / 08$

Signature of Certifier
Radiological Survey Release for Waste Disposal RCT Initials

Nht This container/load meets the criteria for no added man-made radioactive material This container/load meets the criteria for NA Radcon Manual Table 4.2 release limits. due to process knowledge and origin.

SIGNATURE: see original $\lesssim$ DATE: $6-1908$ $n$ FRM-0646 (08/06) 


$\begin{array}{lllllll}\text { SWO USE (Select One) } & \text { AREA } & \square 23 & \square 6 & \square 9 & \text { ¿ LANDFILL }\end{array}$

For waste characterization, approval, and/or assistance, contact Solid Waste Operation (SWO) at 5-7898.

\section{REQUIRED: WASTE GERERATOR INFORMATION}

(This form is for rolloffs, dump trucks, and other onsite disposal of materials.)

Waste Generator: MIKE FLOYD

Phone Number: 5-6653

Location / Origin: $\quad$ CAU 121 // CAS 12-01-02 // AREA 12

\begin{tabular}{|c|c|c|c|}
\hline Waste Category: (check one) & $\square$ Commercial & $\bigotimes$ Industrial & \\
\hline Waste Type: $\quad$ NTS & $\square$ Putrescrible & $\triangle$ FFACO-onsite & $\square$ WAC Exception \\
\hline$\square$ Non-Putrescible & $\square$ Asbestos Containing Material & $\square$ FFACO-offsite & $\square$ Historic DOE/NV \\
\hline Pollution Prevention Category: (check one) & $\triangle$ Environmental management & $\square$ Defense Projects & $\square$ YMP \\
\hline Pollution Prevention Category: (check one) & $\triangle$ Clean-Up & $\square$ Routine & \\
\hline Method of Characterization: (check one) & $\triangle$ Sampling \& Analysis & $\square$ Process Knowledg & $\square$ Contents \\
\hline
\end{tabular}

Prohibited Waste at all three Radioactive waste; RCRA waste; Hazardous waste; Free liquids, PCBs above TSCA regulatory NTS landfills: levels, and Medical wastes (needles, sharps, bloody clothing).

Additional Prohibited Waste at the Area 9 U10C Landfill:

Sewage Sludge, Animal carcasses, Wet garbage (food waste); and Friable asbestos

\section{REQUIRED: WASTE CONTENTS ALLOWABLE WASTES}

Check all allowable wastes that are contained within this load:

NOTE: Waste disposal at the Area 6 Hydrocarbon Landfill must have come into contact with petroleum hydrocarbons or coolants, such as: gasoline (no benzene, lead); jet fuel; diesel fuel; lubricants and hydraulics; kerosene; asphaltic petroleum hydrocarbon; and ethylene glycol.

Acceptable waste at any NTS landfill: $\quad \square$ Pape

Asphalt $\square$ Metal $\square$ Wood $\quad$ Soil

Soil

$\square$ Rocks / unaltered geologic materials

$\square$ Empty containers

Plastic

$\square$ Cable

$\square$ Rubber (excluding tires)

$\square$ Demolition debris

Manufactured items: (swamp coolers, furniture, rugs, carpet, electronic components, PPE, etc.)

Additional waste accepted at the Area 23 Mercury Landfill: $\square$ Office Waste $\square$ Food Waste $\square$ Animal Carcasses $\square$ Asbestos

Non-Friable (contact SWO if regulated load)

Quantity:

Additional waste accepted at the Area 9 U10c Landfill:
$\square$ Non-friable asbestos
Drained automobiles and military vehicles
Light ballasts (contact SWO)
Drained fuel filters (gas \& diesel)
Solid fractions from sand/oil/water
Hydrocarbons (contact SWO) $\bigotimes$ Other $<2 \mathrm{ppm}$ for PCB
Deconned Underground and Above Ground Tanks

Additional waste accepted at the Area 6 Hydrocarbon Landfill:
$\square$ Septic sludge
$\square$ Rags
$\square$ Drained fuel filters (gas \& diesel)
Crushed non-teme plated oil filters
Plants
Soil
$\square$ Sludge from sand/oil/water separators
PCBs below 50 parts per million

\section{REQUIRED: WASTE GENERATOR SIGNATURE}

Initials: (if initialed, no radiological clearance is necessary.)

The above mentioned waste was generated outside of a Controlled Waste Management Area (CWMA) and to the best of my knowledge, does not contain radiological materials.

To the best of my knowledge, the waste described above contains only those mat site. I have verified this through the waste characterization method identified abo prohibited and allowable waste items. I have contacted Property Management anı is approved for disposal in the landfill.

Print Name: Mike Floyd, $\cap 11$

Signature: /s/ M Floyd

Note: "Food waste, office trash and animal carcasses do not require a radiologica must have signed removal certification statement with Load Verification."

\section{SWO USE ONLY}

Load Weight (net from كcale òr estimate):
Signature of Certifier:

$$
7 / 10 / 08
$$

Ran -11 n...nnd for disnosal at this Radiological Survey Release for Waste Disposal
RCT Initials

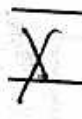
This container/load meets the criteria for no added man-made radioactive material This container/load meets the criteria for Radcon Manual Table 4.2 release limits. This container/load is exempt from surve due to-process knowlerne and origin survey

SIGNATURE: see original

/s/ D Bickford DATE: $7 / 60 / 08$ 
CAU 121 Closure Report

Section: Appendix D

Revision: 0

Date: September 2008

\section{APPENDIX D}

\section{SITE CLOSURE PHOTOGRAPHS}


CAU 121 Closure Report

Section: Appendix D

Revision: 0

Date: September 2008

\section{THIS PAGE INTENTIONALLY LEFT BLANK}


PHOTOGRAPH LOG

\begin{tabular}{|c|c|c|l||}
\hline $\begin{array}{c}\text { PHOTOGRAPH } \\
\text { NUMBER }\end{array}$ & DATE & $\begin{array}{c}\text { CORRECIVE } \\
\text { ACTION SITE }\end{array}$ & \multicolumn{1}{|c||}{ DESCRIPTION } \\
\hline \hline 1 & $02 / 13 / 2008$ & $12-01-01$ & $\begin{array}{l}\text { Aboveground storage tank after rolling to allow sampling, before } \\
\text { removal }\end{array}$ \\
\hline 2 & $02 / 13 / 2008$ & $12-01-01$ & Aboveground storage tank removal \\
\hline 3 & $02 / 13 / 2008$ & $12-01-01$ & Corrective Action Site after completion of field activities \\
\hline 4 & $02 / 13 / 2008$ & $12-01-02$ & Aboveground storage tank before field activities \\
\hline 5 & $05 / 29 / 2008$ & $12-01-02$ & $\begin{array}{l}\text { Aboveground storage tank location after tank removal, during } \\
\text { excavation }\end{array}$ \\
\hline 6 & $06 / 02 / 2008$ & $12-01-02$ & Excavation sample locations \\
\hline 7 & $07 / 10 / 2008$ & $12-01-02$ & $\begin{array}{l}\text { Final excavation showing proximity to Area 12 Camp water tank } \\
\text { and surrounding access pad }\end{array}$ \\
\hline 8 & $07 / 10 / 2008$ & $12-01-02$ & $\begin{array}{l}\text { Final excavation fairly representative of surface slope of volcanic } \\
\text { tuff. Rocks within excavated area are fragments of tuff that were } \\
\text { broken off by the backhoe. }\end{array}$ \\
\hline 9 & $09 / 15 / 2008$ & $12-01-02$ & Corrective Action Site after completion of field activities \\
\hline 10 & $03 / 26 / 2008$ & $12-22-26$ & Aboveground storage tank before start of field activities \\
\hline 11 & $04 / 17 / 2008$ & $12-22-26$ & Aboveground storage tank removal \\
\hline 12 & $04 / 15 / 2008$ & $12-22-26$ & Drum area, gridded and marked for sample collection \\
\hline 13 & $04 / 15 / 2008$ & $12-22-26$ & $\begin{array}{l}\text { Sample location when tank was located to the north of the } \\
\text { operational tank area }\end{array}$ \\
\hline 14 & $04 / 15 / 2008$ & $12-22-26$ & $\begin{array}{l}\text { Tank area marked for sample collection when tank was operational, } \\
\text { near train tracks }\end{array}$ \\
\hline & & &
\end{tabular}


CAU 121 Closure Report

Section: Appendix D

Revision: 0

Date: September 2008

\section{THIS PAGE INTENTIONALLY LEFT BLANK}




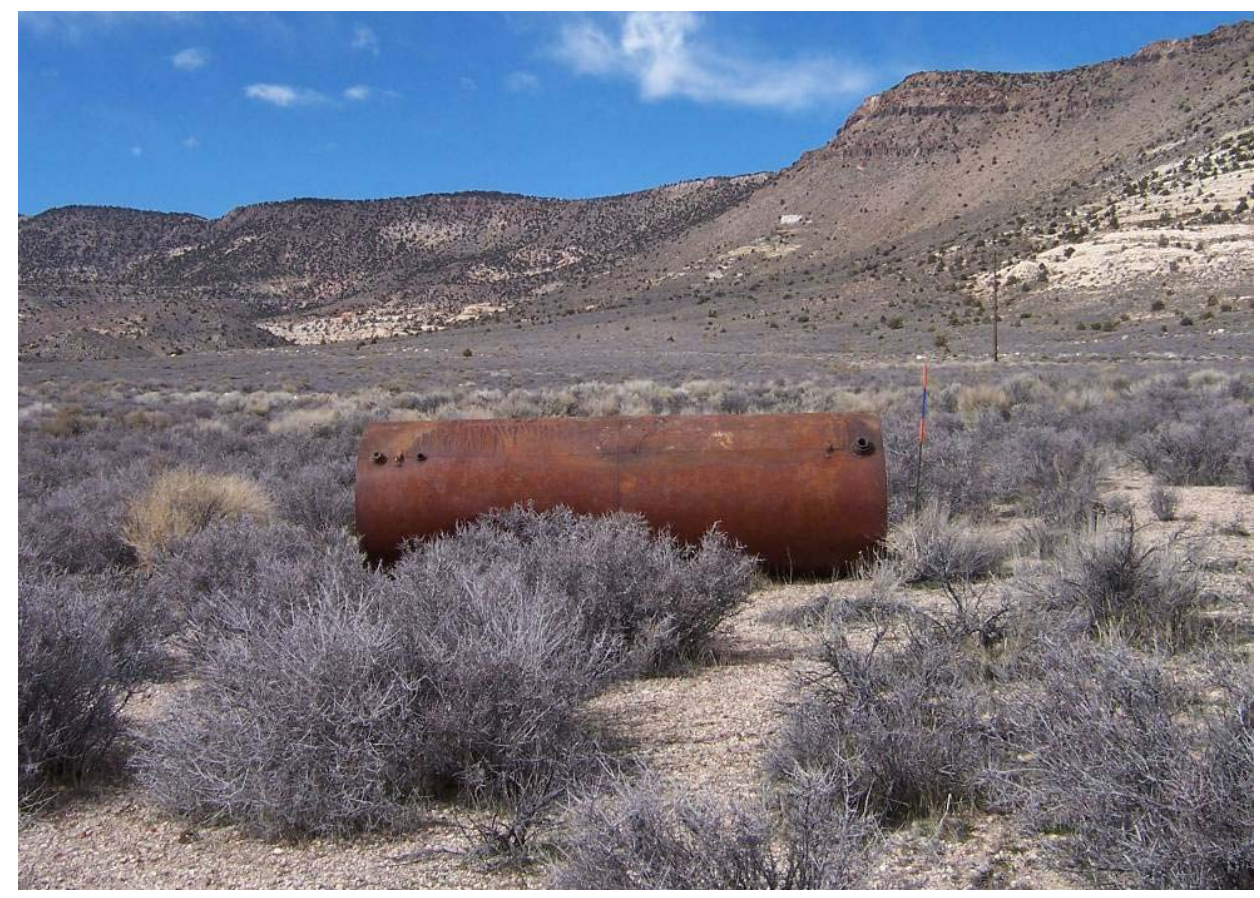

Photograph 1. CAS 12-01-01: Aboveground storage tank after rolling to allow sampling, before removal (02/13/2008)

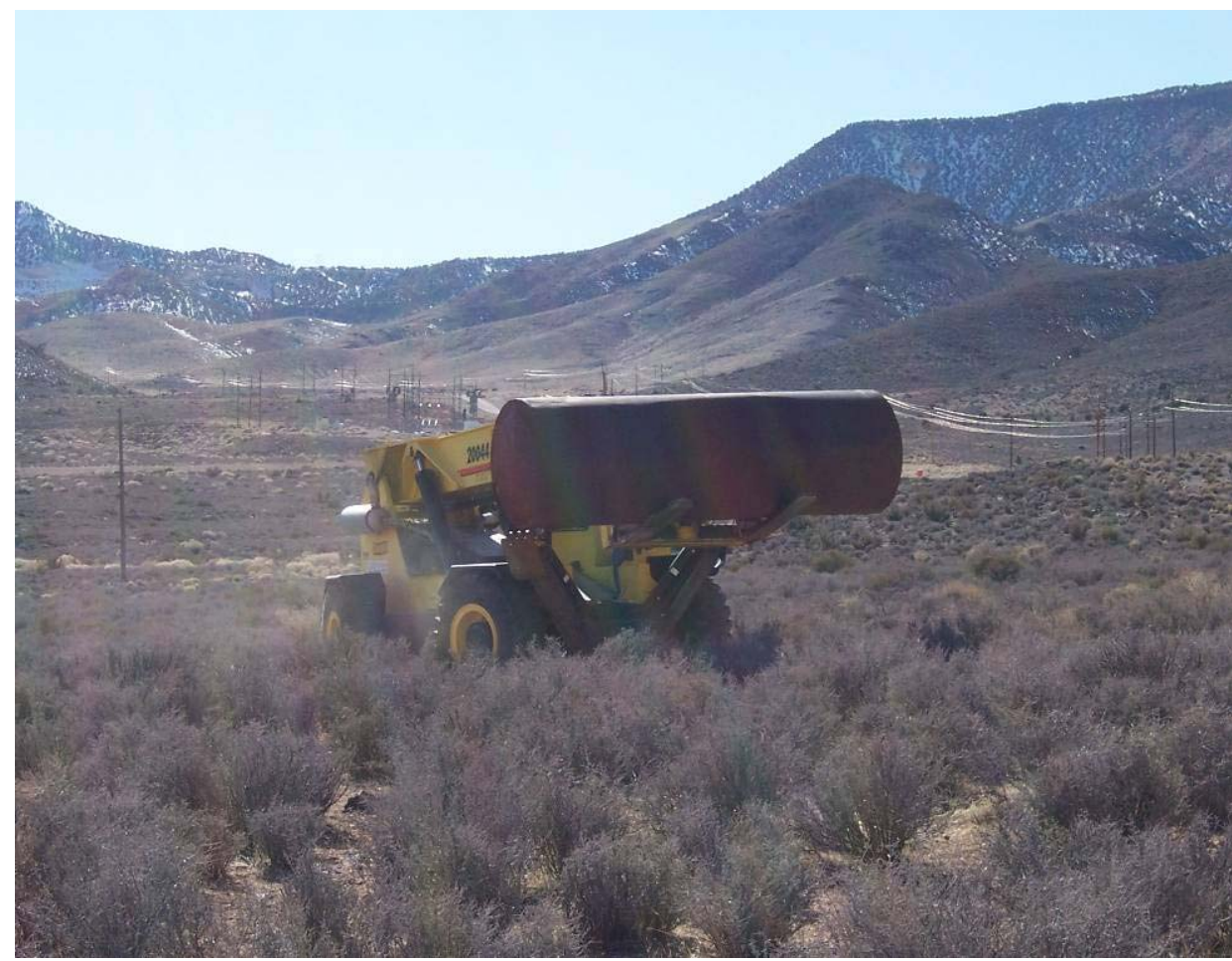

Photograph 2. CAS 12-01-01: Aboveground storage tank removal (02/13/2008) 


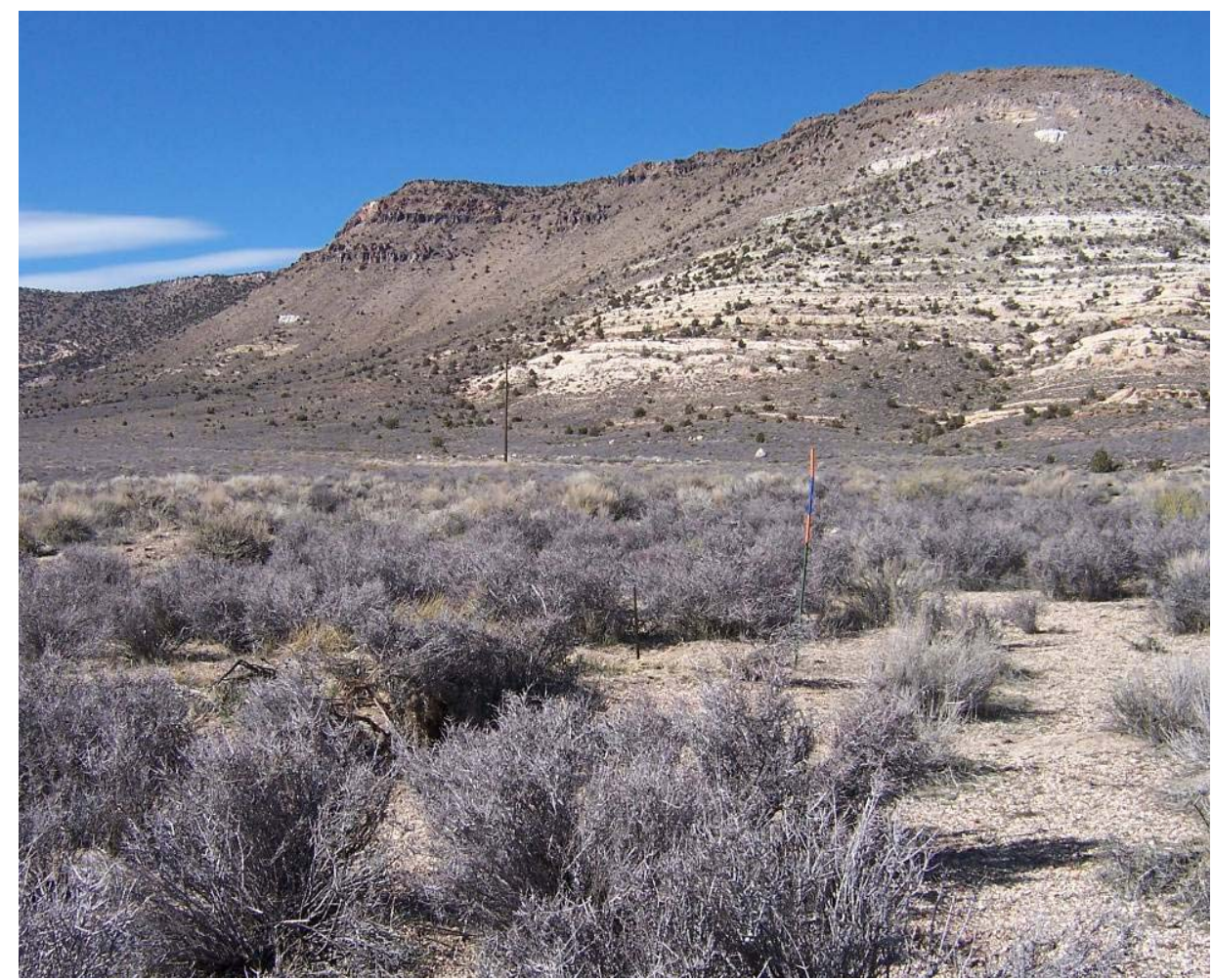

Photograph 3. CAS 12-01-01: Corrective Action Site after completion of field activities $(02 / 13 / 2008)$

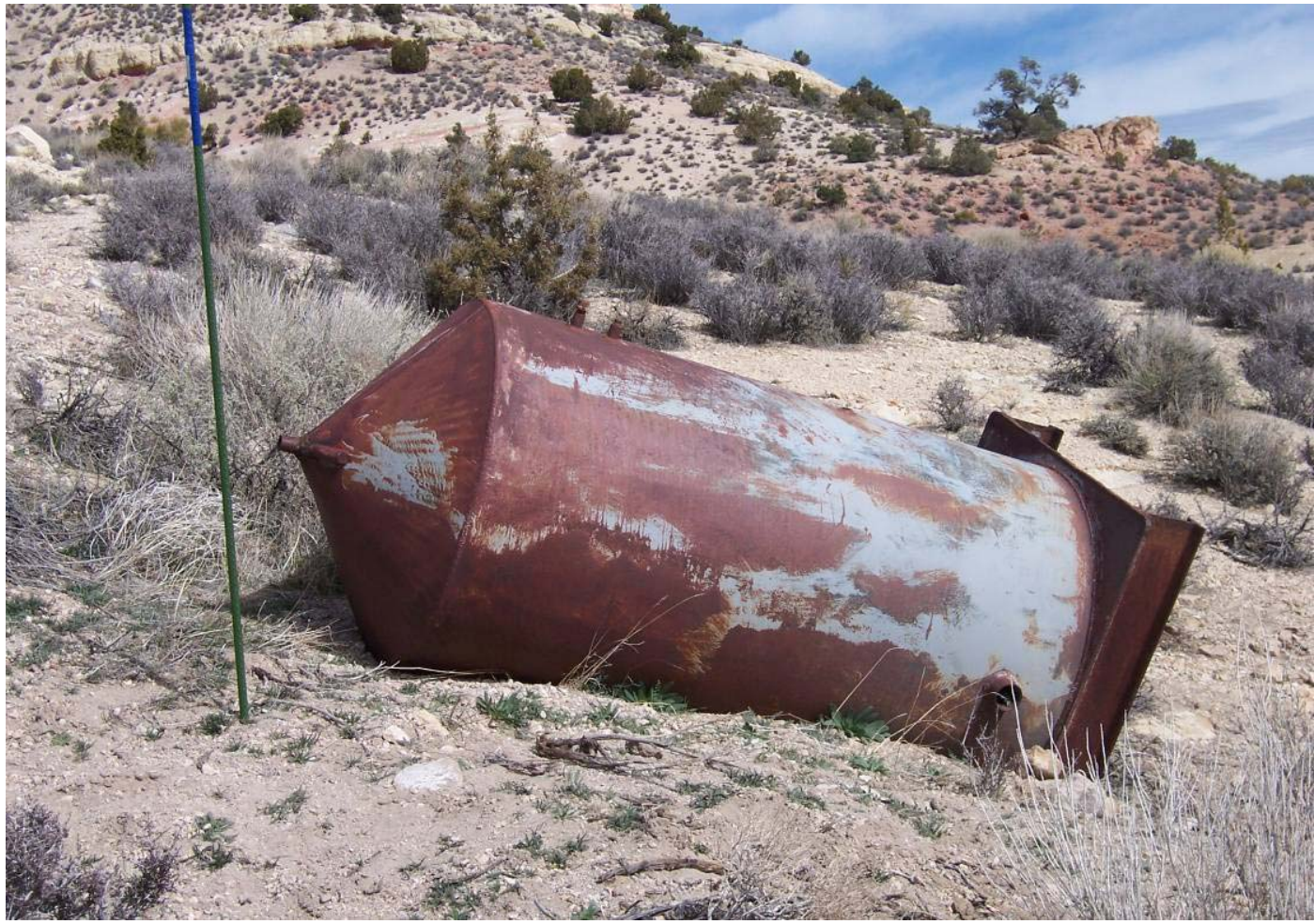

Photograph 4. CAS 12-01-02: Aboveground storage tank before field activities (02/13/2008) 


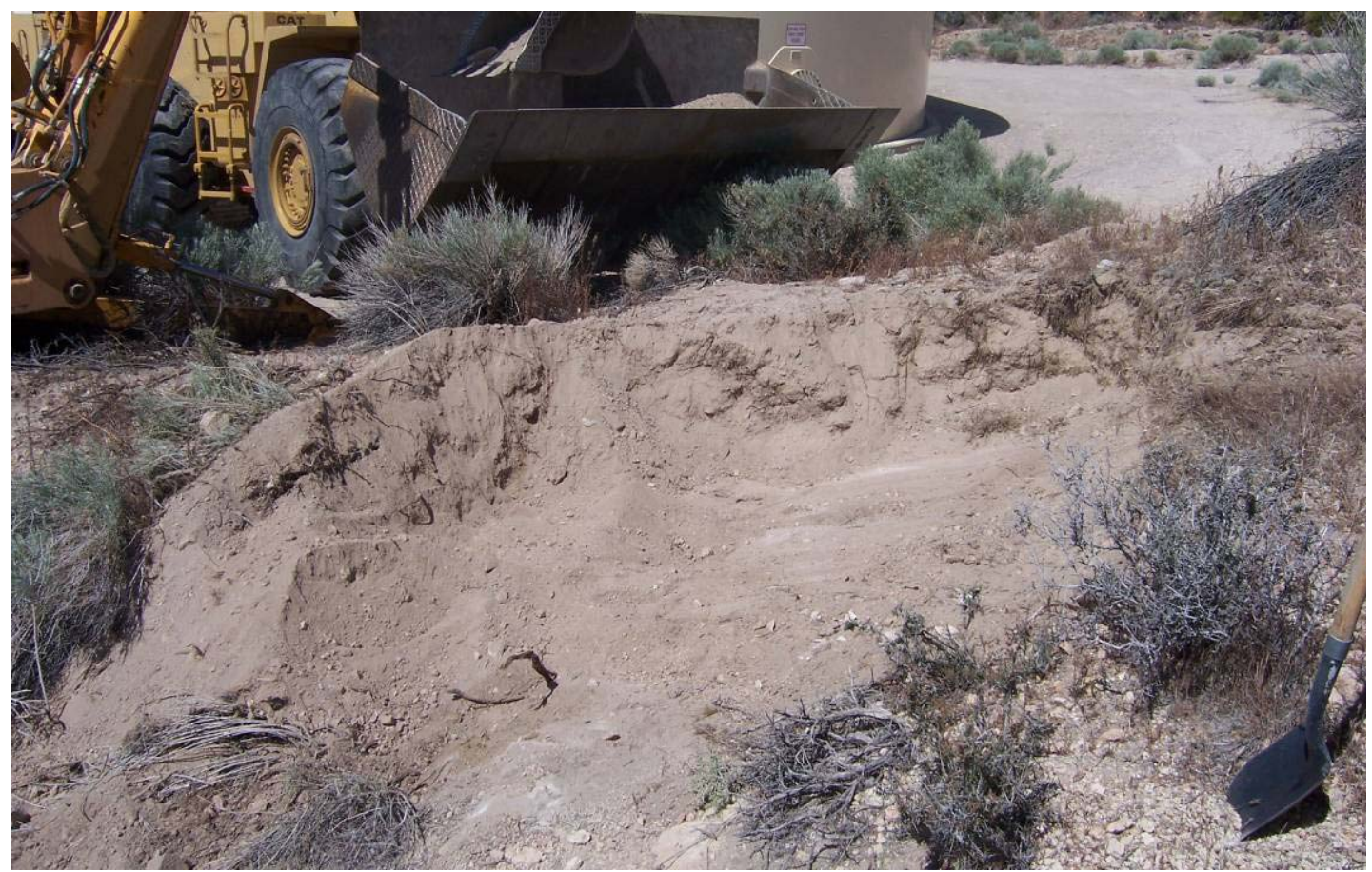

Photograph 5. CAS 12-01-02: Aboveground storage tank location after tank removal, during excavation $(05 / 29 / 2008)$

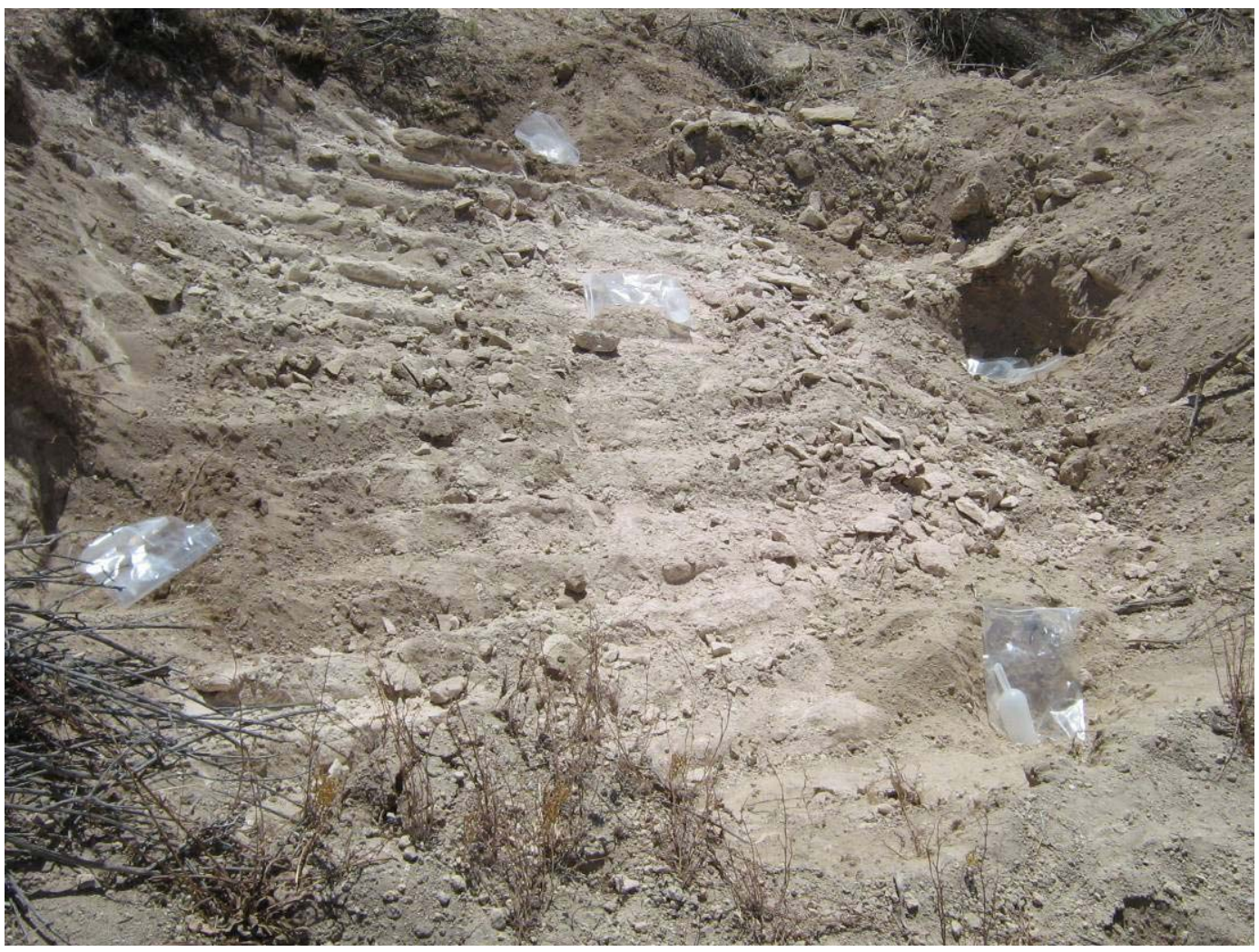

Photograph 6. CAS 12-01-02: Excavation sample locations (06/02/2008) 


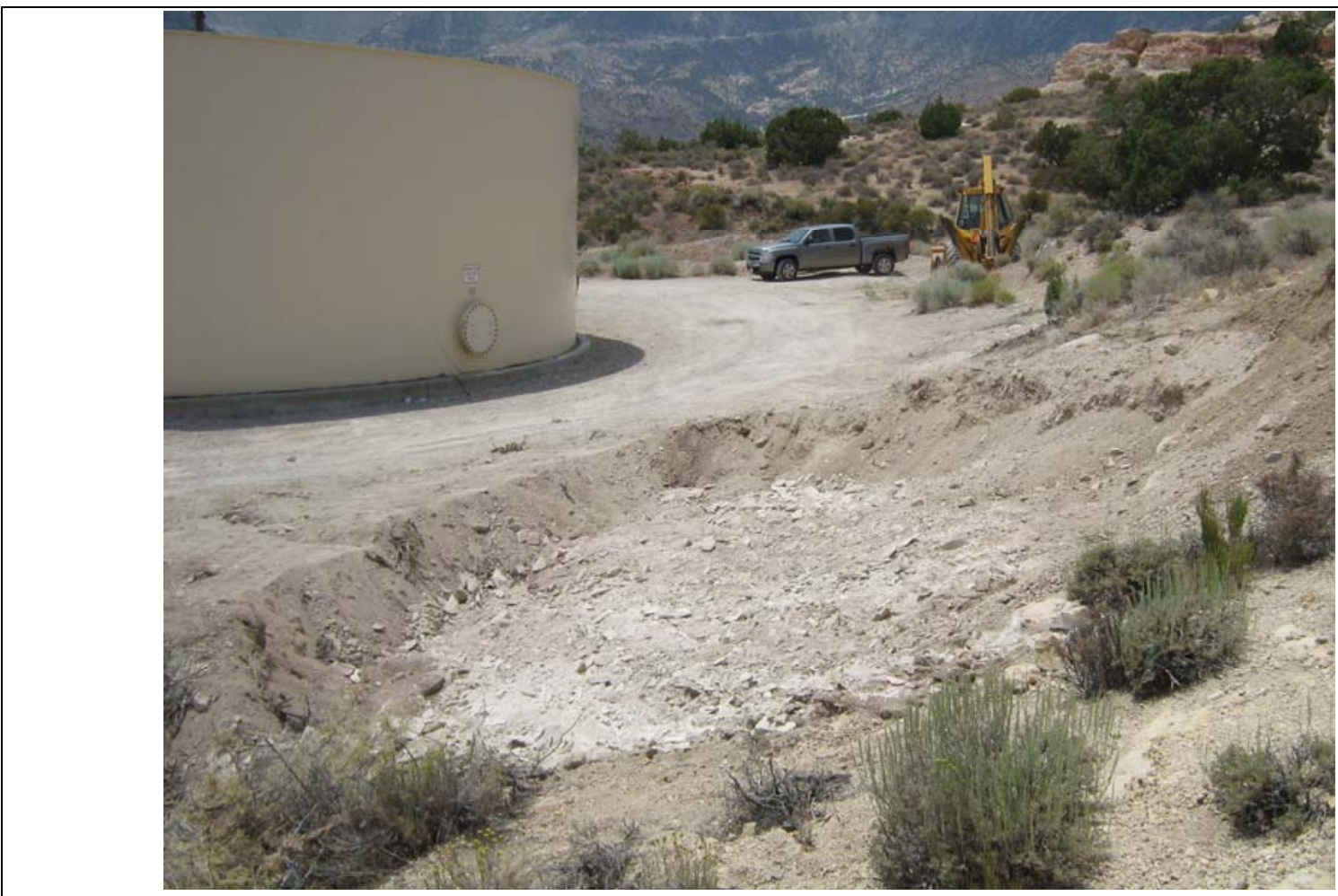

Photograph 7. CAS 12-01-02: Final excavation showing proximity to Area 12 Camp water tank and surrounding access pad (07/10/2008)

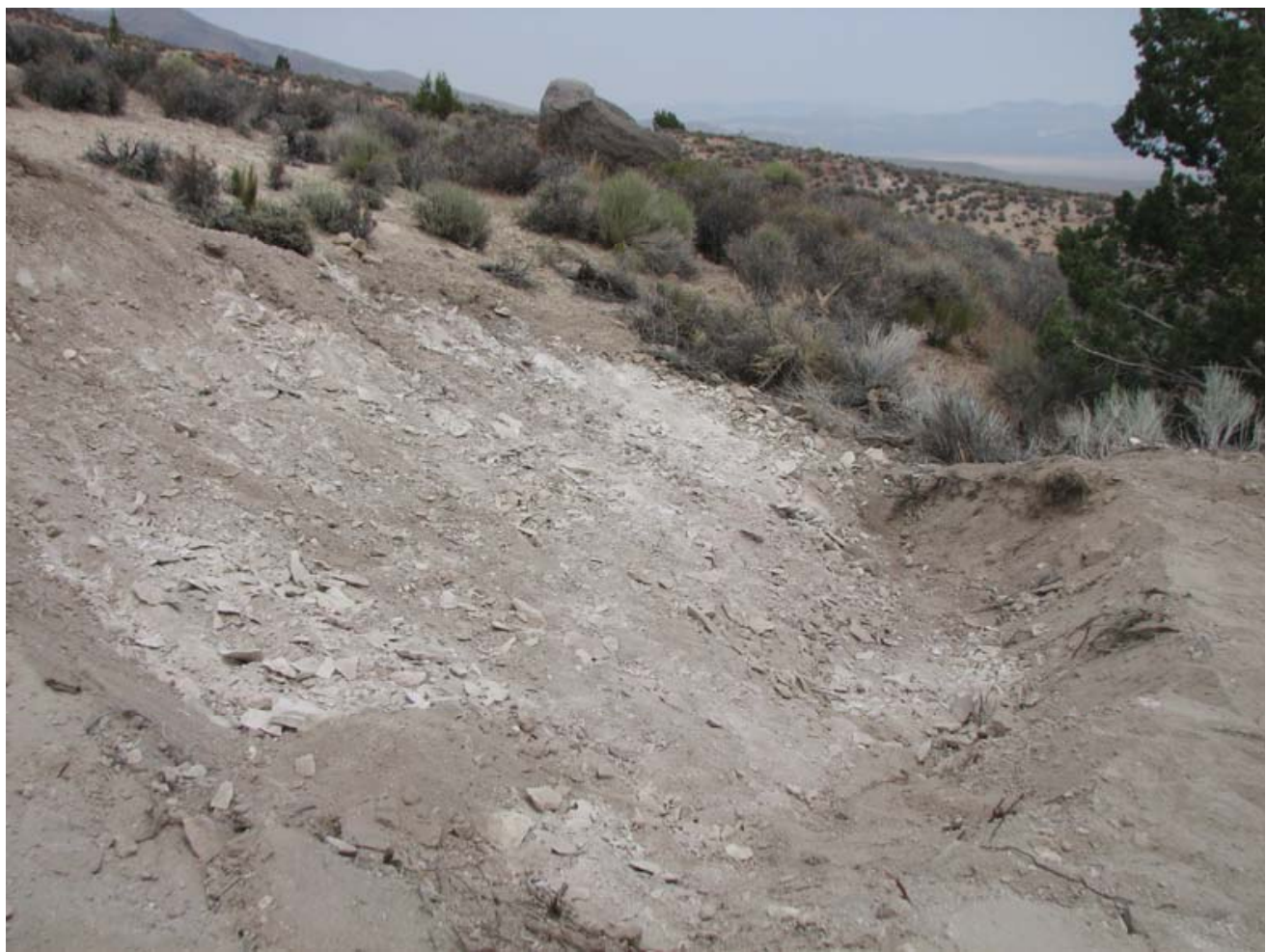

Photograph 8. CAS 12-01-02: Final excavation fairly representative of surface slope of volcanic tuff. Rocks within excavated area are fragments of tuff that were broken off by the backhoe. $(07 / 10 / 2008)$ 


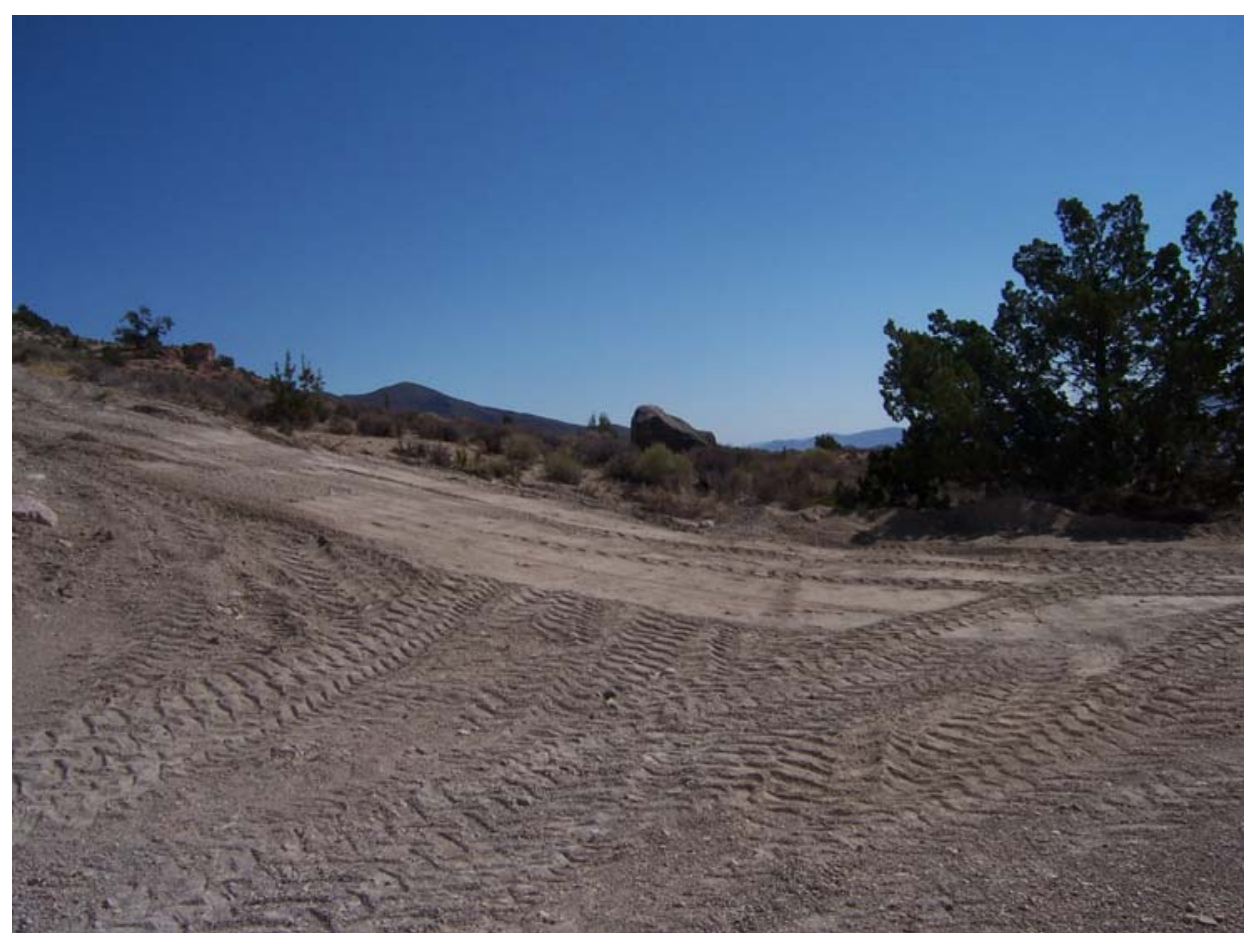

Photograph 9. CAS 12-01-02: Corrective Action Site after completion of field activities $(09 / 15 / 2008)$

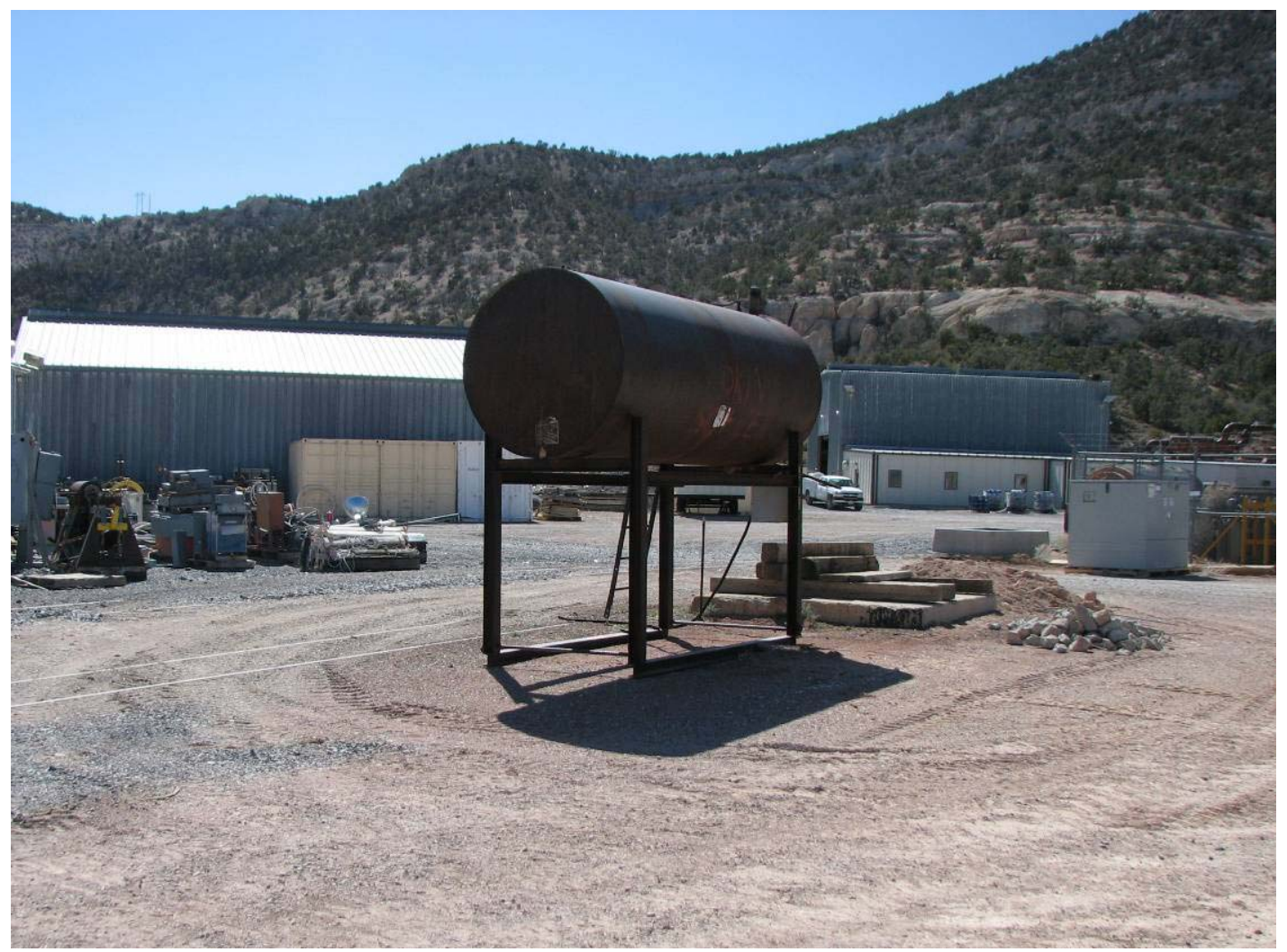

Photograph 10. CAS 12-22-26: Aboveground storage tank before start of field activities $(03 / 26 / 2008)$ 


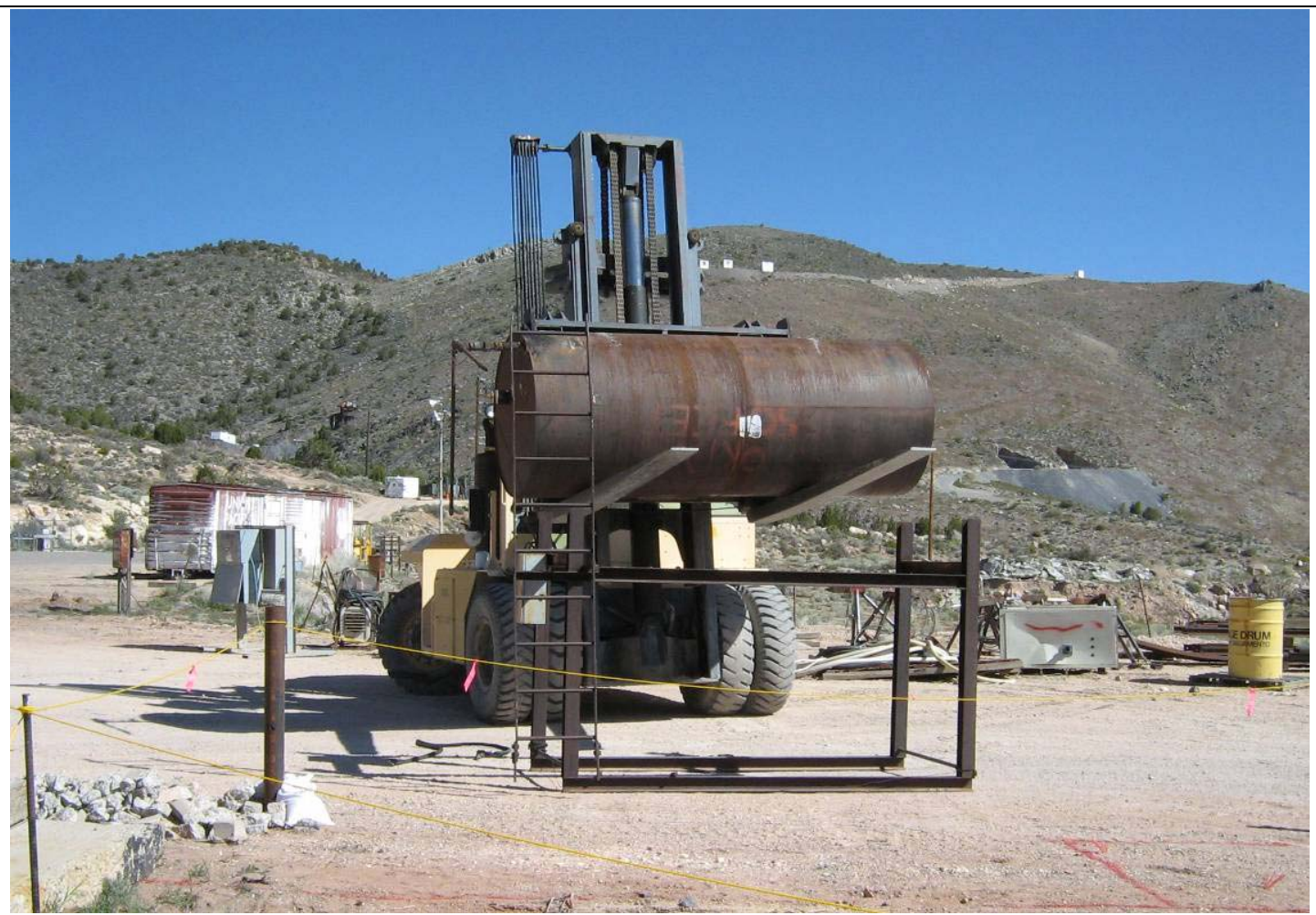

Photograph 11. CAS 12-22-26: Aboveground storage tank removal (04/17/2008)

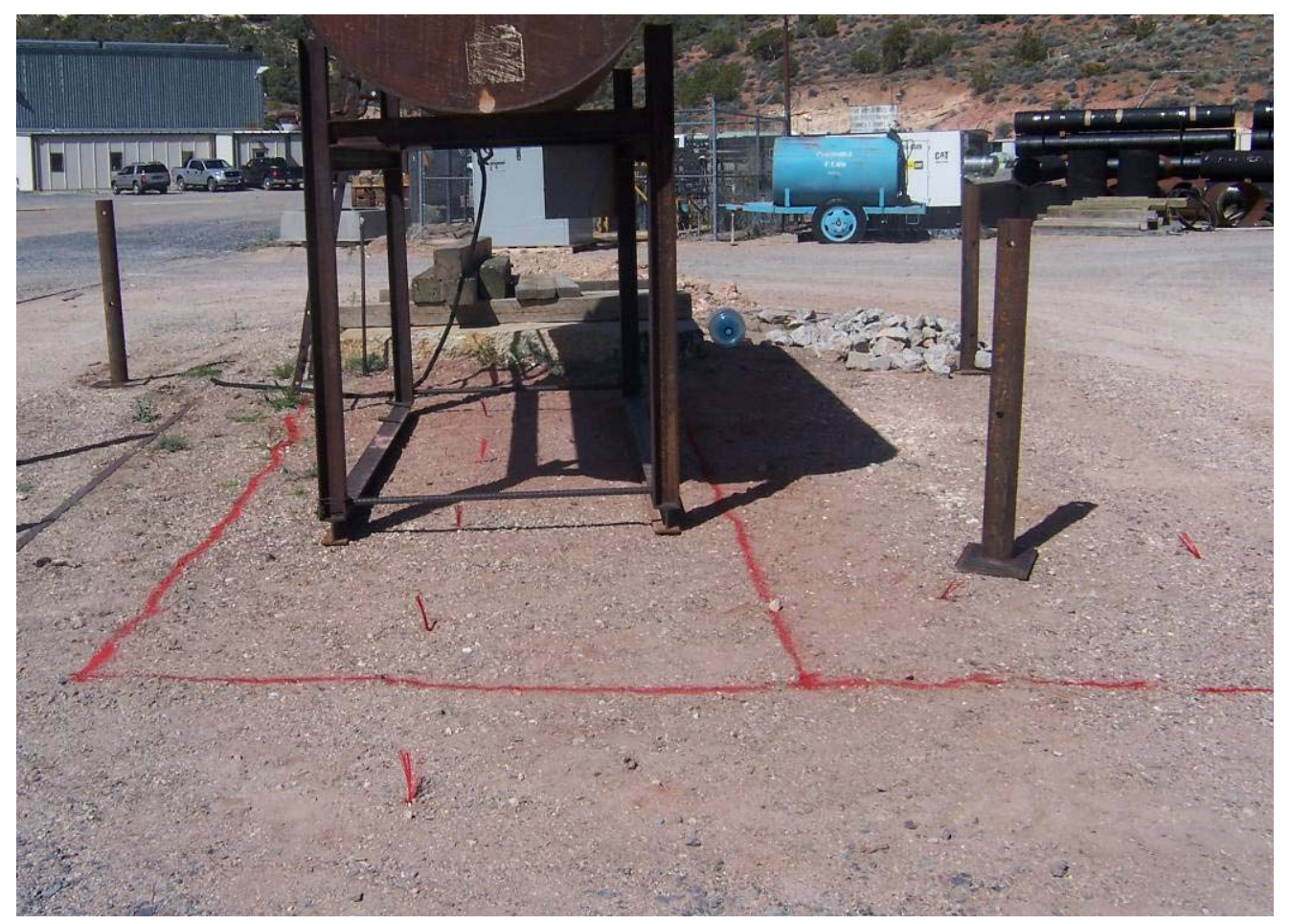

Photograph 12. CAS 12-22-26: Drum area, gridded and marked for sample collection $(04 / 15 / 2008)$ 
CAU 121 Closure Report

Section: Appendix D

Revision: 0

Date: September 2008

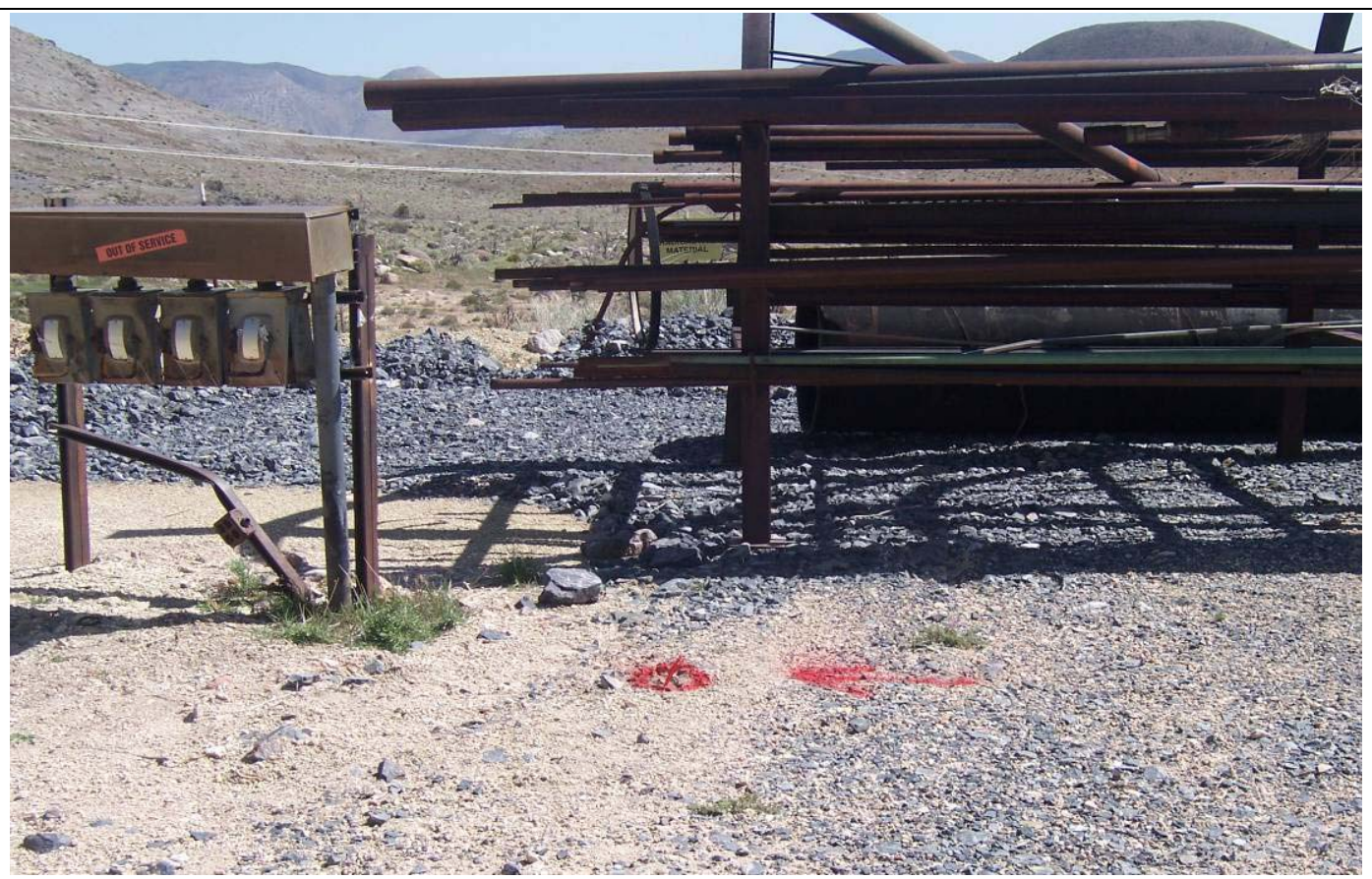

Photograph 13. CAS 12-22-26: Sample location when tank was located to the north of the operational tank area $(04 / 15 / 2008)$

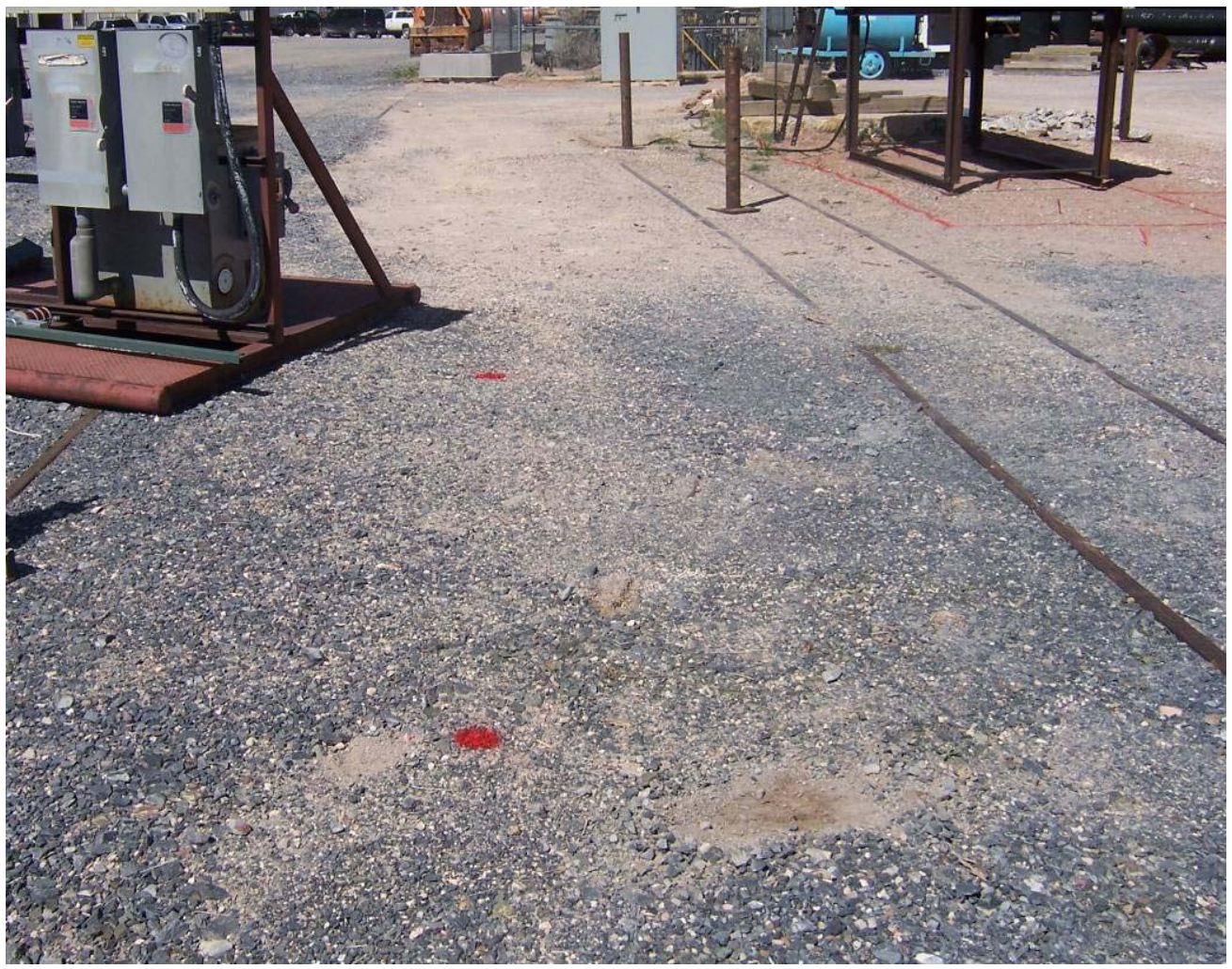

Photograph 14. CAS 12-22-26: Tank area marked for sample collection when tank was operational, near train tracks $(04 / 15 / 2008)$ 
CAU 121 Closure Report

Section: Appendix D

Revision: 0

Date: September 2008

\section{THIS PAGE INTENTIONALLY LEFT BLANK}




\section{APPENDIX E}

\section{NEVADA DIVISION OF ENVIRONMENTAL RESTORATION COMMENT RESPONSE FORM}


CAU 121 Closure Report

Section: Appendix E

Revision: 0

Date: September 2008

\section{THIS PAGE INTENTIONALLY LEFT BLANK}




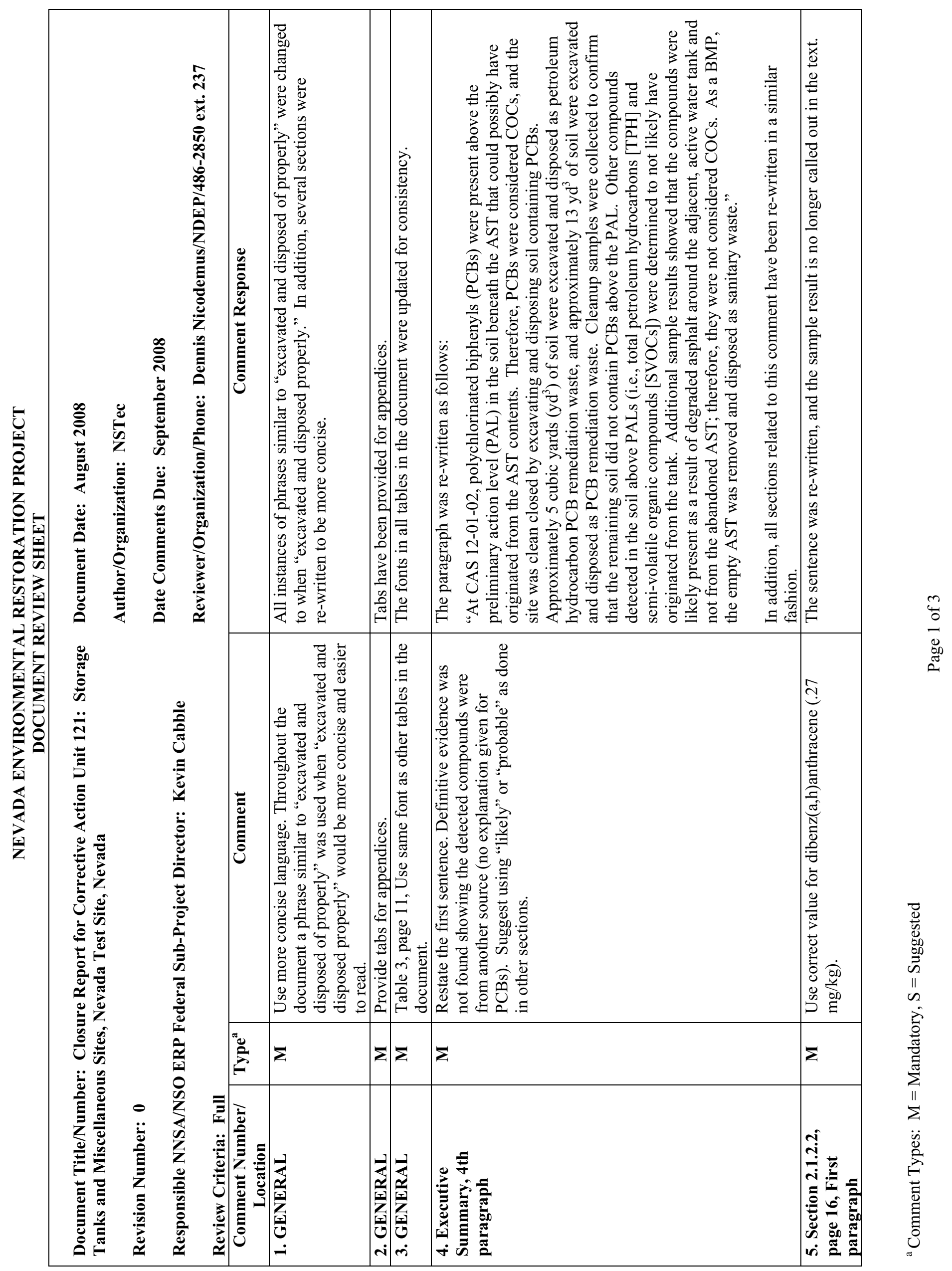




\begin{tabular}{|c|c|c|c|c|c|c|c|}
\hline 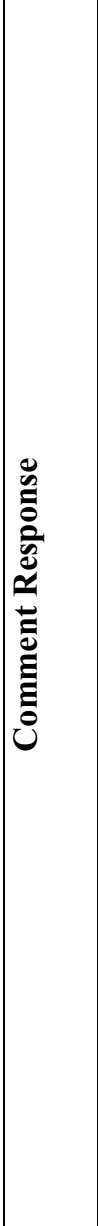 & 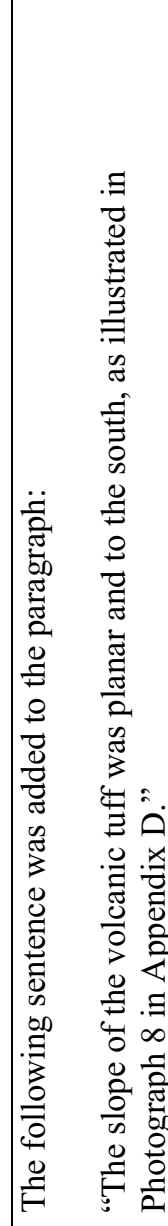 & 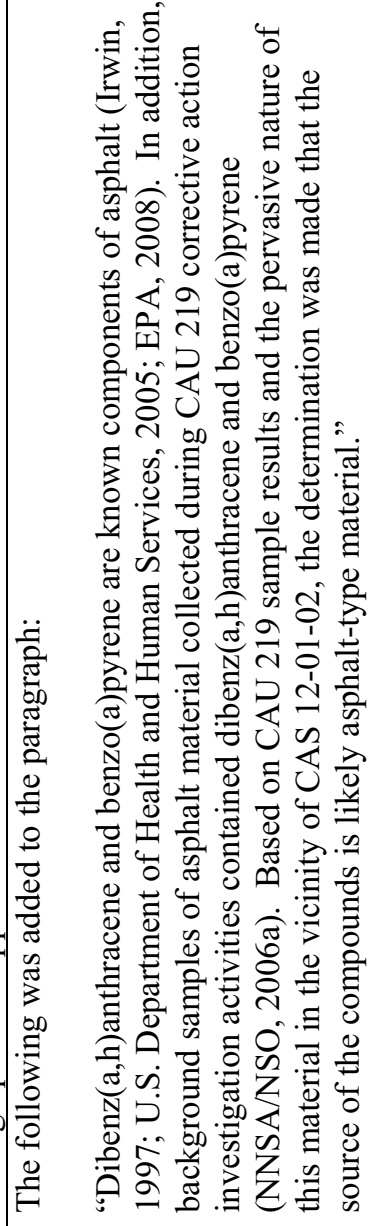 & 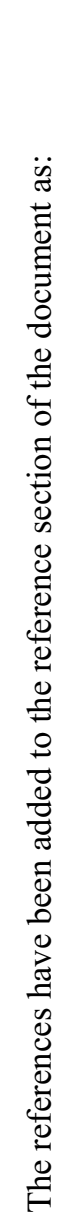 & 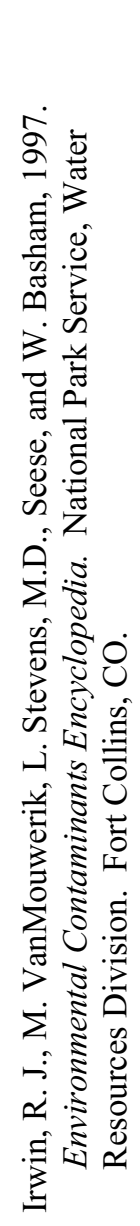 & 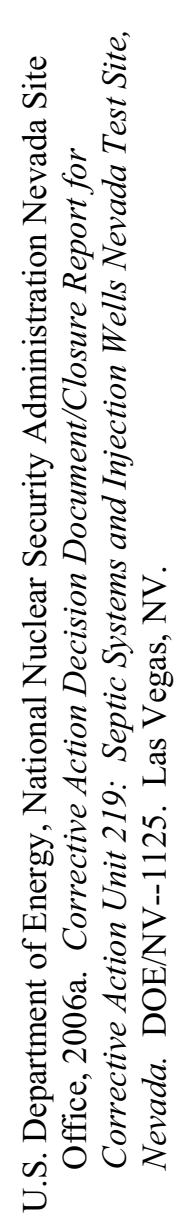 & 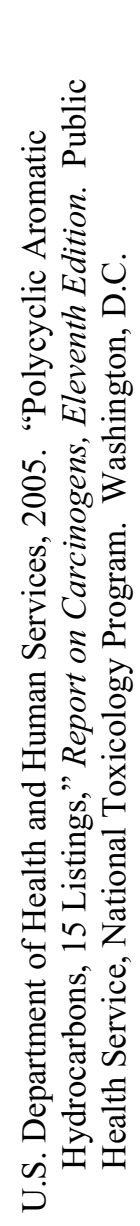 & 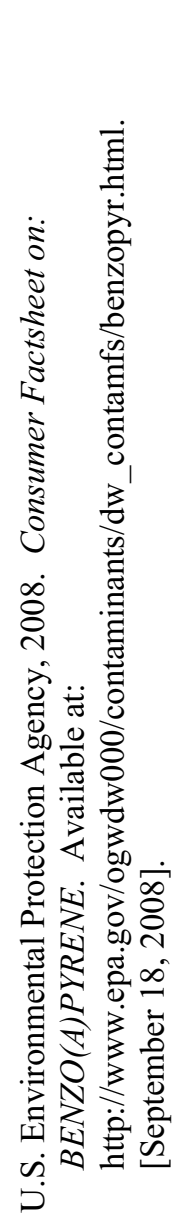 \\
\hline 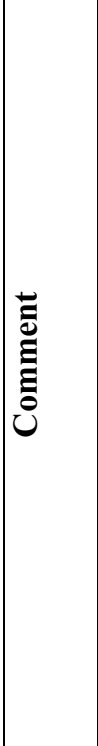 & 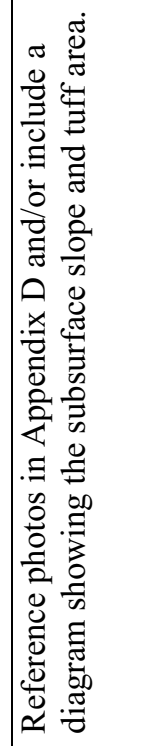 & 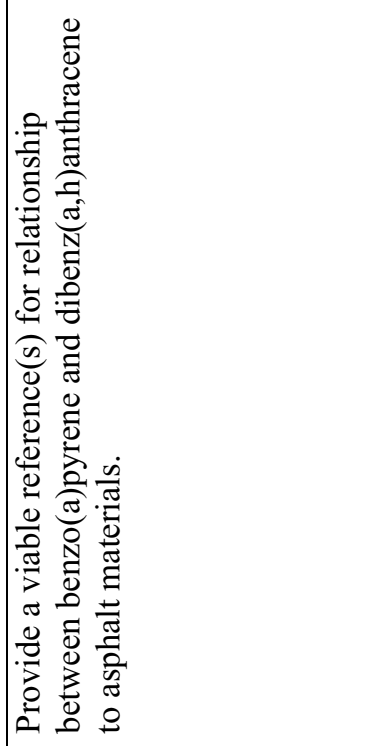 & & & & & \\
\hline 总 & $\Sigma$ & $\Sigma$ & & & & & \\
\hline 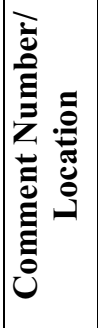 & 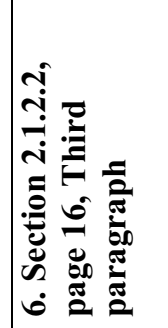 & 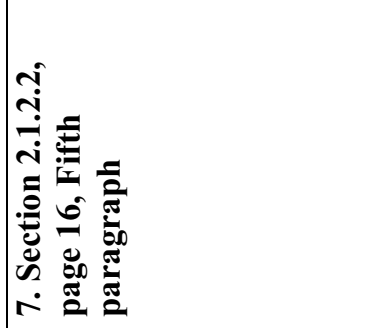 & & & & & \\
\hline
\end{tabular}




\begin{tabular}{|c|c|c|c|}
\hline & 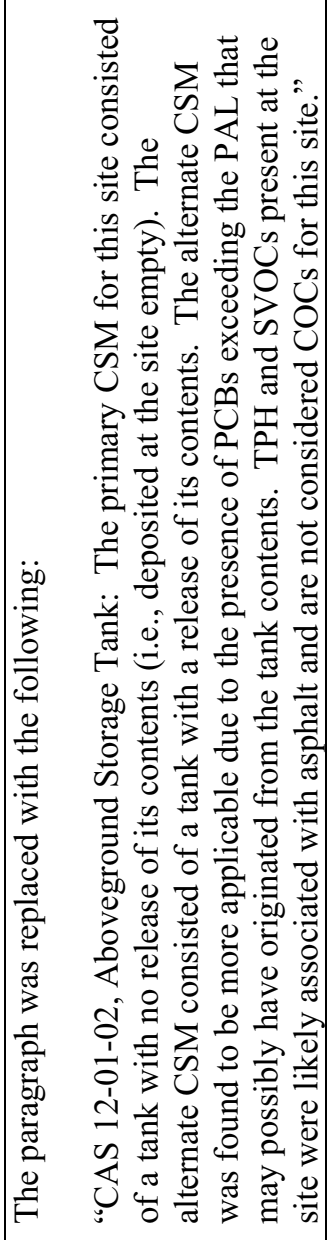 & 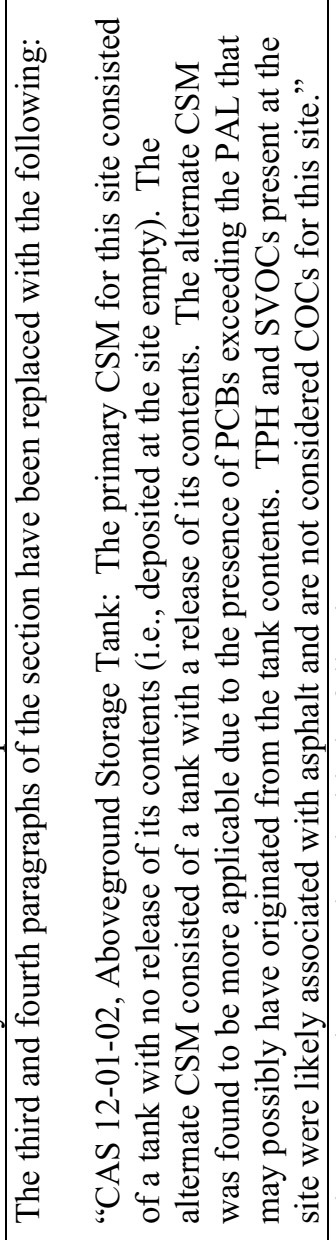 & 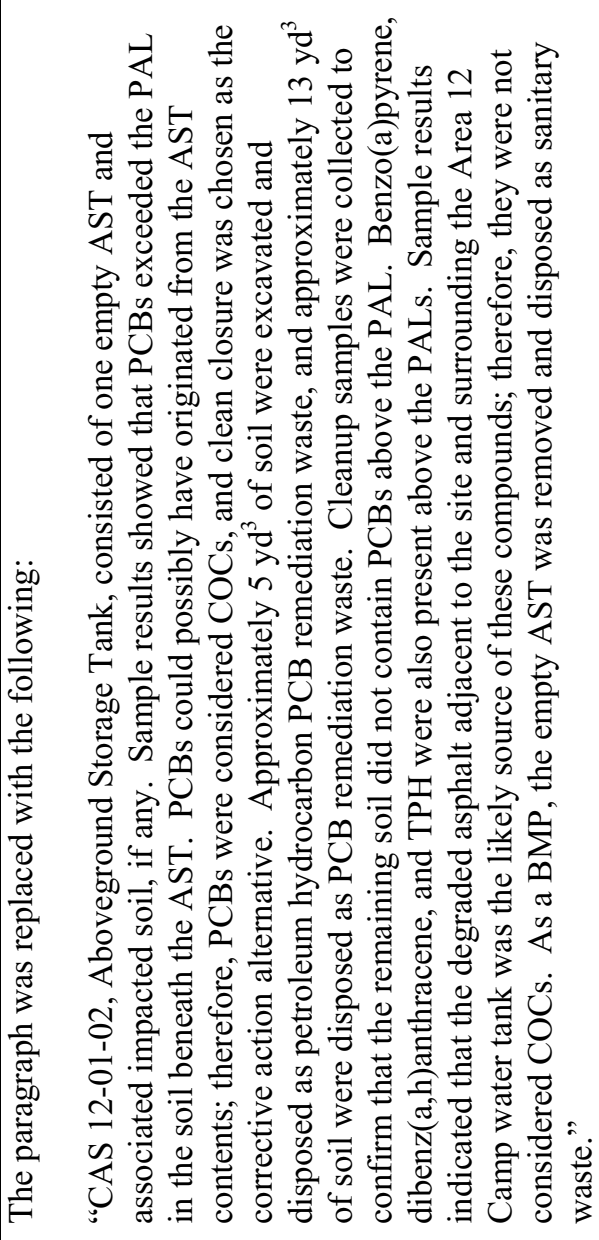 \\
\hline & 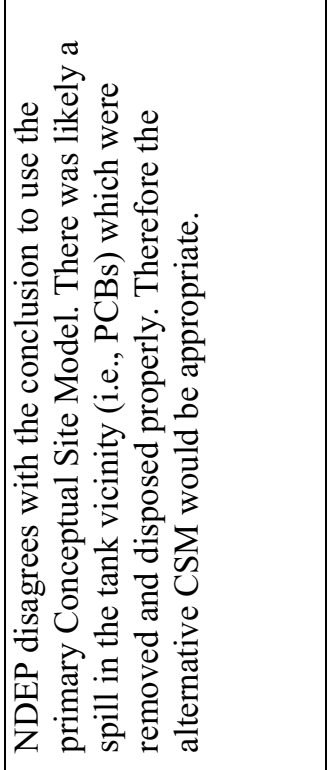 & 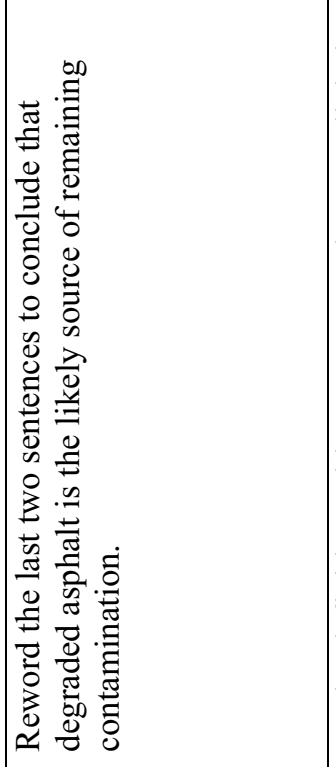 & 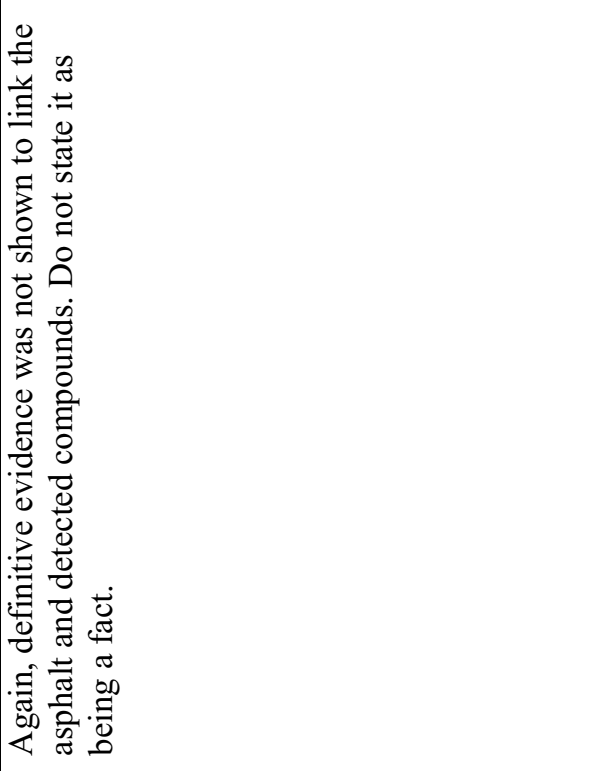 \\
\hline 离 & $\Sigma$ & $\Sigma$ & $\Sigma$ \\
\hline 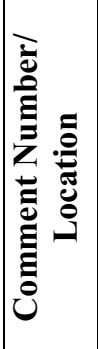 & 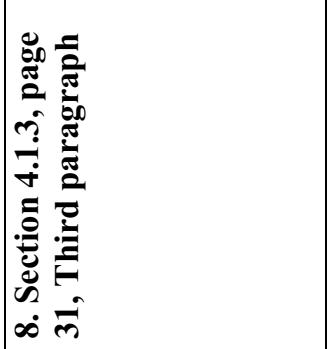 & 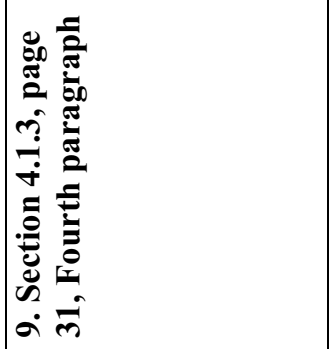 & 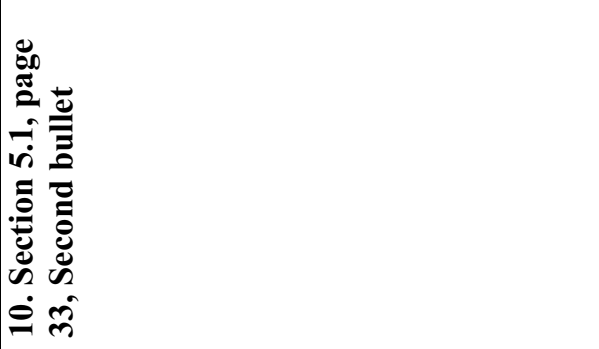 \\
\hline
\end{tabular}

$m$
4
0
0
0
0
$\approx$
0 
CAU 121 Closure Report

Section: Appendix E

Revision: 0

Date: September 2008

\section{THIS PAGE INTENTIONALLY LEFT BLANK}


CAU 121 Closure Report

Section: Library Distribution List

Revision: 0

Date: September 2008

\section{LIBRARY DISTRIBUTION LIST}


CAU 121 Closure Report

Section: Library Distribution List

Revision: 0

Date: September 2008

\section{THIS PAGE INTENTIONALLY LEFT BLANK}




\section{LIBRARY DISTRIBUTION LIST}

U.S. Department of Energy

National Nuclear Security Administration

Nevada Site Office

Technical Library

P.O. Box 98518, M/S 505

Las Vegas, NV 89193-8518

U.S. Department of Energy

Office of Scientific and Technical Information

P.O. Box 62

Oak Ridge, TN 37831-0062

Southern Nevada Public Reading Facility

c/o Nuclear Testing Archive

P.O. Box 98521, M/S 400

Las Vegas, NV 89193-8521

Manager, Northern Nevada FFACO

Public Reading Facility

c/o Nevada State Library \& Archives

Carson City, NV 89701-4285
1 (Uncontrolled, electronic copy)

1 (Uncontrolled, electronic copy)

2 (Uncontrolled, electronic copies)

1 (Uncontrolled, electronic copy) 
CAU 121 Closure Report

Section: Library Distribution List

Revision: 0

Date: September 2008

THIS PAGE INTENTIONALLY LEFT BLANK 